\title{
Mathematics professional development needs of general education and special education teachers
}

\author{
Kathryn L. Servilio \\ West Virginia University
}

Follow this and additional works at: https://researchrepository.wvu.edu/etd

\section{Recommended Citation}

Servilio, Kathryn L., "Mathematics professional development needs of general education and special education teachers" (2009). Graduate Theses, Dissertations, and Problem Reports. 4529.

https://researchrepository.wvu.edu/etd/4529

This Dissertation is protected by copyright and/or related rights. It has been brought to you by the The Research Repository @ WVU with permission from the rights-holder(s). You are free to use this Dissertation in any way that is permitted by the copyright and related rights legislation that applies to your use. For other uses you must obtain permission from the rights-holder(s) directly, unless additional rights are indicated by a Creative Commons license in the record and/ or on the work itself. This Dissertation has been accepted for inclusion in WVU Graduate Theses, Dissertations, and Problem Reports collection by an authorized administrator of The Research Repository @ WVU.

For more information, please contact researchrepository@mail.wvu.edu. 
MATHEMATICS PROFESSIONAL DEVELOPMENT NEEDS OF GENERAL EDUCATION AND SPECIAL EDUCATION TEACHERS

\author{
by \\ Kathryn L. Servilio \\ Dissertation submitted to the College of Human Resources and Education \\ at West Virginia University \\ in partial fulfillment of the requirements \\ for the degree of
Doctor of Education
in
Special Education

\begin{abstract}
Approved by
Dr. Barbara Ludlow, Committee Chairperson

Dr. Elizabeth Dooley

Dr. Kalie Kossar

Dr. Perry Phillips

Dr. Richard Walls

Department of Special Education
\end{abstract}

Morgantown, West Virginia 2009

Keywords: teacher training; professional development; mathematics education; management; school management; school effectiveness

Copyright 2009 Kathryn L. Servilio 


\begin{abstract}
MATHEMATICS PROFESSIONAL DEVELOPMENT NEEDS OF GENERAL EDUCATION AND SPECIAL EDUCATION TEACHERS
\end{abstract}

\title{
by Kathryn L. Servilio
}

The Mathematics Professional Development Inventory (MPDI) was designed to assess the teachers' rating of areas they need math content knowledge, professional development need of mathematics content knowledge, an academic area in which they need more knowledge, an academic area in which they feel they do not need more knowledge, their ability to teach mathematics, professional development need for teaching mathematics, their need for more strategies for teaching mathematics, and an area in which they do not need more strategies for teaching mathematics. This quantitative study used a non-parametric test to examined the relationship between variables of teacher demographics (mathematics teachers who teach at least 1 mathematics class), comparisons between teachers who teach in elementary schools and teachers who teach in secondary schools, comparisons between general education and special education teachers, and comparisons between elementary special education and secondary special education teachers on their math professional development needs. The study was conducted in two school systems in Maryland. Chi-Square analysis demonstrated statistically significant differences in the needs identified by special education teachers, math teachers who teach math all day compared to those who teach a variety of subjects, teacher's years of experience, and the number of mathematics classes that were taken. 


\section{DEDICATION}

The author wishes to dedicate this project to Eileen Laibson, for her devotion, enthusiasm, and love of students and the experiences she provided in teaching. 


\section{ACKNOWLEDGMENTS}

My Family, for all their support throughout the process.

Dr. Ludlow, for her reminders, impeccable editing skills, and flexibility.

Dr. Kossar, who I say is my claim to fame, because she noticed me when I was her student and mentored me throughout the whole process.

Dr. Walls, for his patience and willingness to help.

Dr. Dooley, for her support and ability to look at the bigger picture.

Dr. Phillips, for his ability to "say it with a smile" and caring nature.

Dr. Teets, for his swift response in approving and supporting the study.

Sue Waggoner, for her constant communication and link to potential participants.

Rebecca Ingham, for her access into one of the school systems.

Megan Ross, for listening to me and trying to support in any way possible.

Greg Perkins, for his extra "push" to accept and continue through the program.

Marra Dougherty, for her ability to keep me in the right direction.

Jessica Fratz, for her faithful encouragement and support.

Mary Clark, for her empowering words of wisdom.

The Roosevelt's, for their ability to relax me after a long day of writing. 
TABLE OF CONTENTS

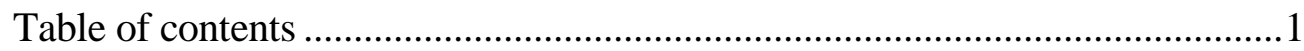

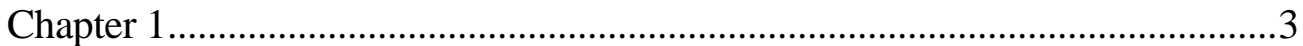

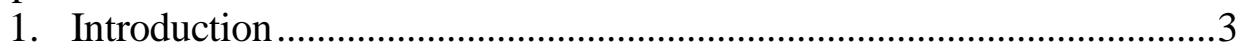

2. Issues with Highly Qualified Status ..................................................4

3. Relationship between Highly Qualified Teachers and

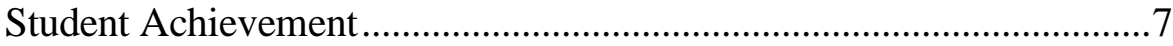

4. Schools Face Negative Consequences for Failure to Document Adequate Yearly Progress ................................................8

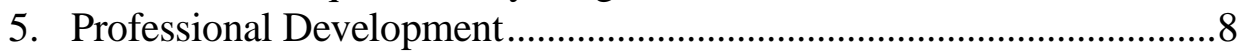

6. Research on Professional Development in Mathematics .....................11

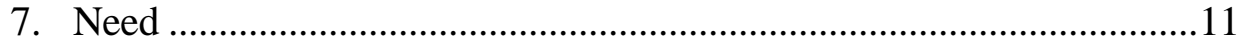

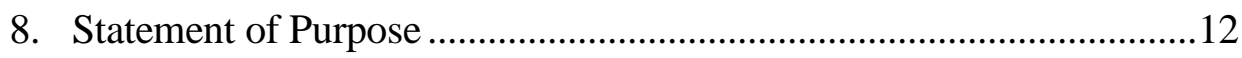

9. Research Questions........................................................................ 12

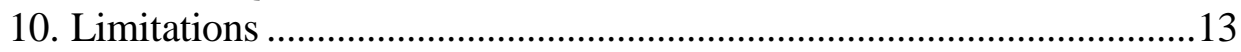

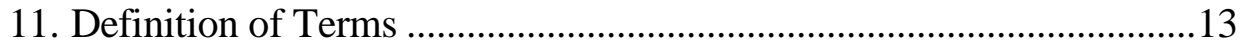

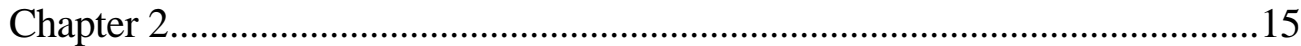

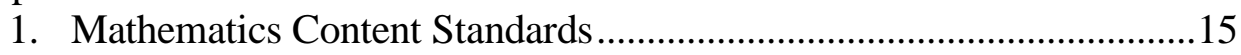

2. Professional Development...................................................................17

3. Professional Development in Mathematics .........................................22

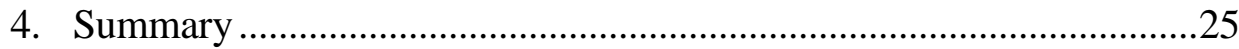

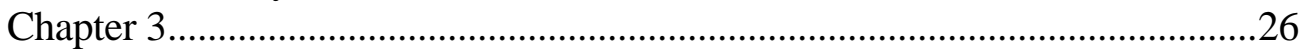

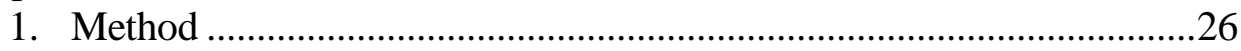

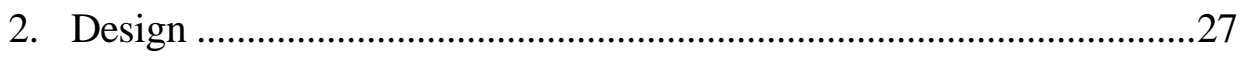

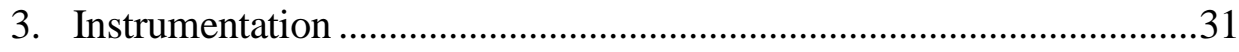

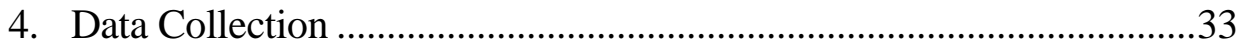

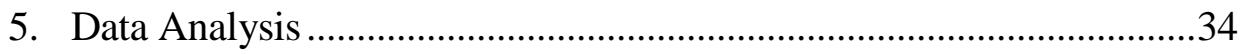

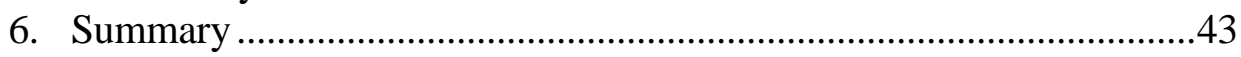

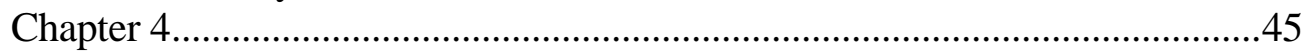

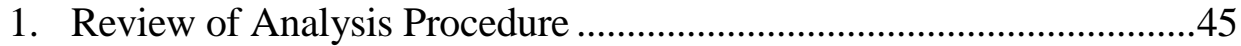

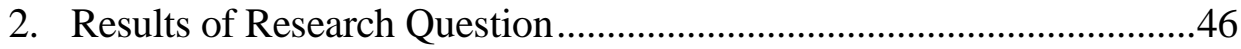

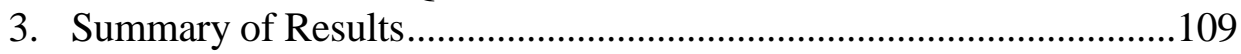

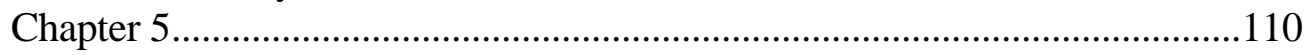

1. Summary of Purpose ..................................................................110

2. Summary of Procedures ...............................................................112

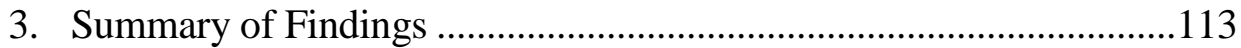

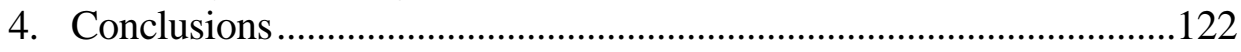

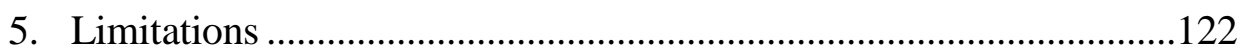

6. Recommendations...........................................................................123

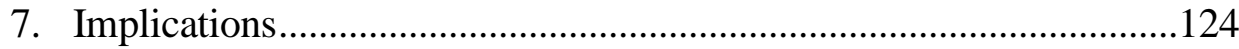




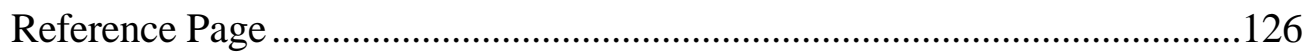

Appendix A: Math Professional Development Inventory ..............................138

Appendix B: Cover Letter for Survey .......................................................159

Appendix C: Responses from 3 Potential School Systems............................161

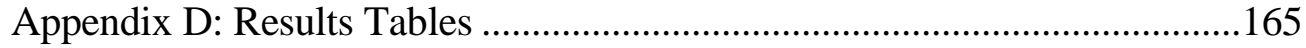




\section{H A P T E R 1}

Introduction

In 2001, the No Child Left Behind Act (NCLB), formerly the Elementary and Secondary Education Act (of April 11, 1965), was passed, making way for the newest updates in education policy (Safier, 2007). This law mandated high content standards and achievement for all students as well as certified teachers who are also highly qualified in core content areas. NCLB specified that by the end of 2006 all teachers must meet federal requirements for highly qualified status, a deadline that was later extended to the end of the 2007 school year (Henig, 2006). The implications of the highly qualified requirement in NCLB and its effects on education have been widely discussed (Safier, 2007). In 1999-2000, the academic year just prior to the enactment of NCLB, $99 \%$ of public school teachers had at least a baccalaureate degree and some graduate degrees while nearly 92\% held regular teaching certificates (Ingersoll, 2003). Even though most teachers were certified, approximately $20 \%$ taught some courses out of their field of expertise (Ingersoll, 2003). The intention of the highly qualified requirement was to set the expectation that all teachers would be superior candidates and better prepared for the job (Safier, 2007).

The Individuals with Disabilites Act (IDEA) (1997 and 2004) not only acknowledged the importance of holding high expectations for teachers but also extended these standards to teachers of students with special needs, requiring special educators also to become highly qualified in the content areas they are assigned to teach (Louie, Brodesky, Brett, Yang, \& Tan, 2008). The states were also mandated to include students with disabilities in their assessment systems and show how those students make adequate yearly progress in reading and mathematics (Louie, et al., 2008). These requirements from NCLB and IDEA raised issues related to defining requirements for 
highly qualified status for special educators and preparing personnel to become highly qualified not only in special education but also in content areas.

Issues with Highly Qualified Status

Many mathematics and special education teachers teaching today are not highly qualified due to (a) training programs (Safier, 2007) and (b) shortages and attrition (Ingersoll, 1997; United States Department of Education (USDE) (2008), that force many schools to hire unqualified personnel (USDE, 2001). One reason that teachers may not be highly qualified is because of the training program that prepared them (Safier, 2007). Most college and university programs have been developed to achieve only highly qualified status for the state where the institution is, so that if a graduate wants to teach in a different state, he/she may or may not qualify for highly qualified status within that state. If a teacher does not have adequate preparation for his/her position, inservice training and other professional development activities may not be enough to solve the problem at hand and bring him or her up to par (Ingersoll, 2005). The problem of unqualified teachers will continue until all training programs are modified to ensure graduates meet highly qualified requirements (Ingersoll, 2005). Safier (2007) reports highly qualified status is affected by three variables: (a) a teacher's familiarity with the law, (b) a teacher's qualifications (e.g., personality, type of degree, type of certification), and (c) a teacher's educational experience.

In some cases, teachers have not mastered the academic content, especially in mathematics. Liping Ma (1999) conducted a study with preservice elementary education teachers and found that out of 116 students when given a pretest on basic mathematics skills (e.g., ratios, addition, fractions, simple percentages), only $10 \%$ scored above $70 \%$, and only $6.9 \%$ scored at $80 \%$ or better. Ma, who also found that many practicing teachers did not know how to find area or 
perimeter, stated, "people who truly understand the concept of area or perimeter do not forget how to calculate it" (p. 103). More recently, Goldman (2007) found that many of her college students (childhood education, grades 1-6) did not have the in-depth knowledge and understanding of mathematics. In addition, many of her students shared with her that when they were students they were told what to do and given practice problems, for which they memorized the process. The regulations of NCLB have stimulated many teacher-preparation programs to change or strengthen curricula to provide more intensive courses in mathematics.

Even though NCLB has stimulated teacher preparation programs to change and improve their curricula, there are still shortages within the field of mathematics and special education. From 2004-05 through 2007-08, the U.S. Department of Education reported that there were shortages in mathematics (7-12) and in special education (Autism, 7-12, Gifted, 6-12, Learning Disabled, 7-12, Mentally Retarded, 7-12, Multi-Handicapped, 7-12, Speech, and Visual-Hearing Impaired) (2008). The National Center for Education Statistics found that, of public schools teaching vacancies for the 2003-2004 school year, $67.4 \%$ were in special education and 55.6\% were in mathematics (USDE, 2003-04). Further, of the public schools that had teaching vacancies in special education and mathematics during 2003-2004 school year, 29.2\% had difficulty or did not fill special education positions and $28.8 \%$ had difficulty or did not fill the mathematics positions (USDE, 2003-04). Boe, Cook, Bobbitt, and Terhanian (1998) found that there was a shortage of about 29,000 fully certified teachers in special education, a number that was almost double the number of teachers needed in general education. This number continued to rise, and in 2000, almost $98 \%$ of school districts reported special education teacher shortages (Fideler, Foster, \& Schwartz). Due to these shortages in both mathematics and special education, nationally, almost 40,000 positions are 
filled by uncertified teachers (United States Department of Education, 2001). Last year, the Maryland State Board of Education reported shortages in 20 key areas in every county in Maryland, both mathematics and special education fell into this category (Maryland State Board of Education, 2008).

Ingersoll (1997) stated that there might not be a problem in the shortages of the mathematics teachers if school systems would retain the teachers that they hire. Nearly $20 \%$ of U.S. teachers leave the field after their first year of teaching (National Center for Educational Statistics, 2007); this number increases to a little less than $30 \%$ after the first four years of teaching. The numbers are even greater for special education teachers. In the first five years of teaching, almost $40 \%$ of beginning special education teachers leave the field (Billingsley, 2004; McLeskey, Tyler, \& Flippin, 2004). This percentage is almost twice that of beginning teachers who leave general education within the first years of teaching (Billingsley, Carlson, \& Klein, 2004; Miller, Brownell, \& Smith, 1999; Smith \& Ingersoll, 2004). There is minimal empirical research that specifically addresses attrition of teachers who teach mathematics (Fisher, n.d.).

Recent data in the state of Maryland reflect this problem; in 2006-2007, more than 5,000 teachers left the state school system (Maryland State Department of Education, 2008). Looking at new teacher candidates who would be able to fill these positions; there were 95 students who earned a degree in mathematics education, and 354 students who earned a degree in special education. Both of these numbers increased in 2008-2009 where there were 126 students who earned a degree in mathematics education, and 391 students that earned a degree in special education. This number, however, still is not enough to meet the need to stuff the number of positions that need to be filled. The Maryland State Department (2008) states that, "it is clear that 
Maryland institutions of higher education have never produced the number of new teachers needed to be hired by the local school systems each year" (p. 67).

\section{Relationship between Highly Qualified Teachers and Student Achievement}

When teachers are not highly qualified in their content area, students may fail to make adequate yearly progress. Many students, especially in high need schools, are taught by mathematics teachers who are trained in other fields, are emergency hires, or have content background but not appropriate teaching skills (Darling-Hammond, 2007). Ingersoll \& Gruber (1996) found that more than four million students who are enrolled in mathematics classes in grades 7-12 are taught by teachers who do not have a minor in mathematics or mathematics education. Depending upon the location of the high school (e.g., rural, urban), there is even a higher percentage of schools that do not have a qualified mathematics teacher (Education Trust, 1996). These statistics are impacting the students whom they teach and may be one of the factors that explain why students with disabilities do not make adequate yearly progress in mathematics (State Accountability Profiles, 2008). During 2006-2007, there were more than 88,300 schools in the United States that were not making adequate yearly progress or were in need of improvement (State Accountability Profiles, 2008). Taking a closer look, almost 30\% of schools within each state were not making adequate yearly progress, and $18 \%$ of these schools were in need of improvement (State Accountability Profiles, 2008). Furthermore, when looking at the mid-Atlantic region (Pennsylvania, Maryland, New Jersey, Delaware, and District of Columbia), the students with disabilities subgroup was more likely to fail to meet adequate yearly progress targets (Johnson, Peck, \& Wise, 2007). When looking at the statistics for Maryland, 18\% of schools reported data for students with disabilities, and $17 \%$ of schools reported failing to meet adequate 
yearly progress targets for students with disabilities (Johnson, Peck \& Wise, 2007). Thus, almost all of the schools in Maryland who reported data for students with disabilities showed that they missed adequate yearly progress targets for those students. Schools Face Negative Consequences for Failure to Document Adequate Yearly Progress

Schools have two years to meet the state's target for adequate yearly progress (U.S. Department of Education, 2004). All the test scores are published in the newspaper, and the school system or specific schools within that school system are put on a warning list (U.S. Department of Education, 2004). After two years of not meeting AYP targets, children attending a Title 1 School are eligible for school choice. The third year that a school does not meet AYP targets, it must provide students with supplemental educational services (U.S. Department of Education, 2004). After several years of not meeting AYP targets, the school's Title 1 funding may be withdrawn (U.S. Department of Education, 2004). During this time, the school needs to show improvement, take corrective action, or employ restructuring measures where the goal is to meet the state's targets for adequate yearly progress. If the school continues not to meet those goals, the state may take over the school or close it (Burch \& Spillane, 2003). To prevent this from happening, the professional development needs of teachers must be identified so administrators can implement professional development activities that will help them present curriculum and deliver instruction that will enable students to improve achievement and obtain higher scores on standardized tests to meet AYP targets.

\section{Professional Development}

Some believe that teachers and administrators need to improve before schools will be able to improve (Guskey, 2002; Wise, 1991). One way to support the improvement of teachers and 
administrators is by providing professional development; however, there often is a lack of appropriate professional development (Guskey, 1994).

Guskey (1994) argued that teachers wanted appropriate professional development to help them become more effective in the classroom. However, many of the sessions that teachers are attending are not applicable (Firestone, Mangin, Martinez, \& Polosky, 2005). Research shows that teachers did not want to attend if they were not gaining valuable information (Ball \& Cohen, 1999; Cutler \& Ruopp, 1993). In turn, if the sessions were not focused on mathematics or special education, teachers did not want to attend because the information that was provided was not useful and relevant in their classrooms.

One idea to improve professional development was researched by Yoon, Duncan, Less, Scarloss, \& Shapley (2007), who found schools require that teachers have at least 14 hours of professional development per school year. This suggests that, if all teachers were held to this standard, student achievement would improve. Yoon, Stevenson, Dantley, \& Holcomb (1999) state that providing professional development that is effective is a key to improving schools. Teachers feel that professional development programs provide the most opportunity for job growth and development as well as the easiest access to on the job training (Fullan, 1991; Fullan, 1993). Furthermore, professional development is also a way to enhance teacher abilities and promote professional fulfillment (Huberman, 1995).

When designing professional development, one key question that needs to be considered is (Guskey, 1986): What increases teachers' participation in professional development? Fullan (1999) found that most teachers feel that becoming a better teacher means that they are increasing the amount of knowledge acquired by their students. Teachers define the success of their teaching 
based upon the behavior and engagement of their students rather than their own behaviors or other measures. An example of this would be a teacher defining success based on how the students interacted with the lesson and behaved during the lesson rather than how much information the teacher presented to them.

Research has found that professional development needs to be on-going and available (Alkins, Banks-Santilli, Elliott, Guttenberg, \& Kamil, 2006; Gehrke \& McCoy, 2007; Watzke, 2007). The needs identified by beginning and experienced teachers must be assessed and addressed throughout the school year (Alkins, et al., 2006). For example, at in the beginning of the year, teachers may need professional development focusing on collaboration and co-teaching; as the school year progresses their needs for professional development may change, so at mid-year the teachers may need professional development in collaborative teacher conferences. Professional development also needs to relate specifically to the content of the classroom curriculum (Cwikla, 2002; Gehrke \& McCoy, 2007; Gehrke \& Murri, 2006). Such on-going and specific professional development activities will provide support to veteran teachers and also foster the development of beginning teachers (Gehrke \& Murri, 2006).

Some researchers (Stevenson, Dantley, Holcomb, 1999) found that the number one reason teachers would consider remaining in the field was if the professional development improved compared to what their school system was currently offering. To improve professional development, some research suggested grouping teachers based upon their background, years of experience, and views of learning (Cwikla, 2002), as well as involving the teachers in the planning stage (Corcoran, 1995). When teachers were asked to help in designing professional development, 
they are more apt to participate due to the fact that they were involved in the decision making process about the types of professional development that were offered.

\section{Research on Professional Development in Mathematics}

Mathematics professional development needs to be successful so that teachers gain appropriate and applicable knowledge that enables them to raise students' test scores. Cwikla (2004) completed a qualitative study of mathematics professional development. The participants were 110 middle school mathematics teachers who had seven years of teaching experience or less, and were interviewed about their perceptions of professional development. She found that mathematics teachers with seven years of experience or less were not pleased with their mentors or collaboration within their department. The researcher also noted that these teachers would welcome their mentors to complete and discuss classroom observations. Even more compelling, the less experienced mathematics teachers were dissatisfied with the responses from the more experienced mathematics teachers and astonished that the more experienced mathematics teachers lacked mathematics content knowledge.

There has been research in the field of mathematics education but most of the studies are about teacher development, teacher change, and professional education (Carpenter \& Fennema, 1992; Cognition and Technology Group at Vanderbilt, 1997; Cwikla, 2002; Kazemi \& Franke, 2000). Mathematics professional development research is on the rise but, as a whole, this research has been unfocused (Cwikla, 2004). Existing studies have not been examined on similar variables, which makes the features of mathematics professional development programs difficult to identify (Cwikla, 2003; Cwikla, 2004).

Need 
This research adopted a proactive approach, in that the researcher asked mathematics teachers to identify and rank their mathematics professional development needs. The research questions were developed after an examination of state assessments, professional development standards, and mathematics professional development standards. This study was timely because schools need to understand the mathematics professional development needs of teachers so they can provide professional development activities that support teachers in meeting adequate yearly progress targets for all students in this content area.

\section{Statement of Purpose}

The primary purpose of this study was to examine the professional development needs identified by general education and special education mathematics teachers (identified as teachers who taught at least one mathematics class). The secondary purpose was to examine the similarities and differences in identified needs of general education and special education mathematics teachers by grade levels (elementary vs. secondary), teacher classification (general education vs. special education) and for special educators by grade level. This information will help stakeholders develop more appropriate and effective professional development programs for the teachers' school systems.

\section{Research Questions}

The research questions for this study were:

1.What professional development needs are identified by general education and special education teachers who have responsibility for teaching at least one mathematics class? 
2.What are similarities and differences in identified mathematics professional development needs by general education and special education mathematics teachers by grade level (elementary vs. secondary)?

3. What are similarities and differences in identified mathematics professional development needs by teacher classification (general education vs. special education)?

4.What are similarities and differences in identified mathematics professional development needs of special education teachers by grade level (elementary vs. secondary)?

\section{Limitations}

This research has several limitations. First, all participants were from two school systems in Maryland so answers to the questions may differ from those of teachers in other areas of the country. Second, the survey was handed out at the end of the school year, and the timing could have potentially affected the number of voluntary participants. Finally, the survey was administered electronically so the participants may not have volunteered to complete it because of the non-existent rapport with the researcher, because of their limited knowledge of and experience with the technology.

Definition of Terms

Adequate yearly progress (AYP). Each state's individual measure of annual progress toward the goal of $100 \%$ of students achieving the state academic standard (Louie, et al., 2008). 
Mathematics content. Knowledge in the areas of Algebra, Geometry, Measurement, Statistics, Probability, Number and Operations, Processes (communication, problem solving, reasoning and proof, representation, and connections).

Mathematics strategies. Specific methods or approaches to achieve a learning outcome in mathematics. For example, when teaching the students order of operations using the acrostic poem "PEMDAS."

School improvement plan. A two-year plan for those schools and districts who do not meet targets for adequate yearly progress for two consecutive years (Louie, et al., 2008).

Title 1 school. A school that receives funding from Title 1, Part A, of the No Child Left Behind Act. This money is used to provide additional services to those students who are not meeting the standards, or who are at risk of not meeting the standards (U. S. Department of Education, 2008). Professional development. Activities designed to increase the content knowledge and skills of professional educators so that they improve their teaching. Examples of professional development would be working with experienced professionals through coursework, workshops, research, or seminars. 


\section{H A P T E R 2}

\section{Literature Review}

The central purpose of this study was to examine the professional development needs identified by mathematics teachers (responsible for teaching at least one mathematics class), including similarities and differences identified by grade levels (elementary vs. secondary), and teacher classification (general education vs. special education), as well as similarities and differences identified by special education teachers by grade level (elementary vs. secondary). This review of the literature addresses the following topics:

1. Mathematics content standards

2.Professional development
a.standards
b. evidence of effectiveness
c.teachers' perceptions
d. impact on improving teacher outcomes

3.Professional development in mathematics

a.needs identified by general education teachers

b. needs identified by special education teachers

\section{Summary}

\section{Mathematics Content Standards}

In 1989, the National Council of Teachers of Mathematics (NCTM) was given the task of creating standards for mathematics education through teaching and curriculum standards (NCTM, 
2004; NCTM, 1989). These standards were designed to address mathematics applications, as well as the different depths of mathematics concepts (i.e., levels of concepts with problem solving). NCTM collaborated with stakeholders in the mathematics community to revise and improve the original standards developed in 1989 finally publishing Principles and Standards for School Mathematics in 2000. This document (NCTM, 2004) addressed six principles (equity, curriculum, teaching, learning, assessment, and technology and standards: five process standards and five content standards. The process standards included problem solving, reasoning and proof, communication, connections, and representation. The content standards included numbers and operations, algebra, geometry, measure, and data analysis and probability. This document broke down the development of how students should learn mathematics skills from kindergarten through grade 12 through content standards. The content standards were detailed with behavior specific definitions of what the student needs to know in that grade level (Fernandez \& Jones, 2006).

Some evidence has suggested that, in schools that have used these standards and curricula that supports reform, students outscored control groups (Reys, Reys, Lapan, Holliday, \& Wasman, 2003; Schoenfeld, 2002; Senk \& Thompson, 2003). Schoenfeld (2002) reviewed the implementation and evaluation of the NCTM standards in the Pittsburgh, Pennsylvania public school system. This system served about 40,000 students in 97 public schools (Schoenfeld, 2002). He theorized that improving mathematics education in the United States required (a) a quality mathematics curriculum, (b) an educated, stable, professional teaching community, (c) a quality evaluation that is associated with the curricular goals (based on NCTM standards), and (d) progressive steps to achieving master in mathematics content. He felt that the new mathematics curricula (based on NCTM standards and solid assessments) enabled students to perform better as 
well as helped to close mathematics achievement gaps. A quantitative study was conducted by Lubienski (2006) with $13,5114^{\text {th }}$ graders who were assessed by National Assessment of Educational Progress (NAEP), teacher-reported data, and achievement scores. This study was a sub-section of a larger report on $4^{\text {th }}$ grade and $8^{\text {th }}$ graders that found that teacher knowledge of NCTM standards, was a positive predictor of $4^{\text {th }}$ grade and $8^{\text {th }}$ grade student achievement.

Some researchers that have criticized mathematics reform efforts, and do not support it because test scores on NAEP had flat lined during the 1990s, after a period of growth prior to that decade (Loveless \& Diperna, 2000). Information available at websites about mathematics reform (such as Mathematicsematicallycorrect.com or NYCHold.com) shows that even though some researchers have reported the success of the standards, the public is not as convinced of this reform on a larger scale. Some newspaper articles on the website are from the public about mathematics reform state, "the fundamental flaws in the progressive reform movement undermine any hope of fulfillment of the very goals the movement hoped to achieve (Carson, 2004)" or "a solid basis in core math skills is what every child deserves to have from his education. . . if our kids are performing less well than others, it's time to provide them with the curriculum that is proven to help them achieve what others have achieved (Kantor-Goldenberg, 2006).”

\section{Professional Development}

To develop mathematics content knowledge and strategies, teachers need professional development. "The profession has begun to engage in serious standard-setting that reflects a growing knowledge base and a growing consensus about what teachers should know and be able to do to help all students learn according to challenging standards. Most states have launched efforts to restructure schools and invest in greater teacher knowledge (Darling-Hammond, 1996, p. 4).” 
One way to improve teachers' knowledge and understanding is to provide them with professional development (Guskey, 1994). This section reviews the (a) professional development standards, (b) evidence of effectiveness, (c) teachers' perceptions, and (d) impact of professional development on teacher educators.

\section{Professional development standards. The National Staff Development Council (NSDC)}

(2008) standards were developed to help guide the design of professional development based on "results-driven, standards-based, job-embedded" strategies (pg. 1). There are three types of standards: (a) context, (b) process, and (c) content. The context standard discussed goal-orientated learning communities, knowledgeable leaders to continue to improve the professional development, and resources that will support learners. The process standard addressed the use of data to examine growth of students, and sustain continuous improvement. The use of different forms of evaluation was addressed under this standard, as well as the use of research-based activities, the design of learning strategies that meet a specific goal, student learning, and collaboration. The final standard, the content standard, addressed learning based on different types of students, high expectations, and "safe, orderly, and supportive environment" (2008, pg. 6). This standard also discussed that any staff development needs to deepen the educator's content knowledge through the use of research-based strategies and academic standards. Finally, the content standard addressed the teachers' knowledge and skills in the area of the student's family and other individuals who were involved with the child.

Evidence of effectiveness of professional development. After review of these standards, it is important to also consider studies of the effectiveness of professional development. Different professional development models (e.g., collaborative groups) have been shown to increase teacher 
effectiveness (Guttierez 2002; Langer, Colton, and Goff 2003; Little, Gearhart, Curry, \& Kafka, 2003). Professional development that engages teachers with other peers has shown to increase participants' knowledge and ability to incorporate it into the classroom (Banilower and Shimkus 2004). Other researchers have also studied the effectiveness of professional development. Thomas Guskey (2003) completed a meta-analysis of 13 studies to identify the characteristics of effective professional development. He theorized that the effectiveness of professional development is dimensional and complex. Guskey stated, “Take, for example, professional development specifically designed to enhance teachers' content and pedagogical knowledge. Schools in economically depressed areas that have trouble attracting and keeping well qualified teachers and, as a result, have many teachers teaching in subjects outside their area of certification, may benefit greatly from such programs" (p. 749).

Gimbert, Bol, \& Wallace (2007) conducted a mixed-methods comparative study of inservice training with 4 high school mathematics teachers and 2 middle school mathematics teachers who were beginning Algebra 1 teachers. Classroom observations using a Likert scale administered 3 to 4 times per semester, data from standardized state test, and district level quarterly assessments were the data sources. The results showed that teacher training had a significant influence on student achievement in the area of statistics as it relates to Algebra 1 but not in any of the other content areas.

From 2000-2004, 20 New York City public schools and 240 teachers were involved in a quantitative study of implementing specific professional development with the objective of improving students' mathematics skills (Cavanagh, 2005). After implementation of the 
professional development activities, almost $90 \%$ of the 6,000 students improved their mathematics content test scores across racial, ethnic, and gender categories.

Teachers' perceptions of professional development. After review of the effectiveness of professional development, it is important to consider the views of stakeholders who participate in this form of development. Four researchers in the field theorized about and conducted studies that addressed the teachers' perceptions about professional development.

Guskey (1994) theorized that educators not only want appropriate professional development but they also want practical and specific solutions to the problems they are having in the classroom. Supporting Guskey and furthering the theory of teachers' perceptions about professional development, Ball and Cohen (1999) also hypothesized that professional development needs to be presented in a way that is useful for teachers in their classrooms. They suggested that during these sessions teachers want to have examples of materials and activities to work as well as an opportunity to incorporate and adapt them for their own classrooms (Little, 1993).

Cutler \& Ruopp (1993) conducted a mixed-methods study with 32 middle school mathematics teachers in Massachusetts. The participants were enrolled in the Middle School Mathematics Project, a professional development program that taught teachers real-life applications of mathematics and science. The project was designed to show students the importance of math in the work place as well as provide role models for women and people of color in the field of mathematics. One of the teacher's quotes from the qualitative data stated, “. . .most people don't realize that teachers almost never get to talk to anyone about their work, to learn from one another, to be professionals together. Because of you and this project, I now have colleagues I'm not afraid to ask for help, colleagues who will cheer me on to try new things even 
when I fail"' (p. 37). Researchers theorized that teachers do not want to give up a lot of time away from their students unless they feel that the experience they are gaining is valuable and important to their teaching.

A quantitative study conducted by Bezzina (2006) with beginning teachers (i.e., within their first three years of teaching) in primary and secondary schools in Malta found that the majority of teachers felt it was important to keep up with up-to-date professional development. Forty-five percent of the teachers responded positively to professional development from (a) course work, (b) seminars, and (c) meetings. Other forms of professional development such as teaching with other teachers, workshops, and conferences did not receive a high rating. The teachers felt that the reason that there was no professional development in their schools or that there was not enough professional development was "time constraints (28\%)" (p. 424), "reluctance to change (22\%)" (p. 424), and "lack of financial resources (21\%)" (p. 424).

Impact on improving teacher outcomes. Three districts serving large numbers of poor students in New Jersey participated in an action research project (Firestone, et al., 2005). The schools ranged from 7,500 to 12,000 students. The researchers conducted interviews and reviewed documents (e.g., school improvement plans, budgets, records). The results showed that a subjectorientation approach to professional development (emphasizing teaching strategies for subject areas) was the most successful. Fourteen out of 28 participants reported that the strategies methods (i.e., methods for student-centered education where students actively contribute in the learning process, group work that facilitated conversation and collaboration, evaluation strategies that helped students control their learning, and ideas on how to relate content with context outside of the classroom) were helpful in increasing the knowledge and skills teachers need to improve and 
change instructional practice. However, 6 of the 28 teachers (mostly from high school) stated that the professional development did not meet their needs because it did not address on the subject that they taught. These results suggest that professional development may only meet teachers' needs if it addresses the subject area that they teach.

\section{Professional Development in Mathematics}

The importance of mathematics professional development comes as no surprise. The United States has been ranked $25^{\text {th }}$ out of 30 nations (between Spain and Portugal) in mathematics literacy (Darling-Hammond, 2007). The National Commission on Teaching America's Future (1996) found that almost $25 \%$ of high school teachers lack a minor in the field that they teach, a number that is even higher in mathematics, so often teachers who teach math classes are not certified. These alarming statistics have led some to design and study professional development programs in the area of mathematics. This section is organized by mathematics professional development needs identified by (a) general education teachers, and (b) special education teachers. It is important to note that the studies that are discussed under the subheading Needs Identified by General Education Teachers are studies that also include the special education teachers. Those discussed under the sub-heading of Needs Identified by Special Education Teachers are studies that only included special education teachers.

Needs identified by general education teachers. In a qualitative study conducted by Burch and Spillane (2003), 15 elementary school administrators and 15 curriculum coordinators from 8 urban districts provided suggestions about professional development through interviews, observations, and video-tapes of practice leadership. One participant (a curriculum coordinator) noted the importance of providing support within the school. She stated that teachers told her, "The 
first time we did this last year and it was very difficult but they said to us, "You know what? We would've never guessed these kids could've done this. It really shows what they can do (p. 531532). Through the support of the coordinator, the teachers were able to note the success of their students. The researchers also found that, through meetings and classroom visits teachers were more receptive to staff development because they were able to ask questions and fully understand the process.

Wooilla, Boscardin, and Dodds (1997) conducted a qualitative study with 22 educators in a K-6 elementary school. They found that other time commitments (e.g., faculty meetings, curriculum meetings, individualized education team meetings) impacted the amount of time available for mathematics professional development. One teacher discussed her difficulty in planning her professional development project: "Either having a time when she comes in and takes a look for ten minutes, or we sit down once a week for fifteen minutes, but it's either going to be in small chunks like that or it's just going to continue to "plane" the way it's going now" (p. 300). Another participant discussed her need to incorporate professional development into the work week, "Once you've put boundaries on it. . the time commitment has got to be put in so that it becomes like another meeting or another class, and it's really a part of the backbone of the week" (p. 301). An additional teacher discussed the requirement for peer support when implementing professional development, and stated, "We needed. . the commitment to each other, Christine and I to each other, to have these meetings and to keep this contract because it was so beneficial to both of us. In the beginning the commitment to the meetings was because (the research assistant) was going to come with her tape recorder [all laugh]" (p. 303). 
In a qualitative study conducted by Oelklaus (1999), three in-depth probes were used and administered over three years with 60 staff developers and teachers in Texas. The researcher concluded that, if staff developers did not have experience, then they had a hard time designing the professional development for other people. So, she found that personal experience was extremely influential in the design, development, and implementation of professional development. In the same study, Oelkaus (1999) also asked staff developers why they did not offer teachers the staff development that they need. She suggested that it was because administrators did not have the experience or vision to develop or offer effective teacher training, policy makers were not providing adequate resources, and teachers did not want to get involved. During a final in-depth probe, 120 teachers who participated stated that they were being asked what staff development that they needed, but the ideas that they offered were not being implemented in professional development sessions.

According to Corcoran (1995), it is important that, as districts and school systems design their programs they first need to involve the teachers who are going to participate in the process. He further theorized that, "teachers have a great deal of insight into what has made professional development effective or ineffective in the past, and will be more likely to support changes to the current system if they have been a significant part of the improvement process" (p. 9).

In summary, teachers feel that they need repetition and continuous support throughout the school-year (Burche \& Spillane, 2003). Teachers' thoughts and ideas on professional development need to be considered because they will be more willing to participate (Corcoran, 1995; Oelklaus, 1999). If they are working with other teachers they need the commitment to each other to meet together to continually work on professional development (Wooilla, et al., 1997). To even further 
enhance this point, a specific time for this collaboration needs to be put in place so it becomes a part of the routine (Wooilla, et al., 1997).

Needs identified by special education teachers. Kimmel, Deek, and O’Shea (1999) conducted a three year study with 84 participants (three cohorts of 28 elementary and middle school teachers who worked with students with disabilities) in the New Jersey/New York metropolitan area. Cohorts were added each succeeding year of the research project. The researchers found that, in the mathematics professional development that they designed for the participants; the teachers had a "serious gap" linking their understanding of the need for adaptations and their ability to administer the adaptations in their classrooms for students who were diverse learners.

\section{Summary}

Since relatively little is known about mathematics professional development of teachers, especially special education teachers, more research is needed. Guskey (2002) stated that teachers, administrators, and parents play an important role in the development of students. This study addressed the needs identified by one specific group of stakeholders: the teachers. The research variables were selected for this study are based on the work of Cwikla (2002; 2004) who studied the knowledge of K-12 teachers related to the NCTM standards. 


\title{
C H A P T E R 3
}

\author{
Method
}

\section{Introduction}

This chapter restates the purpose of the research and the research questions and describes the process for selection of participants was described. The design of the instrument, the Professional Development Mathematics Inventory, is discussed as well as the steps that were taken to make it a valid and reliable instrument to measure teachers' reported needs of mathematics professional development. The data collection procedures and the methods of data analysis that were used to answer each of the research questions are also described.

\section{Research Questions}

The purpose of this study was to examine the professional development needs identified by general education mathematics teachers and special education mathematics teachers in three school districts in Maryland. The research questions were developed to assess the perceptions of general education mathematics teachers and special education mathematics teachers, including the similarities and differences of the professional development needs for these two groups. The research questions were as follows:

1. What professional development needs are identified by general education and special education teachers who have responsibility for teaching at least one mathematics class? 
2. What are similarities and differences in identified mathematics professional development needs by general education and special education mathematics teachers by grade level (elementary vs. secondary)?

3. What are similarities and differences in identified mathematics professional development needs by teacher classification (general education vs. special education)?

4. What are similarities and differences in identified mathematics professional development needs of special education teachers by grade level (elementary vs. secondary)?

This chapter is organized in four sections: (a) Design, (b) Instrumentation, (c) Data Collection, and (d) Data Analysis.

Design

This research employed a quantitative approach using the casual comparative design (Johnson \& Christensen, 2007). The casual comparative design attempts to identify a relationship between variables across two or more groups. Each of the research questions stated above compared two groups: the first research question compared all teachers who teach at least one math class; the second research question compared teachers who teach in elementary schools and teachers who teach in secondary schools; the third research question compared general education teachers and special education teachers; and the fourth research question compared elementary special education teachers and secondary special education teachers. In these research questions, no variables are being manipulated; instead, the influence of different characteristics on how the teachers report their mathematics professional development needs was examined. 
For the first question, the independent variables were demographic characteristics (e.g., years of experience, level of education, certification, gender), and the dependent variable was how respondents identified items on a survey of professional development needs in mathematics. For the second question, the independent variable was general education and special education mathematics teachers' grade level (elementary vs. secondary) and the dependent variable was how respondents rated items on a survey of professional development needs in mathematics. For the third question, the independent variable was teacher classification (general education vs. special education) and the dependent variable was how respondents rated items on a survey of professional development needs in mathematics. For the fourth question, the independent variable was grade level (elementary vs. secondary) of special education teachers and the dependent variable was how respondents rate items on a survey of professional development needs in mathematics.

\section{Participants}

Participants were selected from a subset of general education mathematics teachers and special education mathematics teachers in three school systems in Maryland. The number of people living in each county and the number of people per square mile were used to identify the school systems selected to participate in this study: one small, one medium, and one large. The smallest school system had 4,668 students enrolled, compared to the middle school system with 40,212 students enrolled, and the largest school system with 107,043 students enrolled.

School System 1 (SS 1) had approximately 29,859 people (U.S. Census Bureau, 2000), or 46.1 people per square mile. The people who live within the county were $98.7 \%$ Caucasian, $0.6 \%$ Black, and $0.5 \%$ Hispanic or Latino and $0.4 \%$ of the people report two or more races. At that time, 4,668 students were enrolled in this school system (Council of Chief State School Officers, 2008). 
The students attended 2 high schools, 2 middle schools, 9 K-6 elementary schools, 2 K-8 elementary schools, and 1 alternative school. There were 12.9 students per teacher (Council of Chief State School Officers, 2008). There were approximately 361 teachers in this school system (S. Waggoner, personal communication, December 4, 2008). There were approximately 217 elementary teachers and 144 secondary teachers.

School System 2 (SS 2) had approximately 241,402 people, or 496.4 people per square mile (U.S. Census Bureau, 2000). The people who lived within the county are $84.0 \%$ Caucasian, 12.2\% Black, 2.1\% Asian, and 2.4\% Hispanic or Latino and 1.5\% of the people report two or more races. At that time, 40,212 students were enrolled in this school system (Council of Chief State School Officers, 2008). The students in SS 2 had the opportunity to attend 12 high schools, 11 middle schools, 33 elementary schools, and 2 alternative schools. There were 15.9 students per teacher (Council of Chief State School Officers, 2008). There were approximately 2,841 teachers in this school system (R. Plunkett, personal communication, December 3, 2008). There were approximately 1,643 elementary teachers and 1,198 secondary teachers.

School System 3 (SS 3) had approximately 787,384 people, or 1,260.1 people per square mile (U.S. Census Bureau, 2000). The people who lived within the county are $69.6 \%$ Caucasian, 24.7\% Black, $4.0 \%$ Asian, and 2.7\% Hispanic or Latino and $1.3 \%$ of the people reported two or more races. At that time, 107,043 students were enrolled in this school system (Council of Chief State School Officers, 2008). The students in SS 3 had the opportunity to attend 29 high schools, 31 middle schools, 105 elementary schools, and 5 alternative schools. There were 14.5 students per teacher (Council of Chief State School Officers, 2008). Approximately 8,850 teachers were in this 
school system (R. Spencer, personal communication, December 3, 2008). There were approximately 5,621 elementary teachers and 3,229 secondary teachers.

After the study was approved by the dissertation committee and the West Virginia University Institutional Review Board (IRB), each school system was contacted to begin the procedures for applying for permission to conduct research. Once the study was approved the school system, the researcher contacted, that system's research coordinator and asked him/her to send the survey to the listserv (i.e., teachers within that school system). The researcher monitored the number of surveys completed.

Two of the selected school systems agreed to participate in the study: SS 2 ultimately chose not to participate (Appendix C). All teachers in each of the two school systems which approved the study were sent the survey; however, only those who identified themselves as teaching at least one mathematics class and also choose to complete the survey became participants. Thus, the criteria for selection of the participants were that they held a position in a public school within one of these two counties, their position as either a general education teacher or a special education teacher included the assignment to teach at least one class in mathematics, and they voluntarily chose to participate in the study. In each of the two participating school systems, the teachers were contacted by e-mail and asked to voluntarily complete the survey. When participants began the survey, the first question that they were asked was "Do you teach at least one subject in mathematics?" If the participants answered "yes" then they continued with the survey. If the participants answered "no" they were thanked for their time and prompted with a brief explanation as to why they were not appropriate participants for the study. The predicted sample size of teachers who teach mathematics in the two school systems was 6,175 , a number determined by the 
fact that most elementary and special education teachers taught mathematics, and about $10 \%$ of secondary teachers taught mathematics. The goal was to recruit at least $50 \%$ of teachers from each school system or a total of 3,088 teachers.

Two weeks after distribution of the survey, the desired sample size had not been reached, so the researcher contacted the school administrators again to encourage teachers to volunteer to participate. The researcher sent an e-mail to the administrators to ask that they encourage their teachers to complete the survey. After three weeks, there was still a need for volunteers, so the administrators received a phone call to prompt participants to participate.

At the beginning of the study, the research coordinator was contacted in SS 1 and she sent out the e-mail to the potential participants. The researcher then contacted the principal's in SS 3 to request that they forward on the study to their teachers. From the two school systems, 484 participants volunteer to complete the survey, 26 participants entered the survey but did not teach at least one math class, so the sample was 458 math teachers. Of those 458 math teachers; 69 of them taught special education, 383 of them taught general education, and 5 of the participants did not specify their current position. The participants included 58 males, 390 females, and 9 participants did not specify their gender. The desired sample size was not achieved and this was because of many factors (e.g., end of the year and teacher's did not want to complete, principal's never sent out the e-mail the teachers).

\section{Instrumentation}

Since there was currently not an instrument to evaluate teachers' views about mathematics professional development, the researcher designed an assessment. The instrument, titled Mathematics Professional Development Inventory (MPDI), was a tool that assessed teachers' 
ratings of their professional development needs related to mathematics. The assessment was designed to include a set of questions about demographic characteristics, followed by a series of statements in subcategories, using a 5-point Likert scale with descriptors adapted to each item (such as "extremely needed" to "not needed" or "exceptional" to "poor").

The instrument's content validity was ensured through multiple steps: (a) review of the professional literature in teaching mathematics and mathematics professional development, (b) review of the Maryland Mathematics Content Standards, (c) independent examination of the MPDI items by two mathematics experts, and (d) independent examination of the MPDI items by three general education mathematics teachers and two special education mathematics teachers. Experts in this study were defined as individuals holding a doctorate in mathematics or mathematics education, as well as at least 2 years teaching experience at the university or college level. Two mathematics experts reviewed the instrument; one reviewer was a faculty member within the College of Human Resources and Education at West Virginia University, and the other was a faculty member in special education at the University of Missouri-Columbia who was known nationally in the mathematics professional development community. These expert reviewers were asked to screen the assessment for content, wording, and ambiguity. After this review of the survey statements, three general education mathematics teachers and two special education mathematics teachers (one from each of the following areas: general education mathematics elementary teacher, general education mathematics middle school teacher, general education mathematics high school teacher, inclusive special education mathematics teacher, and self-contained special education mathematics teacher) from another school system not participating in the study also reviewed the statements for content, wording, and ambiguity. The participants who reviewed the survey 
statements were selected by their qualifications that included certification in general education or special education and teaching experience related to mathematics for at least five years. The general education mathematics elementary teacher taught at an elementary school in Morgantown, West Virginia, and had been in this position for 8 years. The general education mathematics middle school teacher taught at middle school in Stamford, Connecticut, and had been in this position for 5 years. The general education mathematics high school teacher taught at a high school in Morgantown, West Virginia. The inclusive special education mathematics teacher taught at a high school in Morgantown, West Virginia, and had been in this position for over 20 years. The inclusive special education teacher co-taught mathematics with the general education high school mathematics teacher. The self-contained special education teacher taught at a middle school in Ridgewood, New Jersey, and had been in this position for 13 years.

The suggestions that were made by the reviewers were mainly wording of the questions, layout of the survey, and typos. All of the reviewers comments were taken into consideration and the survey was changed appropriately. The survey (Appendix A) that is included reflects these changes.

\section{Data Collection}

Data were collected from the identified teachers by means of an online survey containing the MPDI items. This survey had (a) a "cover letter" or introduction presenting an overview of the study, (b) an explanation of a drawing for a prize for completing the study, and (c) a website link for the individuals to go to and complete the survey (See Appendix). In the cover letter, besides the introduction and website link, there was an explanation that after completion of the survey there was an entry form to complete if they wanted to enter to win a prize (\$100 VISA gift card). Next, 
there were two sections of the survey; the first section of the survey asked respondents to answer demographic characteristics, and the second section of the survey asked respondents to respond to questions about different mathematics professional development needs. For example, one of the statements in the survey asked, "How much mathematics professional development do you feel

you need," to which the participant responded using a Likert scale with responses "A lot," "Quite a bit," "Some," "A little," or "None."

After completion of the survey, participants were asked if they want to enter to win a Visa gift card for $\$ 100.00$. The drawing was to encourage participants to complete the survey. This opportunity to participate in the drawing came up separately after the participant completed the survey and pushed the submit button. At that point, a screen appeared that asked participants if they would like to enter into a drawing, with a brief explanation that their contact information was not attached to the survey that was just completed, and there was no way the researcher or anyone else could connect the survey responses with the information from the drawing. If a participant chose to enter the drawing, s/he typed in name, address, and phone number, and then submitted this information into the pool of other participants. After all participants completed the survey, one participant who completed an entry for the gift card after the survey was randomly selected to receive the gift card, which was mailed to the person.

\section{Data Analysis}

Quantitative analysis was conducted using the numeric data obtained from items on the Mathematics Professional Development Inventory (MPDI). Items 1-13 on the MPDI were responses to demographic questions that served as independent variables. Items 14-41 were ratings of professional development needs that served as dependent variables. Items 15, 19-26, 28, and 
32-41 were put into the survey at the request of the school systems, and were not analyzed for this study. Demographic data and ratings data were entered into SPSS 16.0 for each of the participants. In doing so, the researcher compared scores to determine the (1) professional development needs identified by teachers who teach at least one mathematics class (scores across all participants), (2) similarities and differences between grade levels (elementary vs. secondary) using scores sorted by grade level, (3) similarities and differences between teacher classification (e.g., general education teacher vs. special education teacher) with scores sorted by teacher classification and, (4) similarities and differences between elementary special education teachers and secondary special education teachers with scores of special education teachers only sorted by grade level. The frequencies and percentages of the responses are displayed in tables, comparisons are displayed in graphs, and the findings of statistical analyses are presented in the narrative.

Research Question 1. To answer Research Question 1 and determine the professional development needs identified by teachers who teach at least one mathematics class, data from questions $14,16,17,18,27,29,30$, and 31 on the survey were used (See Table A). The independent variables for each of these questions were years of teaching experience, specific grade level, gender, number of math classes that they teach, school organization, role in education, degree, number of math methods courses taken, number of math content courses taken, certification, certified in mathematics, and highly qualified in mathematics. The dependent variable for question 14 and 27 was the professional development rating (for mathematics content or for mathematics teaching strategies). The dependent variable for questions 16 and 29 was the additional mathematics professional development need rating (for mathematics content or for mathematics teaching strategies). The dependent variable for questions 17 and 30 was the 
mathematics professional development area that is needed rating (for mathematics content or for mathematics teaching strategies). The dependent variable for questions 18 and 31 was the rating of the mathematics area that is not needed (for mathematics content or for mathematics teaching strategies).

For each of the 11 independent variables, the relationships to the dependent variables were displayed as frequency tables because the variables are nominal (e.g., Gender) or ordinal (e.g. Rating of Content Knowledge) rather than continuous (i.e., interval or ratio). Non-parametric rather than parametric statistics were used to interpret the data in this study; Chi-Square was used to compare the frequencies to see if they were significantly different between groups (Fraenkel \& Wallen, 2009). The table showed a visual display of data. If the Chi-Square analysis yielded a statistically significant difference the $p$ is <.05. 
Table A

Variables and Analysis for Research Question 1:

Professional Development Needs for Teachers Who Teach at Least One Mathematics Class

\begin{tabular}{|c|c|c|}
\hline $\begin{array}{l}\text { Survey } \\
\text { Item }\end{array}$ & Independent Variables & Example of Choice \\
\hline 1 & Gender & $\mathrm{M}, \mathrm{F}$ \\
\hline 2 & Number of Math Classes they Teach & $1,2,3,4 \ldots$ \\
\hline 5 & School Organization & One classroom, Rotate \\
\hline 6 & Role in Special Education & Self-contained, resource room ... \\
\hline 7 & Degree & Doctorate, Masters, Bachelor's with. .. \\
\hline 8 & Number of Math Content Courses Taken & $1-2,3-4 \ldots$ \\
\hline 9 & Number of Math Methods Courses Taken & $1-2,3-4 \ldots$ \\
\hline 10 & Years of Experience & $1^{\text {st }}$ year, $1-3,4-9 .$. \\
\hline 11 & Certification Year & 4 categories \\
\hline 12 & Certified in Mathematics & Yes, No \\
\hline 13 & Highly Qualified in Mathematics & Yes, No \\
\hline $\begin{array}{l}\text { Question \# } \\
\text { on Survey }\end{array}$ & Dependent Variables & Rating of: \\
\hline 14 & Math Content Knowledge & $\begin{array}{l}\text { Exceptional, Above Average, Average, } \\
\text { Below Average, Poor }\end{array}$ \\
\hline 16 & $\begin{array}{l}\text { Professional Development Need of } \\
\text { Mathematics Content Knowledge }\end{array}$ & $\begin{array}{l}\text { Excellent, Above Average, Average, } \\
\text { Below Average, Poor }\end{array}$ \\
\hline 17 & Need More Knowledge in Subject & $\begin{array}{l}\text { Algebra, Geometry, Measurement, } \\
\text { Statistics, Probability, Number and } \\
\text { Operations, Processes }\end{array}$ \\
\hline 18 & Do Not Need More Knowledge in Subject & $\begin{array}{l}\text { Algebra, Geometry, Measurement, } \\
\text { Statistics, Probability, Number and } \\
\text { Operations, Processes }\end{array}$ \\
\hline 27 & Ability to Teach Mathematics & $\begin{array}{l}\text { Exceptional, Above Average, Average, } \\
\text { Below Average, Poor }\end{array}$ \\
\hline 29 & $\begin{array}{l}\text { Professional Development Need for Teaching } \\
\text { Math }\end{array}$ & $\begin{array}{l}\text { Excellent, Above Average, Average, } \\
\text { Below Average, Poor }\end{array}$ \\
\hline 30 & $\begin{array}{llll}\text { Need More } & \text { Strategies } & \text { for } & \text { Teaching } \\
\text { Mathematics } & & & \end{array}$ & $\begin{array}{l}\text { Algebra, Geometry, Measurement, } \\
\text { Statistics, Probability, Number and } \\
\text { Operations, Processes }\end{array}$ \\
\hline 31 & $\begin{array}{l}\text { Do Not Need More Strategies for Teaching } \\
\text { Math }\end{array}$ & $\begin{array}{l}\text { Algebra, Geometry, Measurement, } \\
\text { Statistics, Probability, Number and } \\
\text { Operations, Processes }\end{array}$ \\
\hline \multicolumn{3}{|c|}{ Analysis } \\
\hline
\end{tabular}

Note. Survey Item 3 was not analyzed in this research question because it was answered in Research Question 2. Survey Item 4 was not analyzed in this research question because it was a question to identify which school system the respondent was from. Survey Items 15, 19-26, 28, 32-41 were not analyzed because they were put into the survey at request of the school system. 
Research Question 2. To answer Research Question 2 and determine if mathematics teachers working at different grade levels (elementary or secondary) responded similarly or differently in identifying professional development needs, questions $14,16,17,18,27,29,30$, and 31 on the survey were used (See Table B). The independent variable for this question was grade level (i.e., elementary versus secondary). The dependent variable for questions 14 and 27 was the professional development rating (for mathematics content or for mathematics teaching strategies). The dependent variable for questions 16 and 29 was the additional mathematics professional development need rating (for mathematics content or for mathematics teaching strategies). The dependent variable for questions 17 and 30 was the rating of the mathematics professional development area that is needed (for mathematics content or for mathematics teaching strategies). The dependent variable for questions 18 and 31 was the rating of the mathematics area that is not needed (for mathematics content or for mathematics teaching strategies).

For the independent variable, Grade Level, the relationships to the dependent variables were displayed as frequency tables because the variables are nominal (i.e., Grade Level) or ordinal (e.g. Rating of Content Knowledge) rather than continuous (i.e., interval or ratio). Non-parametric rather than parametric statistics were used to interpret the data in this study; Chi-Square was used to compare the frequencies to see if they were significantly different between groups (Fraenkel \& Wallen, 2009). If the Chi-Square analysis yielded a statistically significant difference the $p$ is <.05. 
Table B

Variables and Analysis for Research Question 2:

Similarities and Differences in Identified Needs by Grade Level

\begin{tabular}{|c|c|c|}
\hline $\begin{array}{l}\text { Survey } \\
\text { Item }\end{array}$ & Independent Variables & Example of Choice \\
\hline 3 & Grade Level & Elementary, Secondary \\
\hline $\begin{array}{c}\text { Survey } \\
\text { Item }\end{array}$ & Dependent Variables & Rating of: \\
\hline 14 & Math Content Knowledge & $\begin{array}{l}\text { Exceptional, Above Average, } \\
\text { Average, Below Average, Poor }\end{array}$ \\
\hline 16 & $\begin{array}{l}\text { Professional Development Need of Mathematics } \\
\text { Content Knowledge }\end{array}$ & $\begin{array}{l}\text { Excellent, Above Average, } \\
\text { Average, Below Average, Poor }\end{array}$ \\
\hline 17 & Need More Knowledge in Subject & $\begin{array}{l}\text { Algebra, Geometry, } \\
\text { Measurement, Statistics, } \\
\text { Probability, Number and } \\
\text { Operations, Processes }\end{array}$ \\
\hline 18 & Do Not Need More Knowledge in Subject & $\begin{array}{l}\text { Algebra, Geometry, } \\
\text { Measurement, Statistics, } \\
\text { Probability, Number and } \\
\text { Operations, Processes }\end{array}$ \\
\hline 27 & Ability to Teach Mathematics & $\begin{array}{l}\text { Exceptional, Above Average, } \\
\text { Average, Below Average, Poor }\end{array}$ \\
\hline 29 & Professional Development Need for Teaching Math & $\begin{array}{l}\text { Excellent, Above Average, } \\
\text { Average, Below Average, Poor }\end{array}$ \\
\hline 30 & Need More Strategies for Teaching Mathematics & $\begin{array}{l}\text { Algebra, Geometry, } \\
\text { Measurement, Statistics, } \\
\text { Probability, Number and } \\
\text { Operations, Processes }\end{array}$ \\
\hline 31 & Do Not Need More Strategies for Teaching Math & $\begin{array}{l}\text { Algebra, Geometry, } \\
\text { Measurement, Statistics, } \\
\text { Probability, Number and } \\
\text { Operations, Processes }\end{array}$ \\
\hline \multicolumn{3}{|c|}{ Analysis } \\
\hline
\end{tabular}

Note. Survey Items 15, 19-26, 28, 32-41 were not analyzed because they were put into the survey at the request of the school system. 
Research Question 3. To answer Research Question 3 and determine if mathematics teachers with different classifications (e.g., general education or special education) responded similarly or differently in identifying professional development needs, questions $14,16,17,18,27$, 29, 30, and 31 on the survey were used (See Table C). The independent variable for this question was teacher classification (i.e., general education versus special education). The dependent variable for questions 14 and 27 was the professional development rating (for mathematics content or for mathematics teaching strategies). The dependent variable for questions 16 and 29 was the additional mathematics professional development need rating (for mathematics content or for mathematics teaching strategies). The dependent variable for questions 17 and 30 was the mathematics professional development area that is needed rating (for mathematics content or for mathematics teaching strategies). The dependent variable for questions 18 and 31 was the rating of the mathematics area that is not needed (for mathematics content or for mathematics teaching strategies).

For each of the independent variable, Teacher Classification, the relationship to the dependent variables were displayed as frequency tables because the variables are nominal (i.e., Teacher Classification) or ordinal (e.g. Rating of Content Knowledge) rather than continuous (i.e., interval or ratio). Non-parametric rather than parametric statistics were used to interpret the data in this study; Chi-Square was used to compare the frequencies to see if they were significantly different between groups (Fraenkel \& Wallen, 2009). If the Chi-Square analysis yielded a statistically significant difference the $p$ is $<.05$. 
Table C

Variables and Analysis for Research Question 3:

Similarities and Differences in Identified Needs by Teacher Classification

\begin{tabular}{|c|c|c|}
\hline $\begin{array}{c}\text { Survey } \\
\text { Item }\end{array}$ & Independent Variables & Example of Choice \\
\hline 2 & Teacher Classification & $\begin{array}{l}\text { General Education, Special } \\
\text { Education }\end{array}$ \\
\hline $\begin{array}{c}\text { Survey } \\
\text { Item }\end{array}$ & Dependent Variables & Rating of: \\
\hline 14 & Math Content Knowledge & $\begin{array}{l}\text { Exceptional, Above Average, } \\
\text { Average, Below Average, Poor }\end{array}$ \\
\hline 16 & $\begin{array}{l}\text { Professional Development Need of Mathematics } \\
\text { Content Knowledge }\end{array}$ & $\begin{array}{l}\text { Excellent, Above Average, } \\
\text { Average, Below Average, Poor }\end{array}$ \\
\hline 17 & Need More Knowledge in Subject & $\begin{array}{l}\text { Algebra, Geometry, } \\
\text { Measurement, Statistics, } \\
\text { Probability, Number and } \\
\text { Operations, Processes }\end{array}$ \\
\hline 18 & Do Not Need More Knowledge in Subject & $\begin{array}{l}\text { Algebra, Geometry, } \\
\text { Measurement, Statistics, } \\
\text { Probability, Number and } \\
\text { Operations, Processes }\end{array}$ \\
\hline 27 & Ability to Teach Mathematics & $\begin{array}{l}\text { Exceptional, Above Average, } \\
\text { Average, Below Average, Poor }\end{array}$ \\
\hline 29 & Professional Development Need for Teaching Math & $\begin{array}{l}\text { Excellent, Above Average, } \\
\text { Average, Below Average, Poor }\end{array}$ \\
\hline 30 & Need More Strategies for Teaching Mathematics & $\begin{array}{l}\text { Algebra, Geometry, } \\
\text { Measurement, Statistics, } \\
\text { Probability, Number and } \\
\text { Operations, Processes }\end{array}$ \\
\hline 31 & Do Not Need More Strategies for Teaching Math & $\begin{array}{l}\text { Algebra, Geometry, } \\
\text { Measurement, Statistics, } \\
\text { Probability, Number and } \\
\text { Operations, Processes }\end{array}$ \\
\hline \multicolumn{3}{|c|}{ Analysis } \\
\hline & $\begin{array}{l}\text { ith each independent variable to assess } r \\
\text { he Chi-Square test yielded a value of } p<\text {. }\end{array}$ & $\begin{array}{l}\text { onships to the appropriate } \\
\text { ere was a statistically }\end{array}$ \\
\hline
\end{tabular}

Note. Survey Items 15, 19-26, 28, 32-41 were not analyzed because they were put into the survey at the request of the school system. 
Research Question 4. To answer Research Question 4 and determine if special education teachers working at different grade levels (elementary or secondary) responded similarly or differently in identifying professional development needs, questions $14,16,17,18,27,29,30$, and 31 on the survey were used (See Table D). The independent variable for this question was special education teachers' grade level (i.e., elementary versus secondary). The dependent variable for questions 14 and 27 was the professional development rating (for mathematics content or for mathematics teaching strategies). The dependent variable for questions 16 and 29 was the additional mathematics professional development need rating (for mathematics content or for mathematics teaching strategies). The dependent variable for questions 17 and 30 was the mathematics professional development area that is needed rating (for mathematics content or for mathematics teaching strategies). The dependent variable for questions 18 and 31 was the rating of the mathematics area that is not needed (for mathematics content or for mathematics teaching strategies).

For each of the independent variable, Special Education Teachers' Grade Level, the relationship to the dependent variables were displayed as frequency tables because the variables are nominal (i.e., Special Education Teachers' Grade Level) or ordinal (e.g. Rating of Content Knowledge) rather than continuous (i.e., interval or ratio). Non-parametric rather than parametric statistics were used to interpret the data in this study; Chi-Square was used to compare the frequencies to see if they were significantly different between groups (Fraenkel \& Wallen, 2009). If the Chi-Square analysis yielded a statistically significant difference the $p$ is <.05. 
Table D

Variables and Analysis for Research Question 4:

Similarities and Differences in Identified Needs by Special Education Teachers' Grade Level

\begin{tabular}{|c|c|c|}
\hline $\begin{array}{c}\text { Survey } \\
\text { Item }\end{array}$ & Independent Variables & Example of Choice \\
\hline 3 & Grade Level & Elementary, Secondary \\
\hline $\begin{array}{c}\text { Survey } \\
\text { Item }\end{array}$ & Dependent Variables & Rating of: \\
\hline 14 & Math Content Knowledge & $\begin{array}{l}\text { Exceptional, Above Average, } \\
\text { Average, Below Average, Poor }\end{array}$ \\
\hline 16 & $\begin{array}{l}\text { Professional Development Need of Mathematics } \\
\text { Content Knowledge }\end{array}$ & $\begin{array}{l}\text { Excellent, Above Average, } \\
\text { Average, Below Average, Poor }\end{array}$ \\
\hline 17 & Need More Knowledge in Subject & $\begin{array}{l}\text { Algebra, Geometry, } \\
\text { Measurement, Statistics, } \\
\text { Probability, Number and } \\
\text { Operations, Processes }\end{array}$ \\
\hline 18 & Do Not Need More Knowledge in Subject & $\begin{array}{l}\text { Algebra, Geometry, } \\
\text { Measurement, Statistics, } \\
\text { Probability, Number and } \\
\text { Operations, Processes }\end{array}$ \\
\hline 27 & Ability to Teach Mathematics & $\begin{array}{l}\text { Exceptional, Above Average, } \\
\text { Average, Below Average, Poor }\end{array}$ \\
\hline 29 & Professional Development Need for Teaching Math & $\begin{array}{l}\text { Excellent, Above Average, } \\
\text { Average, Below Average, Poor }\end{array}$ \\
\hline 30 & Need More Strategies for Teaching Mathematics & $\begin{array}{l}\text { Algebra, Geometry, } \\
\text { Measurement, Statistics, } \\
\text { Probability, Number and } \\
\text { Operations, Processes }\end{array}$ \\
\hline 31 & Do Not Need More Strategies for Teaching Math & $\begin{array}{l}\text { Algebra, Geometry, } \\
\text { Measurement, Statistics, } \\
\text { Probability, Number and } \\
\text { Operations, Processes }\end{array}$ \\
\hline \multicolumn{3}{|c|}{ Analysis } \\
\hline $\begin{array}{l}\text { de } \\
\text { si }\end{array}$ & $\begin{array}{l}\text { used with each independent variable to assess rel } \\
\text { ble. If the Chi-Square test yielded a value of } p<.0 \\
\text { rence. }\end{array}$ & $\begin{array}{l}\text { ionships to the appropriate } \\
\text { there was a statistically }\end{array}$ \\
\hline
\end{tabular}

Note. Survey Items 15, 19-26, 28, 32-41 were not analyzed because they were put into the survey at the request of the school system.

Summary 
This chapter restated the purpose of the research and the research questions. It described how participants were selected through purposeful sampling of general education mathematics teachers and special education mathematics teachers in two school systems. It described how the instrument was designed to be a valid and reliable measure of teachers' views of their professional development needs. This chapter also presented the data collection procedures and the methods of the data analysis that will be used to answer each of the research questions. 


\section{CHAPTER 4}

\section{Results}

The purpose of this chapter is to report the findings of this study. The chapter begins with a review of the research questions and a review of the analysis procedure. The chapter then presents the results of the data analysis that answer the research questions of this study, and closes with a summary of findings. The research questions were as follows:

1. What professional development needs are identified by general education and special education teachers who have a responsibility for teaching at least one mathematics class?

2. What are similarities and differences in identified mathematics professional development needs by general education and special education mathematics teachers by grade level (elementary vs. secondary)?

3. What are similarities and differences in identified mathematics professional development needs by teacher classification (general education vs. special education)?

4. What are similarities and differences in identified mathematics professional development needs of special education teachers by grade level (elementary vs. secondary)?

Review of Analysis Procedure

The data was collected from the MPDI over the course of three weeks during Spring 2009, and each participant answered the online survey once. The ratings of items 1-12 on the MPDI were 
demographic questions served as independent variables. The ratings of items 13-41 were ratings that served as dependent variables. Items 14, 18-25, 27, and 31-41 were put into the survey at the request of the school system, and were not analyzed for this study. A Chi-Square analysis method was calculated for the independent and dependent variables to determine significance $(p<.05)$.

At the beginning of the study, the research coordinator was contacted in SS 1, and she sent out the e-mail to the potential participants. The researcher then contacted the principal's in SS 3 to request that they forward on the study to their teachers. From the two school systems, 484 participants volunteered to complete the survey, 26 participants entered the survey but did not teach at least one math class, so the sample was 458 math teachers. Of those 458 math teachers, 69 of them taught special education, 383 of them taught general education, and 5 of the participants did not specify their current position. The participants included 58 males, 390 females, and 9 participants did not specify their gender.

\section{Results by Research Questions}

The results in this section are organized first by the research question. Then within the research question, a summary of results are presented in a table. Finally, the data with significant differences are displayed in a graph and discussed. The frequency and percentage tables for each of the research questions are found in Appendix D.

Research Question 1: What professional development needs are identified by general education and special education teachers who have a responsibility for teaching at least one mathematics class?

To answer Research Question 1, a summary of the results is presented in Table T. The 11 independent variables are identified, as well as the survey item and dependent variable, and the 
results from the Chi-Square analysis. The table is followed by a section discussing the findings for each independent variable. If the statistical test was significant there is a graph to visually display the results.

Table T

Summary of Results for Research Question 1:

Professional Development Needs for Teachers Who Teach at Least One Mathematics Class

\begin{tabular}{|c|c|c|c|c|}
\hline $\begin{array}{l}\text { Survey } \\
\text { Item }\end{array}$ & Independent Variable & $\begin{array}{l}\text { Survey } \\
\text { Item }\end{array}$ & Dependent Variable & Statistical Result \\
\hline 1 & Gender & 14 & Math Content Knowledge & $\chi 2(4)=11.0, p<.05$ \\
\hline 1 & Gender & 16 & $\begin{array}{l}\text { Professional Development } \\
\text { Need of Mathematics } \\
\text { Content Knowledge }\end{array}$ & $\chi 2(4)=4.5, \mathrm{NS}$ \\
\hline 1 & Gender & 17 & $\begin{array}{l}\text { Need More Knowledge in } \\
\text { Subject }\end{array}$ & $\chi 2(12)=10.2, \mathrm{NS}$ \\
\hline 1 & Gender & 18 & $\begin{array}{l}\text { Do Not Need More } \\
\text { Knowledge in Subject }\end{array}$ & $\chi 2(12)=9.1, \mathrm{NS}$ \\
\hline 1 & Gender & 27 & $\begin{array}{l}\text { Ability to Teach } \\
\text { Mathematics }\end{array}$ & $\chi^{2(4)}=4.0, \mathrm{NS}$ \\
\hline 1 & Gender & 29 & $\begin{array}{l}\text { Professional Development } \\
\text { Need for Teaching Math }\end{array}$ & $\chi^{2(4)}=8.4, \mathrm{NS}$ \\
\hline 1 & Gender & 30 & $\begin{array}{l}\text { Need More Strategies for } \\
\text { Teaching Mathematics }\end{array}$ & $\chi 2(12)=17.9, p<.05$ \\
\hline 1 & Gender & 31 & $\begin{array}{l}\text { Do Not Need More } \\
\text { Strategies for Teaching } \\
\text { Math }\end{array}$ & $\chi 2(12)=15.5, p<.05$ \\
\hline 2 & $\begin{array}{l}\text { Number of Math } \\
\text { Classes they Teach }\end{array}$ & 14 & Math Content Knowledge & $\chi 2(20)=51.0, p<.05$ \\
\hline 2 & $\begin{array}{l}\text { Number of Math } \\
\text { Classes they Teach }\end{array}$ & 16 & $\begin{array}{l}\text { Professional Development } \\
\text { Need of Mathematics } \\
\text { Content Knowledge }\end{array}$ & $\chi 2(20)=22.7, \mathrm{NS}$ \\
\hline 2 & $\begin{array}{l}\text { Number of Math } \\
\text { Classes they Teach }\end{array}$ & 17 & $\begin{array}{l}\text { Need More Knowledge in } \\
\text { Subject }\end{array}$ & $\chi 2(30)=45.1, p<.05$ \\
\hline 2 & $\begin{array}{l}\text { Number of Math } \\
\text { Classes they Teach }\end{array}$ & 18 & $\begin{array}{l}\text { Do Not Need More } \\
\text { Knowledge in Subject }\end{array}$ & $\chi 2(30)=54.5, p<.05$ \\
\hline 2 & $\begin{array}{l}\text { Number of Math } \\
\text { Classes they Teach }\end{array}$ & 27 & $\begin{array}{l}\text { Ability to Teach } \\
\text { Mathematics }\end{array}$ & $\chi^{2(20)}=19.1, \mathrm{NS}$ \\
\hline 2 & $\begin{array}{l}\text { Number of Math } \\
\text { Classes they Teach }\end{array}$ & 29 & $\begin{array}{l}\text { Professional Development } \\
\text { Need for Teaching Math }\end{array}$ & $\chi 2(20)=16.4, \mathrm{NS}$ \\
\hline 2 & $\begin{array}{l}\text { Number of Math } \\
\text { Classes they Teach }\end{array}$ & 30 & $\begin{array}{l}\text { Need More Strategies for } \\
\text { Teaching Mathematics }\end{array}$ & $\chi 2(30)=44.3, p<.05$ \\
\hline
\end{tabular}




\begin{tabular}{|c|c|c|c|c|}
\hline 2 & $\begin{array}{l}\text { Number of Math } \\
\text { Classes they Teach }\end{array}$ & 31 & $\begin{array}{l}\text { Do Not Need More } \\
\text { Strategies for Teaching } \\
\text { Math }\end{array}$ & $\chi^{2(30)}=50.7, p<.05$ \\
\hline 5 & School Organization & 14 & \begin{tabular}{|l} 
Math Content Knowledge \\
\end{tabular} & $\chi^{2(8)}=45.8, p<.05$ \\
\hline 5 & School Organization & 16 & $\begin{array}{l}\text { Professional Development } \\
\text { Need of Mathematics } \\
\text { Content Knowledge } \\
\end{array}$ & $\chi^{2(8)}=18.6, p<.05$ \\
\hline 5 & School Organization & 17 & $\begin{array}{l}\text { Need More Knowledge in } \\
\text { Subject }\end{array}$ & $\chi^{2(12)}=14.1, \mathrm{NS}$ \\
\hline 5 & School Organization & 18 & $\begin{array}{l}\text { Do Not Need More } \\
\text { Knowledge in Subject }\end{array}$ & $\chi^{2(12)}=43.5, p<.05$ \\
\hline 5 & School Organization & 27 & $\begin{array}{l}\text { Ability to Teach } \\
\text { Mathematics }\end{array}$ & $\chi^{2(8)}=18.5, p<.05$ \\
\hline 5 & School Organization & 29 & $\begin{array}{l}\text { Professional Development } \\
\text { Need for Teaching Math }\end{array}$ & $\chi 2(8)=6.7, \mathrm{NS}$ \\
\hline 5 & School Organization & 30 & $\begin{array}{l}\text { Need More Strategies for } \\
\text { Teaching Mathematics }\end{array}$ & $\chi^{2(12)}=19.9, p<.05$ \\
\hline 5 & School Organization & 31 & $\begin{array}{l}\text { Do Not Need More } \\
\text { Strategies for Teaching } \\
\text { Math }\end{array}$ & $\chi^{2(12)}=36.7, p<.05$ \\
\hline 6 & Role in Education & 14 & Math Content Knowledge & $\chi^{2(16)}=9.5, \mathrm{NS}$ \\
\hline 6 & Role in Education & 16 & $\begin{array}{l}\text { Professional Development } \\
\text { Need of Mathematics } \\
\text { Content Knowledge }\end{array}$ & $\chi^{2(16)}=21.9, \mathrm{NS}$ \\
\hline 6 & Role in Education & 17 & $\begin{array}{l}\text { Need More Knowledge in } \\
\text { Subject }\end{array}$ & $\chi^{2(24)}=15.6, \mathrm{NS}$ \\
\hline 6 & Role in Education & 18 & $\begin{array}{l}\text { Do Not Need More } \\
\text { Knowledge in Subject }\end{array}$ & $\chi^{2(24)}=22.7, \mathrm{NS}$ \\
\hline 6 & Role in Education & 27 & $\begin{array}{l}\text { Ability to Teach } \\
\text { Mathematics }\end{array}$ & $\chi 2(16)=7.8, \mathrm{NS}$ \\
\hline 6 & Role in Education & 29 & $\begin{array}{l}\text { Professional Development } \\
\text { Need for Teaching Math }\end{array}$ & $\chi^{2}(16)=21.7, \mathrm{NS}$ \\
\hline 6 & Role in Education & 30 & $\begin{array}{l}\text { Need More Strategies for } \\
\text { Teaching Mathematics }\end{array}$ & $\chi^{2(24)}=25.1, \mathrm{NS}$ \\
\hline 6 & Role in Education & 31 & $\begin{array}{l}\text { Do Not Need More } \\
\text { Strategies for Teaching } \\
\text { Math }\end{array}$ & $\chi^{2}(24)=28.0, \mathrm{NS}$ \\
\hline 7 & Degree & 14 & \begin{tabular}{|l} 
Math Content Knowledge \\
\end{tabular} & $\chi 2(36)=37.1, \mathrm{NS}$ \\
\hline 7 & Degree & 16 & $\begin{array}{l}\text { Professional Development } \\
\text { Need of Mathematics } \\
\text { Content Knowledge }\end{array}$ & $\chi^{2(36)}=96.9, p<.05$ \\
\hline 7 & Degree & 17 & $\begin{array}{l}\text { Need More Knowledge in } \\
\text { Subject }\end{array}$ & $\chi^{2(72)}=55.1, \mathrm{NS}$ \\
\hline
\end{tabular}




\begin{tabular}{|c|c|c|c|c|}
\hline 7 & Degree & 18 & $\begin{array}{l}\text { Do Not Need More } \\
\text { Knowledge in Subject }\end{array}$ & $\chi 2(72)=61.1, \mathrm{NS}$ \\
\hline 7 & Degree & 27 & $\begin{array}{l}\text { Ability to Teach } \\
\text { Mathematics }\end{array}$ & $\chi 2(36)=37.3, p<.05$ \\
\hline 7 & Degree & 29 & $\begin{array}{l}\text { Professional Development } \\
\text { Need for Teaching Math }\end{array}$ & $\chi 2(36)=40.6, \mathrm{NS}$ \\
\hline 7 & Degree & 30 & $\begin{array}{l}\text { Need More Strategies for } \\
\text { Teaching Mathematics }\end{array}$ & $\chi^{2(72)}=56.1, \mathrm{NS}$ \\
\hline 7 & Degree & 31 & $\begin{array}{l}\text { Do Not Need More } \\
\text { Strategies for Teaching } \\
\text { Math }\end{array}$ & $\chi^{2(72)}=49.0, \mathrm{NS}$ \\
\hline 8 & $\begin{array}{l}\text { Number of Math } \\
\text { Content Courses } \\
\text { Taken }\end{array}$ & 14 & Math Content Knowledge & $\chi 2(16)=104.1, p<.05$ \\
\hline 8 & $\begin{array}{l}\text { Number of Math } \\
\text { Content Courses } \\
\text { Taken }\end{array}$ & 16 & $\begin{array}{l}\text { Professional Development } \\
\text { Need of Mathematics } \\
\text { Content Knowledge }\end{array}$ & $\chi 2(16)=27.7, p<.05$ \\
\hline 8 & $\begin{array}{l}\text { Number of Math } \\
\text { Content Courses } \\
\text { Taken }\end{array}$ & 17 & $\begin{array}{l}\text { Need More Knowledge in } \\
\text { Subject }\end{array}$ & $\chi^{2(24)}=50.9, p<.05$ \\
\hline 8 & $\begin{array}{l}\text { Number of Math } \\
\text { Content Courses } \\
\text { Taken }\end{array}$ & 18 & $\begin{array}{l}\text { Do Not Need More } \\
\text { Knowledge in Subject }\end{array}$ & $\chi 2(24)=58.6, p<.05$ \\
\hline 8 & $\begin{array}{l}\text { Number of Math } \\
\text { Content Courses } \\
\text { Taken }\end{array}$ & 27 & $\begin{array}{l}\text { Ability to Teach } \\
\text { Mathematics }\end{array}$ & $\chi^{2(16)}=59.1, p<.05$ \\
\hline 8 & $\begin{array}{l}\text { Number of Math } \\
\text { Content Courses } \\
\text { Taken }\end{array}$ & 29 & $\begin{array}{l}\text { Professional Development } \\
\text { Need for Teaching Math }\end{array}$ & $\chi 2(16)=24.6, \mathrm{NS}$ \\
\hline 8 & $\begin{array}{l}\text { Number of Math } \\
\text { Content Courses } \\
\text { Taken }\end{array}$ & 30 & $\begin{array}{l}\text { Need More Strategies for } \\
\text { Teaching Mathematics }\end{array}$ & $\chi 2(24)=32.4, \mathrm{NS}$ \\
\hline 8 & $\begin{array}{l}\text { Number of Math } \\
\text { Content Courses } \\
\text { Taken }\end{array}$ & 31 & $\begin{array}{l}\text { Do Not Need More } \\
\text { Strategies for Teaching } \\
\text { Math }\end{array}$ & $\chi 2(24)=61.2, p<.05$ \\
\hline$\overline{9}$ & $\begin{array}{l}\text { Number of Math } \\
\text { Methods Courses } \\
\text { Taken }\end{array}$ & 14 & Math Content Knowledge & $\chi 2(20)=41.9, p<.05$ \\
\hline 9 & $\begin{array}{l}\text { Number of Math } \\
\text { Methods Courses } \\
\text { Taken }\end{array}$ & 16 & $\begin{array}{l}\text { Professional Development } \\
\text { Need of Mathematics } \\
\text { Content Knowledge }\end{array}$ & $\chi 2(20)=20.1, \mathrm{NS}$ \\
\hline 9 & $\begin{array}{l}\text { Number of Math } \\
\text { Methods Courses }\end{array}$ & 17 & $\begin{array}{l}\text { Need More Knowledge in } \\
\text { Subject }\end{array}$ & $\chi 2(30)=27.9, \mathrm{NS}$ \\
\hline
\end{tabular}




\begin{tabular}{|c|c|c|c|c|}
\hline & Taken & & & \\
\hline 9 & $\begin{array}{l}\text { Number of Math } \\
\text { Methods Courses } \\
\text { Taken }\end{array}$ & 18 & $\begin{array}{l}\text { Do Not Need More } \\
\text { Knowledge in Subject }\end{array}$ & $\chi 2(30)=32.2, \mathrm{NS}$ \\
\hline 9 & $\begin{array}{l}\text { Number of Math } \\
\text { Methods Courses } \\
\text { Taken }\end{array}$ & 27 & $\begin{array}{l}\text { Ability to Teach } \\
\text { Mathematics }\end{array}$ & $\chi 2(20)=23.4, \mathrm{NS}$ \\
\hline 9 & $\begin{array}{l}\text { Number of Math } \\
\text { Methods Courses } \\
\text { Taken }\end{array}$ & 29 & $\begin{array}{l}\text { Professional Development } \\
\text { Need for Teaching Math }\end{array}$ & $\chi^{2(20)=30.7, \mathrm{NS}}$ \\
\hline 9 & $\begin{array}{l}\text { Number of Math } \\
\text { Methods Courses } \\
\text { Taken }\end{array}$ & 30 & $\begin{array}{l}\text { Need More Strategies for } \\
\text { Teaching Mathematics }\end{array}$ & $\chi 2(30)=25.9, \mathrm{NS}$ \\
\hline 9 & $\begin{array}{l}\text { Number of Math } \\
\text { Methods Courses } \\
\text { Taken }\end{array}$ & 31 & $\begin{array}{l}\text { Do Not Need More } \\
\text { Strategies for Teaching } \\
\text { Math }\end{array}$ & $\chi 2(30)=27.7, \mathrm{NS}$ \\
\hline 10 & Years of Experience & 14 & Math Content Knowledge & $\chi 2(16)=13.8, \mathrm{NS}$ \\
\hline 10 & Years of Experience & 16 & $\begin{array}{l}\text { Professional Development } \\
\text { Need of Mathematics } \\
\text { Content Knowledge }\end{array}$ & $\chi 2(16)=25.9, \mathrm{NS}$ \\
\hline 10 & Years of Experience & 17 & $\begin{array}{l}\text { Need More Knowledge in } \\
\text { Subject }\end{array}$ & $\chi 2(24)=29.9, \mathrm{NS}$ \\
\hline 10 & Years of Experience & 18 & $\begin{array}{l}\text { Do Not Need More } \\
\text { Knowledge in Subject }\end{array}$ & $\chi 2(24)=44.8, p<.05$ \\
\hline 10 & Years of Experience & 27 & $\begin{array}{l}\text { Ability to Teach } \\
\text { Mathematics }\end{array}$ & $\chi 2(16)=31.9, p<.05$ \\
\hline 10 & Years of Experience & 29 & $\begin{array}{l}\text { Professional Development } \\
\text { Need for Teaching Math }\end{array}$ & $\chi 2(16)=31.5, p<.05$ \\
\hline 10 & Years of Experience & 30 & $\begin{array}{l}\text { Need More Strategies for } \\
\text { Teaching Mathematics }\end{array}$ & $\chi 2(24)=39.3, p<.05$ \\
\hline 10 & Years of Experience & 31 & $\begin{array}{l}\text { Do Not Need More } \\
\text { Strategies for Teaching } \\
\text { Math }\end{array}$ & $\chi 2(24)=39.7, p<.05$ \\
\hline 11 & Certification Year & 14 & \begin{tabular}{|l} 
Math Content Knowledge \\
\end{tabular} & $\chi 2(12)=9.6, \mathrm{NS}$ \\
\hline 11 & Certification Year & 16 & $\begin{array}{l}\text { Professional Development } \\
\text { Need of Mathematics } \\
\text { Content Knowledge }\end{array}$ & $\chi 2(12)=18.2, \mathrm{NS}$ \\
\hline 11 & Certification Year & 17 & $\begin{array}{l}\text { Need More Knowledge in } \\
\text { Subject }\end{array}$ & $\chi^{2(18)}=19.8, \mathrm{NS}$ \\
\hline 11 & Certification Year & 18 & $\begin{array}{l}\text { Do Not Need More } \\
\text { Knowledge in Subject }\end{array}$ & $\chi 2(18)=36.2, p<.05$ \\
\hline 11 & Certification Year & 27 & $\begin{array}{l}\text { Ability to Teach } \\
\text { Mathematics }\end{array}$ & $\chi 2(12)=16.8, \mathrm{NS}$ \\
\hline
\end{tabular}




\begin{tabular}{|c|c|c|c|c|}
\hline 11 & Certification Year & 29 & $\begin{array}{l}\text { Professional Development } \\
\text { Need for Teaching Math }\end{array}$ & $\chi 2(12)=24.2, p<.05$ \\
\hline 11 & Certification Year & 30 & $\begin{array}{l}\text { Need More Strategies for } \\
\text { Teaching Mathematics }\end{array}$ & $\chi^{2(18)}=37.9, p<.05$ \\
\hline 11 & Certification Year & 31 & $\begin{array}{l}\text { Do Not Need More } \\
\text { Strategies for Teaching } \\
\text { Math }\end{array}$ & $\chi 2(18)=24.1, \mathrm{NS}$ \\
\hline 12 & $\begin{array}{l}\text { Certified in } \\
\text { Mathematics }\end{array}$ & 14 & Math Content Knowledge & $\chi^{2(4)}=7.1, \mathrm{NS}$ \\
\hline 12 & $\begin{array}{l}\text { Certified in } \\
\text { Mathematics }\end{array}$ & 16 & $\begin{array}{l}\text { Professional Development } \\
\text { Need of Mathematics } \\
\text { Content Knowledge }\end{array}$ & $\chi 2(4)=10.9, p<.05$ \\
\hline 12 & $\begin{array}{l}\text { Certified in } \\
\text { Mathematics }\end{array}$ & 17 & $\begin{array}{l}\text { Need More Knowledge in } \\
\text { Subject }\end{array}$ & $\chi^{2(6)}=4.1, \mathrm{NS}$ \\
\hline 12 & $\begin{array}{l}\text { Certified in } \\
\text { Mathematics }\end{array}$ & 18 & $\begin{array}{l}\text { Do Not Need More } \\
\text { Knowledge in Subject }\end{array}$ & $\chi 2(6)=3.8, \mathrm{NS}$ \\
\hline 12 & $\begin{array}{l}\text { Certified in } \\
\text { Mathematics }\end{array}$ & 27 & $\begin{array}{l}\text { Ability to Teach } \\
\text { Mathematics }\end{array}$ & $\chi^{2(4)}=2.8, \mathrm{NS}$ \\
\hline 12 & $\begin{array}{l}\text { Certified in } \\
\text { Mathematics }\end{array}$ & 29 & $\begin{array}{l}\text { Professional Development } \\
\text { Need for Teaching Math }\end{array}$ & $\chi^{2(4)}=2.9, \mathrm{NS}$ \\
\hline 12 & $\begin{array}{l}\text { Certified in } \\
\text { Mathematics }\end{array}$ & 30 & $\begin{array}{l}\text { Need More Strategies for } \\
\text { Teaching Mathematics }\end{array}$ & $\chi^{2(6)}=10.2, \mathrm{NS}$ \\
\hline 12 & $\begin{array}{l}\text { Certified in } \\
\text { Mathematics }\end{array}$ & 31 & $\begin{array}{l}\text { Do Not Need More } \\
\text { Strategies for Teaching } \\
\text { Math }\end{array}$ & $\chi 2(6)=15.4, p<.05$ \\
\hline 13 & $\begin{array}{l}\text { Highly Qualified in } \\
\text { Mathematics }\end{array}$ & 14 & Math Content Knowledge & $\chi^{2(4)}=2.8, \mathrm{NS}$ \\
\hline 13 & $\begin{array}{l}\text { Highly Qualified in } \\
\text { Mathematics }\end{array}$ & 16 & $\begin{array}{l}\text { Professional Development } \\
\text { Need of Mathematics } \\
\text { Content Knowledge }\end{array}$ & $\chi^{2(4)}=3.4, \mathrm{NS}$ \\
\hline 13 & $\begin{array}{l}\text { Highly Qualified in } \\
\text { Mathematics }\end{array}$ & 17 & $\begin{array}{l}\text { Need More Knowledge in } \\
\text { Subject }\end{array}$ & $\chi^{2(6)}=3.4, \mathrm{NS}$ \\
\hline 13 & $\begin{array}{l}\text { Highly Qualified in } \\
\text { Mathematics }\end{array}$ & 18 & $\begin{array}{l}\text { Do Not Need More } \\
\text { Knowledge in Subject }\end{array}$ & $\chi 2(6)=13.2, p<.05$ \\
\hline 13 & $\begin{array}{l}\text { Highly Qualified in } \\
\text { Mathematics }\end{array}$ & 27 & $\begin{array}{l}\text { Ability to Teach } \\
\text { Mathematics }\end{array}$ & $\chi^{2(4)}=0.7, \mathrm{NS}$ \\
\hline 13 & $\begin{array}{l}\text { Highly Qualified in } \\
\text { Mathematics }\end{array}$ & 29 & $\begin{array}{l}\text { Professional Development } \\
\text { Need for Teaching Math }\end{array}$ & $\chi^{2(4)}=0.1, \mathrm{NS}$ \\
\hline 13 & $\begin{array}{l}\text { Highly Qualified in } \\
\text { Mathematics }\end{array}$ & 30 & $\begin{array}{l}\text { Need More Strategies for } \\
\text { Teaching Mathematics }\end{array}$ & $\chi^{2(6)}=8.8, \mathrm{NS}$ \\
\hline 13 & $\begin{array}{l}\text { Highly Qualified in } \\
\text { Mathematics }\end{array}$ & 31 & $\begin{array}{l}\text { Do Not Need More } \\
\text { Strategies for Teaching } \\
\text { Math }\end{array}$ & $\chi 2(6)=8.3, \mathrm{NS}$ \\
\hline
\end{tabular}


Note. Survey Item 3 was not analyzed in this research question because it is answered in Research Question 2. Survey Item 4 is not analyzed in this research question because it was a question to identify the school system the respondent was from. Survey Items 15, 19-26, 28, 32-41 were not analyzed because they were put into the survey at request of the school system. NS $=$ Not Statistically Significant. $\chi 2=$ Chi-Square.

Gender. The Gender (Item 1) by Math Content Knowledge (Item 14) analysis yielded a statistically significant finding (Appendix D, Table E1). The graph (Figure 1) shows that 25\% of male teachers reported their mathematics content knowledge to be exceptional, but only $11 \%$ of the female teachers reported their mathematics content knowledge to be exceptional. More than 33\% of females but only $23 \%$ of males reported their math content knowledge as average. Male teachers were more likely to feel their content knowledge is strong compared to female teachers. This suggests that male teachers have more confidence in their math content knowledge than females.

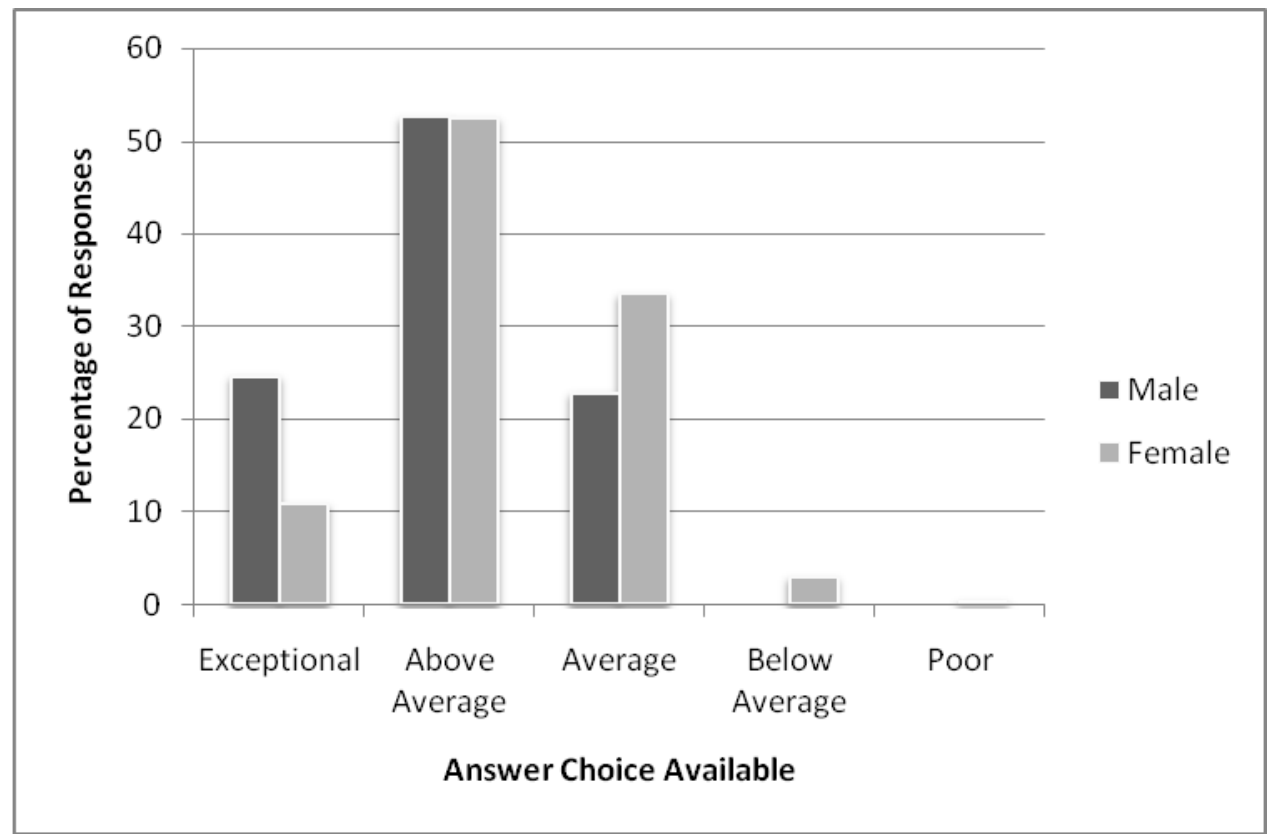

Figure 1. Percentage response for Item 14 (Mathematics Content Knowledge) on the MPDI graphed by Gender.

The Gender (Item 1) by Professional Development Need of Mathematics Content Knowledge (Item 16) analysis did not yield a statistically significant finding (Appendix D, Table 
E2). Overall 53\% of the males and females responded that they needed Some professional development in mathematics content knowledge. This suggests that even though males rate themselves higher in their mathematics content knowledge they still feel that they need the same amount of professional development as females.

The Gender (Item 1) by Need More Knowledge in Subject (Item 17) analysis did not yield a statistically significant finding (Appendix D, Table E3). Overall the males and females responded that they need more professional development in the area of Statistics (28\%) and Process (36\%). This suggests that males and females need more knowledge in the same subject area.

The Gender (Item 1) by Do Not Need More Knowledge in Subject (Item 18) analysis did not yield a statistically significant finding (Appendix D, Table E4). Overall, 46\% of males and females responded that they do not need more professional development in the area of Numbers and Operations. This suggests that males and females do not need more knowledge in the same subject area.

The Gender (Item 1) by Ability to Teach Mathematics (Item 27) analysis did not yield a statistically significant finding (Appendix D, Table E5). Overall, 75\% of males and females responded that they feel they are Exceptional or Above Average in their ability to teach. This suggests that males and females are confident in their ability to teach mathematics.

The Gender (Item 1) by Professional Development Need for Teaching Mathematics (Item 29) analysis did not yield a statistically significant finding (Appendix D, Table E6). Overall, 88\% of males and females responded that they need Some, A Little, or No professional development for teaching mathematics. This research suggests that both males and females feel that they need some, a little, or no professional development in teaching mathematics. Since males and females 
rated their ability to teach mathematics as above average this supports the fact that they do not feel that they need professional development in this area.

The Gender (Item 1) by Need More Teaching Strategies for Teaching Mathematics (Item 30) analysis yielded a statistically significant finding (Appendix D, Table E7). The graph (Figure 2) shows that $22 \%$ of male teachers reported a need for more teaching strategies in Geometry but only $8 \%$ of the female teachers reported a need for more teaching strategies in Geometry. More than $41 \%$ of females but only $25 \%$ of males reported their need for more teaching strategies in Process. Females rated themselves more frequently (41\%) as needing more teaching strategies in Process, while males rated themselves more frequently (22\%) as needing more teaching strategies in Geometry. Male teachers were more likely to report their need for teaching strategies in Geometry compared to female teachers who report their need for teaching strategies in Process. This research suggests that males and females have different areas of math that they need more teaching strategies in, this could be because more male job placements are in high school (and teacher classification in this area also shows a statistically significant finding).

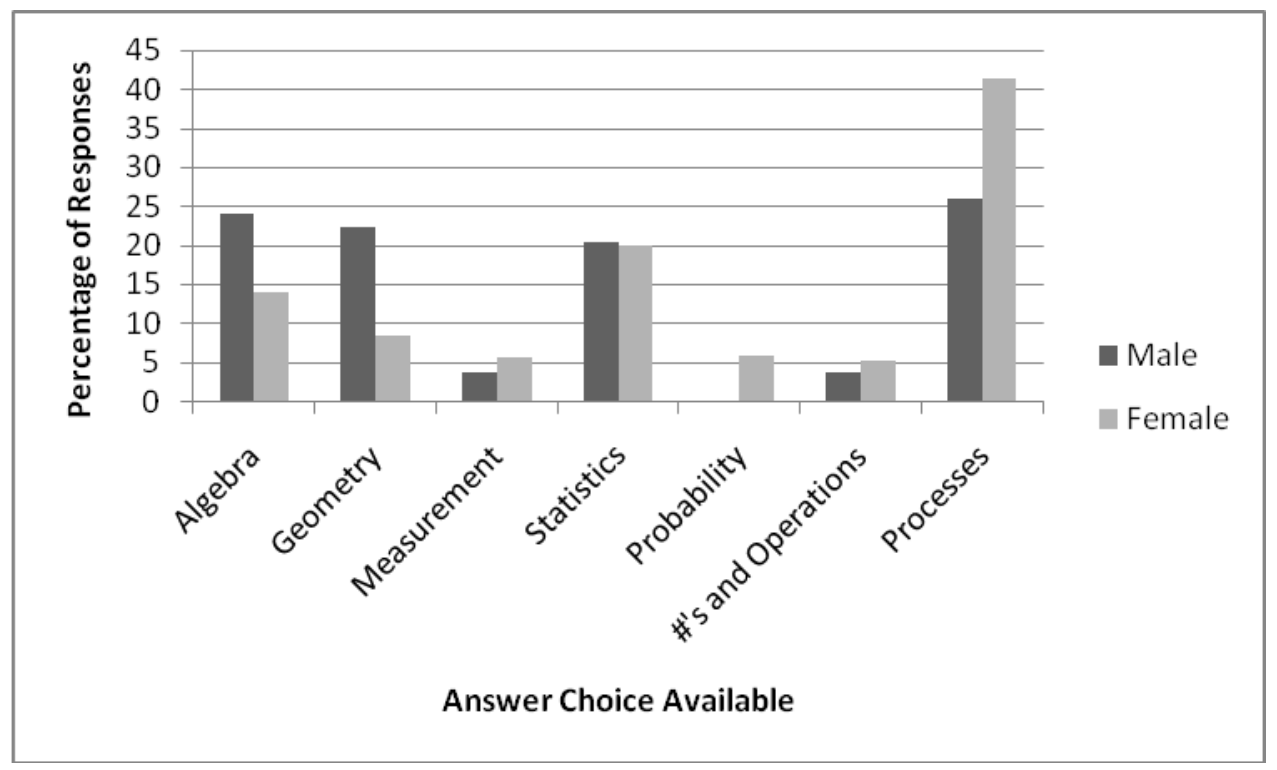


Figure 2. Percentage response for Item 30 (Need for More Strategies for Teaching Mathematics) on the MPDI graphed by Gender.

The Gender (Item 1) by Do Not Need More Teaching Strategies for Teaching Mathematics (Item 31) analysis yielded a statistically significant finding (Appendix D, Table E8). The graph (Figure 3) shows that only $27 \%$ of male teachers responded they do not need more teaching strategies in Numbers and Operations, but a little less than $45 \%$ of the female teachers reported they do not need for more teaching strategies in Numbers and Operations. Male teachers and female teachers identified different needs in math content and teaching strategies in some areas. This research suggests that males and females have different areas of math that they do not need more teaching strategies in, this could be because more male job placements are in high school (and teacher classification in this area also shows a statistically significant finding).

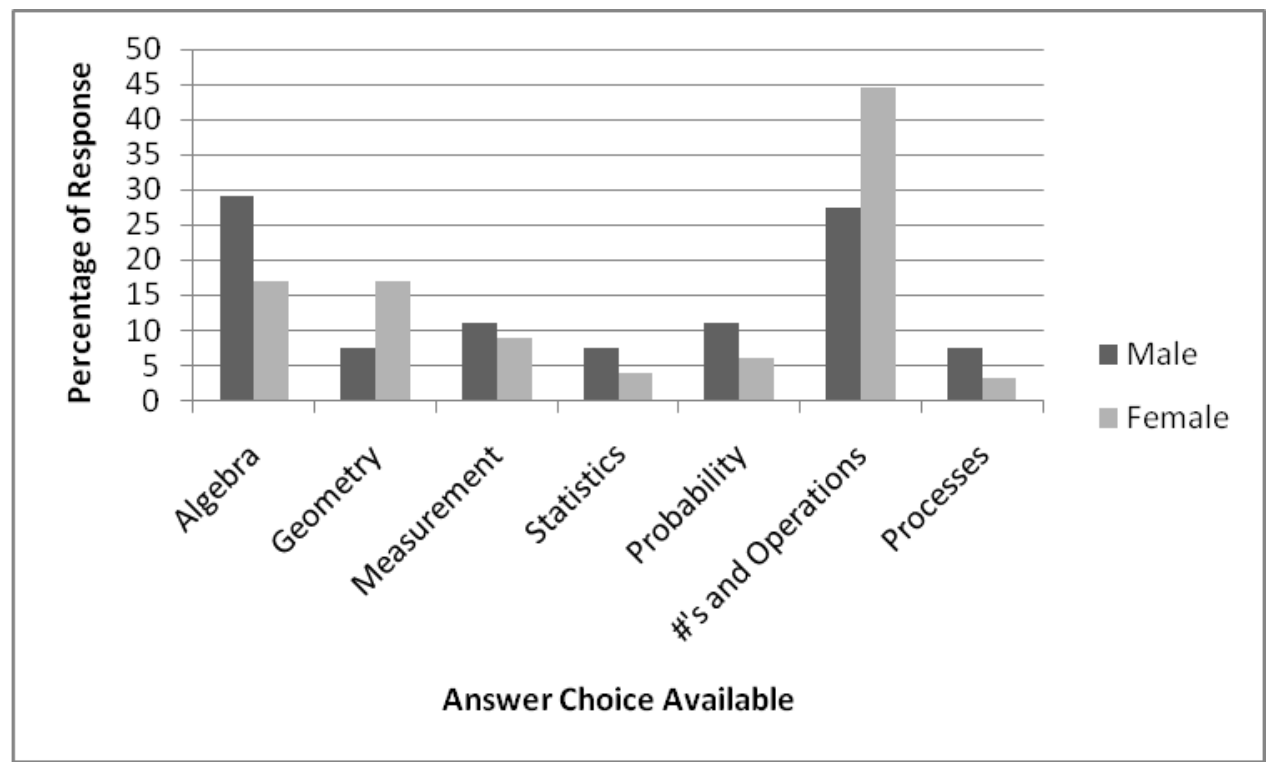

Figure 3. Percentage response for Item 31 (Do Not Need for More Strategies for Teaching Mathematics) on the MPDI graphed by Gender. 
Number of math classes taught. The Number of Math Classes Taught (Item 2) by Math Content Knowledge (Item 14) analysis yielded some statistically significant findings (Appendix D, Table F1). The graph (Figure 4) shows that when teachers were asked to rate themselves as Exceptional in Math Content Knowledge, 5\% of teachers who taught one math class, $23 \%$ of teachers who taught two classes, $16 \%$ of teachers who taught 3 classes, $18 \%$ who taught 4 classes, $26 \%$ who taught 5 classes, and $25 \%$ who taught 6 or more classes. In relationship to the percentage of teachers who rated themselves in Math Content Knowledge as Average, $42 \%$ of teachers who taught one math class, $22 \%$ of teachers who taught two classes, $23 \%$ of teachers who taught 3 classes, $21 \%$ who taught 4 classes, $13 \%$ who taught 5 classes, and $25 \%$ who taught 6 or more classes. Teachers who taught more math classes were more likely to rate themselves as Exceptional (25\% of those who taught 6 or more classes) compared with those who taught fewer classes (5\% of those who taught 1 class). Teachers with more experience were more likely to feel they were strong in math content knowledge than those who had less experience. This suggest that the more classes that one teaches the more confident one is in their math content knowledge.

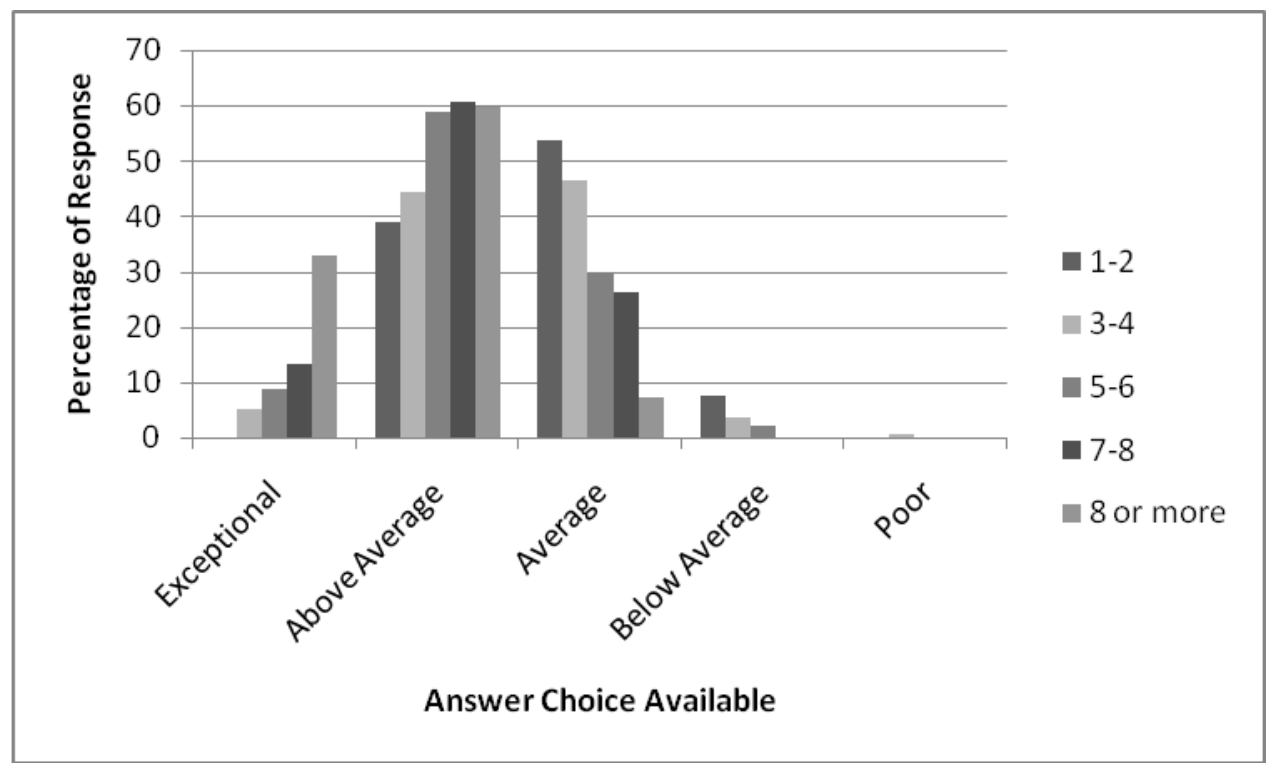


Figure 4. Percentage response for Item 14 (Mathematics Content Knowledge) on the MPDI graphed by Number of Math Classes Taught.

The Number of Math Classes Taught (Item 2) by Professional Development Need of Mathematics Content Knowledge (Item 16) analysis did not yield a statistically significant finding (Appendix D, Table F2). Overall 54\% of the teachers responded that they needed Some professional development in mathematics content knowledge. This suggests that there is not a difference in the number of math classes taught by their professional development needs of mathematics content knowledge.

The Number of Math Classes Taught (Item 2) by Need More Knowledge in Subject (Item 17) analysis yielded a statistically significant finding (Appendix D, Table F3). The graph (Figure 5) shows $39 \%$ of teachers who taught one math class, 35\% of teachers who taught two classes, $19 \%$ of teachers who taught 3 classes, 33\% who taught 4 classes, $37 \%$ who taught 5 classes, and $50 \%$ who taught 6 or more classes felt they needed more knowledge in Process. Teachers who taught 3 classes felt they needed more knowledge in Statistics (35\%). Finally, $8 \%$ of teachers who taught one math class, $6 \%$ of teachers who taught two classes, $21 \%$ of teachers who taught 3 classes, $15 \%$ of teachers who taught 4 classes, $16 \%$ of teachers who taught 5 classes, and $21 \%$ of teachers who taught 6 or more classes felt they needed more knowledge in Geometry. There was no meaningful pattern in number of math classes taught when teachers were asked about a math area that they need more content knowledge. 


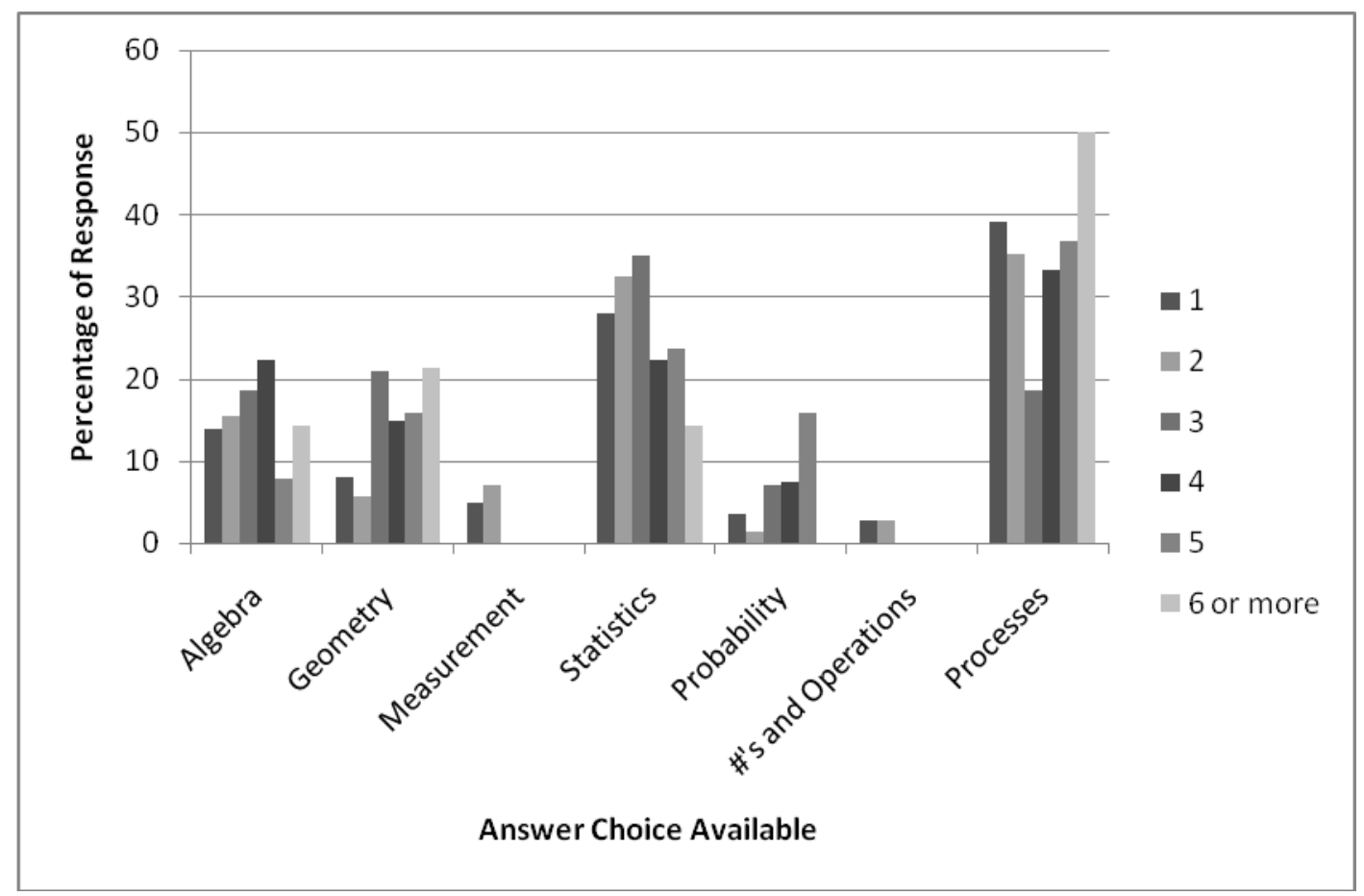

Figure 5. Percentage response for Item 17 (Need More Knowledge in Subject) on the MPDI graphed by Number of Math Classes Taught.

The Number of Math Classes Taught (Item 2) by Do Not Need More Knowledge in Subject (Item 18) analysis yielded a statistically significant finding (Appendix D, Table F4). The relationship (Figure 6 ) shows that $12 \%$ of teachers who taught one math class, $25 \%$ of teachers who taught two classes, $39 \%$ of teachers who taught 3 classes, $25 \%$ of teachers who taught 4 classes, $40 \%$ of teachers who taught 5 classes, and $29 \%$ of teachers who taught 6 or more classes felt they did not need more knowledge in Algebra. In addition, teachers that taught 1 class felt they do not need more knowledge in Numbers and Operations (54\%). In this area there was also a range of responses, $39 \%$ of teachers who taught two classes, $36 \%$ of teachers who taught 3 classes, $46 \%$ who taught 4 classes, $21 \%$ who taught 5 classes, and $43 \%$ who taught 6 or more classes felt that they do not need more knowledge in Numbers and Operations. There was no meaningful pattern in 
number of math classes taught when teachers were asked about a math area that they do not need more content knowledge.

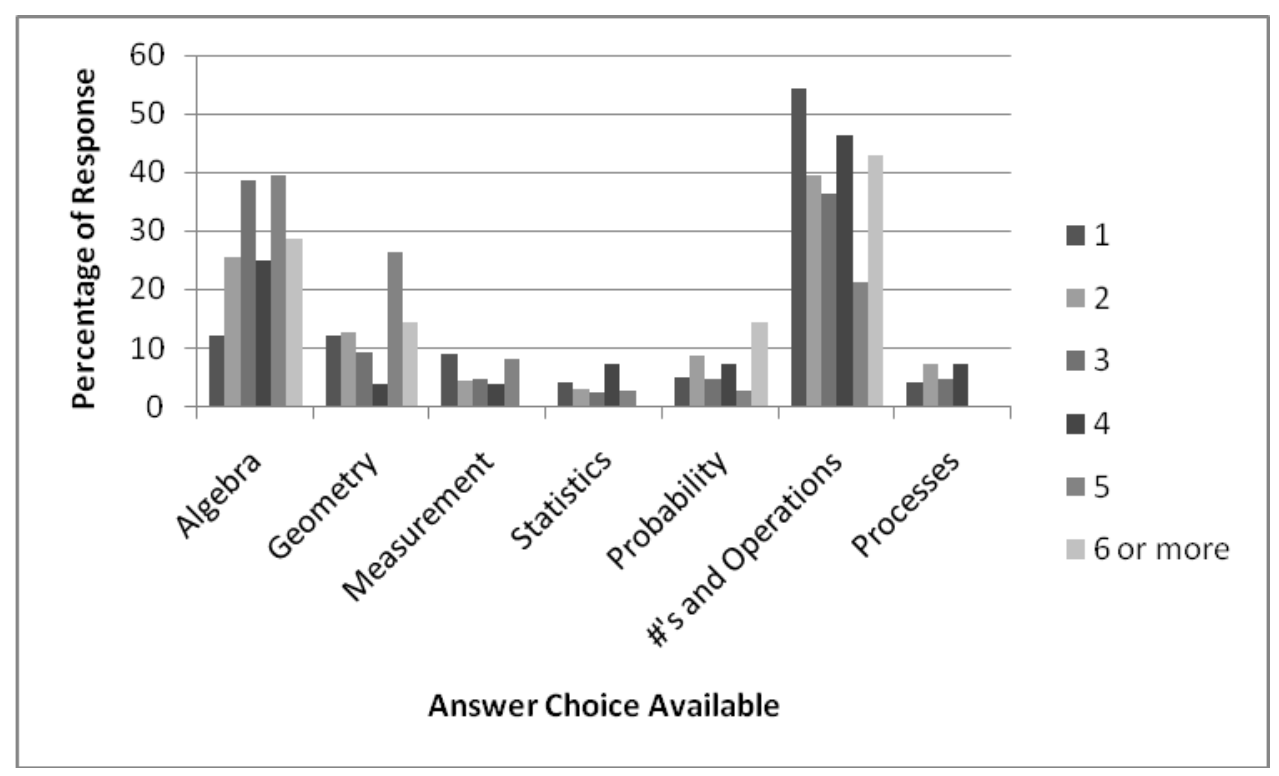

Figure 6. Percentage response for Item 18 (Do Not Need More Knowledge in Subject) on the MPDI graphed by Number of Math Classes Taught.

The Number of Math Classes Taught (Item 2) by Ability to Teach Mathematics (Item 27) analysis did not yield a statistically significant finding (Appendix D, Table F5). Overall, 62\% of teachers feel they are Above Average in their ability to teach, and only $25 \%$ of teachers feel they are Average, Below Average, or Poor in their ability to teach mathematics. Most teachers indicated that their ability to teach mathematics is strong. This suggests that the more math classes that a teacher taught the more confident they were in their ability to teach mathematics.

The Number of Math Classes Taught (Item 2) by Professional Development Need for Teaching Mathematics (Item 29) analysis did not yield a statistically significant finding (Appendix D, Table F6). Overall, $81 \%$ of teachers responded that they need Some, or A Little professional development for teaching mathematics. Teachers who taught 1,2 , or 3 classes rated their need for professional development in teaching mathematics as A Little, while teachers who taught 4, 5, 6 or 
more classes rated their need for professional development in teaching mathematics as Some. This suggests that the number of math classes taught does not impact the teachers rating of math professional development need for teaching mathematics.

The Number of Math Classes Taught (Item 2) by Need More Teaching Strategies (Item 30) analysis yielded a statistically significant finding (Appendix D, Table F7). The graph (Figure 7) shows $40 \%$ of teachers who taught one math class, $40 \%$ of teachers who taught two classes, $16 \%$ of teachers who taught 3 classes, $44 \%$ of teachers who taught 4 classes, $45 \%$ of teachers who taught 5 classes, and $53 \%$ of teachers who taught 6 or more classes felt that they needed more teaching strategies in Process. In addition, the teachers that taught 3 classes rated that they needed more knowledge in Geometry (24\%). Finally, another math content area that had a variety of responses was Geometry, $6 \%$ of teachers who taught one math class, $10 \%$ of teachers who taught two classes, $24 \%$ of teachers who taught 3 classes, $8 \%$ of teachers who taught 4 classes, $23 \%$ of teachers who taught 5 classes, and $12 \%$ of teachers who taught 6 or more classes. There was no meaningful pattern in number of math classes taught when teachers were asked about a math area that they need more teaching strategies. 


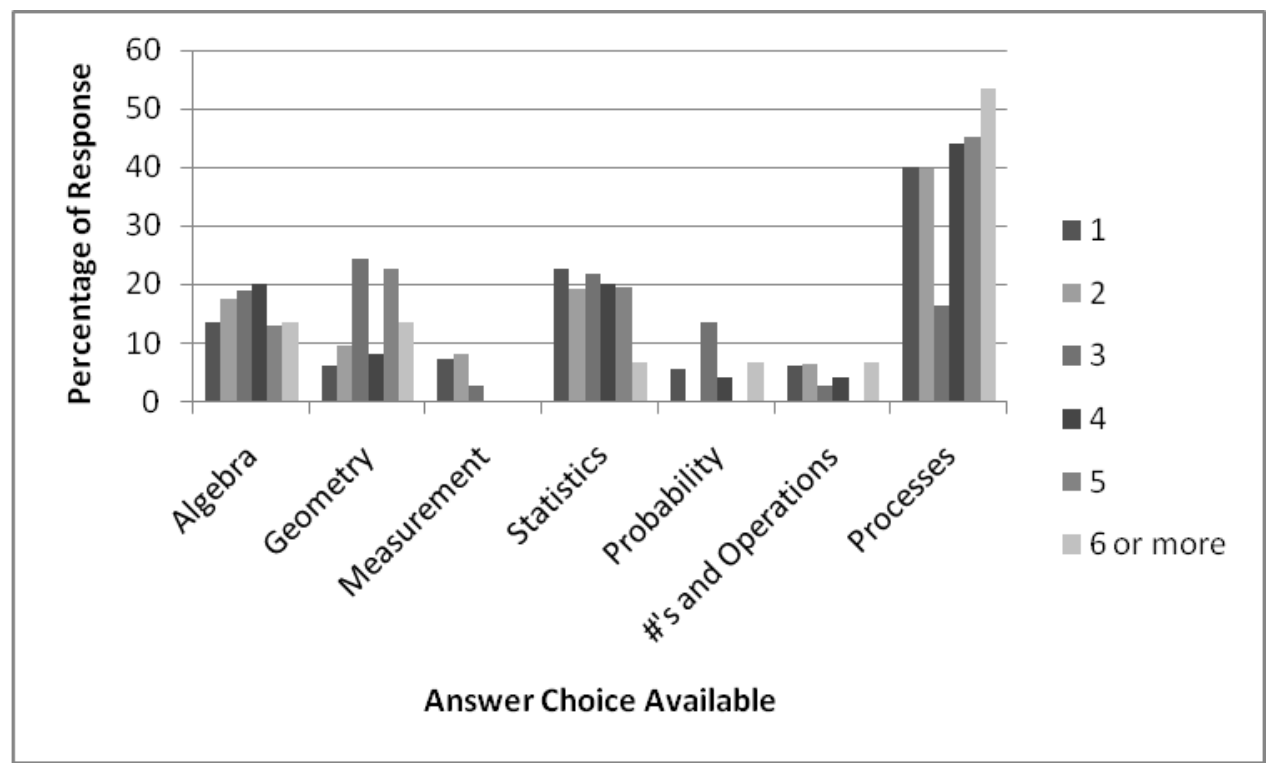

Figure 7. Percentage response for Item 30 (Need for More Strategies for Teaching Mathematics) on the MPDI graphed by Number of Math Classes Taught.

The Number of Math Classes Taught (Item 2) by Do Not Need More Teaching Strategies (Item 31) analysis yielded a statistically significant finding (Appendix D, Table F8). The graph (Figure 8) shows $48 \%$ of teachers who taught one math class, $36 \%$ of teachers who taught two classes, $43 \%$ of teachers who taught 3 classes, $56 \%$ who taught 4 classes, $17 \%$ who taught 5 classes, and 38\% who taught 6 or more classes felt that they do not need more teaching strategies in Numbers and Operations. In addition, the teachers that taught 5 classes rated that they do not need more knowledge in Algebra (36\%). There was no meaningful pattern in number of math classes taught when teachers were asked about a math area that they do not need more teaching strategies. 


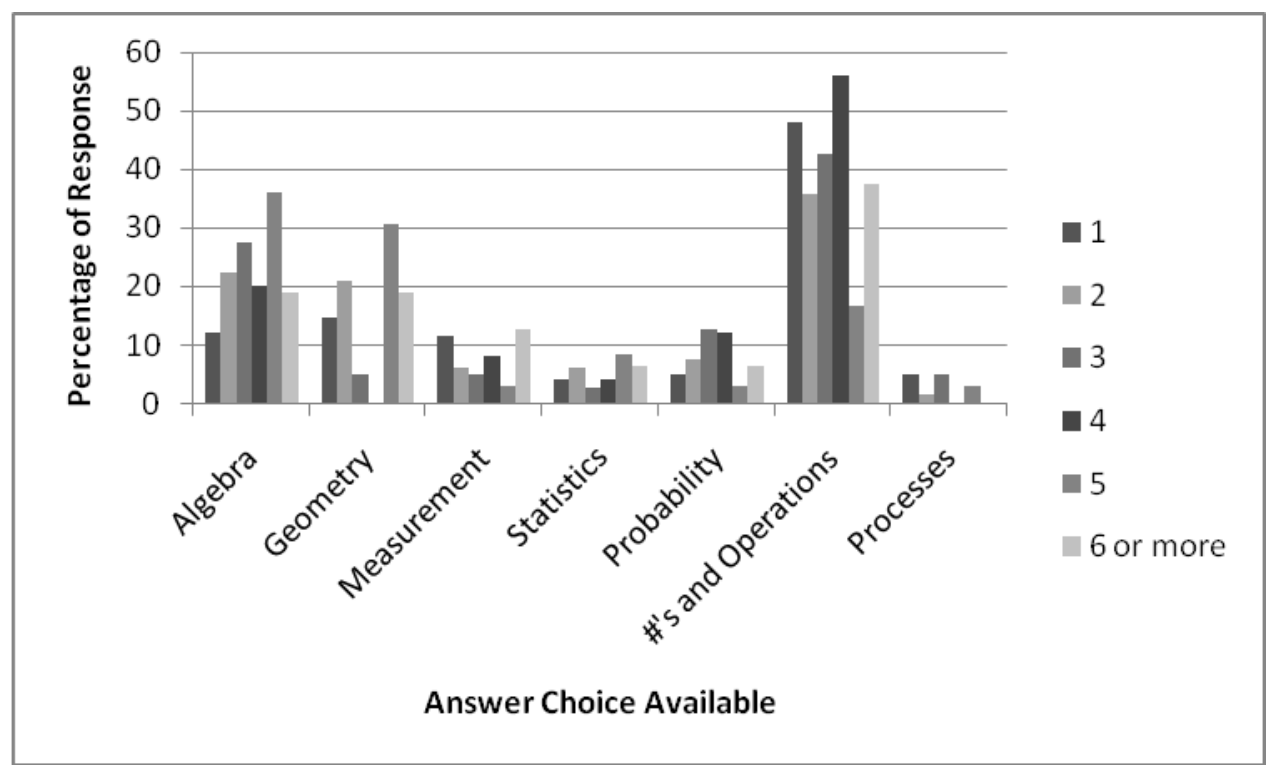

Figure 8. Percentage response for Item 31 (Do Not Need for More Strategies for Teaching Mathematics) on the MPDI graphed by Math Classes Taught.

School organization. School Organization (Item 5) by Math Content Knowledge (Item 14) analysis yielded a statistically significant finding (Appendix D, Table H1). The graph (Figure 9) shows that $7 \%$ of teachers who have students that are assigned to them for the majority of the day responded their mathematics content knowledge to be exceptional. More than $22 \%$ of the teachers who at have students who move from classroom to classroom throughout the day, and $4 \%$ of teachers who have their school organized in another way reported their mathematics content knowledge to be exceptional. In addition, more than $43 \%$ of teachers who have students who are assigned to them for the majority of the day reported their mathematics content knowledge to be Average. More than $20 \%$ of the teachers who have students who move from classroom to classroom throughout the day, and $31 \%$ of teachers who have their school organized in another way reported their mathematics content knowledge to be Average. Teachers who teach for the majority of the day, and the student's remain with him/her for all core academic subjects feel their 
knowledge in mathematics content is different compared to a teacher who has students move from classroom to classroom throughout the day, from one academic subject to another.

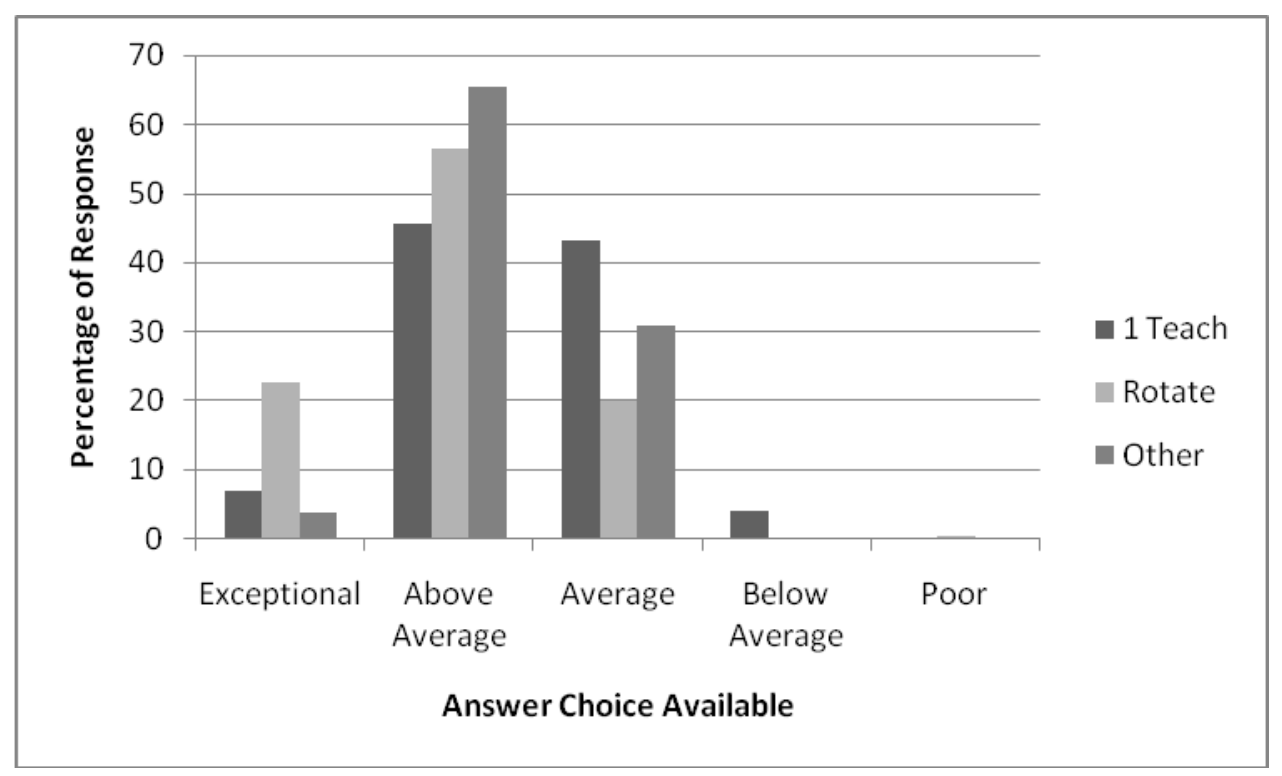

Figure 9. Percentage response for Item 14 (Mathematics Content Knowledge) on the MPDI graphed by School Organization.

School Organization (Item 5) by Professional Development Need of Mathematics Content Knowledge (Item 16) analysis yielded a statistically significant finding (Appendix D, Table H2). The graph (Figure 10) shows that 58\% of teachers who have students that are assigned to them for the majority of the day responded they need Some professional development in mathematics content. A little less than $47 \%$ of the teachers who have students who move from classroom to classroom throughout the day, and $65 \%$ of teachers who have their school organized in another way reported they need Some professional development in mathematics content. Also, more than $24 \%$ of teachers who have students who are assigned to them for the majority of the day reported they need A Little professional development in mathematics content. More than $40 \%$ of the teachers who have students who move from classroom to classroom throughout the day, and 23\% of teachers who have their school organized in another way reported they need A Little 
professional development in mathematics content. Teachers who teach for the majority of the day, and the student's remain with him/her for all core academic subjects feel their need of mathematics professional development is stronger compared to a teacher who has students move from classroom to classroom throughout the day, from one academic subject to another.

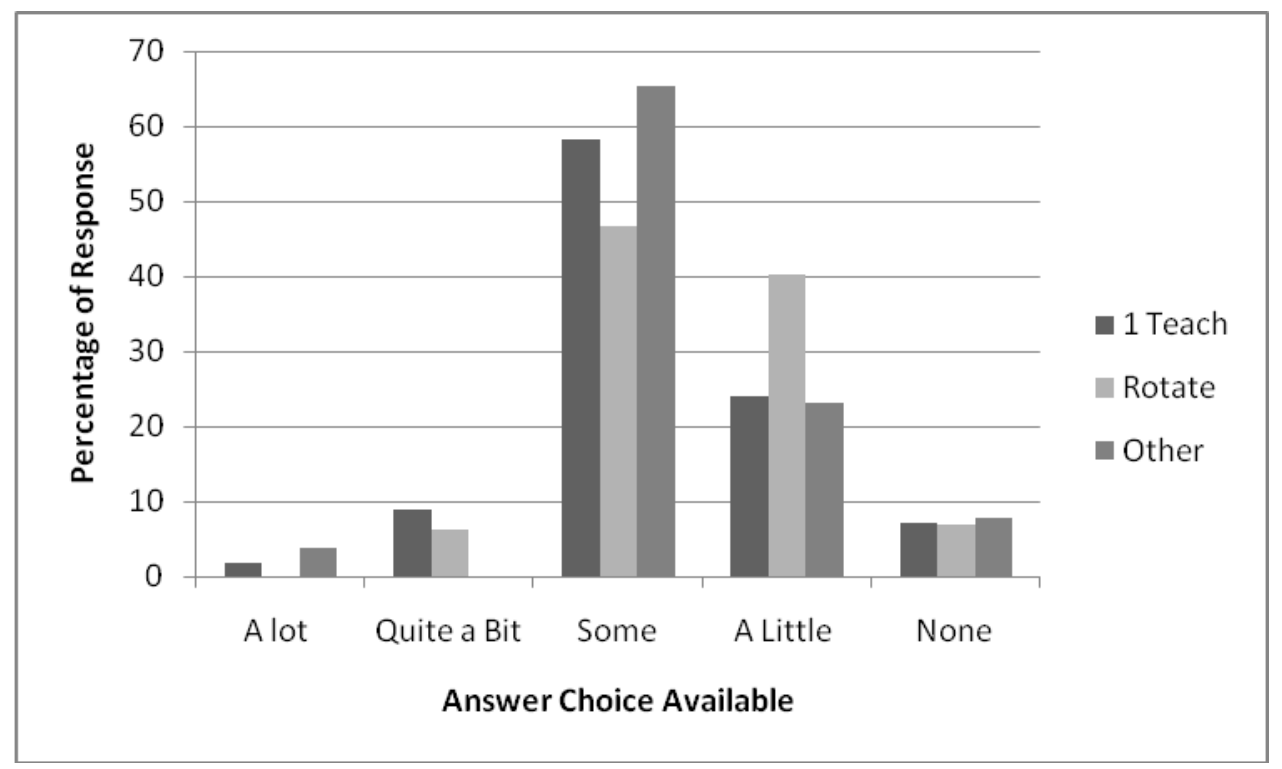

Figure 10. Percentage response for Item 16 (Professional Development Need of Mathematics Content Knowledge) on the MPDI graphed by School Organization.

School Organization (Item 5) by Need More Knowledge in Subject (Item 17) analysis did not yield a statistically significant finding (Appendix D, Table H3). Overall, the teachers responded that they need more professional development in the area of Process (36\%) and Statistics (29\%). This suggests that the way that a school is organized does not impact the teachers need for an area where they need more math content knowledge.

School Organization (Item 5) by Do Not Need More Knowledge in Subject (Item 18) analysis yielded a statistically significant finding (Appendix D, Table H4). The graph (Figure 11) shows when teachers were asked to respond to an area that they do not need more knowledge $10 \%$ of teachers who have students that are assigned to them for the majority of the day reported they do 
not need more knowledge in Algebra. More than $34 \%$ of the teachers who at have students who move from classroom to classroom throughout the day, and a little less than $12 \%$ of teachers who have their school organized in another way reported they do not need more knowledge in Algebra. The highest percentage of responses was $49 \%$ of teachers who have students that are assigned to them for the majority of the day, $37 \%$ of the teachers who have students who move from classroom to classroom throughout the day, and a little less than $58 \%$ of teachers who have their school organized in another way reported they do not need more knowledge in Numbers and Operations. There was no meaningful pattern in school organization when teachers were asked about a math area that they do not need more knowledge.

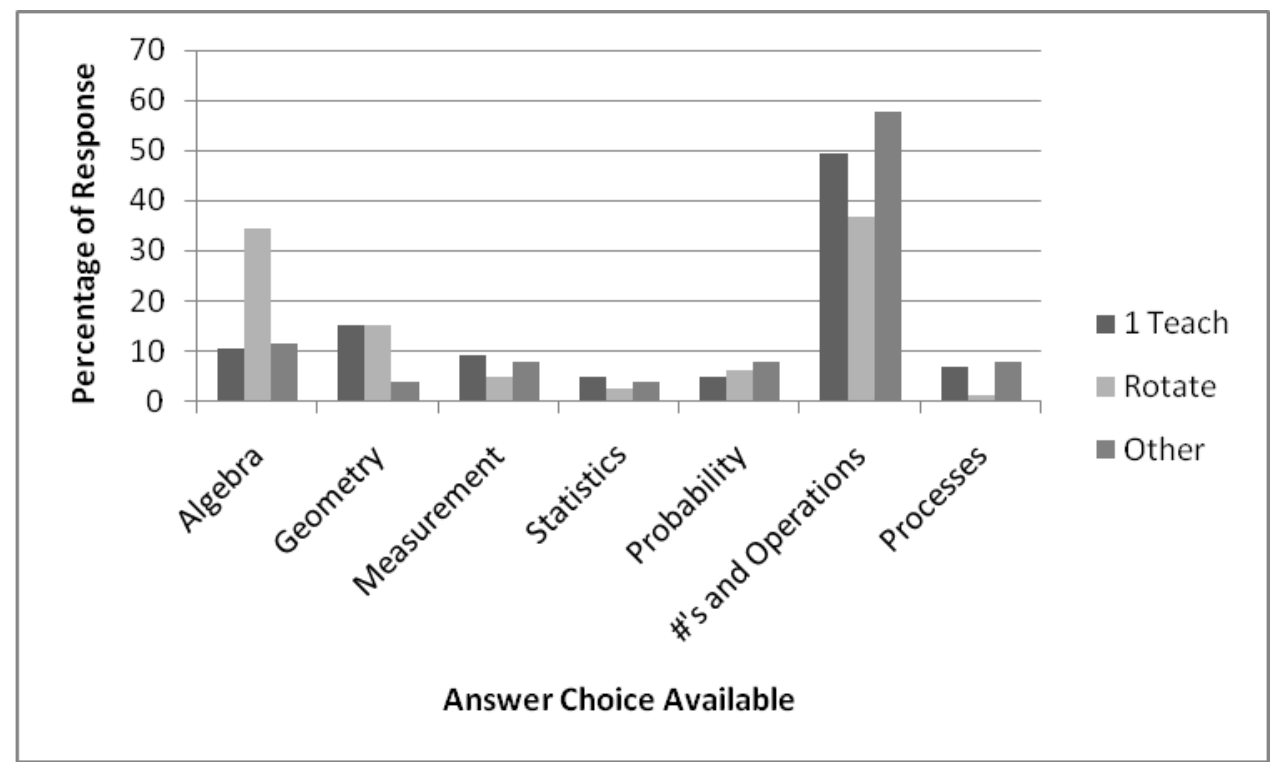

Figure 11. Percentage response for Item 18 (Do Not Need More Knowledge in Subject) on the MPDI graphed by School Organization.

School Organization (Item 5) by Ability to Teach Mathematics (Item 27) analysis yielded a statistically significant finding (Appendix D, Table H5). The figure (Figure 12) shows that when teachers were asked to rate their ability to teach mathematics, $57 \%$ of teachers who have students 
that were assigned to them for the majority of the day reported they were Above Average in their ability to teach mathematics. More than $61 \%$ of the teachers who have students who move from classroom to classroom throughout the day, and a little less than $74 \%$ of teachers who have their school organized in another way reported they are Above Average in their ability to teach mathematics. The teachers who have students that were assigned to them for the majority of the day then reported they were Average (30\%), to teachers who have students who move from classroom to classroom throughout the day that reported they were then more Exceptional (22\%), to teachers who have their school organized in another way reported they were then more Average (17\%). Teachers who teach for the majority of the day and the student's remain with him/her for all core academic subjects feel their need to teach mathematics weaker compared to a teacher who has students move from classroom to classroom throughout the day, from one academic subject to another. This suggests that teachers who teach mathematics throughout the day feel more confident in their ability to teach mathematics than a teacher who teaches other subjects as well as math.

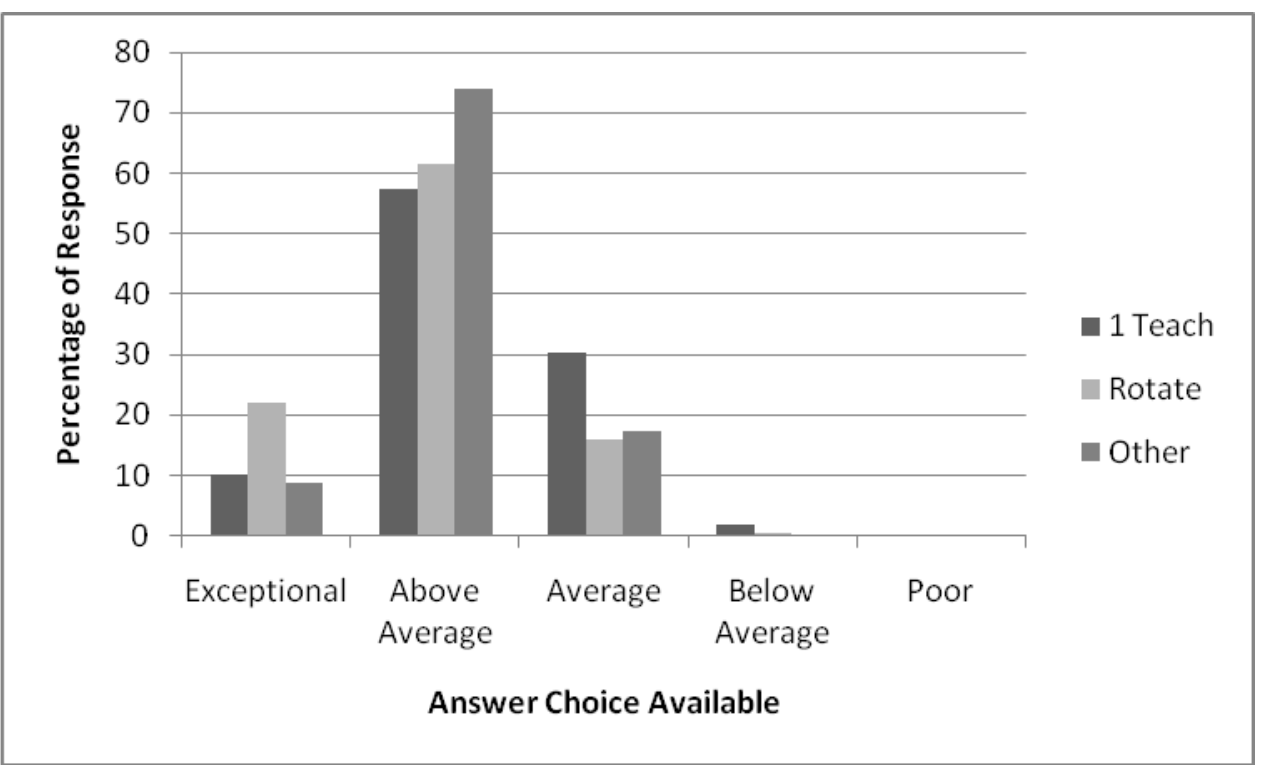


Figure 12. Percentage response for Item 27 (Ability to Teach Mathematics) on the MPDI graphed by School Organization.

School Organization (Item 5) by Professional Development Need for Teaching Mathematics (Item 29) analysis did not yield a statistically significant finding (Appendix D, Table H6). Overall, $84 \%$ of teachers responded that they need Some or A Little professional development for teaching mathematics. This suggests that school organization does not affect the teachers rating on their professional development need for teaching mathematics.

School Organization (Item 5) by Need More Teaching Strategies for Teaching Mathematics (Item 30) analysis yielded a statistically significant finding (Appendix D, Table H7). The graph (Figure 13) shows $48 \%$ of teachers who have students assigned to them for the majority of the day reported they need more teaching strategies in Process. More than 33\% of the teachers who have students who move from classroom to classroom throughout the day, and a little less than $41 \%$ of teachers who have their school organized in another way reported they need more teaching strategies in Process. There was no meaningful pattern in school organization when teachers were asked about an area they need more math teaching strategies. 


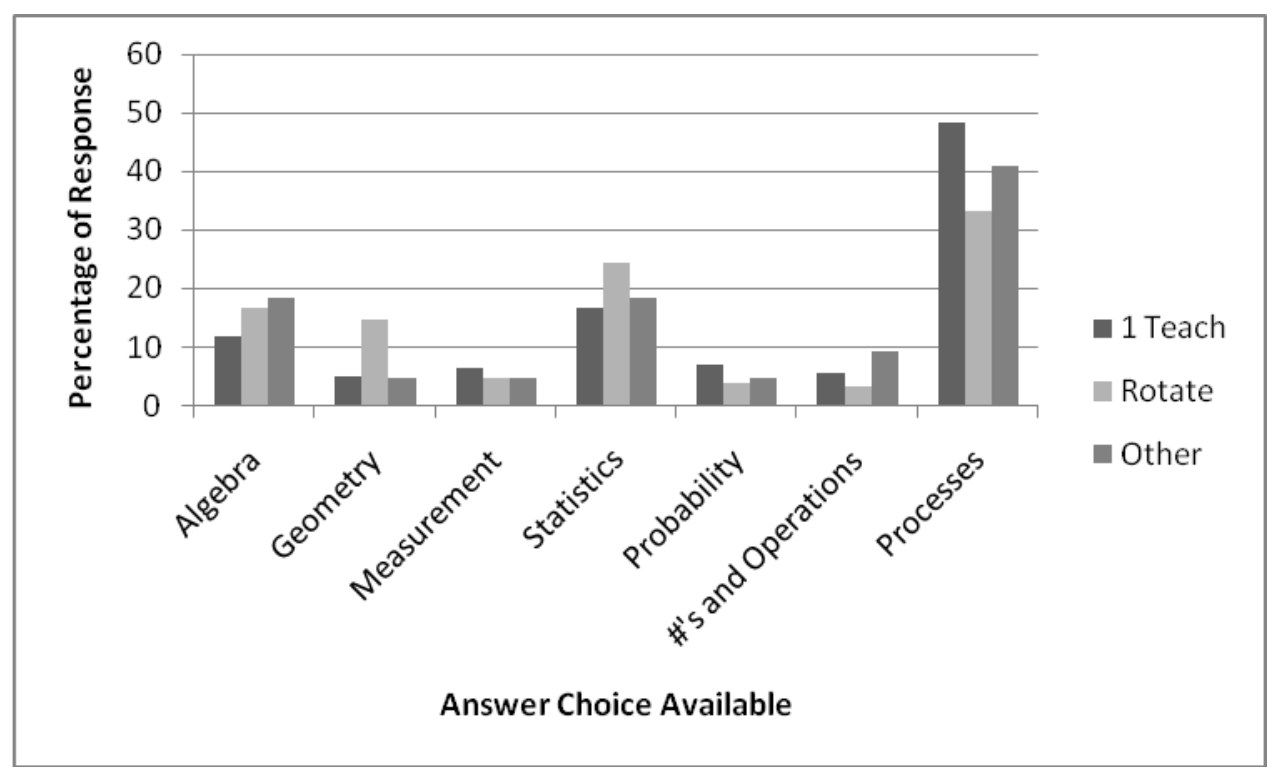

Figure 13. Percentage response for Item 30 (Need for More Strategies for Teaching Mathematics) on the MPDI graphed by School Organization.

School Organization (Item 5) by Do Not Need More Teaching Strategies for Teaching Mathematics (Item 31) analysis yielded a statistically significant finding (Appedix D, Table H8). The graph (Figure 14) shows $46 \%$ of teachers who have students that were assigned to them for the majority of the day reported they need more teaching strategies in Numbers and Operations. More than $35 \%$ of the teachers who have students who move from classroom to classroom throughout the day, and a little less than $41 \%$ of teachers who have their school organized in another way reported they do not need more teaching strategies in Numbers and Operations. There was no meaningful pattern in school organization when teachers were asked about an area they do not need more math teaching strategies. 


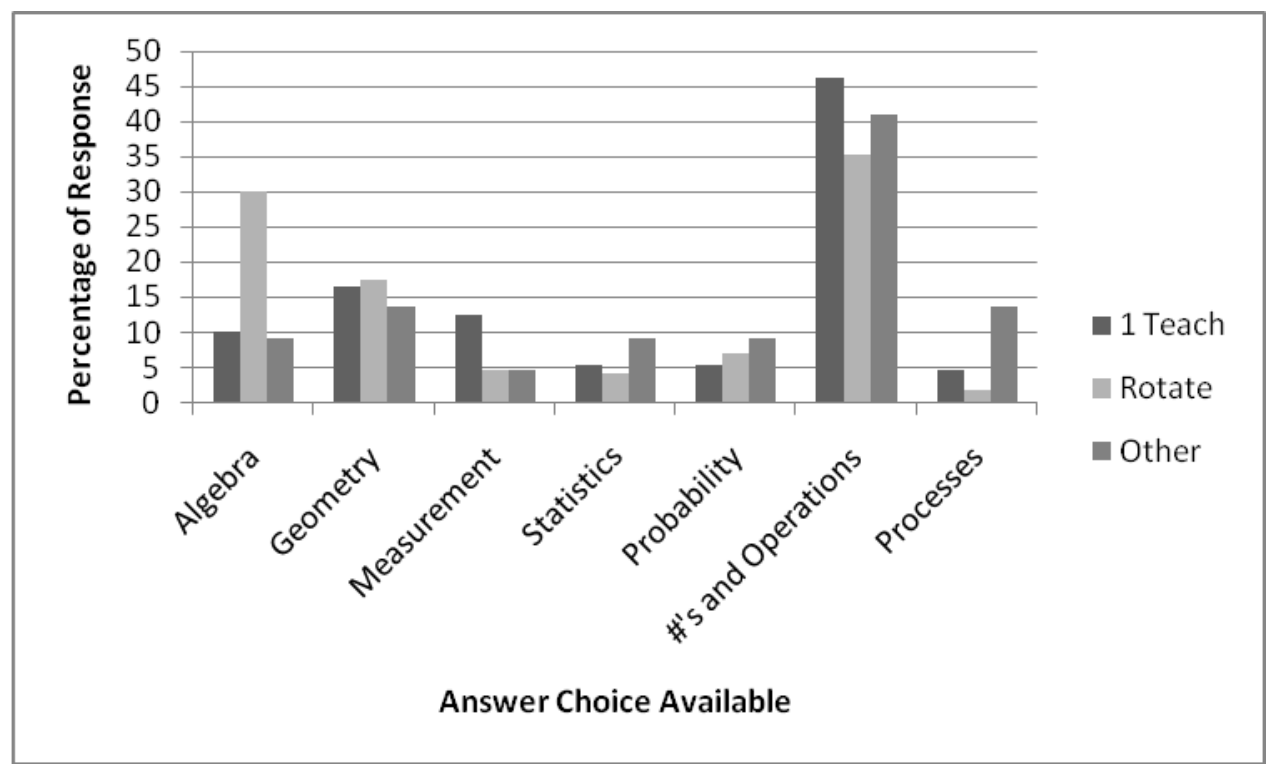

Figure 14. Percentage response for Item 31 (Do Not Need for More Strategies for Teaching Mathematics) on the MPDI graphed by School Organization.

Role in education. Role in Education (Item 6) by Math Content Knowledge (Item 14) did

not yield a statistically significant finding (Appendix D, Table I1). Overall, a little less than 52\% of teachers responded that they have Above Average math content knowledge. This suggest that a teachers role in education does not affect how they rate their math content knowledge.

Role in Education (Item 6) by Professional Development Need of Mathematics Content Knowledge (Item 16) analysis did not yield a statistically significant finding (Appendix D, Table I2). Overall, 53\% of teachers responded that they needed Some professional development in mathematics content knowledge. This suggest that a teachers role in education does not affect how they rate their professional development need of mathematics content knowledge.

Role in Education (Item 6) by Need More Knowledge in Subject (Item 17) analysis did not yield a statistically significant finding (Appendix D, Table I3). Overall, teachers responded that they need more professional development in the area of Statistics (28\%) and Process (36\%). This 
suggest that a teachers role in education does not affect an area that they need more mathematics content knowledge.

Role in Education (Item 6) by Do Not Need More Knowledge in Subject (Item 18) analysis did not yield a statistically significant finding (Appendix D, Table I4). Overall, $45 \%$ of teachers responded they do not need more professional development in the area of Numbers and Operations. This suggest that a teachers role in education does not affect an area that they do not need more mathematics content knowledge.

Role in Education (Item 6) by Ability to Teach Mathematics (Item 27) analysis did not yield a statistically significant finding (Appendix D, Table I5). Overall, 75\% of teachers responded that they feel they are Exceptional or Above Average in their ability to teach. This suggest that a teachers role in education does not affect how they rate their ability to teach mathematics.

Role in Education (Item 6) by Professional Development Need for Teaching Mathematics (Item 29) analysis did not yield a statistically significant finding (Appendix D, Table I6). Overall, $88 \%$ of teachers responded that they need Some, A Little, or No professional development for teaching mathematics. This suggest that a teachers role in education does not affect how they rate their need more teaching mathematics.

Role in Education (Item 6) by Need More Strategies for Teaching Mathematics (Item 30) analysis did not yield a statistically significant finding (Appendix D, Table I7). Overall, teachers responded that they need more professional development in the area of Statistics (20\%) and Process (38\%). This suggest that a teachers role in education does not affect how they rate their need for more strategies for teaching mathematics. 
Role in Education (Item 6) by Do Not Need More Strategies for Teaching Mathematics (Item 31) analysis did not yield a statistically significant finding (Appendix D, Table I8). Overall, $42 \%$ of teachers responded they do not need more professional development in the area of Numbers and Operations. This suggest that a teachers role in education does not affect how they rate an area that they do not need more strategies for teaching mathematics.

Degree. Degree (Item 7) by Math Content Knowledge (Item 14) did not yield a statistically significant finding (Appendix D, Table J1). Overall, a little less than 53\% of teachers responded that they have Above Average math content knowledge. This suggest that a degree in education does not affect how they rate their math content knowledge.

Degree (Item 7) by Professional Development Need of Mathematics Content Knowledge (Item 16) analysis yielded a statistically significant finding (Appendix D, Table J2). The graph (Figure 15) shows that $0 \%$ of teachers with a doctoral degree in special education, $0 \%$ master's degree in special education teachers, $60 \%$ of teachers with a bachelor's degree in special education with special education certification, $44 \%$ of teachers with a bachelor's degree in another area with special education certification, and $22 \%$ with a bachelor's degree in another area with special education permit responded they need Some professional development in mathematics content. For teachers in education, $33 \%$ of teachers with a doctoral degree in education, $51 \%$ master's degree in education, $61 \%$ of teachers with a bachelor's degree in education, $50 \%$ of teachers with a bachelor's degree in another area, and 1\% with a bachelor's degree in another area with general education permit report they need Some professional development in mathematics content. Teachers were more likely to feel their content knowledge is varied based upon their degree. This 
suggests that teachers that have a higher degree feel more confident than novice teachers when asked about their professional development need in mathematics content.

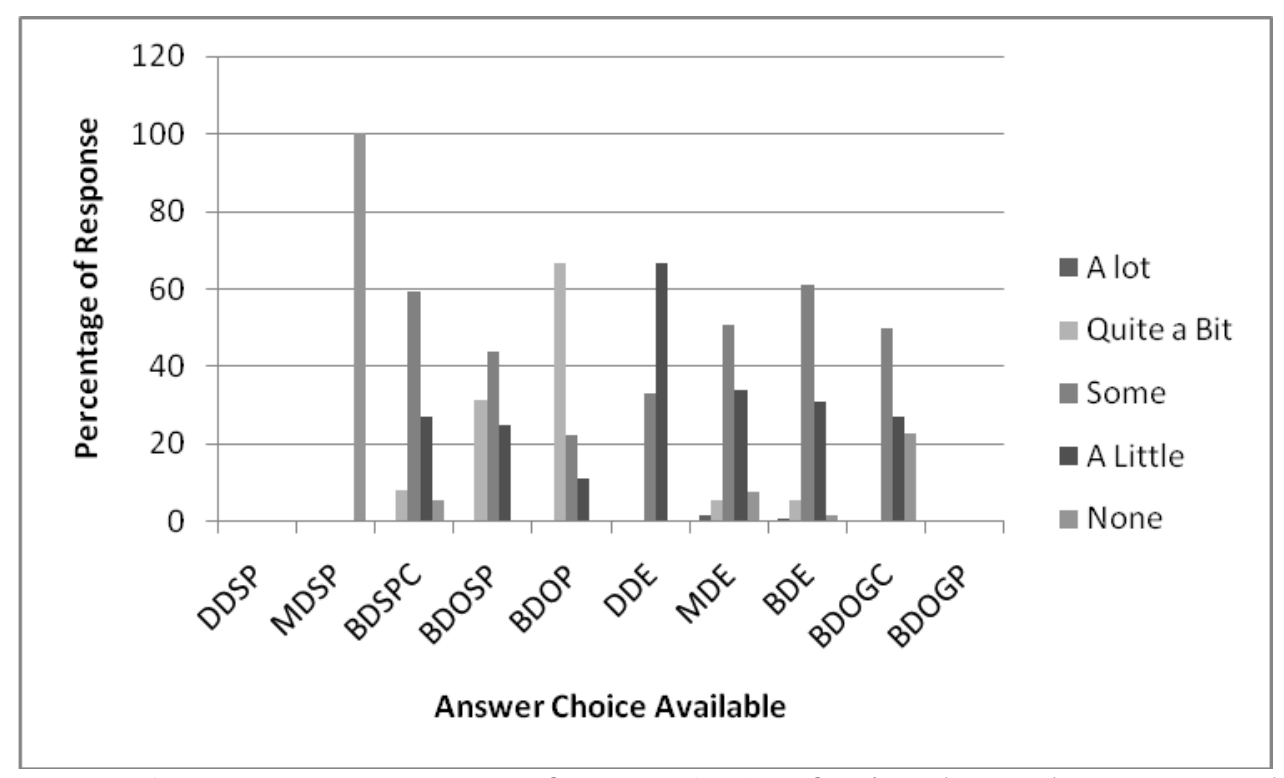

Figure 15. Percentage response for Item 16 (Professional Development Need of Mathematics Content Knowledge) on the MPDI graphed by Degree.

Degree (Item 7) by Need More Knowledge in Subject (Item 17) analysis did not yield a statistically significant finding (Appendix D, Table J3). Overall, teachers responded they need more professional development in the area of Statistics (28\%) and Process (36\%). This suggests that a teachers need for more knowledge does not matter by the degree that they have earned.

Degree (Item 7) by Do Not Need More Knowledge in Subject (Item 18) analysis did not yield a statistically significant finding (Appendix D, Table J4). Overall, 46\% of teachers responded they do not need more professional development in the area of Numbers and Operations. This suggests that a teachers do not need for more knowledge does not matter by the degree that they have earned.

Degree (Item 7) by Ability to Teach Mathematics (Item 27) analysis yielded a statistically significant finding (Appendix D, Table J5). The graph (Figure 16) shows that 0\% of teachers with 
a doctoral degree in special education, $0 \%$ master's degree in special education teachers, $35 \%$ of teachers with a bachelor's degree in special education with special education certification, $69 \%$ of teachers with a bachelor's degree in another area with special education certification, and 57\% with a bachelor's degree in another area with special education permit responded they were Above Average in their ability to teach mathematics. For teachers in education, $67 \%$ of teachers with a doctoral degree in education, $62 \%$ master's degree in education, $67 \%$ of teachers with a bachelor's degree in education, $52 \%$ of teachers with a bachelor's degree in another area, and $100 \%$ with a bachelor's degree in another area with general education permit report they were Above Average in their ability to teach mathematics. Teachers were more likely to feel their ability to teach math is varied based upon their degree. This suggests that the higher the teachers degree the higher the teacher will rank themselves in their ability to teach mathematics.

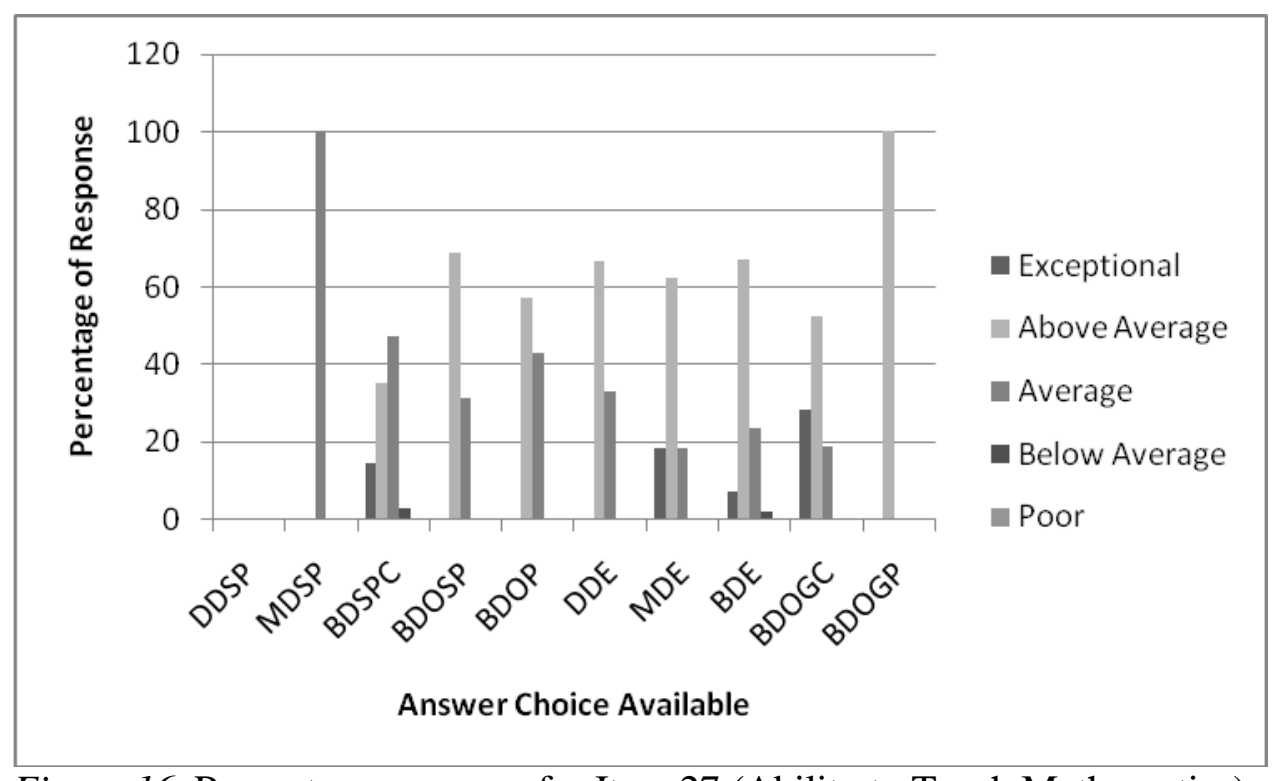

Figure 16. Percentage response for Item 27 (Ability to Teach Mathematics) on the MPDI graphed by Degree. 
Degree (Item 7) by Professional Development Need for Teaching Mathematics (Item 29) analysis did not yield a statistically significant finding (Appendix D, Table J6). Overall, 82\% of teachers responded that they need Some, A Little, or No professional development for teaching mathematics. This suggests that a teachers need for more professional development in teaching mathematics does not matter by the degree that they have earned.

Degree (Item 7) by Need More Strategies for Teaching Mathematics (Item 30) analysis did not yield a statistically significant finding (Appendix D, Table J7). Overall, teachers responded that they need more professional development in the area of Statistics (21\%) and Process (39\%). This suggests that a teachers need for more strategies in teaching mathematics does not matter by the degree that they have earned.

Degree (Item 7) by Do Not Need More Strategies for Teaching Mathematics (Item 31) analysis did not yield a statistically significant finding (Appendix D, Table J8). Overall, 42\% of teachers responded they do not need more professional development in the area of Numbers and Operations. This suggests that a teachers do not need for more teaching strategies does not matter by the degree that they have earned.

Number of math content courses. Number of Math Content Courses (Item 8) by Math Content Knowledge (Item 14) analysis yielded a statistically significant finding (Appendix D, Table K1). The graph (Figure 17) shows that the rating continued to increase as the amount of courses increased: $0 \%$ of teachers who took 1-2 courses, $5 \%$ of teachers who took 3-4 courses, $9 \%$ of teachers who took 5-6 courses, $13 \%$ of teachers who took 7-8 courses, and $33 \%$ of teachers who took 8 or more courses rated themselves as Exceptional in Math Content Knowledge. At the other end of the rating scale, in the Below Average category, the percentages decreased as the number of 
courses increased: $7 \%$ of teachers who took $1-2$ courses, $4 \%$ of teachers who took $3-4,2 \%$ of teachers who took 5-6 courses, $0 \%$ of teachers who took 7-8 courses, and $0 \%$ of teachers who took 8 or more courses. The increased number of courses that a teacher took, the stronger the relationship in a higher response rating of math content knowledge. The decreased number of courses that a teacher took, the stronger the relationship in a lower response rating of math content knowledge. This suggests that the more math content courses that a teacher has taken the higher they will rank themselves in their math content knowledge.

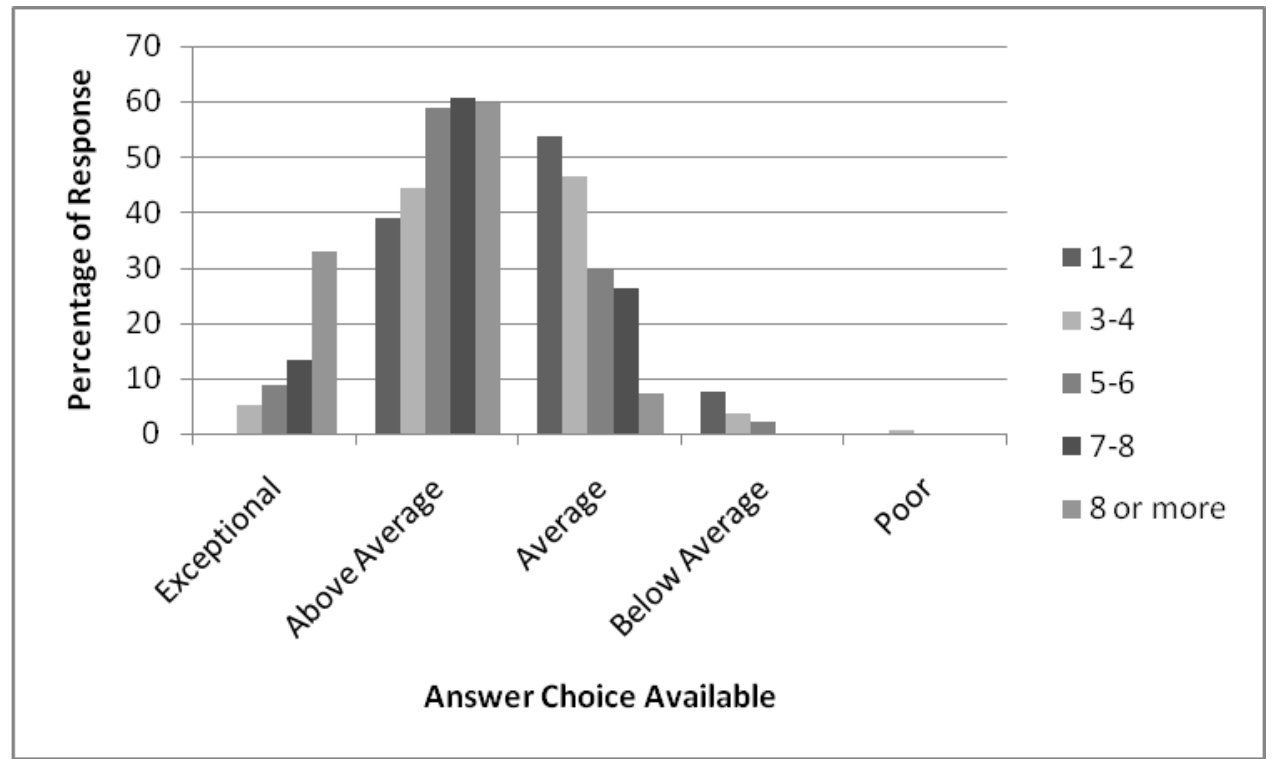

Figure 17. Percentage response for Item 14 (Mathematics Content Knowledge) on the MPDI graphed by Number of Math Content Courses Taken.

Number of Math Content Courses (Item 8) by Professional Development Need of Mathematics Content Knowledge (Item 16) analysis yielded a statistically significant finding (Appendix D, Table K2). The graph (Figure 18) shows 58\% of teachers who took 1-2 courses, $59 \%$ of teachers who took $3-4$ courses, $52 \%$ of teachers who took $5-6$ courses, $55 \%$ of teachers who took 7-8 courses, and $44 \%$ of teachers who took 8 or more courses reported that they need 
Some math professional development in content knowledge. In addition, the graph also displays $24 \%$ of teachers who took $1-2$ courses, $26 \%$ of teachers who took $3-4,35 \%$ of teachers who took 5-6 courses, $29 \%$ of teachers who took 7-8 courses, and $41 \%$ of teachers who took 8 or more courses reported that they need A Little math professional development in content knowledge. The increased number of courses that a teacher took, the stronger the relationship in a lower response rating of math professional development need. This suggests that the less content courses that a teacher has taken the higher they will rank their need for math professional development.

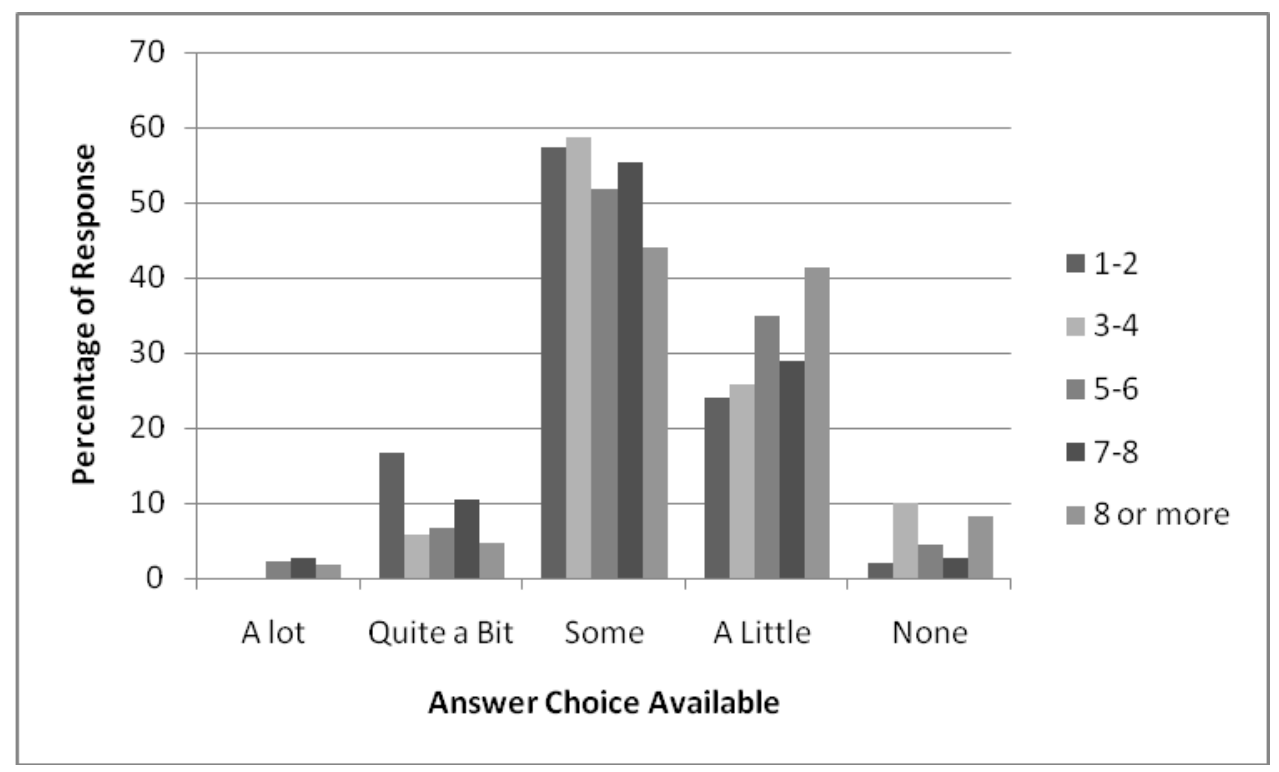

Figure 18. Percentage response for Item 16 (Professional Development Need of Mathematics Content Knowledge) on the MPDI graphed by Number of Math Content Courses Taken.

Number of Math Content Courses (Item 8) by Need More Knowledge in Subject (Item 17) analysis yielded a statistically significant finding (Appendix D, Table K3). The graph (Figure 19) shows $13 \%$ of teachers with 1-2 math content courses, $28 \%$ of teachers with 3-4 math content courses, $23 \%$ of teachers with 5-6 content courses, $18 \%$ of teachers with 7-8 math content courses, and $40 \%$ of teachers with 8 or more content courses felt they needed more knowledge in Statistics. In addition, 53\% of teachers with 1-2 math content courses, $37 \%$ of teachers with 3-4 math content 
courses, $45 \%$ of teachers with 5-6 content courses, $29 \%$ of teachers with 7-8 math content courses, and $24 \%$ of teachers with 8 or more content courses felt they needed more professional development in Process. There was no meaningful pattern in the number of math content courses when teachers were asked about an area they need more math content knowledge.

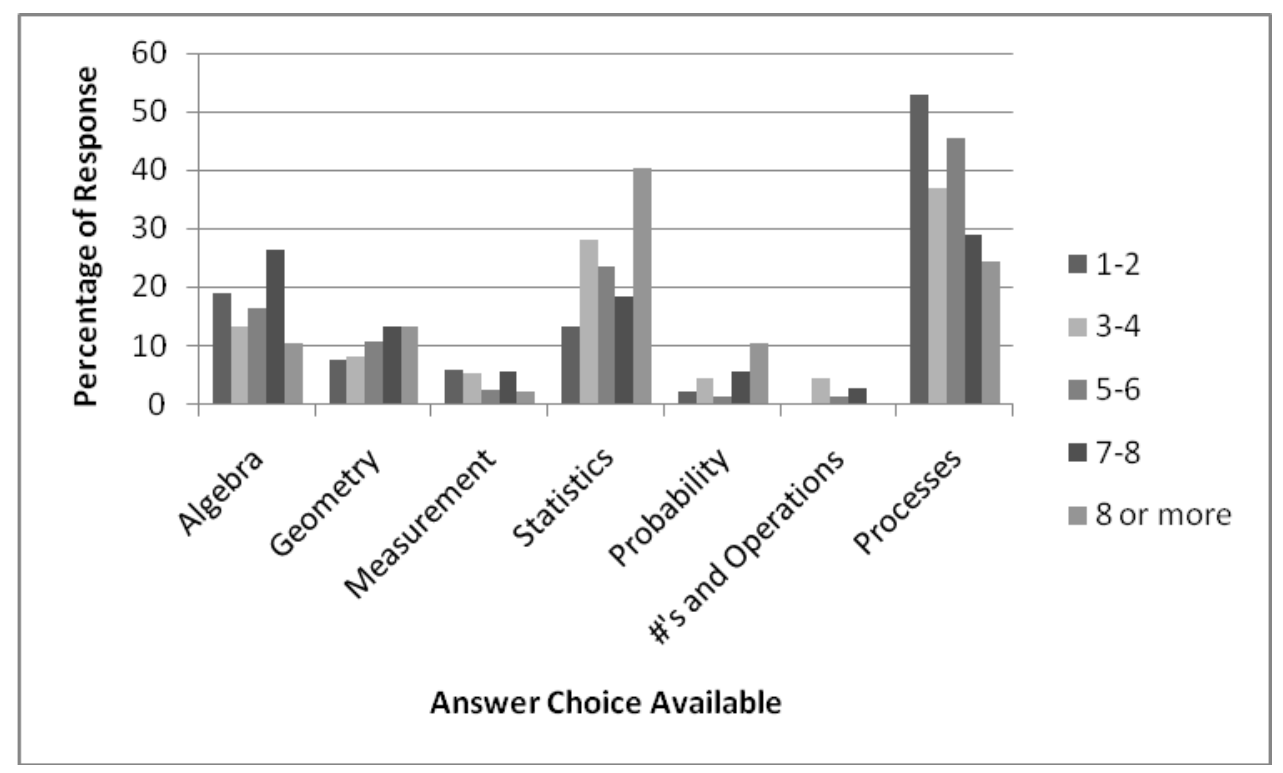

Figure 19. Percentage response for Item 17 (Need More Knowledge in Subject) on the MPDI graphed by Number of Math Content Courses Taken.

Number of Math Content Courses (Item 8) by Do Not Need More Knowledge in Subject (Item 18) analysis yielded a statistically significant finding (Appendix D, Table K4). The graph (Figure 20) shows $12 \%$ of teachers who took 1-2 math content courses, $12 \%$ of teachers who took 3-4 math content courses, $15 \%$ of teachers who took 5-6 content courses, $16 \%$ of teachers who took 7-8 math content courses, and $40 \%$ of teachers who took 8 or more content courses reported that they need professional development in Algebra. In addition, 49\% of teachers who took 1-2 math content courses, $58 \%$ of teachers who took 3-4 math content courses, $49 \%$ of teachers who took 5-6 content courses, $47 \%$ of teachers who took 7-8 math content courses, and $28 \%$ of teachers who took 8 or more content courses reported that they do not need professional development in 
Numbers and Operations. There was no meaningful pattern in the number of math content courses when teachers were asked about an area they do not need more math content knowledge.

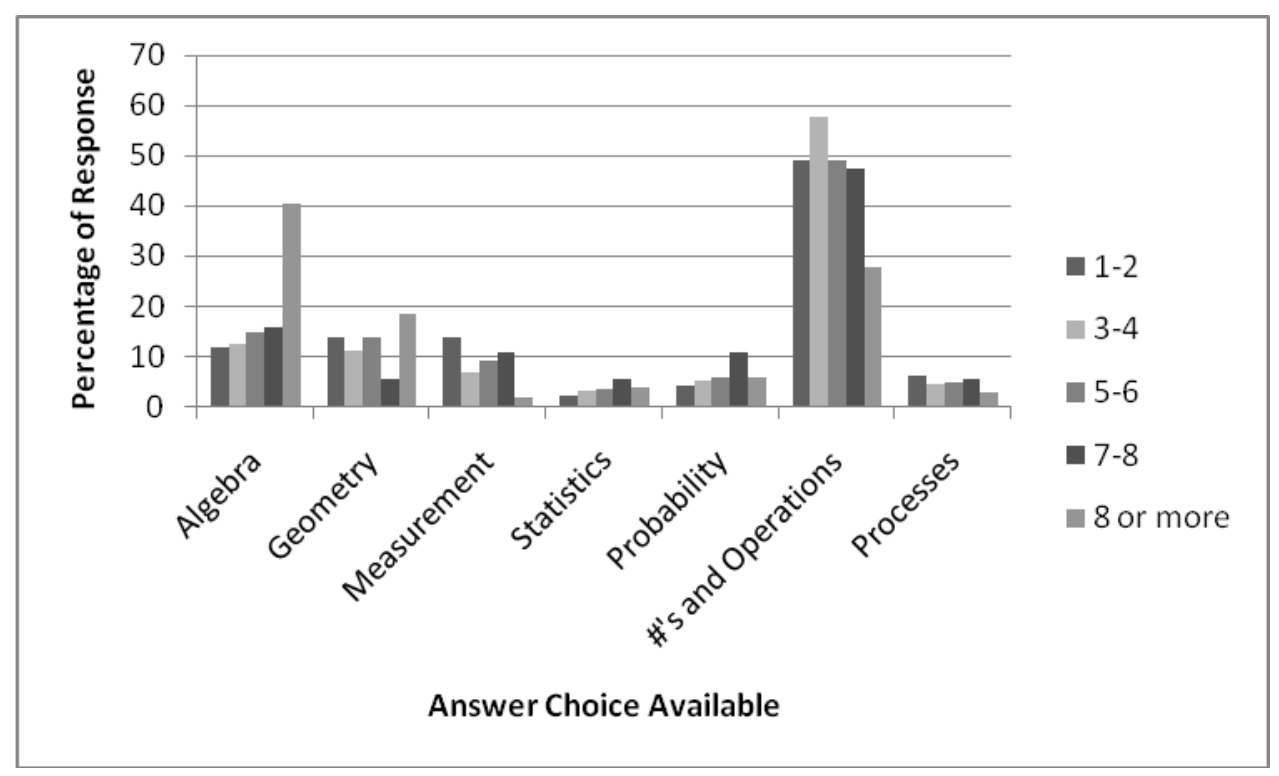

Figure 20. Percentage response for Item 18 (Do Not Need More Knowledge in Subject) on the MPDI graphed by Number of Math Content Courses Taken.

Number of Math Content Courses (Item 8) by Ability to Teach Mathematics (Item 27) analysis yielded a statistically significant finding (Appendix D, Table K5). The graph (Figure 21) shows that $45 \%$ of teachers who took 1-2 math content courses reported they are Average in their ability to teach mathematics. In addition, $32 \%$ of teachers who took $3-4$ courses, $24 \%$ of teachers who took 5-6 courses, $22 \%$ of teachers who took 7-8 courses, and 6\% of teachers who took 8 or more courses reported having Average ability to teach mathematics. Finally, $4 \%$ of teachers who took 1-2 math content courses, $10 \%$ of teachers who took 3-4 math content courses, $6 \%$ of teachers who took 5-6 content courses, $30 \%$ of teachers who took 7-8 math content courses, and $27 \%$ of teachers who took 8 or more content courses reported having Exceptional ability to teach mathematics. The increased number of courses that a teacher took, the stronger the relationship in a 
higher response rating of ability to teach mathematics. This suggests that the more math content courses that they have taken the higher they rank themselves in their ability to teach mathematics.

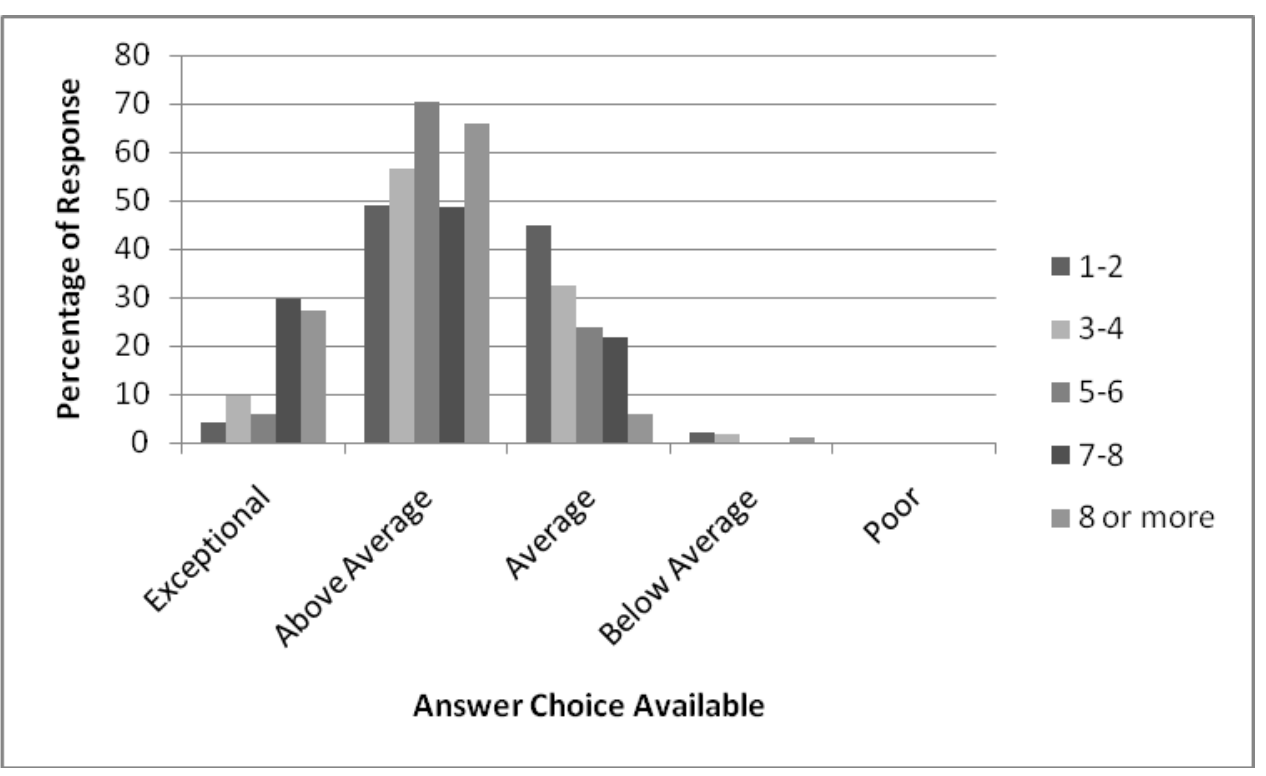

Figure 21. Percentage response for Item 27 (Ability to Teach Mathematics) on the MPDI graphed by Number of Math Content Courses Taken.

Number of Math Content Courses (Item 8) by Professional Development Need for Teaching Mathematics (Item 29) analysis did not yield a statistically significant finding (Appendix D, Table K6). Overall, 89\% of teachers reported that they need Some, A Little, or No professional development for teaching mathematics. This suggests that the number of math content courses does not affect the professional development need for teaching mathematics.

Number of Math Content Courses (Item 8) by Need More Strategies for Teaching Math (Item 30) analysis did not yield a statistically significant finding (Appendix D, Table K7). Overall, $39 \%$ of teachers reported that they need more math teaching strategies for the area of process. This suggests that the number of math content courses does not matter when teachers report their need for more strategies for teaching mathematics. 
Number of Math Content Courses (Item 8) by Do Not Need More Strategies for Teaching Math (Item 31) analysis yielded a statistically significant finding (Appendix D, Table K8). The relationship (Figure 22) shows $13 \%$ of teachers who took 1-2 math content courses, $10 \%$ of teachers who took 3-4 math content courses, $12 \%$ of teachers who took 5-6 content courses, $14 \%$ of teachers who took 7-8 math content courses, and 39\% of teachers who took 8 or more content courses reported they need professional development in Algebra. In addition, $40 \%$ of teachers who took 1-2 math content courses, 55\% of teachers who took 3-4 math content courses, $42 \%$ of teachers who took 5-6 content courses, $46 \%$ of teachers who took 7-8 math content courses, and $28 \%$ of teachers who took 8 or more content courses reported they need professional development in Numbers and Operations. There was no meaningful pattern in the number of math content courses when teachers were asked about an area they do not need more mathematics strategies.

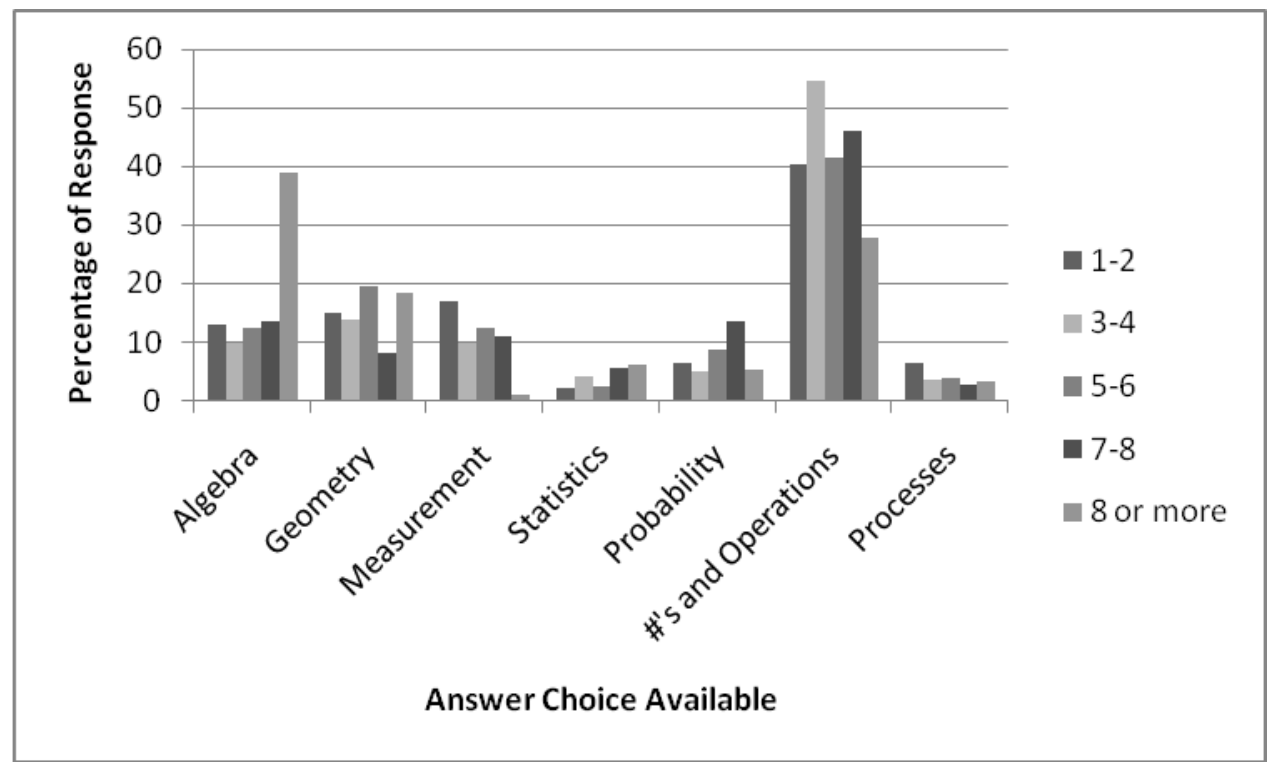

Figure 22. Percentage response for Item 31 (Do Not Need for More Strategies for Teaching Mathematics) on the MPDI graphed by Number of Math Content Courses Taken.

Number of math methods courses taken. Number of Math Methods Courses (Item 9) by Math Content Knowledge (Item 14) analysis yielded a statistically significant finding (Appendix 
D, Table L1). The graph (Figure 23) shows that $41 \%$ of teachers who took 1 math methods course, $53 \%$ of teachers who took 2 math methods courses, $71 \%$ of teachers who took 3 math methods courses, $64 \%$ of teachers who took 4 math content courses, $58 \%$ of teachers who took 5 math methods courses, and $100 \%$ of teacher that took 6 or more math methods courses responded that they are Above Average in Math Content Knowledge. Teachers who took 6 or more math methods courses were more likely to feel their content knowledge is strong compare to teachers who took 1 math methods course. This suggests that the more math strategies courses that were taken the higher they teachers rated themselves in their math content knowledge.

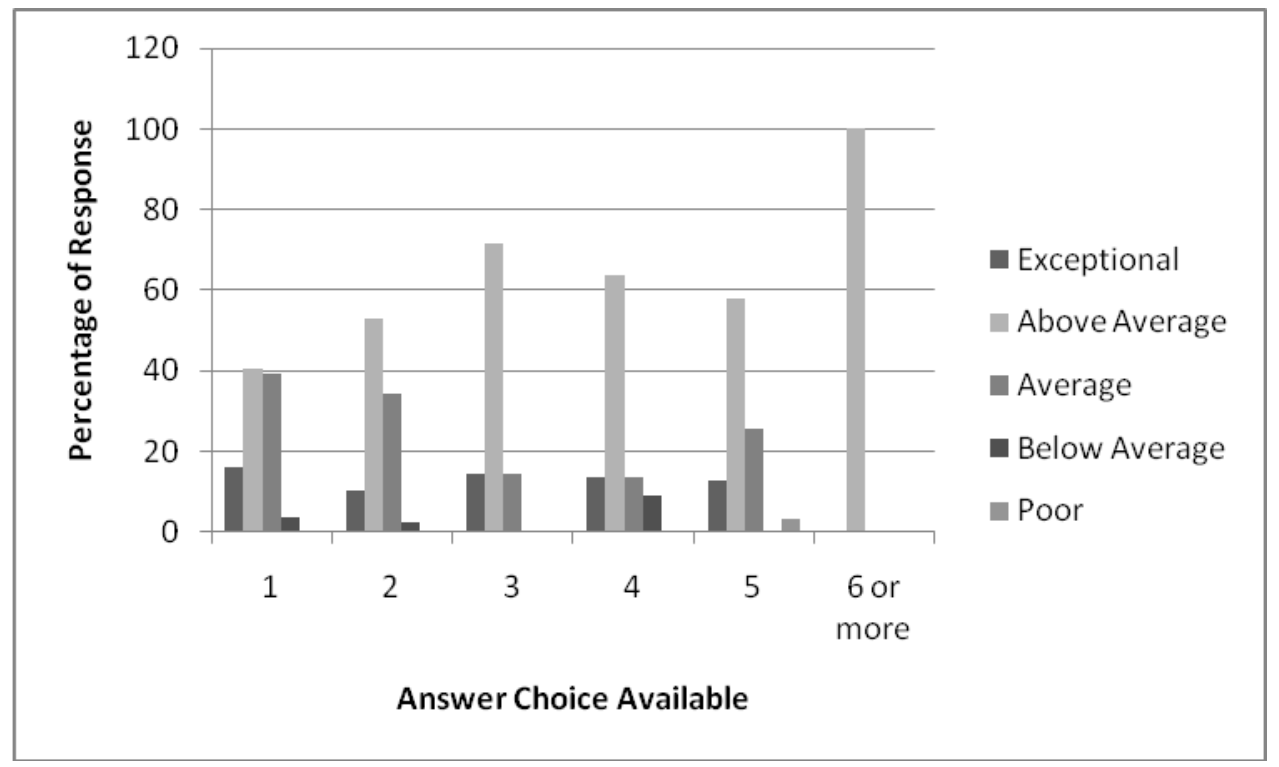

Figure 23. Percentage response for Item 14 (Mathematics Content Knowledge) on the MPDI graphed by Number of Math Methods Courses Taken.

Number of Math Methods Courses (Item 9) by Professional Development Need of Mathematics Content Knowledge (Item 16) analysis did not yield a statistically significant finding (Appendix D, Table L2). Overall, 54\% of teachers reported that they needed Some professional development in mathematics content knowledge. This suggests that the number of math methods 
courses does not affect how teachers rate their professional development need of mathematics content knowledge.

Number of Math Methods Courses (Item 9) by Need More Knowledge in Subject (Item 17) analysis did not yield a statistically significant finding (Appendix D, Table L3). Overall, teachers reported that they need more professional development in the area of Statistics (29\%) and Process (35\%). This suggests that the number of math methods courses does not affect an area that the teachers feel they need more knowledge in subject.

Number of Math Methods Courses (Item 9) by Do Not Need More Knowledge in Subject (Item 18) analysis did not yield a statistically significant finding (Appendix D, Table L4). Overall, $45 \%$ of teachers reported they do not need more professional development in the area of Numbers and Operations. This suggests that the number of math methods courses does not affect an area that the teachers feel they do not need more knowledge in subject.

Number of Math Methods Courses (Item 9) by Ability to Teach Mathematics (Item 27) analysis did not yield a statistically significant finding (Appendix D, Table L5). Overall, 76\% of teachers reported that they feel they are Exceptional or Above Average in their ability to teach. This suggests that the number of math methods courses does not affect how teachers rate their ability to teach mathematics.

Number of Math Methods Courses (Item 9) by Professional Development Need for Teaching Mathematics (Item 29) analysis did not yield a statistically significant finding (Appendix D, Table L6). Overall, $88 \%$ of teachers reported that they need Some, A Little, or No professional development for teaching mathematics. This suggests that the number of math methods courses does not affect how teachers rate their professional development need for teaching mathematics. 
Number of Math Methods Courses (Item 9) by Need More Strategies for Teaching Mathematics (Item 30) analysis did not yield a statistically significant finding (Appendix D, Table L7). Overall, teachers reported that they need more professional development in the area of Statistics (21\%) and Process (38\%). This suggests that the number of math methods courses does not affect how teachers rate their professional development need of strategies for teaching mathematics.

Number of Math Methods Courses (Item 9) by Do Not Need More Strategies for Teaching Mathematics (Item 31) analysis did not yield a statistically significant finding (Appendix D, Table L8). Overall, $41 \%$ of teachers reported they do not need more professional development in the area of Numbers and Operations. This suggests that the number of math methods courses does not affect how teachers rate their professional development area where they do not need more mathematics teaching strategies.

Years of experience. Years of Experience (Item 10) by Math Content Knowledge (Item 14) did not yield a statistically significant finding (Appendix D, Table M1). Overall, a little less than $52 \%$ of teachers reported that they have Above Average math content knowledge. This suggests that novice and verteran teachers rate their math content knowledge the same.

Years of Experience (Item 10) by Professional Development Need of Mathematics Content Knowledge (Item 16) analysis did not yield a statistically significant finding (Appendix D, Table M2). Overall, $53 \%$ of teachers reported that they needed Some professional development in mathematics content knowledge. This suggests that novice and verteran teachers rate their professional development need of mathematics content knowledge the same and that their experience does not play a role. 
Years of Experience (Item 10) by Need More Knowledge in Subject (Item 17) analysis did not yield a statistically significant finding (Appendix D, Table M3). Overall, teachers reported that they need more professional development in the area of Statistics (28\%) and Process (36\%). This suggests that verteran and novice teachers have the same mathematics area that they need more knowledge in subject.

Years of Experience (Item 10) by Do Not Need More Knowledge in Subject (Item 18) analysis yielded a statistically significant finding (Appendix D, Table M4). The graph (Figure 20) shows that $28 \%$ of teachers with less than 1 year of experience, $33 \%$ of teachers with 1-3 years of experience, $18 \%$ of teachers with 4-9 years of experience, $18 \%$ of teachers with $10-19$ years of experience, and $22 \%$ of teachers with 20 or more years of experience reported they do not need more knowledge in Algebra. In addition, 44\% of teachers with less than 1 year of experience, $26 \%$ of teachers with 1-3 years of experience, $42 \%$ of teachers with $4-9$ years of experience, $56 \%$ of teachers with10-19 years of experience, and $49 \%$ of teachers with 20 or more years of experience reported they do not need more knowledge in Numbers and Operations. There was no meaningful pattern in years of experience when teachers were asked about an area they do not need more math content knowledge. This suggests that veteran and novice teachers have differing areas that they do not need more knowledge in subject. 


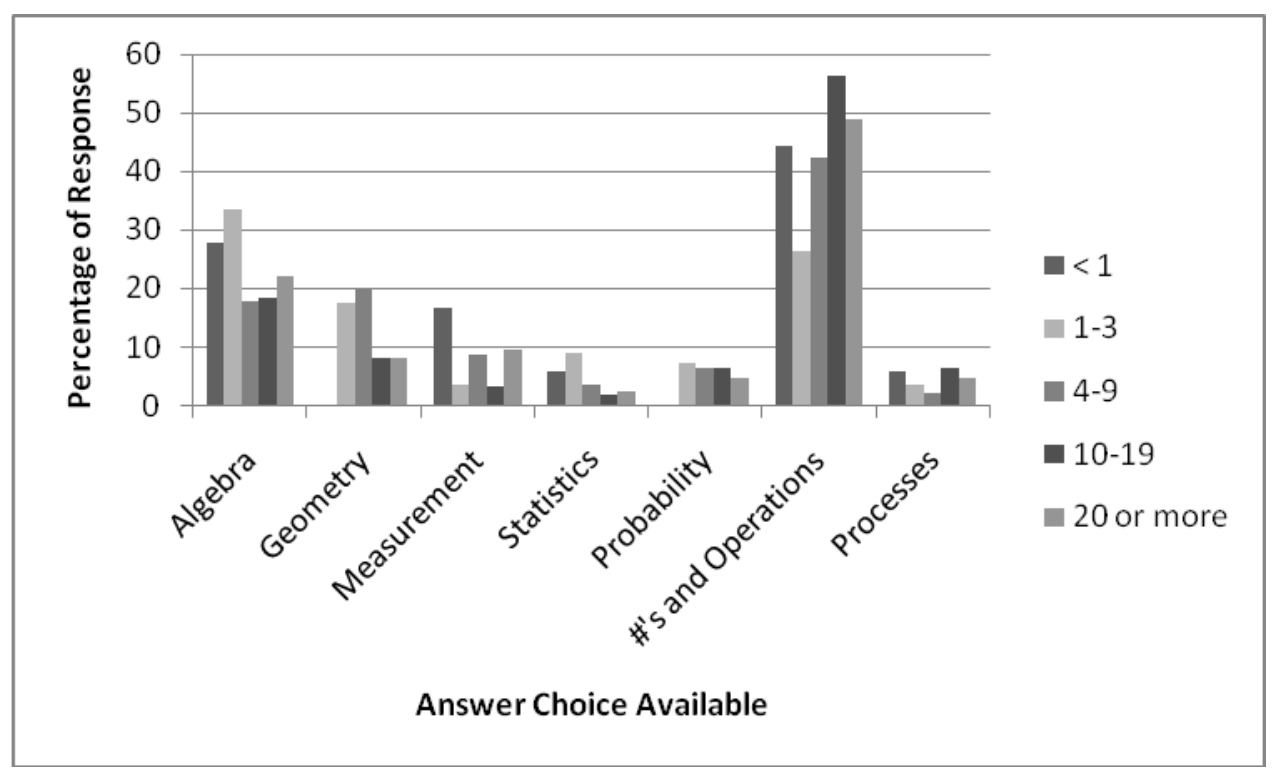

Figure 24. Percentage response for Item 18 (Do Not Need More Knowledge in Subject) on the MPDI graphed by Years of Experience.

Years of Experience (Item 10) by Ability to Teach Mathematics (Item 27) analysis yielded a statistically significant finding (Appendix D, Table M5). The graph (Figure 25) shows that 63\% of teachers with less than 1 year of experience, $24 \%$ of teachers with 1-3 years of experience, $27 \%$ of teachers with 4-9 years of experience, $26 \%$ of teachers with $10-19$ years of experience, and $10 \%$ of teachers with 20 or more years reported they have Average ability in teaching mathematics. In addition, $0 \%$ of teachers with less than 1 year, $6 \%$ of teachers with $1-3$ years, $13 \%$ of teachers with 4-9 years of experience, $16 \%$ of teachers with 10-19 years of experience, and $24 \%$ of teachers with 20 or more years of experience reported they have Exceptional ability in teaching mathematics.

Teachers with more years of experience were more likely to feel their ability to teach math is strong compared to teachers with less years of experience. This suggests that the more experience a teacher has the more confidence they have in teaching mathematics. 


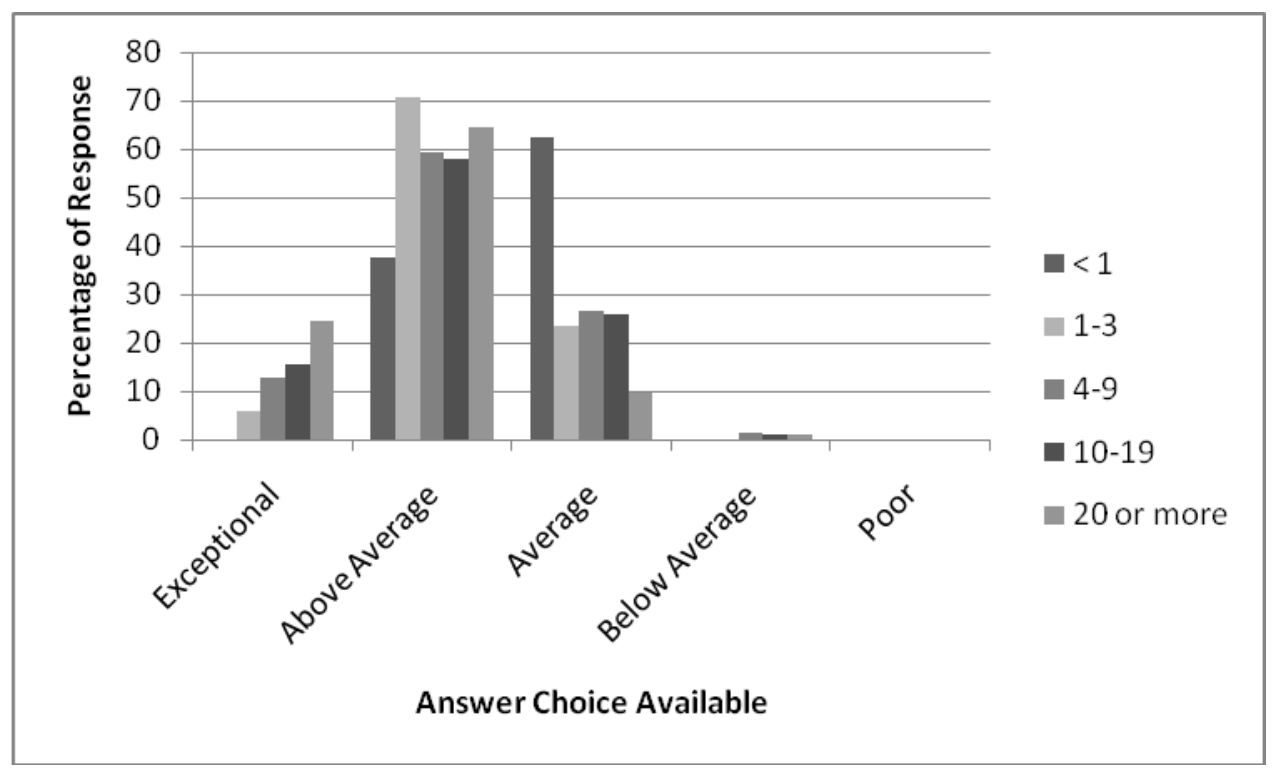

Figure 25. Percentage response for Item 27 (Ability to Teach Mathematics) on the MPDI graphed by Years of Experience.

Years of Experience (Item 10) by Professional Development Need for Teaching Math (Item 29) analysis yielded a statistically significant finding (Appendix D, Table M6). The graph (Figure 26) shows that $10 \%$ of teachers with less than 1 year of experience, $27 \%$ of teachers with 1-3 years of experience, $35 \%$ of teachers with 4-9 years of experience, $45 \%$ of teachers with 10-19 years of experience, and $54 \%$ of teachers with 20 or more years reported they need A Little math professional development. In addition, $60 \%$ of teachers with less than 1 year, $33 \%$ of teachers with 1-3 years, $43 \%$ of teachers with 4-9 years of experience, $42 \%$ of teachers with $10-19$ years of experience, and $42 \%$ of teachers with 20 or more years of experience reported they need Some math professional development. Teachers with fewer years of experience were more likely to feel they need more professional development compared to teachers with less years of experience. This suggests that the more years of experience a teacher has the less likely they are to rate that they need professional development in teaching mathematics. 


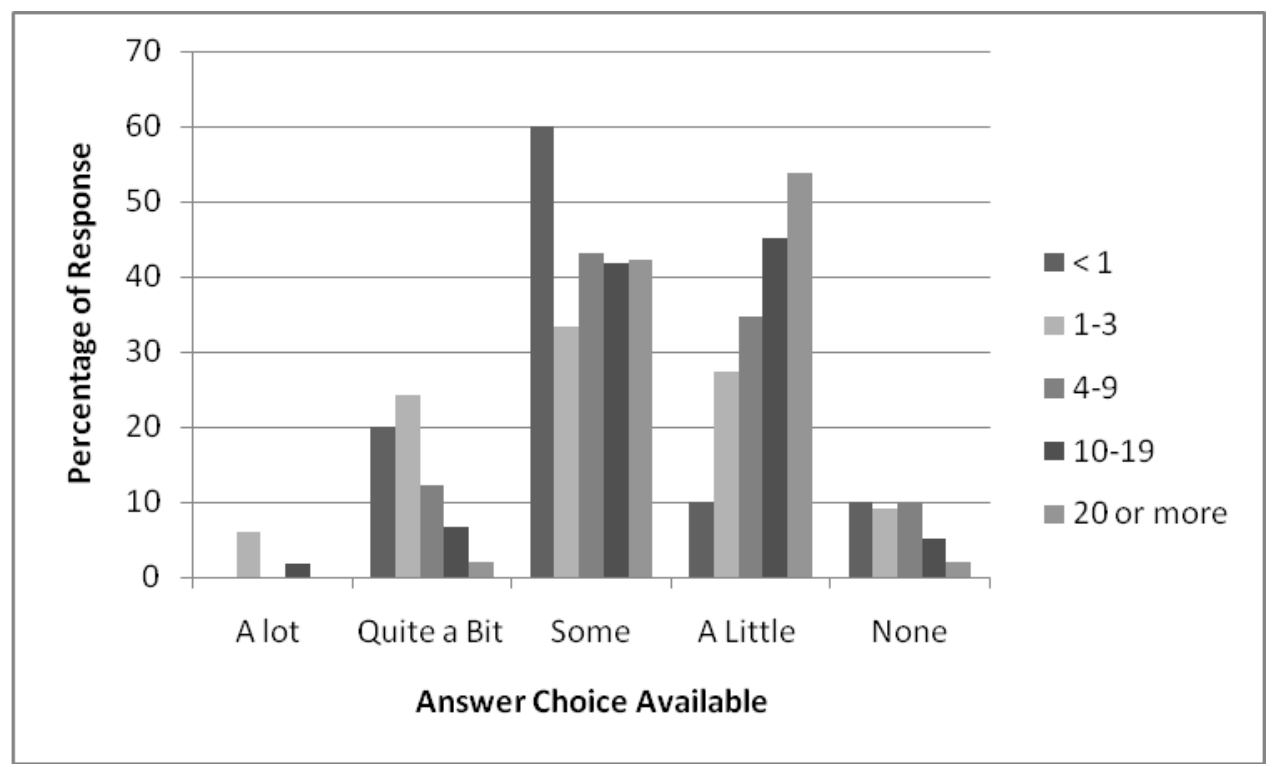

Figure 26. Percentage response for Item 29 (Professional Development Need for Teaching Math) on the MPDI graphed by Years of Experience.

Years of Experience (Item 10) by Need More Strategies for Teaching Mathematics (Item 30) analysis yielded a statistically significant finding (Appendix D, Table M7). The graph (Figure 27) shows $25 \%$ of teachers with less than 1 year of experience, $13 \%$ of teachers with $1-3$ years of experience, $10 \%$ of teachers with $4-9$ years of experience, $10 \%$ of teachers with $10-19$ years of experience, and $6 \%$ of teachers with 20 or more years of experience reported they need more strategies for teaching mathematics in Geometry. There was no meaningful pattern in years of experience when teachers were asked about an area they need more math teaching strategies. 


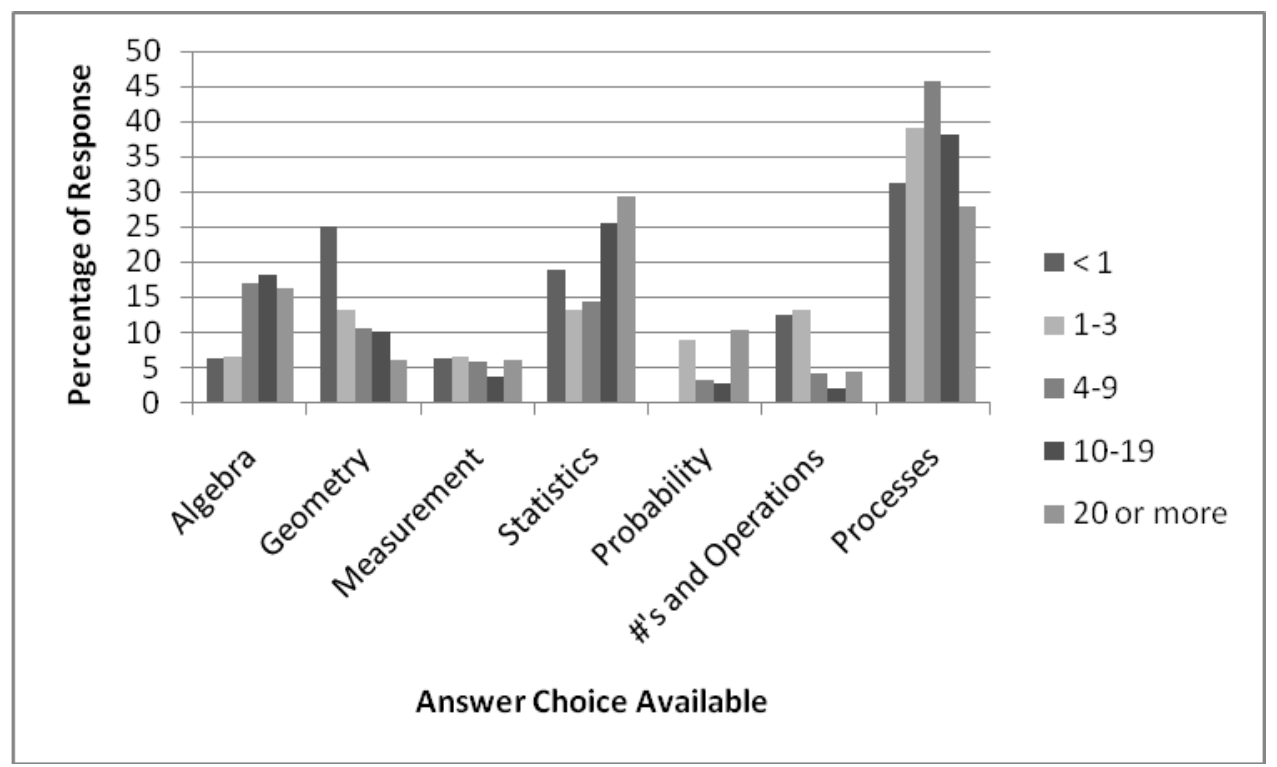

Figure 27. Percentage response for Item 30 (Need for More Strategies for Teaching Mathematics) on the MPDI graphed by Years of Experience.

Years of Experience (Item 10) by Do Not Need More Strategies for Teaching Math (Item 31) analysis yielded a statistically significant finding (Appendix D, Table M8). The graph (Figure 28) shows that $31 \%$ of teachers with less than 1 year of experience, $32 \%$ of teachers with $1-3$ years of experience, $14 \%$ of teachers with $4-9$ years of experience, $16 \%$ of teachers with $10-19$ years of experience, and $21 \%$ of teachers with 20 or more years of experience reported they do not need more strategies for teaching math in Algebra. In addition, $31 \%$ of teachers with less than 1 year of experience, $32 \%$ of teachers with 1-3 years of experience, $40 \%$ of teachers with $4-9$ years of experience, $54 \%$ of teachers with10-19 years of experience, and 38\% of teachers with 20 or more years of experience reported they do not need more strategies for teaching math in Numbers and Operations. There was no meaningful pattern in years of experience when teachers were asked about an area they do not need more math teaching strategies. 


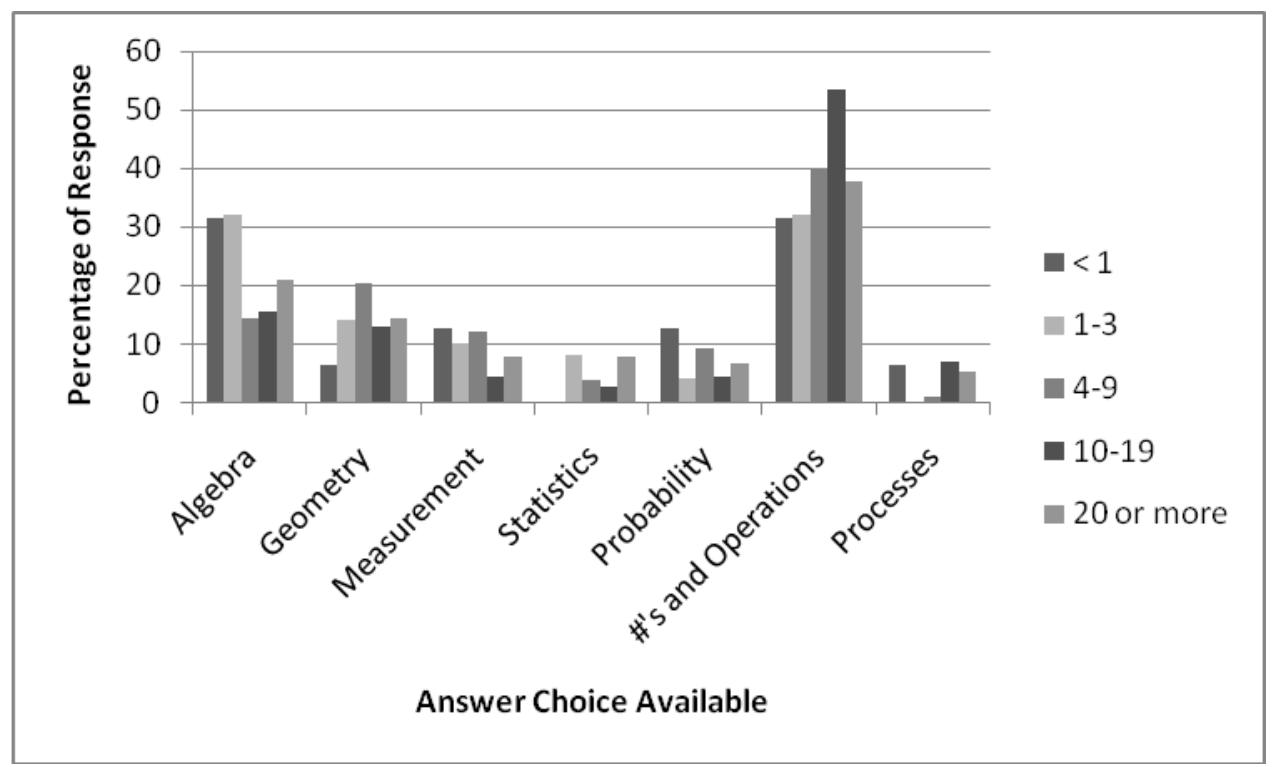

Figure 28. Percentage response for Item 31 (Do Not Need for More Strategies for Teaching Mathematics) on the MPDI graphed by Years of Experience.

Certification year. Certification Year (Item 11) by Math Content Knowledge (Item 14) did not yield a statistically significant finding (Appendix D, Table N1). Overall, a little less than 52\% of teachers responded that they have Above Average math content knowledge. This suggests that certification year does not affect their math content knowledge.

Certification Year (Item 11) by Professional Development Need of Mathematics Content Knowledge (Item 16) analysis did not yield a statistically significant finding (Appendix D, Table N2). Overall, $53 \%$ of teachers responded that they needed Some professional development in mathematics content knowledge. This suggests that certification year does not affect their professional development need of mathematics content knowledge.

Certification Year (Item 11) by Need More Knowledge in Subject (Item 17) analysis did not yield a statistically significant finding (Appendix D, Table N3). Overall, teachers reported that they need more professional development in the area of Statistics (28\%) and Process (36\%). This 
suggests that certification does not play as a factor when teachers rate an area that they need more knowledge in subject.

Certification Year (Item 11) by Do Not Need More Knowledge in Subject (Item 18) analysis yielded a statistically significant finding (Appendix D, Table N4). The graph (Figure 29) shows that $18 \%$ of teachers that were certified before $1997,18 \%$ of teachers that were certified between 1997 and 2003, 26\% of teachers that were certified between 2004 and 2009, and 50\% of teachers that were not certified reported they do not need more knowledge in Algebra. There was no meaningful pattern in certification year when teachers were asked about an area they do not need more math content knowledge.

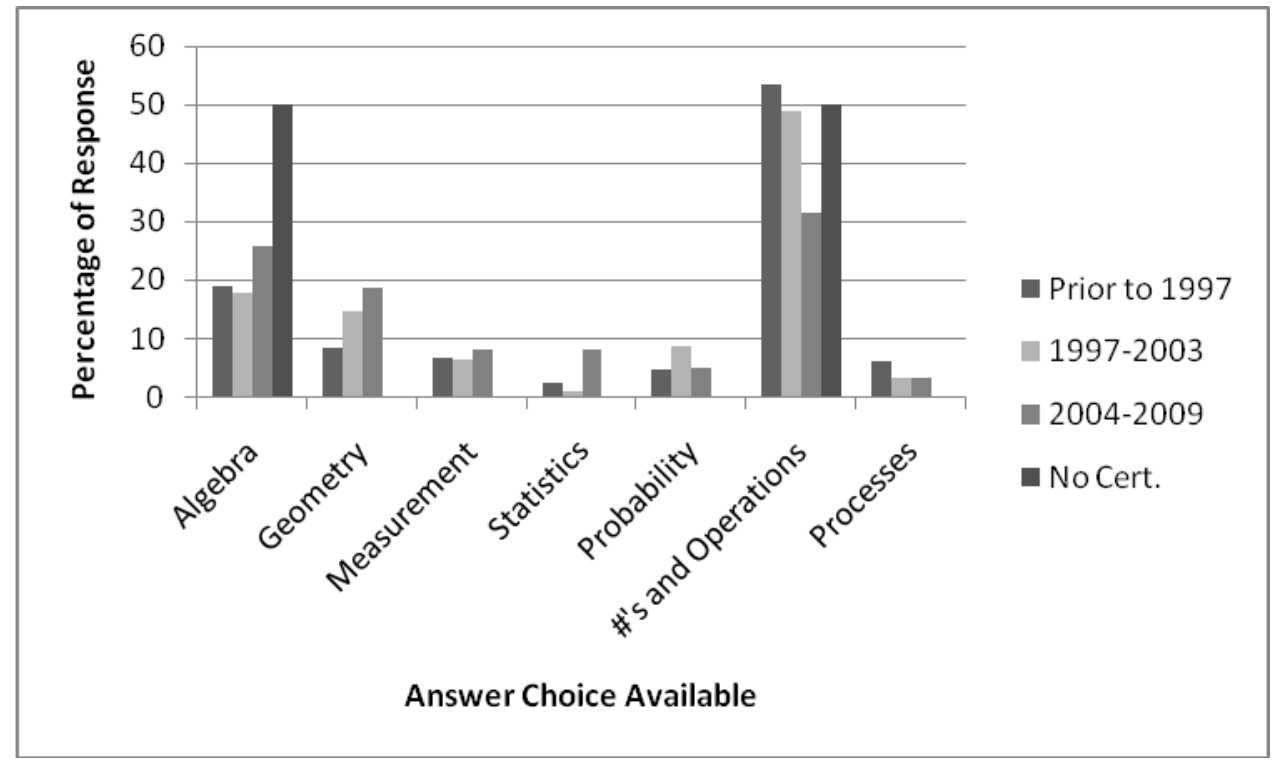

Figure 29. Percentage response for Item 18 (Do Not Need More Knowledge in Subject) on the MPDI graphed by Certification Year.

Certification Year (Item 11) by Ability to Teach Mathematics (Item 27) analysis did not yield a statistically significant finding (Appendix D, Table N5). Overall, 75\% of males and females responded that they feel they are Exceptional or Above Average in their ability to teach. This 
suggests that certification year does not affect a teachers rating in their ability to teach mathematics.

Certification Year (Item 11) by Professional Development Need for Teaching Math (Item 29) analysis yielded a statistically significant finding (Appendix D, Table N6). The graph (Figure 30) shows that $46 \%$ of teachers who were certified before $1997,41 \%$ of teachers who were certified between 1997 and 2003, 29\% of teachers who were certified between 2004 and 2009, and $0 \%$ of teachers who were not certified reported needing A Little math professional development. Teachers who were certified before 1997 were more likely to feel their need for math professional development is strong compared to teachers who were certified between 2004 and 2009. This suggests that teachers who were certified prior to IDEA and NCLB need more professional development in the area of teaching math.

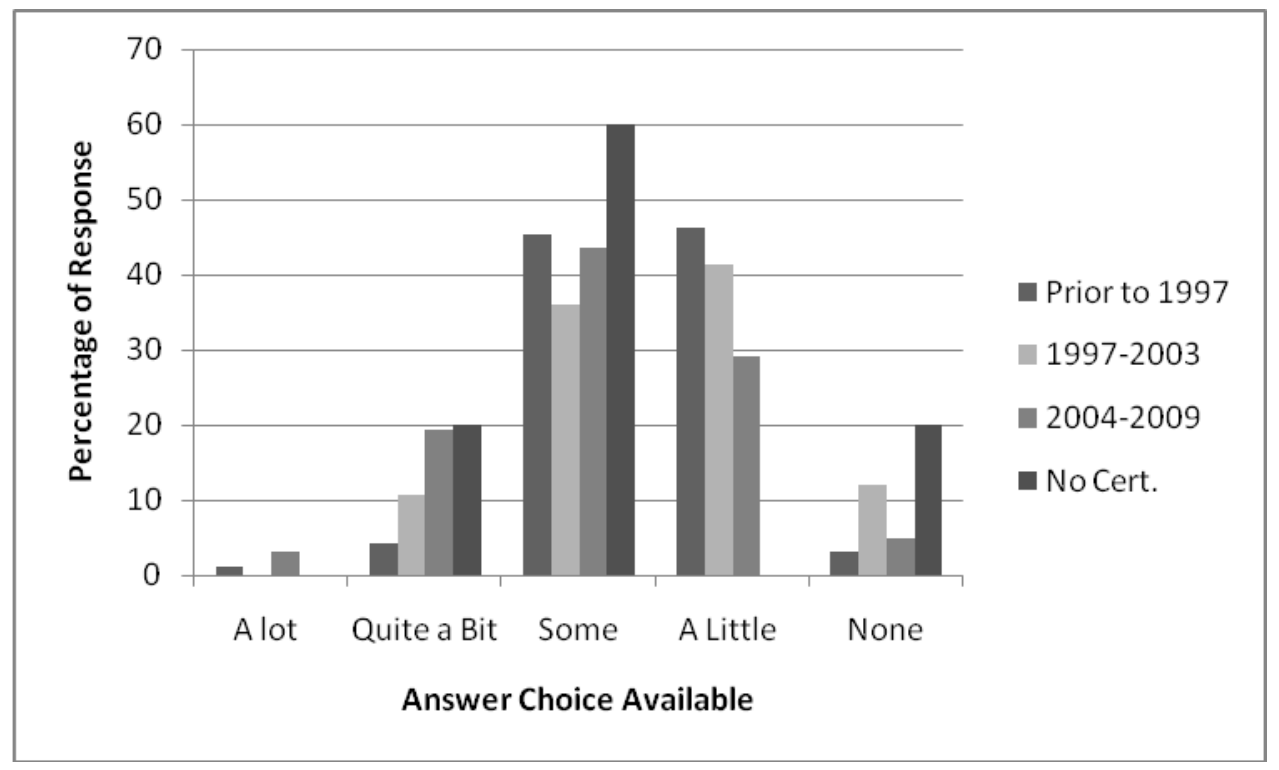

Figure 30. Percentage response for Item 29 (Professional Development Need for Teaching Math) on the MPDI graphed by Certification Year.

Certification Year (Item 11) by Need More Strategies for Teaching Mathematics (Item 30) analysis yielded a statistically significant finding (Appendix D, Table N7). The graph (Figure 31) 
shows that $7 \%$ of teachers that were certified before $1997,10 \%$ of teachers that were certified between 1997 and 2003, 14\% of teachers that were certified between 2004 and 2009, and 50\% of teachers that were not certified reported they need more strategies in teaching Geometry. There was no meaningful pattern in certification year when teachers were asked about an area they need more math teaching strategies.

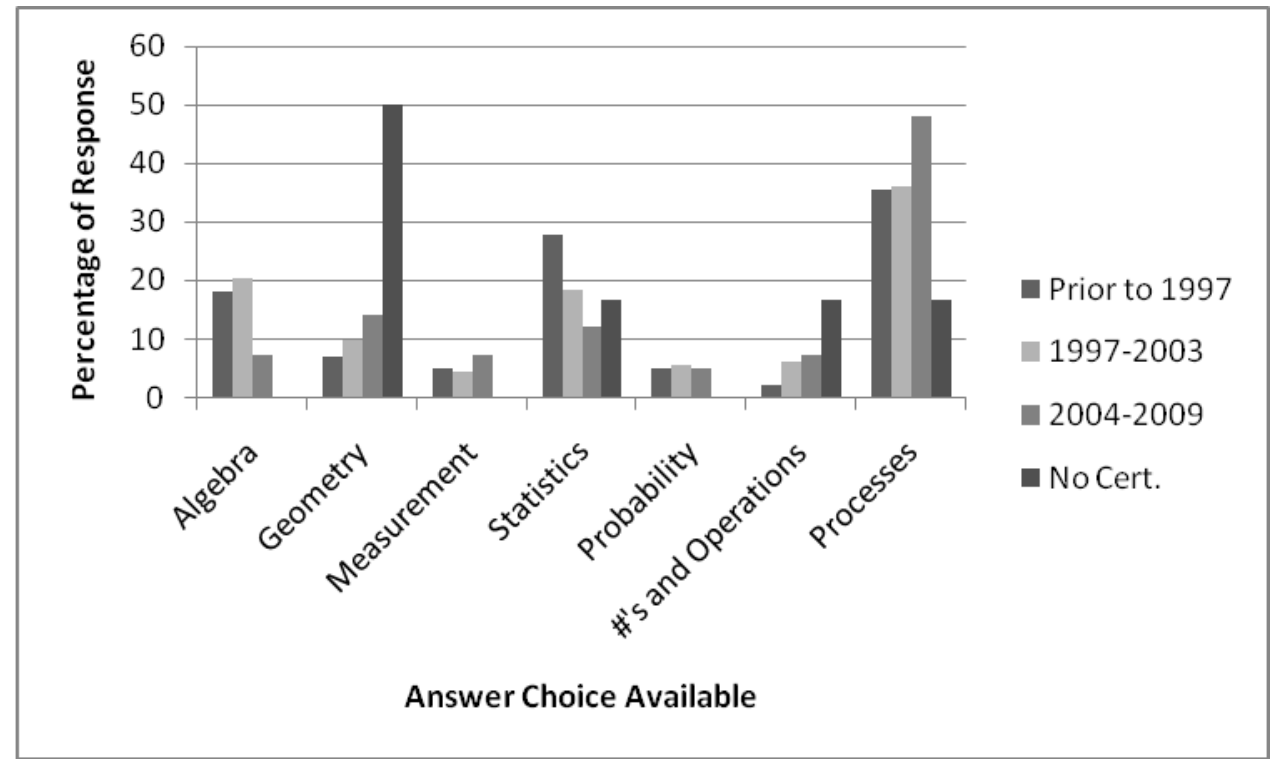

Figure 31. Percentage response for Item 30 (Need for More Strategies for Teaching Mathematics) on the MPDI graphed by Certification Year.

Certification Year (Item 11) by Do Not Need More Strategies for Teaching Math (Item 31) analysis did not yield a statistically significant finding (Appendix D, Table N8). Overall, teachers responded that they need more professional development in the area of Numbers and Operations (42\%). This suggests that certification year does not affect an area that teachers do not need more strategies for teaching math.

Certification in math. Certification in Math (Item 12) by Math Content Knowledge (Item 14) did not yield a statistically significant finding (Appendix D, Table O1). Overall, a little less 
than $52 \%$ of teachers responded that they have Above Average math content knowledge. This suggests that math certification does not affect teachers' rating on their math content knowledge.

Certification in Math (Item 12) by Professional Development Need of Mathematics Content Knowledge (Item 16) analysis yielded a statistically significant finding (Appendix D, Table O2). The graph (Figure 32) shows 6\% of teachers that were math certified and 17\% of teachers that were not math certified reported that they need Quite a Bit of professional development in the area of content knowledge. Teachers who are certified in math were more likely to feel their content knowledge is strong compared to teachers who were not certified in math. This suggests that teachers who were not certified in math felt that they needed more math professional development in content than those who were certified in math.

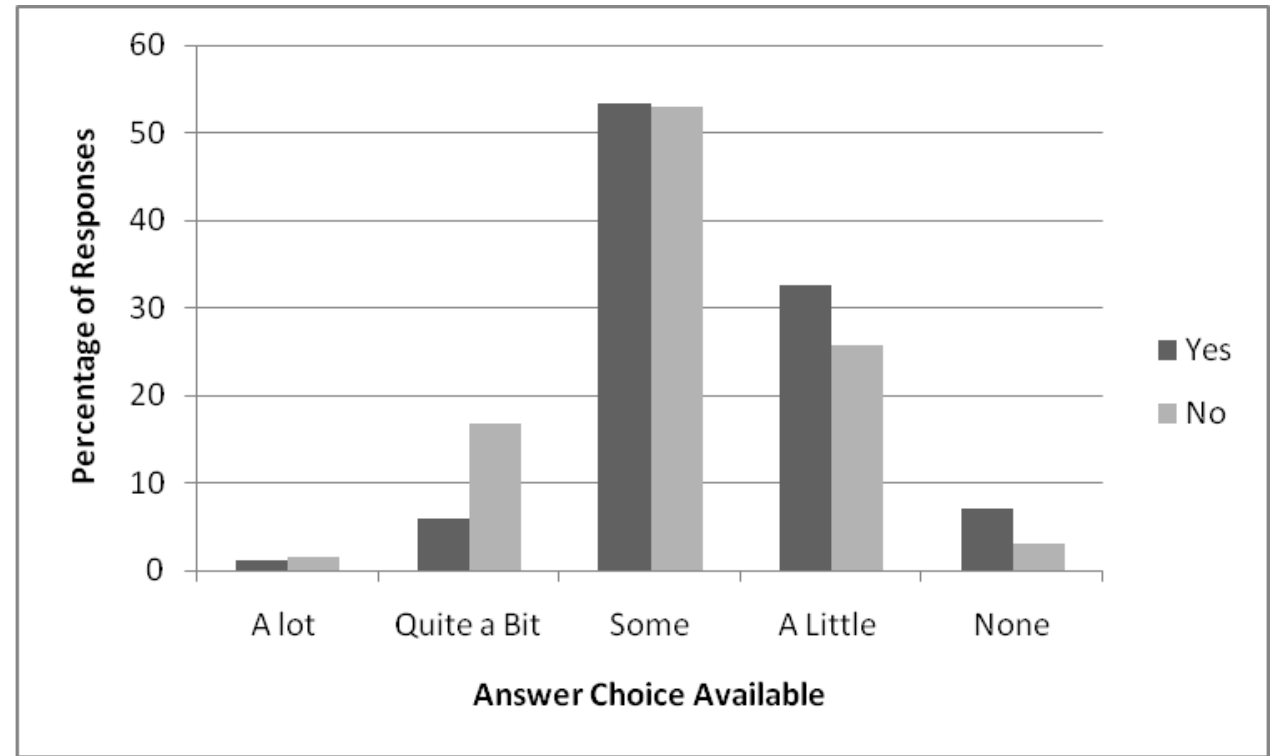

Figure 32. Percentage response for Item 16 (Professional Development Need of Mathematics Content) on the MPDI graphed by Certified in Mathematics.

Certification in Math (Item 12) by Need More Knowledge in Subject (Item 17) analysis did not yield a statistically significant finding (Appendix D, Table O3). Overall, teachers reported that they need more professional development in the area of Statistics (28\%) and Process (36\%). This 
suggests that certification in math does not have a difference in a specific area where teachers need more knowledge in subject.

Certification in Math (Item 12) by Do Not Need More Knowledge in Subject (Item 18) analysis did not yield a statistically significant finding (Appendix D, Table O4). Overall, 46\% of teachers reported they do not need more professional development in the area of Numbers and Operations.

Certification in Math (Item 12) by Ability to Teach Mathematics (Item 27) analysis did not yield a statistically significant finding (Appendix D, Table O5). Overall, 75\% of teachers responded that they feel they are Exceptional or Above Average in their ability to teach.

Certification in Math (Item 12) by Professional Development Need for Teaching Mathematics (Item 29) analysis did not yield a statistically significant finding (Appendix D, Table O6). Overall, $88 \%$ of teachers responded that they need Some, A Little, or No professional development for teaching mathematics.

Certification in Math (Item 12) by Need More Strategies for Teaching Mathematics (Item 30) analysis did not yield a statistically significant finding (Appendix D, Table O7). Overall, teachers responded that they need more professional development in the area of Statistics (21\%) and Process (39\%).

Certification in Math (Item 12) by Do Not Need More Strategies for Teaching Mathematics (Item 31) analysis yielded a statistically significant finding (Appendix D, Table O8). The graph (Figure 33) shows that $21 \%$ of teachers that were math certified and $5 \%$ of teachers that were not math certified reported that they did not need more strategies in teaching Algebra. There was no 
meaningful pattern in certification in math when teachers were asked about an area they do not need more math teaching strategies.

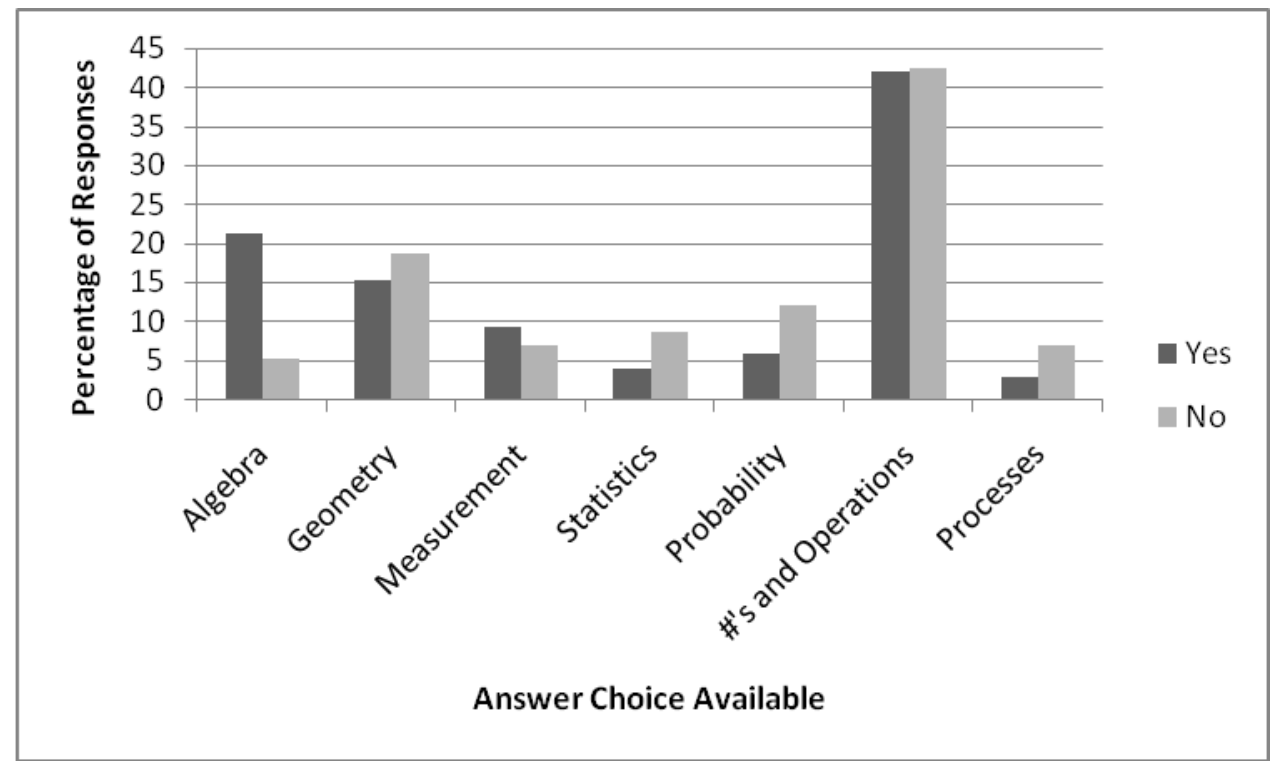

Figure 33. Percentage response for Item 31 (Do Not Need for More Strategies for Teaching Mathematics) on the MPDI graphed by Certified in Mathematics.

Highly qualified status. Highly Qualified (Item 13) by Math Content Knowledge (Item 14) did not yield a statistically significant finding (Appendix D, Table Q1). Overall, a little more than $53 \%$ of teachers responded that they have Above Average math content knowledge. This suggests that highly qualified status does not affect a teachers' rating on their math content knowledge.

Highly Qualified (Item 13) by Professional Development Need of Mathematics Content Knowledge (Item 16) did not yield a statistically significant finding (Appendix D, Table Q2). Overall, 53\% of teachers responded that they need Some professional development in mathematics content. This suggests that highly qualified status does not affect teachers' rating on their professional development need of mathematics content knowledge. 
Highly Qualified (Item 13) by Need More Knowledge in Subject (Item 17) analysis did not yield a statistically significant finding (Appendix D, Table Q3). Overall, teachers responded that they need more professional development in the area of Statistics (28\%) and Process (36\%). This suggests that highly qualified status does not affect teachers' rating on an area that they need more knowledge.

Highly Qualified (Item 13) by Do Not Need More Knowledge in Subject (Item 18) analysis yielded a statistically significant finding (Appendix D, Table Q4). The graph (Figure 29) shows $40 \%$ of teachers that were certified in math and $56 \%$ of teachers that were not certified in math chose this math content area. There was no meaningful pattern in highly qualified when teachers were asked about an area they do not need more content knowledge.

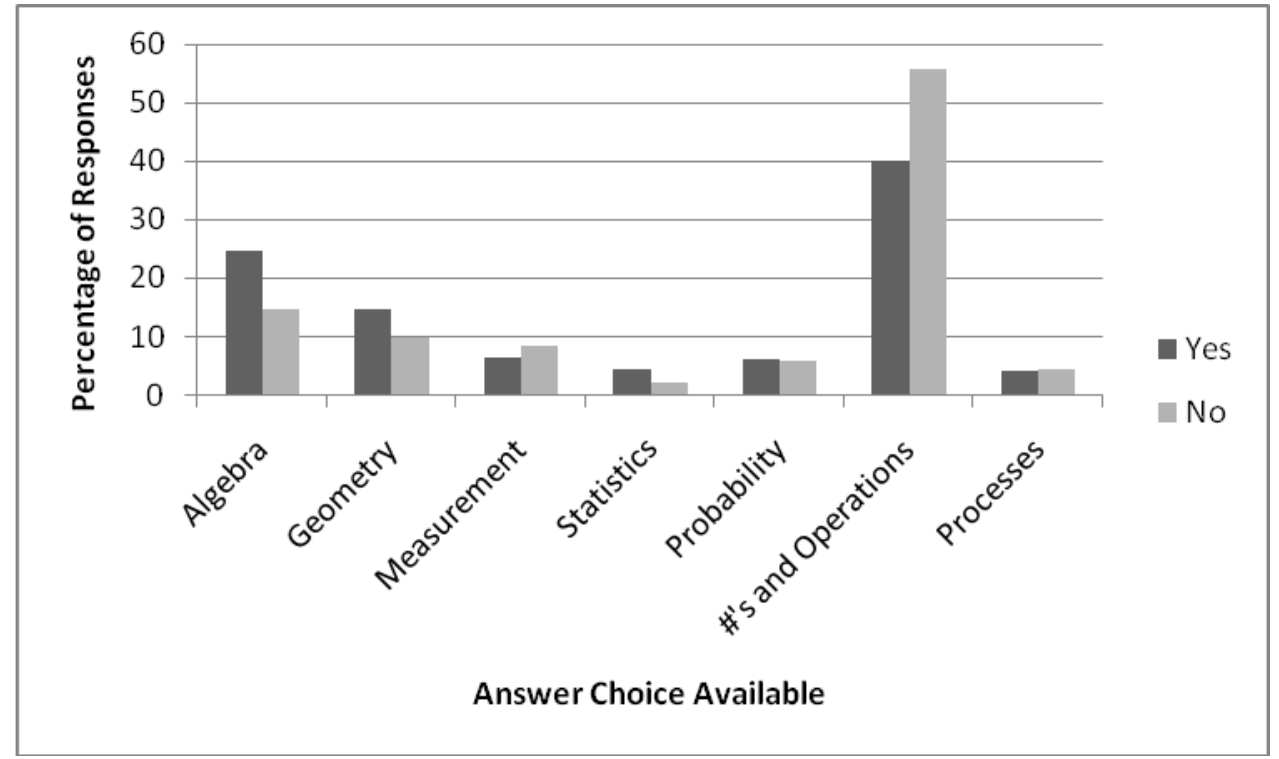

Figure 34. Percentage response for Item 18 (Do Not Need More Knowledge in Subject) on the MPDI graphed by Highly Qualified in Mathematics.

Highly Qualified (Item 13) by Ability to Teach Mathematics (Item 27) analysis did not yield a statistically significant finding (Appendix D, Table Q5). Overall, 75\% of teachers 
responded that they feel they are Exceptional or Above Average in their ability to teach. This suggests that highly qualified status does not affect a teachers ability to teach mathematics.

Highly Qualified (Item 13) by Professional Development Need for Teaching Mathematics (Item 29) analysis did not yield a statistically significant finding (Appendix D, Table Q6). Overall, $88 \%$ of teachers responded that they need Some, A Little, or No professional development for teaching mathematics. This suggests that highly qualified status does not affect the amount of professional development need for teaching mathematics.

Highly Qualified (Item 13) by Need More Strategies for Teaching Mathematics (Item 30) analysis did not yield a statistically significant finding (Appendix D, Table Q7). Overall, teachers responded that they need more professional development in the area of Statistics (20\%) and Process (39\%). This suggests that highly qualified status does not affect an area of math that teachers need more strategies for teaching mathematics.

Highly Qualified (Item 13) by Do Not Need More Strategies for Teaching Math (Item 31) analysis did not yield a statistically significant finding (Appendix D, Table Q8). Overall, teachers responded that they need more professional development in the area of Numbers and Operations (41\%). This suggests that highly qualified status does not affect an area of math that teachers do not need more strategies for teaching mathematics.

Research Question 2: What are similarities and differences in identified mathematics professional development needs by general education and special education mathematics teachers by grade level (elementary vs. secondary)?

Table U Summary of Results for Research Question 2: 
Professional Development Needs for Teachers Who Teach at Least One Mathematics Class

\begin{tabular}{|l|l|l|l|l|}
\hline $\begin{array}{c}\text { Survey } \\
\text { Item }\end{array}$ & \multicolumn{1}{|c|}{$\begin{array}{c}\text { Independent } \\
\text { Variable }\end{array}$} & $\begin{array}{c}\text { Survey } \\
\text { Item }\end{array}$ & \multicolumn{1}{|c|}{ Dependent Variable } & Statistical Result \\
\hline 3 & Grade Level & 14 & Math Content Knowledge & $\chi 2(4)=42.3, p<.05$ \\
\hline 3 & Grade Level & 16 & $\begin{array}{l}\text { Professional Development Need } \\
\text { of Mathematics Content } \\
\text { Knowledge }\end{array}$ & $\chi 2(4)=11.9, p<.05$ \\
\hline 3 & Grade Level & 17 & Need More Knowledge in Subject & $\chi 2(6)=57.2, p<.05$ \\
\hline 3 & Grade Level & 18 & $\begin{array}{l}\text { Do Not Need More Knowledge in } \\
\text { Subject }\end{array}$ & $\chi 2(6)=62.9, p<.05$ \\
\hline 3 & Grade Level & 27 & Ability to Teach Mathematics & $\chi 2(4)=9.15, p<.05$ \\
\hline 3 & Grade Level & 29 & $\begin{array}{l}\text { Professional Development Need } \\
\text { for Teaching Math }\end{array}$ & $\chi 2(4)=6.7$, NS \\
\hline 3 & Grade Level & 30 & $\begin{array}{l}\text { Need More Strategies for } \\
\text { Teaching Mathematics }\end{array}$ & $\chi 2(6)=48.4, p<.05$ \\
\hline 3 & Grade Level & 31 & $\begin{array}{l}\text { Do Not Need More Strategies for } \\
\text { Teaching Math }\end{array}$ & $\chi 2(6)=48.6, p<.05$ \\
\hline
\end{tabular}

Note. Survey Items 15, 19-26, 28, 32-41 were not analyzed because they were put into the survey at request of the school system. NS $=$ Not Statistically Significant. $\chi 2=$ Chi-Square.

Grade Level (Item 3) by Math Content Knowledge (Item 14) analysis yielded a statistically significant finding (Table G1). The graph (Figure 35) shows $8 \%$ of elementary teachers and $27 \%$ if secondary teachers reported their math content knowledge as Exceptional. In addition, 38\% of elementary teachers and $14 \%$ of secondary teachers rated their math content knowledge as Average. Secondary teachers were more likely to feel their content knowledge is strong compared to elementary teachers. This suggests that secondary teachers are more confident in their math content knowledge. 


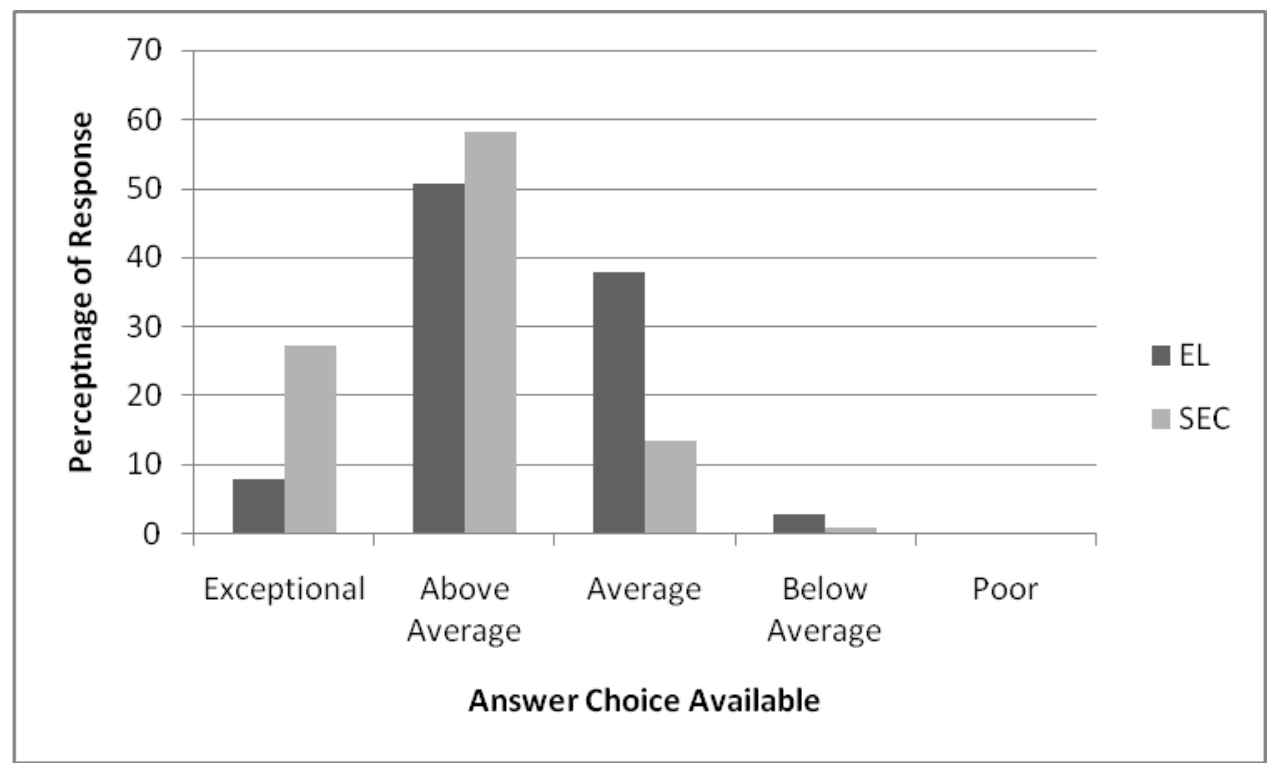

Figure 35. Percentage response for Item 14 (Mathematics Content Knowledge) on the MPDI graphed by Grade Level (Elementary or Secondary).

Grade Level (Item 3) by Professional Development Need of Mathematics Content Knowledge (Item 16) analysis yielded a statistically significant finding (Table G2). The graph (Figure 36) shows $57 \%$ of elementary teachers but $41 \%$ of secondary teachers reported that they needed Some professional development in the area of content knowledge. Elementary teachers were more likely feel their need for math professional development is strong compared to secondary teachers. This suggests that elementary teachers feel that they need more professional development in mathematics content knowledge. 


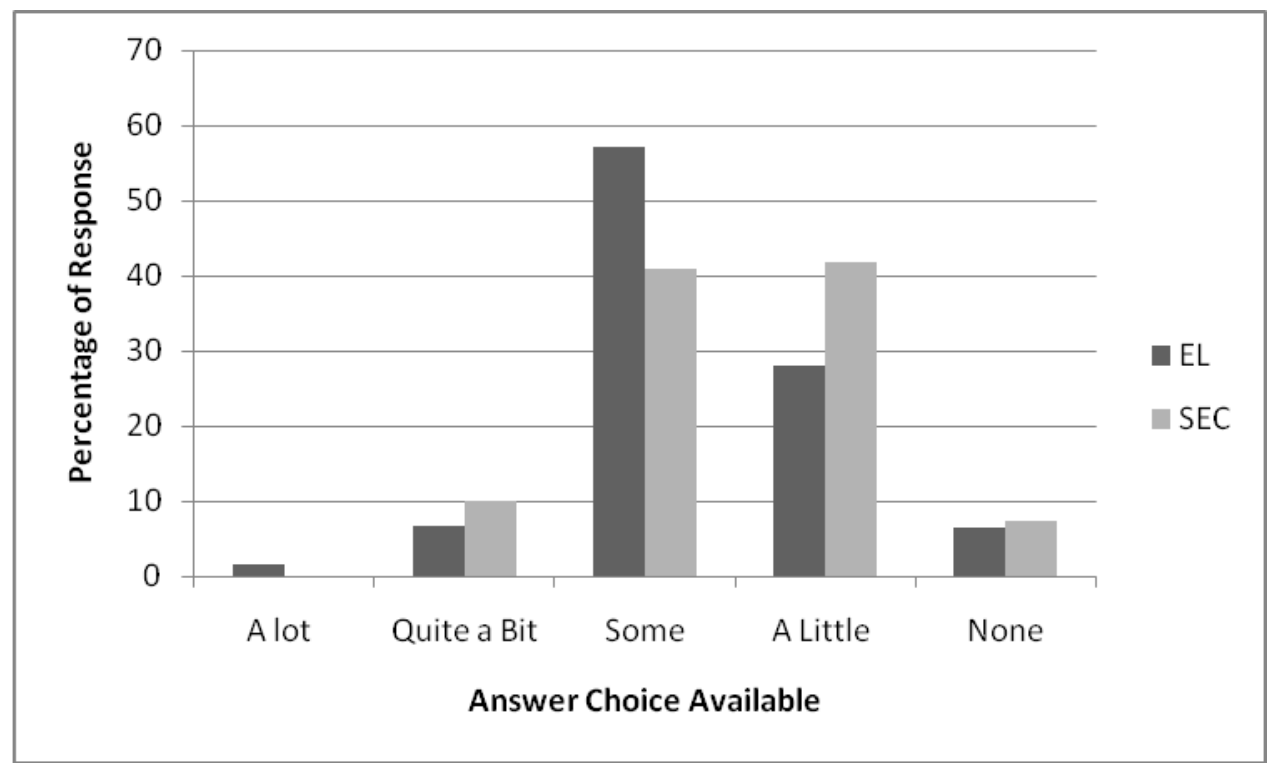

Figure 36. Percentage response for Item 16 (Professional Development Need of Mathematics Content Knowledge) on the MPDI graphed by Grade Level (Elementary or Secondary).

Grade Level (Item 3) by Need More Knowledge in Subject (Item 17) analysis yielded a statistically significant finding (Appendix D, Table G3). The graph (Figure 37) shows that 43\% of elementary teachers but $17 \%$ of secondary teachers reported they need professional development in Process. In addition, $6 \%$ of elementary teachers but $23 \%$ of secondary teachers reported they need professional development in Geometry. Elementary teachers were more likely to feel they need more knowledge in process compared to secondary teachers. 


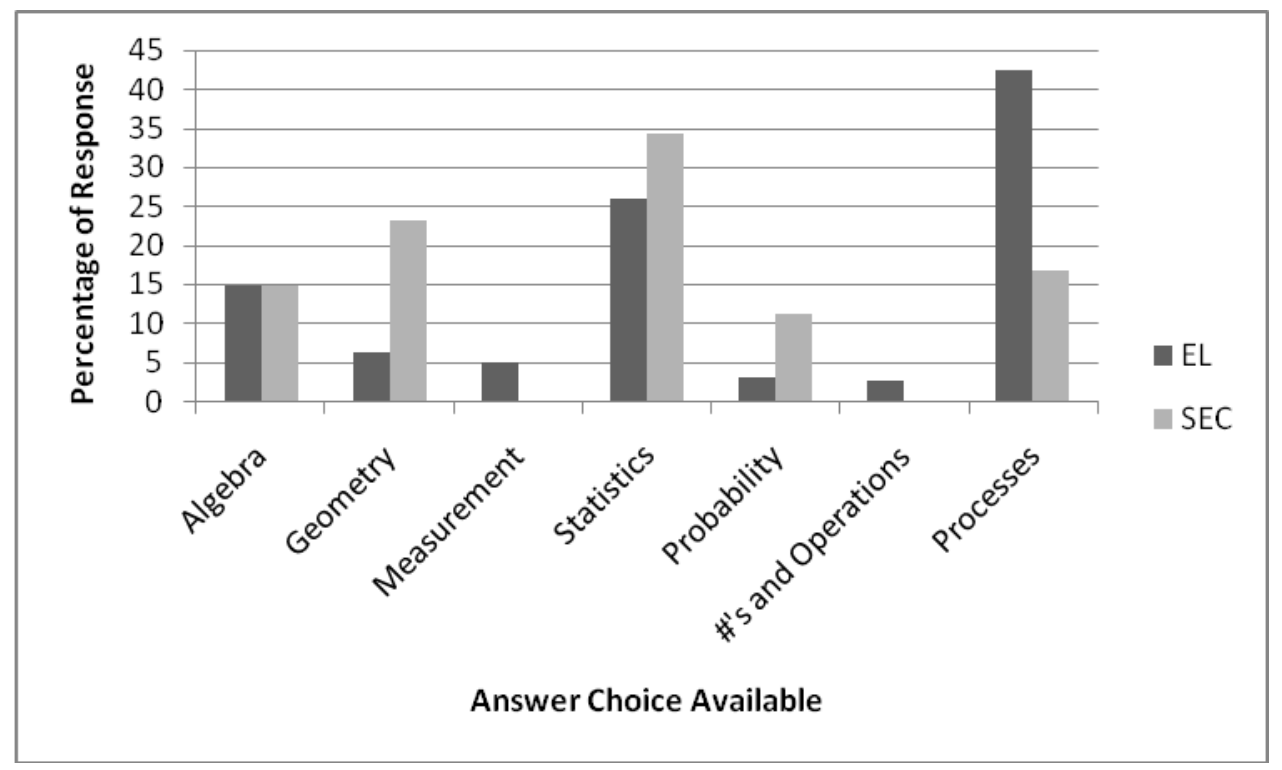

Figure 37. Percentage response for Item 17 (Need More Knowledge in Subject) on the MPDI graphed by Grade Level (Elementary or Secondary).

Grade Level (Item 3) by Do Not Need More Knowledge in Subject (Item 18) analysis yielded a statistically significant finding (Appendix D, Table G4). The graph (Figure 38) shows that $50 \%$ of elementary teachers and $32 \%$ of secondary teachers reported they do not need more knowledge in Numbers and Operations. In addition, $13 \%$ of elementary teachers and $46 \%$ of secondary teachers reported they do not need more knowledge in Algebra. Elementary teachers were more likely to feel they do not need more knowledge in numbers and operations compared to secondary teachers. 


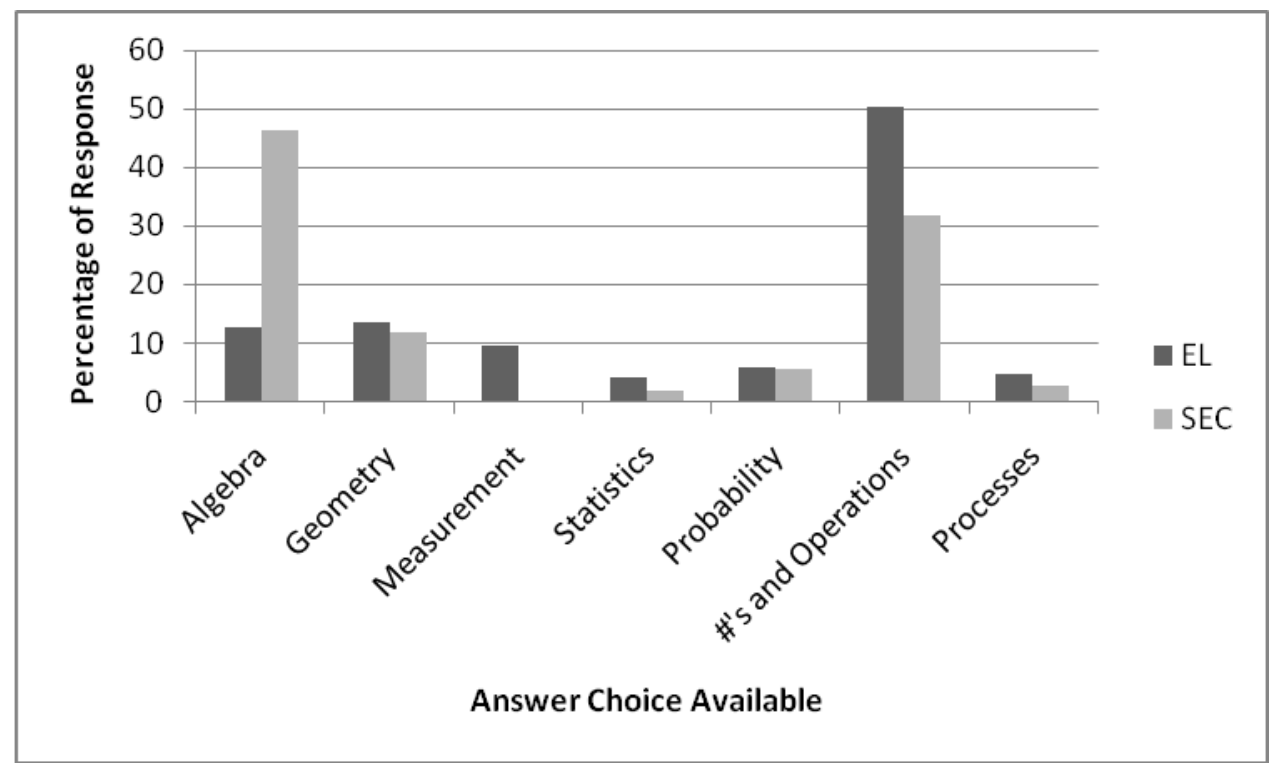

Figure 38. Percentage response for Item 18 (Do Not Need More Knowledge in Subject) on the MPDI graphed by Grade Level (Elementary or Secondary).

Grade Level (Item 3) by Ability to Teach Mathematics (Item 27) analysis yielded a statistically significant finding (Appendix D, Table G5). The graph (Figure 39) shows that $11 \%$ of elementary teachers but $23 \%$ of secondary teachers reported they are Exceptional in their ability to teach mathematics. In addition, $26 \%$ of elementary teachers but $18 \%$ of secondary teachers reported that they are Average in their ability to teach mathematics. Secondary teachers were more likely to feel their ability to teach mathematics is strong compared to elementary teachers. This suggests that secondary teachers are more confident in their ability to teach mathematics. 


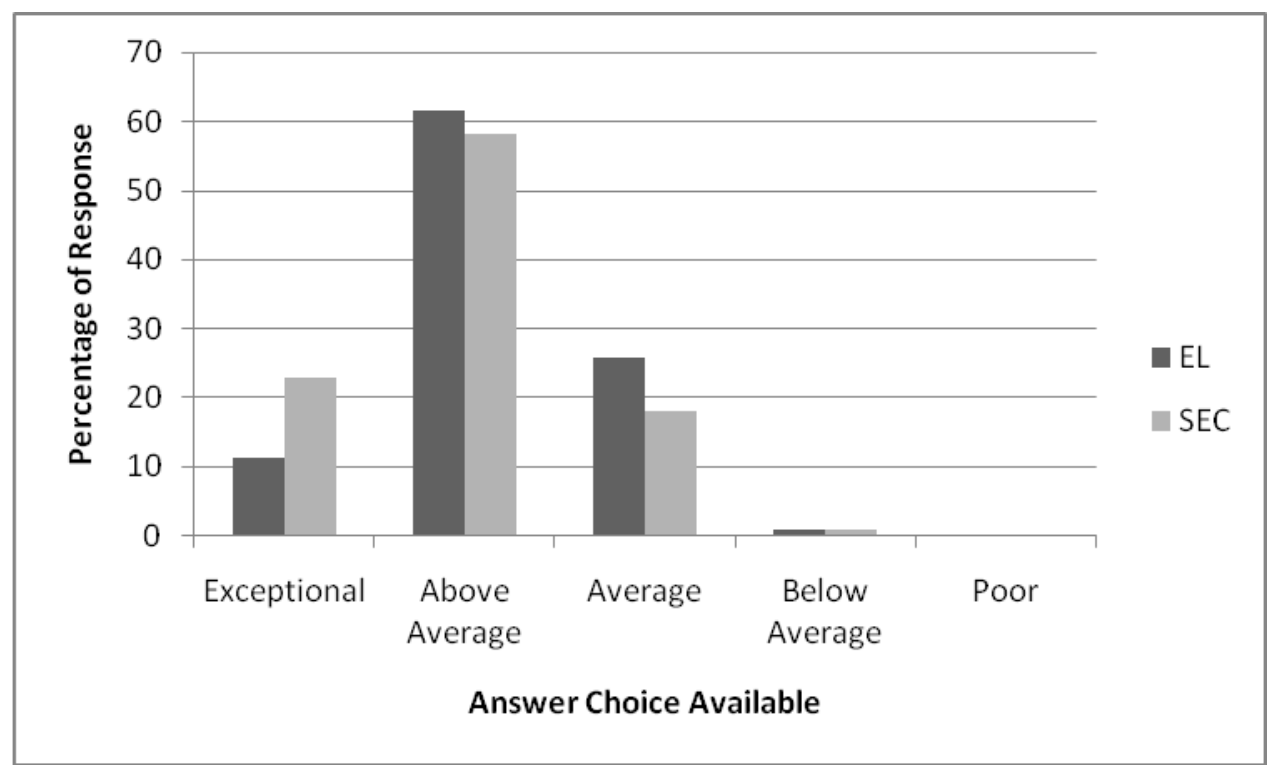

Figure 39. Percentage response for Item 27 (Ability to Teach Mathematics) on the MPDI graphed by Grade Level (Elementary or Secondary).

Grade Level (Item 3) by Professional Development Need for Teaching Mathematics (Item 29) analysis did not yield a statistically significant finding (Appendix D, Table G6). Overall, 92\% of teachers responded that they need Some, A Little, or No professional development for teaching mathematics. This suggests that elementary and secondary teachers have similar professional development needs for teaching mathematics.

Grade Level (Item 3) by Need More Strategies for Teaching Mathematics (Item 30) analysis yielded a statistically significant finding (Appendix D, Table G7). The graph (Figure 40) shows $5 \%$ of elementary teachers but $26 \%$ of secondary teachers reported that they need professional development in teaching Geometry. In addition, $44 \%$ of elementary teachers but $24 \%$ of secondary teachers reported that they need professional development in teaching process. Elementary teachers were more likely to report they need teaching strategies in Process compared to secondary teachers. 


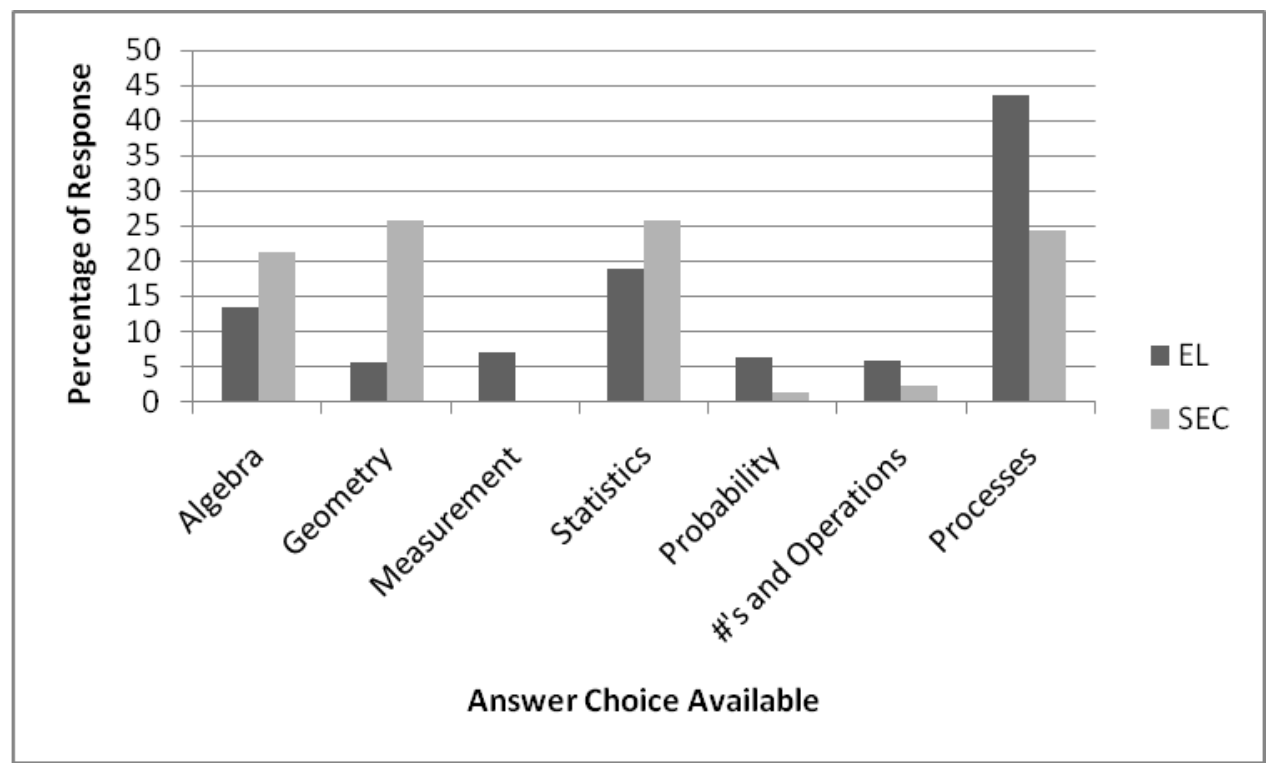

Figure 40. Percentage response for Item 30 (Need for More Strategies for Teaching Mathematics) on the MPDI graphed by Grade Level (Elementary or Secondary).

Grade Level (Item 3) by Do Not Need More Strategies for Teaching Mathematics (Item 31) analysis yielded a statistically significant finding (Appendix D, Table G8). The graph (Figure 41) shows that $11 \%$ of elementary teachers and $40 \%$ of secondary teachers reported that they did not need more strategies in teaching Algebra. In addition, $46 \%$ of elementary teachers and $31 \%$ of secondary teachers reported that they did not need more strategies in teaching Number and Operations. Elementary teachers were more likely to report they do not need teaching strategies in Number and Operations compared to secondary teachers. 


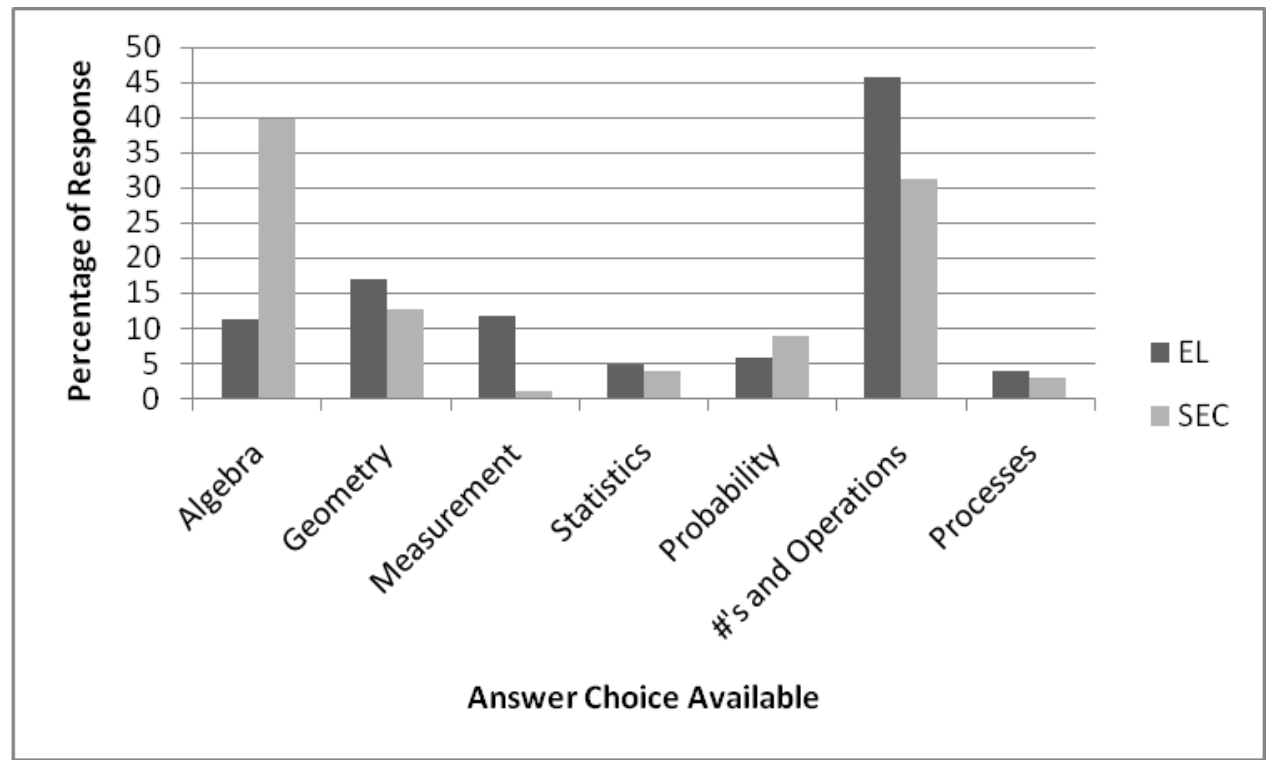

Figure 41. Percentage response for Item 31 (Do Not Need for More Strategies for Teaching Mathematics) on the MPDI graphed by Grade Level (Elementary or Secondary).

Research Question 3: What are similarities and differences in identified mathematics professional development needs by teacher classification (general education vs. special education)?

Table V

Summary of Results for Research Question 3:

Professional Development Needs for Teachers Who Teach at Least One Mathematics Class

\begin{tabular}{|c|c|c|c|c|}
\hline $\begin{array}{c}\text { Survey } \\
\text { Item }\end{array}$ & Independent Variable & $\begin{array}{c}\text { Survey } \\
\text { Item }\end{array}$ & Dependent Variable & $\begin{array}{c}\text { Statistical } \\
\text { Result }\end{array}$ \\
\hline 2 & Teacher Classification & 14 & Math Content Knowledge & $\begin{array}{l}\chi 2(4)=12.6, \\
p<.05\end{array}$ \\
\hline 2 & Teacher Classification & 16 & $\begin{array}{l}\text { Professional Development } \\
\text { Need of Mathematics } \\
\text { Content Knowledge }\end{array}$ & $\begin{array}{l}\chi 2(4)=21.1, \\
p<.05\end{array}$ \\
\hline 2 & Teacher Classification & 17 & $\begin{array}{l}\text { Need More Knowledge in } \\
\text { Subject }\end{array}$ & $\begin{array}{l}\chi 2(6)=13.6, \\
p<.05\end{array}$ \\
\hline 2 & Teacher Classification & 18 & $\begin{array}{l}\text { Do Not Need More } \\
\text { Knowledge in Subject }\end{array}$ & $\chi^{2}(6)=5.0, \mathrm{NS}$ \\
\hline 2 & Teacher Classification & 27 & $\begin{array}{l}\text { Ability to Teach } \\
\text { Mathematics }\end{array}$ & $\begin{array}{l}\chi 2(4)=14.3 \\
p<.05\end{array}$ \\
\hline 2 & Teacher Classification & 29 & $\begin{array}{l}\text { Professional Development } \\
\text { Need for Teaching Math }\end{array}$ & $\begin{array}{l}\chi 2(4)=10.1, \\
p<.05\end{array}$ \\
\hline 2 & Teacher Classification & 30 & $\begin{array}{l}\text { Need More Strategies for } \\
\text { Teaching Mathematics }\end{array}$ & $\chi 2(4)=10.4, \mathrm{NS}$ \\
\hline
\end{tabular}




\begin{tabular}{|l|l|l|l|l|}
\hline 2 & Teacher Classification & 31 & $\begin{array}{l}\text { Do Not Need More } \\
\text { Strategies for Teaching } \\
\text { Math }\end{array}$ & $\chi 2(6)=6.1$, NS \\
\hline
\end{tabular}

Note. Survey Items 15, 19-26, 28, 32-41 were not analyzed because they were put into the survey at request of the school system. NS $=$ Not Statistically Significant. $\chi 2=$ Chi-Square.

Teacher Classification (Item 2) by Math Content Knowledge (Item 14) analysis yielded a statistically significant finding (Appendix D, Table R1). The graph (Figure 42) shows $14 \%$ of general education teachers but $4 \%$ of special education teachers reported that they were Exceptional in Math Content Knowledge. In addition, $30 \%$ of general teachers but $4 \%$ of special education teachers rated their math content knowledge as Average. General education teachers were more likely to feel their content knowledge is strong compared to special education teachers. This suggests that general education teachers are more confident in their math content knowledge.

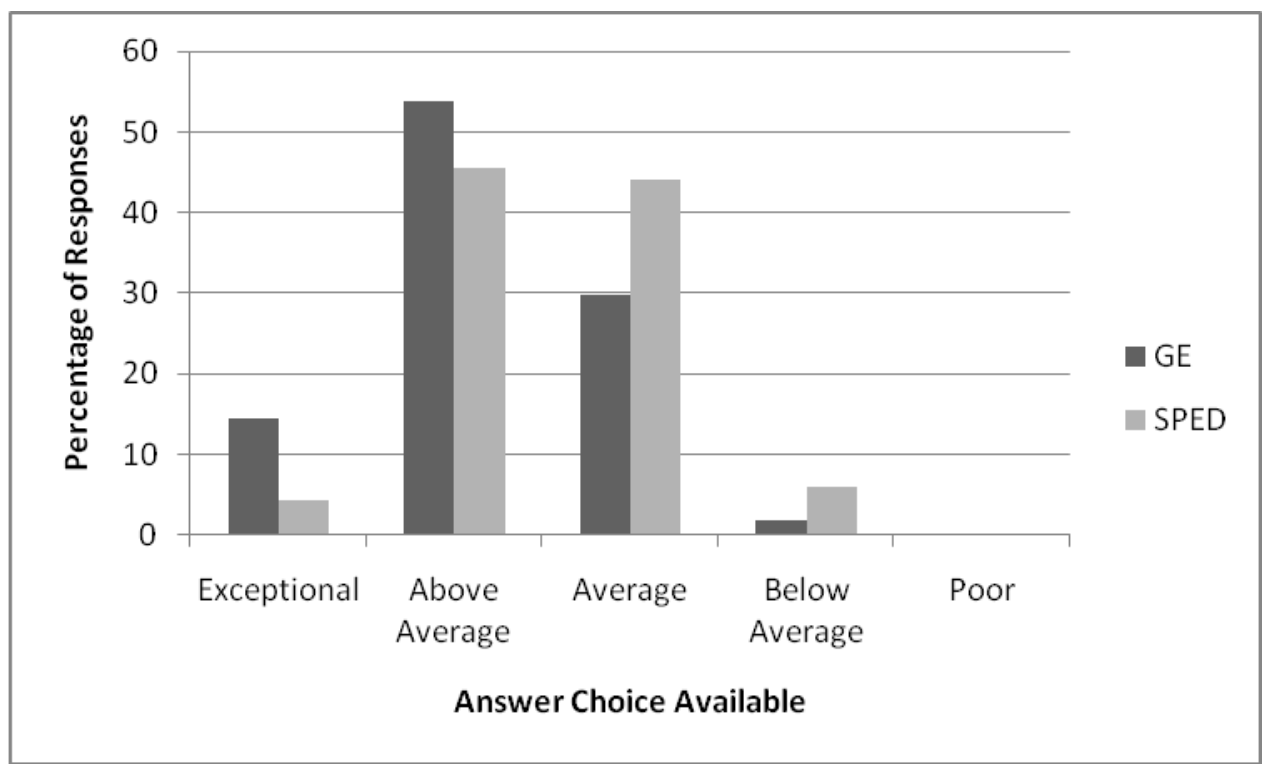

Figure 42. Percentage response for Item 14 (Mathematics Content Knowledge) on the MPDI graphed by Teacher Classification (General Education or Special Education).

Teacher Classification (Item 2) by Professional Development Need of Mathematics Content Knowledge (Item 16) analysis yielded a statistically significant finding (Appendix D, 
Table R2). The graph (Figure 43) shows that $5 \%$ of general teachers but $21 \%$ of special education teachers reported that they need Quite a Bit professional development in the area of content knowledge. Special education teachers were more likely to feel they need more professional development compared to general education teachers. Special education teachers rated that their knowledge in math content was lower than general educators, so this answer supports the fact that they also need mathematics professional development in content knowledge.

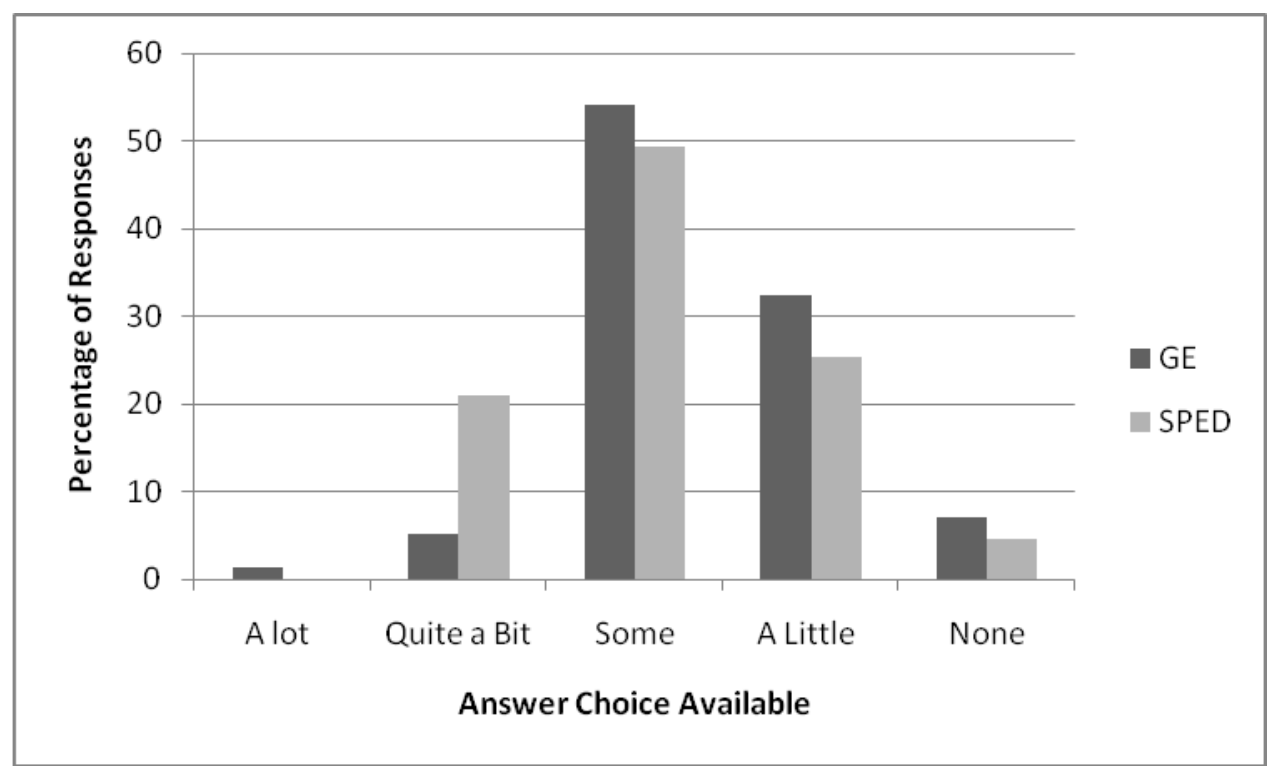

Figure 43. Percentage response for Item 16 (Professional Development Need of Mathematics Content Knowledge) on the MPDI graphed by Teacher Classification (General Education or Special Education).

Teacher Classification (Item 2) by Need More Knowledge in Subject (Item 17) analysis yielded a statistically significant finding (Appendix D, Table R3). The graph (Figure 44) shows that $30 \%$ of general teachers but $18 \%$ of special education teachers reported that they need more professional development in Statistics. In addition, $9 \%$ of general teachers but $21 \%$ of special education teachers reported that they need more professional development in Geometry. General education teachers were more likely to report that they need more knowledge in Statistics 
compared to general education teachers who were more likely to report that they need more knowledge in Geometry.

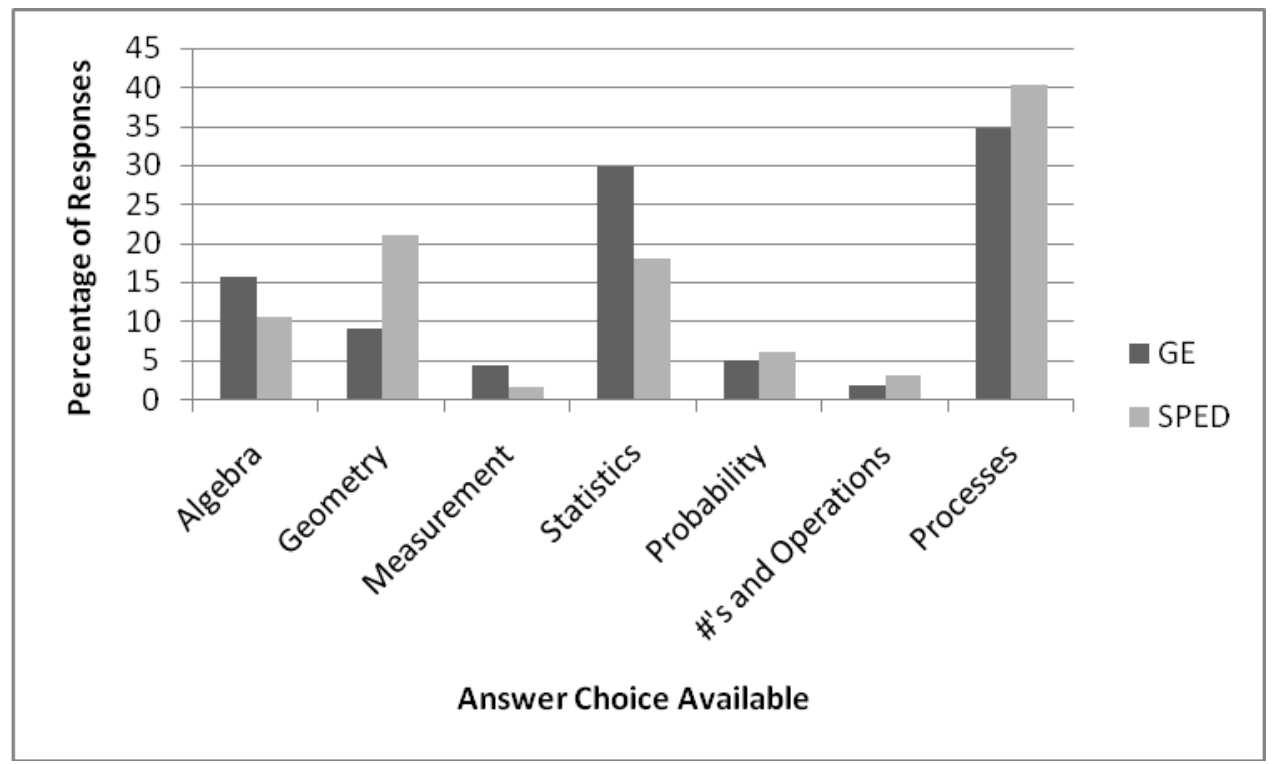

Figure 44. Percentage response for Item 17 (Need More Knowledge in Subject) on the MPDI graphed by Teacher Classification (General Education or Special Education).

Teacher Classification (Item 2) by Do Not Need More Knowledge in Subject (Item 18) analysis did not yield a statistically significant finding (Appendix D, Table R4). Overall, 45\% of teachers reported they do not need more professional development in the area of Numbers and Operations.

Teacher Classification (Item 2) by Ability to Teach Mathematics (Item 27) analysis yielded a statistically significant finding (Appendix D, Table R5). The graph (Figure 45) shows that 21\% of general education teachers but $42 \%$ of special education teachers reported they are Average in their ability to teach mathematics. General education teachers were more likely to feel their ability to teach mathematics is strong compared to special education teachers. General education teachers were more confident in their ability to teach mathematics compared to special education teachers. 


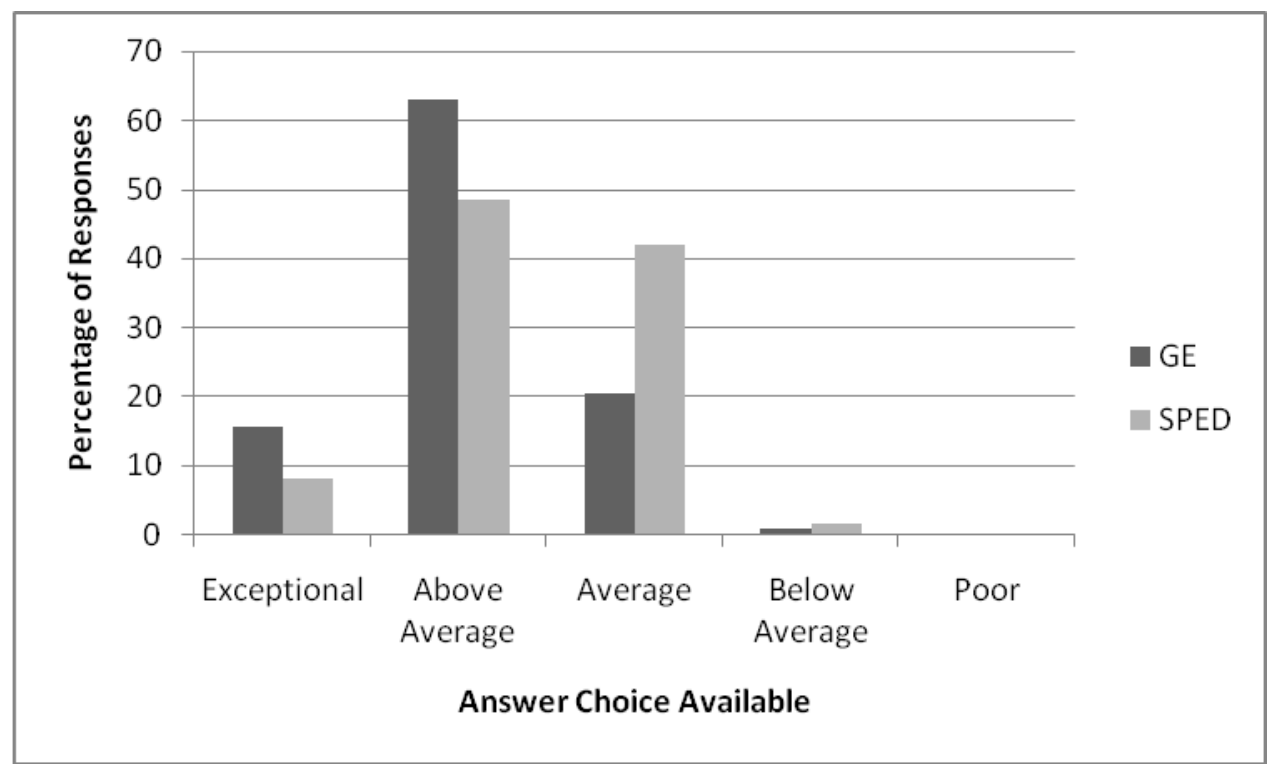

Figure 45. Percentage response for Item 27 (Ability to Teach Mathematics) on the MPDI graphed by Teacher Classification (General Education or Special Education).

Teacher Classification (Item 2) by Professional Development Need for Teaching Math (Item 29) analysis yielded a statistically significant finding (Appendix D, Table R6). The graph (Figure 46 ) shows that $8 \%$ of general education teachers but $25 \%$ of special education teachers reported they need Quite a Bit math professional development. In addition, $41 \%$ of general education teachers but $28 \%$ of special education teachers reported that they need Some professional development in teaching mathematics. Special education teachers were more likely to report a need for professional development in teaching math than general educators. 


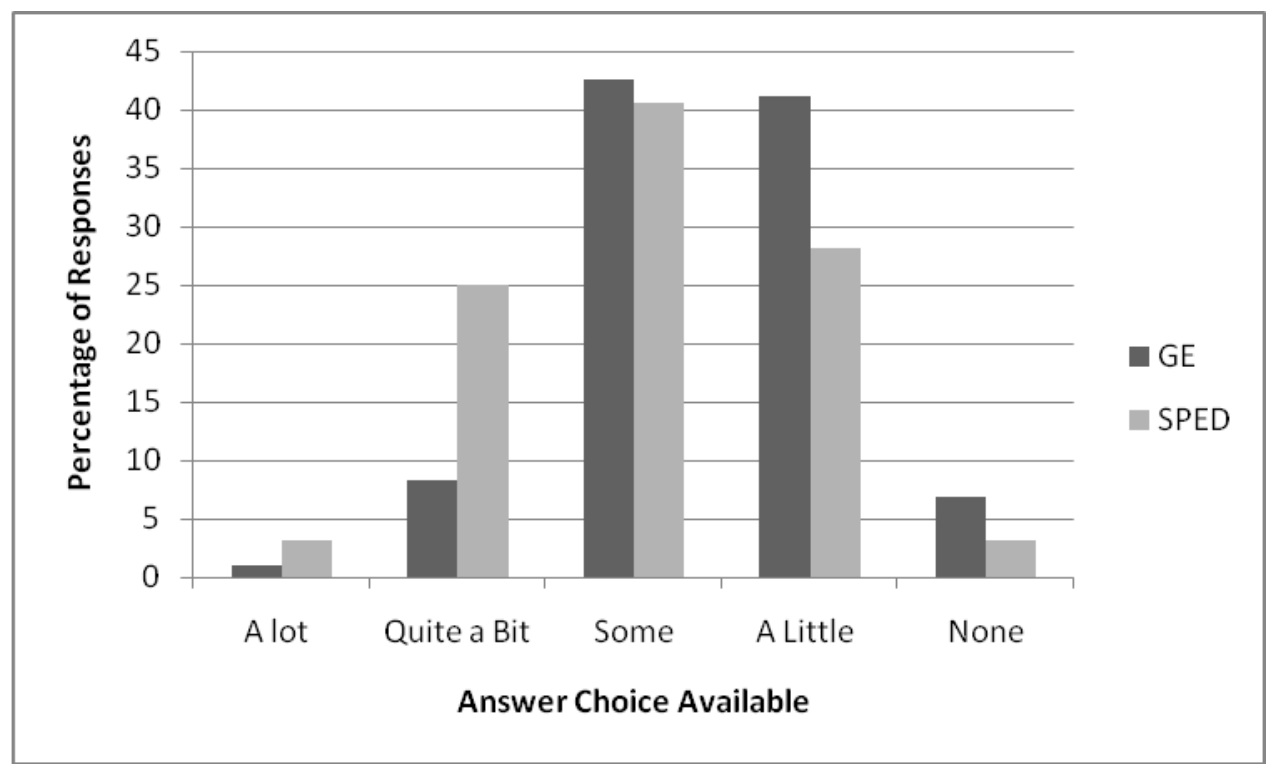

Figure 46. Percentage response for Item 29 (Professional Development Need for Teaching Math) on the MPDI graphed by Teacher Classification (General Education or Special Education).

Teacher Classification (Item 2) by Need More Strategies for Teaching Math (Item 30) analysis did not yield a statistically significant finding (Appendix D, Table R7). Overall, general education and special education teachers reported that they need more professional development in the area of Process $(39 \%)$.

Teacher Classification (Item 2) by Do Not Need More Strategies for Teaching Math (Item 31) analysis did not yield a statistically significant finding (Appendix D, Table R8). Overall, general education and special education teachers reported that they need more professional development in the area of Numbers and Operations (42\%).

Research Question 4: What are similarities and differences in identified mathematics professional development needs of special education teachers by grade level (elementary vs. secondary)?

Table W

Summary of Results for Research Question 4:

Professional Development Needs for Teachers Who Teach at Least One Mathematics Class 


\begin{tabular}{|c|c|c|c|c|}
\hline $\begin{array}{c}\text { Survey } \\
\text { Item }\end{array}$ & Independent Variable & $\begin{array}{c}\text { Survey } \\
\text { Item }\end{array}$ & Dependent Variable & $\begin{array}{l}\text { Statistical } \\
\text { Result }\end{array}$ \\
\hline $1 \& 2$ & $\begin{array}{lrl}\text { Special } & \text { Education } & \& \\
\text { Teacher Classification } & \end{array}$ & 14 & Math Content Knowledge & $\chi 2(4)=0.2, \mathrm{NS}$ \\
\hline $1 \& 2$ & $\begin{array}{lcc}\text { Special } & \text { Education } & \& \\
\text { Teacher Classification } & \end{array}$ & 16 & $\begin{array}{l}\text { Professional Development } \\
\text { Need of Mathematics } \\
\text { Content Knowledge }\end{array}$ & $\chi 2(4)=3.6, \mathrm{NS}$ \\
\hline $1 \& 2$ & $\begin{array}{lrl}\text { Special Education } & \& \\
\text { Teacher Classification } & \end{array}$ & 17 & $\begin{array}{l}\text { Need More Knowledge in } \\
\text { Subject }\end{array}$ & $\begin{array}{l}\chi 2(6)=14.2, \\
p<.05\end{array}$ \\
\hline $1 \& 2$ & $\begin{array}{lrl}\text { Special Education } & \& \\
\text { Teacher Classification } & \end{array}$ & 18 & $\begin{array}{l}\text { Do Not Need More } \\
\text { Knowledge in Subject }\end{array}$ & $\chi^{2}(6)=8.8, \mathrm{NS}$ \\
\hline $1 \& 2$ & $\begin{array}{lrl}\text { Special Education } & \& \\
\text { Teacher Classification } & \end{array}$ & 27 & $\begin{array}{l}\text { Ability to Teach } \\
\text { Mathematics }\end{array}$ & $\chi 2(4)=1.3, \mathrm{NS}$ \\
\hline $1 \& 2$ & $\begin{array}{lrl}\text { Special Education } & \& \\
\text { Teacher Classification } & \end{array}$ & 29 & $\begin{array}{l}\text { Professional Development } \\
\text { Need for Teaching Math }\end{array}$ & $\chi 2(4)=1.4, \mathrm{NS}$ \\
\hline $1 \& 2$ & $\begin{array}{lr}\text { Special Education } & \& \\
\text { Teacher Classification } & \end{array}$ & 30 & $\begin{array}{l}\text { Need More Strategies for } \\
\text { Teaching Mathematics }\end{array}$ & $\chi 2(4)=11.1, \mathrm{NS}$ \\
\hline $1 \& 2$ & $\begin{array}{lcc}\text { Special } & \text { Education } & \& \\
\text { Teacher Classification } & \end{array}$ & 31 & $\begin{array}{l}\text { Do Not Need More } \\
\text { Strategies for Teaching } \\
\text { Math }\end{array}$ & $\chi 2(6)=10.7, \mathrm{NS}$ \\
\hline
\end{tabular}

Note. Survey Items 15, 19-26, 28, 32-41 were not analyzed because they were put into the survey at request of the school system. NS $=$ Not Statistically Significant. $\chi 2=$ Chi-Square.

Special Education and Teacher Classification (Item 1 \& 2) by Math Content Knowledge (Item 14) did not yield a statistically significant finding (Appendix D, Table S1). Overall, 90\% of special education teachers reported that they have Above Average or Average math content knowledge. This suggests that special education teacher classification does not matter when looking at a teacher's math content knowledge.

Special Education and Teacher Classification (Item 1 \& 2) by Professional Development Need of Mathematics Content Knowledge (Item 16) analysis did not yield a statistically significant finding (Appendix D, Table S2). Overall, 49\% of special education teachers reported that they needed Some professional development in mathematics content knowledge. 
Special Education and Teacher Classification (Item 1 \& 2) by Need More Knowledge in Subject (Item 17) analysis yielded a statistically significant finding (Appendix D, Table S3). The relationship (Figure 47 ) shows that $12 \%$ of elementary special education teachers but $47 \%$ of secondary special education teachers reported that they need more knowledge in Geometry. In addition, $50 \%$ of elementary special education teachers but $12 \%$ of secondary special education teachers reported that they need more knowledge in Process. Elementary special education teachers were more likely to report that they need more knowledge in Process compared to secondary special education teachers.

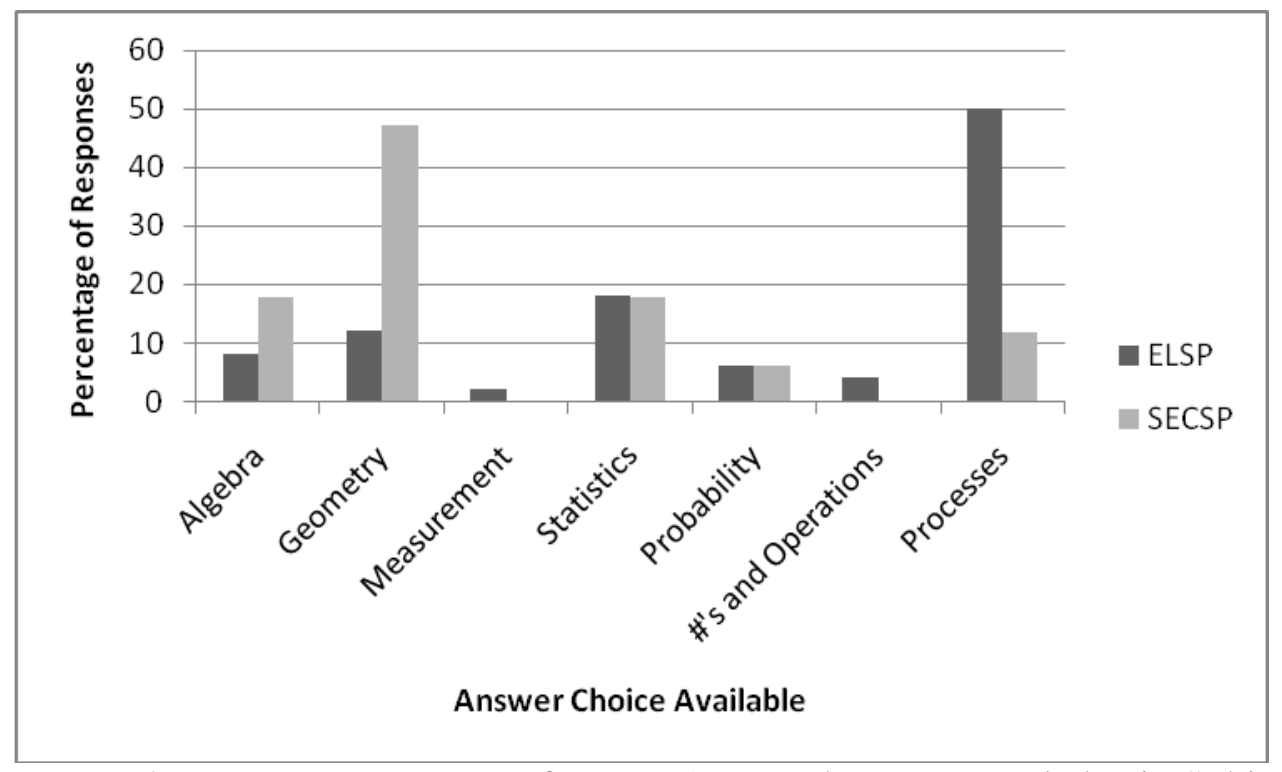

Figure 47. Percentage response for Item 17 (Need More Knowledge in Subject) on the MPDI graphed by Special Education Teacher Classification (Elementary Special Education or Secondary Special Education).

Special Education and Teacher Classification (Item 1 \& 2) by Do Not Need More Knowledge in Subject (Item 18) analysis did not yield a statistically significant finding (Appendix D, Table S4). Overall, $52 \%$ of special education teachers reported they do not need more professional development in the area of Numbers and Operations. 
Special Education and Teacher Classification (Item $1 \& 2$ ) by Ability to Teach Mathematics (Item 27) analysis did not yield a statistically significant finding (Appendix D, Table S5). Overall, $90 \%$ of special education teachers rated that they feel they are Above Average or Average in their ability to teach mathematics. This suggests that special education teacher classification does not affect a teachers' ability to teach mathematics.

Special Education and Teacher Classification (Item 1 \& 2) by Professional Development Need for Teaching Mathematics (Item 29) analysis did not yield a statistically significant finding (Appendix D, Table S6). Overall, 72\% of special education teachers responded that they need Some, A Little, or No professional development for teaching mathematics. This suggests that special education teacher classification does not affect a teachers' professional development need for teaching mathematics.

Special Education and Teacher Classification (Item 1 \& 2) by Need More Strategies for Teaching Mathematics (Item 30) analysis did not yield a statistically significant finding (Appendix D, Table S7). Overall, special education teachers responded that they need more professional development in the area of Process (45\%). This suggests that special education teacher classification does not affect an academic area that a teacher needs more strategies for teaching mathematics.

Special Education and Teacher Classification (Item $1 \&$ 2) by Do Not Need More Strategies for Teaching Mathematics (Item 31) analysis did not yield a statistically significant finding (Appendix D, Table S8). Overall, 52\% of special education teachers report they do not need more professional development in the area of Numbers and Operations. This suggests that special 
education teachers have similar needs in areas that they do not need more strategies for teaching mathematics.

Summary of Results

This chapter presented the findings of the statistical analyses of the data to answer each of the four research questions. The findings are displayed in a table with graphs to illustrate significant differences and discussed in the narrative. Further information can be found in Appendix D. 


\section{CHAPTER 5}

Summary of Findings, Recommendations, and Implications for the Field

This final chapter contains the summary, conclusions, and recommendations for the study.

This chapter is divided by (a) summary of purpose, (b) summary of procedures, (c) summary of sample, (d) summary of findings, (e) conclusions, (f) limitations, (g) recommendations, and (h) implications.

\section{Summary of Purpose}

The primary purpose of this study was to examine the professional development needs identified by general education and special education mathematics teachers who taught at least one mathematics class. The secondary purpose was to examine the similarities and differences in identified needs of general education and special education mathematics teachers by grade levels (elementary vs. secondary), teacher classification (general education vs. special education) and for special educators by grade level (elementary vs. secondary). The objective was to help stakeholders develop more adequate and appropriate professional development programs for school systems in which these teachers worked.

\section{Research Questions}

The research questions that guided this study were:

1.What professional development needs are identified by general education and special education teachers who have a responsibility for teaching at least one mathematics class? 
2. What are similarities and differences in identified mathematics professional development needs by general education and special education mathematics teachers by grade level (elementary vs. secondary)?

3. What are similarities and differences in identified mathematics professional development needs by teacher classification (general education vs. special education)?

4.What are similarities and differences in identified mathematics professional development needs of special education teachers by grade level (elementary vs. secondary)?

This study was presented in five chapters in which, the problem was identified, a review of the literature was presented, the methodology behind the study was explained, the results were reported, and the findings were summarized and interpreted.

Chapter 1 offered an overview of current legislation that impacts teacher qualifications in the classroom as it pertains to special education. A description of current teachers was given, including the percentages of teachers who are highly qualified. The relationship between teacher qualifications and student achievement was explained, including how, when teachers are not meeting the needs of students, school may face negative consequence for failure to meet targets for adequate yearly progress. The role of professional development for teachers was discussed as a strategy to enhance teacher qualifications and improve student outcomes. Research on professional development in mathematics was overviewed. This research was designed to investigate professional development in mathematics, specifically what teachers perceive as their professional development needs in mathematics. The researcher also wanted to identify if there were similarities 
or differences in the needs identified by general education and special education teachers, elementary and secondary, and elementary special education and secondary special education teachers. This information is intended to be shared with stakeholders in the school systems so they can determine if general education and special education, elementary and secondary, and elementary special education and secondary special education teachers could have common mathematics professional development sessions or not.

Chapter 2 provided the professional literature on which the study was based. The National Council of Teachers of Mathematics Content Standards, Maryland Content Standards, and the National Staff Development Standards were reviewed to identify key academic components. The literature on professional development and its impact on teachers and students was reviewed. Finally, the literature on mathematics professional development for teachers was reviewed to determine the research variables that needed to be addressed.

Chapter 3 identified the methodology of the study. In this chapter, the potential participants were described. The design of the study was explained as well as development of the Mathematics Professional Development Inventory (MPDI), a survey created specifically for this research.

Chapter 4 presented analyses of the data that were collected during the study, the results, and a summary of the findings for the dependent variables relate to each of the four research questions. This chapter closed with a summary of the findings.

Chapter 5, this is the final chapter it summarized the study, discussed the findings of related professional literature, and offers recommendations for future research and implications in policy and practice. It also discusses the limitations of the study.

Summary of Procedures 
A quantitative analysis was conducted using the numeric data obtained from items on the Mathematics Professional Development Inventory (MPDI). The ratings of items 1-13 on the MPDI were demographic questions that served as independent variables. The ratings of items 14-41 were ratings that served as dependent variables. Items 15, 19-26, 28, and 32-41 were put into the survey at request of the school system, and were not analyzed for this study. Demographic data and ratings data were entered into SPSS 16.0 for each of the participants.

The analysis strategy was similar across all four research questions. Frequencies of the participants' responses were determined, then a Chi-Square analysis was conducted to determine if there were differences in the frequencies (Gravetter \& Wallnau, 2006). Any difference was considered significant if $p<.05$ (Gravetter \& Wallnau, 2006). When statistically significant differences were identified, results were graphed to identify the sources of the difference.

The survey was administered once, and 458 math teachers participated. Of those 458 math teachers; $69(15 \%)$ of them taught special education, $383(84 \%)$ of them taught general education, and $5(1 \%)$ of the participants did not specify their current position. The participants included 58 (13\%) males, $390(85 \%)$ females, and $9(2 \%)$ participants did not specify their gender. Summary of Findings

The results of the statistical analyses for each of the research questions show the similarities and differences in the independent variables (teacher characteristics) and the dependent variables (mathematics professional development needs) for each of the four research questions.

\section{Research Question 1}

Gender. Participants (male or female) were asked to respond to questions that asked about their need for math content knowledge, an academic area they feel they need more strategies for 
teaching mathematics, and an area they feel that they do not need more strategies for teaching mathematics. All of these responses yielded a statistically significant difference. However, there was no statistically significant difference for professional development they feel they need in mathematics content knowledge, a mathematics academic area in which they feel they need more content knowledge, an area in which they feel they do not need more content knowledge, and their overall ability to teach mathematics, and professional development need for teaching mathematics. Overall, male teachers were more confident (rating of Exceptional) of their mathematics content knowledge. There were also statistically significant differences between males and females teachers in their need for more strategies in teaching mathematics and in the strategies that they do not need in teaching mathematics.

Number of Math Classes Taught. Participants (who had taught 1, 2, 3, 4, 5, 6 or more math classes) were asked to respond to questions that asked about their need for math content knowledge, a math academic area they feel they need more content knowledge, an area they feel that they do not need more content knowledge, an academic area they feel they need more strategies for teaching mathematics, and an area they feel that they do not need more strategies for teaching math. All of these responses yielded a statistically significant difference. However, there was no statistically significant difference for professional development they feel they need in mathematics content knowledge, their overall ability to teach mathematics, and professional development they feel they need for teaching mathematics. Overall, the number of math classes that they taught was strong compared to their rating of needing more content knowledge, do not need more content knowledge, need more strategies for teaching mathematics, and do not need more strategies for teaching mathematics. 
School Organization. Participants (teach all, rotate classes, or other) were asked to respond to questions that asked about their need for math content knowledge, amount of professional development they feel they need in mathematics content, an area they feel that they do not need more content knowledge, and their overall ability to teach mathematics. All of these responses yielded a statistically significant difference. However, there was no statistically significant difference for professional development they feel they need in mathematics content knowledge, a mathematics academic area in which they feel they need more content knowledge, an academic area in which they feel they need more strategies for teaching mathematics, an area they feel that they do not need more strategies for teaching mathematics, and professional development need for teaching mathematics. Overall, school organization was related to the types of teaching strategies that the teachers identify that they need and do not need as well as their math content knowledge and ability to teach.

Role in Education. Participants (type of job within the school system) were asked to respond to questions that asked about their need for math content knowledge, amount of professional development they feel they need in mathematics content, an area they feel that they do not need more content knowledge, and their overall ability to teach mathematics, the professional development they feel they need in mathematics content knowledge, a math academic area in which they feel they need more content knowledge, an academic area in which they feel they need more strategies for teaching mathematics, and an area they feel that they do not need more strategies for teaching math and professional development need for teaching mathematics. There was no statistically significant difference for any of these categories. Overall, their role in 
education appeared to have no relationship to their identified needs for professional development in mathematics.

Degree. Participants (e.g., Doctorate, Master's, Bachelor's) were asked to respond to questions that asked about the amount of professional development they feel they need in mathematics content, and their overall ability to teach mathematics. All of these responses yielded a statistically significant difference. There was no statistically significant difference for their need for mathematics content knowledge, the professional development they feel they need in mathematics content knowledge, an area in which they feel they do not need more content knowledge, a math academic area in which they feel they need more content knowledge, an academic area in which they feel they need more strategies for teaching mathematics, and an area they feel that they do not need more strategies for teaching mathematics and professional development need for teaching math. Overall, teachers were more likely to feel their content knowledge and ability to teach is varied based upon their degree

Number of Math Content Courses Taken. Participants (1-2, 3-4, 5-6, 7-8, or 8 or more courses) were asked to respond to questions that asked about their need for mathematics content knowledge, amount of professional development they feel they need in mathematics content, an area they feel that they need more content knowledge, an area they feel that they do not need more content knowledge, their overall ability to teach mathematics, and an area they feel that they do not need more strategies for teaching mathematics and professional development need for teaching mathematics. All of these responses yielded a statistically significant difference. There was no statistically significant difference for a mathematics academic area in which they feel they need more content knowledge, and an academic area in which they feel they need more strategies for 
teaching mathematics. Overall, the greater the number of mathematics content courses taken, the higher the rating (Exceptional) of their mathematics content knowledge and their ability to teach mathematics. The decreased number of courses that a teacher took, the stronger the relationship in a lower response rating of math content knowledge. The increased number of courses that a teacher took, the stronger the relationship in a lower response rating of math professional development need. The increased number of courses that a teacher took, the stronger the relationship in a higher response rating of ability to teach mathematics.

Number of Math Methods Courses Taken. Participants (1, 2, 3, 4, 5, 6 or more) were asked to respond to a question that asked about their need for math content knowledge. Their responses from that question yielded a statistically significant difference. There was no statistically significant difference for amount of professional development they feel they need in mathematics content, an area in which they feel that they need more content knowledge, an area in which they feel that they do not need more content knowledge, their overall ability to teach mathematics, an area in which they feel that they do not need more strategies for teaching mathematics and professional development need for teaching mathematics a math academic area they feel they need more content knowledge, and an academic area in which they feel they need more strategies for teaching mathematics. Overall, the greater the number of mathematics methods courses taken, the higher the rating (Exceptional, Above Average, or Average) of their mathematics content knowledge. There was no statistically significant difference in their ability to teach mathematics.

Years of Experience. Participants (<1, 1-3, 4-9, 10-19, or 20 or more years) were asked to respond to questions that asked about an area in which they feel that they do not need more content knowledge, their overall ability to teach mathematics, a math academic area they feel they need 
more content knowledge, an academic area in which they feel they need more strategies for teaching mathematics, and an area in which they feel that they do not need more strategies for teaching math and professional development need for teaching math. All of these responses yielded a statistically significant difference. There was no statistically significant difference for professional development they feel they need in mathematics content knowledge, their need for mathematics content knowledge, and amount of professional development they feel they need in mathematics content. Overall, years of experience were related to teachers' ability to teach mathematics as well as areas in which they feel they need and do not need more teaching strategies. The more years of experience that the participants had in the classroom the more likely they were to state that their ability to teach mathematics was Exceptional.

Certification Year. Participants (prior to 1997, 1997-2003, 2004-2009, no certification) were asked to respond to questions that asked about an area they feel that they do not need more content knowledge, an academic area they feel they need more content knowledge, and an academic area they feel they need more strategies for teaching mathematics. All of these responses yielded a statistically significant difference. There was no statistically significant difference in the professional development they feel they need in mathematics content knowledge, their overall ability to teach mathematics, their need for mathematics content knowledge, an area in which they feel that they do not need more strategies for teaching mathematics and professional development need for teaching mathematics, and amount of professional development they feel they need in mathematics content. Overall, Teachers who were certified before 1997 were more likely to feel their need for math professional development is strong compared to teachers who were certified between 2004 and 2009. 
Certified in Mathematics. Participants (certified or not certified) were asked to respond to questions that asked about their professional development they feel they need in mathematics content knowledge, and an area in which they feel that they do not need more strategies for teaching math and professional development need for teaching math. All of these responses yielded a statistically significant difference. There was no statistically significant difference for their overall ability to teach mathematics, their need for math content knowledge, amount of professional development in which they feel they need in mathematics content, an area in which they feel that they do not need more content knowledge, an academic area in which they feel they need more content knowledge, and an academic area in which they feel they need more strategies for teaching mathematics. Overall, the teachers who were certified in mathematics were more likely to feel their content knowledge is strong compared to teachers who were not certified in math.

Highly Qualified in Mathematics. Participants (qualified or not qualified) were asked to respond to a question that asked about an area in which they feel that they do not need more content knowledge. This answer yielded a statistically significant difference. There was no statistically significant difference for their overall ability to teach mathematics, their need for math content knowledge, amount of professional development they feel they need in mathematics content, their professional development they feel they need in math content knowledge, an area in which they feel that they do not need more strategies for teaching math and professional development need for teaching math, an academic area in which they feel they need more content knowledge, and an academic area in which they feel they need more strategies for teaching 
mathematics. Overall, the teachers who were highly qualified in math did not show a pattern in their mathematics professional development needs.

\section{Research Question 2}

Participants (elementary or secondary) were asked to respond to questions that asked about their need for mathematics content knowledge, professional development they feel they need in mathematics content knowledge, an academic area in which they feel they need more content knowledge, an area in which they feel that they do not need more content knowledge, their overall ability to teach mathematics, an academic area in which they feel they need more strategies for teaching mathematics, and an area in which they feel that they do not need more strategies for teaching math. All of these responses yielded a statistically significant difference. There was no statistically significant difference for professional development need for teaching math. Overall, secondary teachers were more confident (rating of Exceptional) in their mathematics content knowledge and ability to teach, and also felt they needed only A Little professional development for mathematics content knowledge. However, there was not a statistically significant difference in their need for professional development for teaching math that indicates that they need Some to A Little.

\section{Research Question 3}

Participants (general education or special education) were asked to respond to questions that asked about their need for mathematics content knowledge, professional development they feel they need in mathematics content knowledge, an academic area in which they feel they need more content knowledge, their overall ability to teach mathematics, and professional development need for teaching mathematics. All of these responses yielded a statistically significant difference. There 
was no statistically significant difference for not needing more knowledge in subject, needing more strategies for teaching mathematics, and not needing more strategies for teaching mathematics. Overall, general education teachers were more confident (rating of Exceptional) in their mathematics content knowledge and ability to teach, so they felt that they needed only Some to A Little professional development for mathematics content knowledge. Special education teachers rated themselves as Average their mathematics content knowledge and ability to teach, so they felt that they needed Quite a Bit, Some, and A Little professional development in mathematics content knowledge and professional development need for teaching mathematics. It is also important to note that general education and special education teachers wanted professional development in different academic areas.

\section{Research Question 4}

Participants (elementary special education teachers or secondary special education teachers) were asked to respond to a question that asked about their need for more subject knowledge. That response yielded a statistically significant difference. There was no statistically significant difference for the professional development they feel they need in math content knowledge, an academic area in which they feel they need more content knowledge, an academic area in which they feel they do not need more content knowledge, their overall ability to teach mathematics, an academic area in which they feel they need more strategies for teaching mathematics, an area in which they feel that they do not need more strategies for teaching mathematics, and professional development need for teaching math. Overall, secondary special education teachers wanted more knowledge in Geometry, compared to elementary special education teachers that wanted more knowledge in Process. This is also comparative across 
research questions where teacher classification (elementary or secondary) responded similarly and was statistically significant.

\section{Conclusions}

Since there was limited research in the area of mathematics professional development (Cwikla, 2003; Cwikla, 2004) there were no studies to compare with the results. The independent research variables were based on Cwikla's qualitative study in 2004, where she grouped teachers from K-12 by background and years of experience. Although the independent variables in her study (background, years of experience, and views of learning) and this study (i.e., gender, number of math classes that they teach, school organization, number of math content courses taken, grade level, teacher classification) were similar, the dependent variables were different the studies are not comparable.

Perhaps the most important finding of this study is that special education teachers recognize they need professional development in mathematics to be effective at promoting student achievement. This suggests that professional development specialists may need to consider offering professional development activities that will enhance their knowledge and skills.

\section{Limitations}

This research had several limitations that limit the generalizability of the findings.

1. Potential participants were contacted via e-mail. In SS 1, the initial e-mail went out from a teacher's e-mail address in the county. There was a problem in the ListServ and the group of participants was not contacted the first week because the ListServ was not accessible from the teacher's e-mail address. When the researcher realized the problem she contacted the principals of each school to see if they would distribute the e-mail to their teachers. 
Many of the principals would not distribute the survey to the potential participants for a variety of reasons (e.g., end of the year, amount of other surveys being conducted in the county). This affected the amount of potential participants who completed the survey and the data may not be represented of teachers.

2. The number of special education teachers who participated in this study (69) was much fewer than the number of general education teachers that chose to participate (383), so the difference between these groups is based on the responses of only a few individuals which may not be represented of special education teachers as a whole. This impacts the findings of the study because it is hard to compare both groups with such discrepant sizes.

3. One of the school systems decided not to participate, so this affected the amount of potential participants who completed the survey. This impacts the findings of the study because there were fewer schools, and fewer school contexts that the data represents, in turn, not producing a representative sample.

\section{Recommendations for Future Research}

After reviewing the findings of this study, there are several recommendations to support and organize future research in the area of mathematics professional development.

1. Similar research needs to be conducted in other school systems in Maryland, in other states, and at the nation level.

2. This study did not develop and implement a professional development program based upon the needs that were identified. Future studies should consider using the results of the survey to design and implement a professional development program, then conducting a follow-up study of the extent to which identified needs were met. 
3. This is the first study that administered the MPDI. The study needs to be repeated to validate this assessment tool in other contexts.

4. Other studies should focus on the independent variables that had the most significant outcomes to examine in-depth the influence of those variables on the mathematics professional development needs of teachers.

5. This study did not ask participants about involvement on previous professional development activities. Other studies might ask participants about prior professional development activities and its impact on their mathematics professional development needs. For example, ask teachers what they feel they are weak in or what area they need more specific professional development. In doing this the research may want to focus on if it is the fact that they do not know enough or is it that they are not effective with students.

\section{Implications for Policy and Practice}

After reviewing the findings of this study and current research in the field, there are several implications for policy and practice to support and organize future research in the area of mathematics professional development.

1. Teachers who feel they are already able to teach mathematics do not feel that they need more teaching strategies. This suggests that professional development sessions may need to show how professional development activities will enhance knowledge and skills in the same way.

2. Teachers who teach math all day have different needs that those teachers who teach different subjects. This suggests that professional development specialists may need to consider multiple perspectives when designing activities that appeal to both groups. 
3. Teachers who teach special education classes were more likely to report that they need professional development in teaching mathematics. This suggests that professional development specialists may need to consider offering professional development activities that will enhance their knowledge and skills.

4. Teachers view content and pedagogy as the same (Puchner, Taylor, O’Donnell, \& Fick, 2008; Thornton, Crim, \& Hawkins, 2009). This suggests professional development specialists may need to communicate clearly about the impact of proposed professional development activities on both content and teaching strategies.

5. Teachers who rate themselves high in knowledge of content also rated themselves high in their ability to teach. This suggests that professional development specialists may need to embed activities designed to develop teaching skills within activities designed to increase content knowledge (n.a., 2008).

6. Males and females may have different views of their professional development needs that will influence their willingness to participate in specific activities (Cavanagh, 2005). This suggests that professional development specialists need to consider multiple perspectives in designing activities that can appeal to both groups.

7. Teachers with more years of experience may need different professional development activities than beginning teachers (Cwikla, 2004). This suggests that professional development specialists may need to design multiple levels of activities to address the concerns of novice and veteran teachers.

8. Preservice teacher education programs need to consider designing courses that distinguish between content and strategies, instead of the courses that combine them together 
(Firestone, et. al, 2005; Harrell, 2009). This way preservice teachers are able to distinguish between knowing the content and teaching the content.

9. Future math professional development programs need to consider: gender, number of math classes that they teach, school organization, number of math content courses taken, grade level, teacher classification, and years of experience when grouping and designing math professional development. 


\section{REFERENCES}

Alkins, K., Banks-Santilli, L., Elliott, P., Guttenberg, N., \& Kamil, M. (2006). Project Quest: A journey of discovery with beginning teachers in urban schools. Equity \& Excellence in Education, 39, 65-80.

Ball, D.L., \& Cohen, D. K. (1999). Developing practice, developing practitioners: Toward a practice-based theory of professional education. In L. Darling-Hammond \& G. Sykes (Eds.), Teaching as the learning profession (pp. 3-32). San Francisco: Jossey-Bass.

Bezzina, C. (2006). Views from the trenches: Beginning teachers' perceptions about their professional development. Journal of In-service Education, 32(4), 411-430.

Billingsley, B. (2004). Special education teacher retention and attrition: A critical analysis of the research literature. Journal of Special Education, 38, 39-55.

Billingsley, B., Carlson, E., \& Klein, S. (2004). The working conditions and induction support of early career special educators. Exceptional Children, 70(3), 333-347.

Boe, E., Cook, L., Bobbitt, S., \& Terhanian, G. (1998). The shortage of fully certified teachers in special and general education. Teacher Education and Special Education, 21(1), 1-21.

Burch, P., \& Spillane, J. P. (2003). Elementary school leadership strategies and subject matter: Reforming mathematics and literacy instruction. The Elementary School Journal, 103(5), 519-535. 
Carpenter, T. P. \& Fennema, E. (1992). Cognitively guided instruction: Building on the knowledge of students and teachers. International Journal of Research in Education, 17(4), 457-470.

Carson, E. (2004, March 17). Re: After holding back third graders, what to do? The New York Times. Retrieved on May 4, 2009, from http://www.nychold.com/let-carson040317.html

Cavanagh, S. (2005). Teacher training leads to higher test scores. Education Week, 24(23), 14.

Cognition and Technology Group at Vanderbilt (1997). The Jasper Project: Lessons in curriculum, instruction, assessment, and professional development. Mahwah, NJ: Lawrence Erlbaum.

Corcoran, T. B. (1995, June 16). Helping teachers teach well: Transforming professional development. Consortium for Policy Research in Education, 1-11.

Council of Chief State School Officers (2008). School Data Direct. Retrieved on November 20, 2008, from, http://www.schooldatadirect.org/?gclid=CPrz68zNuJYCFSUqHgodOCh5Lw

Cutler, A. D., \& Ruopp, F. N. (1993, March). Buying time for teachers' professional development. Educational Leadership, 50(6), 34-37.

Cwikla, J. (2002). Mathematics teachers' report about the influence of various professional development activities. The Professional Educator, 24(2), 75-94. 
Cwikla, J. (2003). The importance of setting learning goals to investigate the effectiveness of teacher professional development. Educational Research Quarterly, 27(2), 4359.

Cwikla, J. (2004). Less experienced mathematics teachers report what is wrong with their professional support system. Teachers and Teaching: Theory and Practice, 10(2), 181-197.

Darling-Hammond, L. (1996, March). The quiet revolution: Rethinking teacher development. Educational Leadership, 53(6), 4-10.

Darling-Hammond, L. (2007). We need to invest in mathematics and science teachers. Chronicle of Higher Education, 54(17), 20.

Darling-Hammond, L., \& McLaughlin, M. (1995). Policies that support professional development in an era of reform. Phi Delta Kappan, 76(8), 597.

Education Trust (1996). Education Watch: The 1996 Education Trust State and National Data Book. Washington, DC: Author.

Fernandez, E., \& Jones, M. (2006, Fall). Emphasizing the NCTM content standards in undergraduate courses for prospective teachers. Mathematics \& Computer Education, 40(3), 237-247.

Fideler, E., Foster, E., \& Schwartz, S. (2000). The urban teacher challenge: Teacher demand and supply in the great city schools. Belmont, MA: Council of the Great City Schools. 
Firestone, W. A., Mangin, M. M., Martinez, M. C., \& Polovsky, T. (2005). Leading coherent professional development: A comparison of three districts. Educational Administration Quarterly, 41(3), 413-448.

Fisher, M. H. (n.d.). Retaining beginning mathematics teachers in the United States. Retrieved on December 3, 2008, from http://mathematics.unipa.it/ grim/21_project/21_charlotte_FisherPaperEdit.pdf

Fraenkel, J.R., \& Wallen, N.E. (2009). How to design and evaluate research in education ( $7^{\text {th }}$ ed.). Retrieved on February 20, 2009, from http://highered.mcgrawhill.com/sites/0073525960/student_view0/chapter11/key_terms.html

Fullan, M. G. (1991). The new meaning of educational change. New York: Teachers College Press.

Fullan, M. G. (1993). Change forces: Probing the depths of educational reform. Bristol, PA: Falmer Press.

Fullan, M. G. (1999). Change forces: The sequel. Bristol, PA: Falmer Press.

Gehrke, R., \& McCoy, K. (2007). Considering the context: Differences between the environments of beginning special educators who stay and those who leave. Rural Special Education Quarterly, 26(3), 32-40.

Gehrke, R., \& Murri, N. (2006). Beginning special educators' intent to stay in special education: Why they like it here. Teacher Educational and Special Education, 29(3), 179-190. 
Gimbert, B., Bol, L., \& Wallace, D. (2007). The influence of teacher preparation on student achievement and the application of national standards by teacher of mathematics in urban secondary schools. Education and Urban Society, 40(1), 91-117.

Goldman, N. (2007, November). Making meaning for mathematics teachers. Association for Supervision and Curriculum Development, 65(3), 75-76.

Gravetter, F.J., \& Wallnau, L.B. (2006). Statistics for the behavioral sciences $\left(7^{\text {th }}\right.$ ed.) Belmont, CA: Wadsworth Publishing.

Guskey, T. R. (1986). Staff development and the process of teacher change. Educational Researcher, 15(5), 5-12.

Guskey, T. R. (1994). Results-oriented professional development: In search of the optimal mix of effective practices. Journal of Staff Development, 15(4), 42-50.

Guskey, T. R. (2002). Professional development and teacher change. Teachers and Teaching: Theory and Practice, 8(3/4), 381-391.

Guskey, T. R. (2003). What makes professional development effective? Phi Delta Kappan, 84(1), 748-750.

Guttierez, P. S. (2002). In search of bedrock: organizing for success with diverse needs children in the classroom. Journal of Latinos in Education, 1(1), 49-64.

Harrell, P. E. (2009). Do state examinations measure teacher quality? Educational Studies, $35(1), 65-79$.

Henig, S. (2006, October 6). Back to school, for teachers. The Chronicle of Higher Education, 53(7), A20-A22. Retrieved February 18, 2008, from Education Research Complete database. 
Huberman, M. (1995). Professional careers and professional development: Some intersections. In T. R. Guskey \& M. Huberman (Eds.), Professional development in education: New paradigms and practices (pp. 193-224). New York: Teachers College Press.

Individuals with Disabilities Act, Pub. L. No. 108-446, 108 (2004). Retrieved on December 22, 2008, from http://idea.ed.gov/.

Ingersoll, R. M. (1997). Teacher turnover and teacher quality: The recurring myth of teacher shortages. Teachers College Record, 99(1), 41-44.

Ingersoll, R. (2003). Out-of-field teaching and the limits of teacher policy. Seattle: Center for the Study of Teaching and Policy, University of Washington.

Ingersoll, R. (2005). Teacher turnover and teacher shortages: An organizational analysis. American Educational Research Journal, 38(3), 499-534.

Ingersoll, R. M., \& Gruber, K. (1996). Out-of-field teaching and educational equality. Washington, D.C.: U.S. Department of Education, National Center for Education Statistics.

Johnson, K. E., Peck, K., \& Wise, J. (2007). Subgroups and adequate yearly progress in Mid-Atlantic Region schools (Issues \& Answers Report, REL 2007-No. 028). Washington, DC: U.S. Department of Education, Institute of Education Sciences, National Center for Education Evaluation and Regional Assistance, Regional Educational Laboratory Mid-Atlantic. Retrieved on December 26, 2008, from http://ies.ed.gov/ncee/edlabs 
Johnson, R.B., \& Christensen, L.B. (2007, December). Educational research: Quantitative, qualitative, and mixed approaches ( $3^{\mathrm{rd}} \mathrm{ed}$.). Thousand Oaks, CA: Sage Publications.

Kantor-Goldenberg, C. (2006, October 18). Put two and two together. New York Daily News. Retrieved on May 7, 2009, from http://www.nychold.com/let-nydn0610yy.html

Kazemi, E., \& Franke, M. L. (2000, April). Teacher learning in mathematics: A community of practice perspective. Paper presented at the American Educational Research Association. New Orleans, Louisiana.

Kimmel, H., Deek, F. P., \& O’Shea, M. (1999). Meeting the needs of diverse student populations: Comprehensive professional development in science, mathematics, and technology for teachers of students with disabilities. School Science Mathematics, 99(5), 241-249.

Langer, G., Colton, A., \& Goff, L. (2003). Collaborative analysis of student work. Alexandria, VA: Association for Supervision and Curriculum Development.

Little, J. W. (1993). Teachers' professional development in a climate of educational reform. Educational Evaluation and Policy Analysis, 15, 129-151.

Little, J., Gearhart, M., Curry, M., \& Kafka, J. (2003). Looking at student work for teacher learning, teacher community, and school reform. Phi Delta Kappan, 85(3), 185-92.

Louie, J., Brodesky, A., Brett, J., Yang, L., \& Tan, Y. (2008, August). Mathematics education practices for students with disabilities and other struggling learners: Case studies of six schools in two northeast and island region states (Issues and 
Answers Report, REL 2008-No. 053). Washington, DC: U.S. Department of Education, Institute of Education Sciences, National Center for Education Evaluation and Regional Assistance, Regional Educational Laboratory Northeast and Islands. Retrieved on December 19, 2008, from http://ies.ed.gov/ncee/edlabs.

Loveless, T., \& Diperna, P. (2000). How well are American students learning? Focus on mathematics achievement (Brown Center Report, Vol. 1, No. 1). Washington, DC: Brookings Institution. Retrieved on December 21, 2009, from http://www.brookings.edu/reports/2007/ /media/Files/rc/reports/2007/1211_educati on_loveless/1211_education_loveless.pdf

Lubienski, S. T. (2006). Examining instruction, achievement, and equity with NAEP mathematics data. Education Policy Analysis Archives, 14(14). Retrieved December 27, 2008, from http://epaa.asu.edu/epaa/v14n14/

Ma, L. (1999). Knowing and teaching elementary mathematics: Teachers' understanding of fundamental mathematics in China and the United States. Mahwah, NJ: Lawrence Erlbaum Associates.

Maryland State Board of Education (2008). Teacher shortages continue throughout Maryland. Retrieved February 23, 2009, from http://somd.com/news/headlines/2008/8731.shtml

Maryland State Department of Education (2008). Maryland Teacher Staffing Report. Retrieved February 23, 2009, from http://www.marylandpublicschools.org/NR/rdonlyres/F3F5D904-0F5E-4FC787CE-464FC17DABB5/18552/MarylandTeacherStaffingReport20082010.pdf 
McLeskey, J., Tyler, N., \& Flippin, S. (2004). The supply of and demand for special education teachers: A review of research regarding the chronic shortage of special education. Journal of Special Education, 38(1), 5-21.

Miller, M. D., Brownell, M. T., \& Smith, S. W. (1999). Factors that predict teachers staying in, leaving, or transferring from the special education classroom. Exceptional Children, 65(2), 201-218.

n.a. (2008). Laying a better foundation to teach elementary school math. American Educator, 32(3), 2-2.

National Center for Educational Statistics (2007, January). Teacher attrition and mobility: Results for the 2004-2005 Teacher Follow-up Survey. National Center of Educational Statistics, 307.

National Commission on Teaching and America's Future. (1996). What matters most: Teaching for America's future. New York: Author.

National Council of Teachers of Mathematics (1989). Curriculum and evaluation standards. The National Council of Teachers of Mathematics. Reston, VA.

National Council of Teachers of Mathematics (2004). Principles and standards for school mathematics. Retrieved on December 2, 2008, from http://standards.nctm.org/document/chapter2/index.htm

National Staff Development Council (2008). NSDC's standards for staff development. Retrieved on December 5, 2008, from http://www.nsdc.org/standards/index.cfm No Child Left Behind Act of 2001, 20 U.S.C. $70 \S 6301$ et seq. (2002). 
Oelklaus, N. (1999). In touch with teachers: Making professional development worthy of teachers' time and effort. American School Board, 186(3), 37-39.

Paul, C. A. (2005). A proposal to address the shortage of highly qualified mathematics teachers. Mathematics Teacher, 98, 456-458.

Plunkett, R. (personal communication, December 3, 2008)

Puchner, L., Taylor, A., O’Donnell, B., \& Fick, K. (2008). Teacher learning and mathematics manipulatives: A collective case study about teacher use of manipulatives in elementary and middle school mathematics lessons. School Science \& Mathematics, 108(7), 313-325.

Reys, R., Reys, B., Lapan, R., Holliday, G., \& Wasman, D. (2003). Assessing the impact of standards-based middle grades mathematics curriculum materials on student achievement. Journal for Research in Mathematics Education, 34(1), 74-95.

Reys, B. J., \& Reys, R. E. (2005). Recruiting mathematics teachers: strategies to consider. Mathematics Teacher, 97, 92-95.

Safier, K.L., (2007). Improving teacher quality in Ohio: The limitations of the highly qualified teacher provision of the No Child Left Behind Act of 2001 (Electronic versions). Journal of Law \& Education, 36(1), 65-87.

Schoenfeld, A. (2002). Making mathematics work for all children: Issues of standards, testing, and equity. Educational Researcher, 31(1), 13-25.

Senk, S., \& Thompson, D. (2003). Standards-based school mathematics curricula: What are they? What do students learn? Hillsdale, NJ: Lawrence Earlbaum Associates. 
Smith, T. \& Ingersoll, R. (2004). What are the effects of induction and mentoring on beginning teacher turnover? American Educational Research Journal, 41, 681-684.

Spencer, R. (personal communication, December 3, 2008)

State Accountability Profiles (2006-2007). Percent of all schools not making Adequate Yearly Progress, and percent of all schools identified as in need of improvement, by state: 2006-07. Washington, DC: US Department of Education, National Center for Educational Statistics. Retrieved December 26, 2008, from http://nces.ed.gov/programs/statereform/saa_tab6.asp

Stevenson, Z., Dantley, S. J., \& Holcomb, Z. J. (1999). Factors influencing the retention of mathematics and science teachers in urban systemic initiative school districts: Administrative perspectives. Journal of Negro Education, 68(3), 442-450.

Thornton, J., Crim, C., \& Hawkins, J. (2009). The impact of an ongoing professional development program on prekindergarten teachers' mathematics practices. Journal of Early Childhood Teacher Education, 30(2), 150-161.

U.S. Census Bureau (2000). State and county quickfacts. Retrieved May 29, 2008, from http://quickfacts.census.gov/qfd/states/24/24005.html

U.S. Department of Education (2001). Twenty-third annual report to Congress. Retrieved January 10, 2009, from http://www.ed.gov/about/reports/annual/osep/2001/index.html

U.S. Department of Education (2003-04). National Center for Education Statistics: Schools and Staffing Survey. Retrieved on May 2, 2009, from http://nces.ed.gov/surveys/sass/tables_2004.asp 
U.S. Department of Education (2004). Title 1: Improving academic achievement of the disadvantaged. Retrieved on December 27, 2008, from http://www.ed.gov/policy/elsec/leg/esea02/pg1.html

U.S. Department of Education (2008, March). Teacher shortage areas nationwide listing 1990-91 through 2007-08. Retrieved on January 3, 2009, from www.ed.gov/about/offices/list/ope/pol/tsa.doc

Vermont Department of Education (2008, April). Frequently asked questions regarding Adequate Yearly Progress (AYP). Retrieved on December 26, 2008, from http://education.vermont.gov/new/pdfdoc/pgm_accountability/ayp_faq_042808.pdf

Waggoner, S. (personal communication, December 4, 2008)

Wayne, A.J., Yoon, K.S., Zhu, P., Cronen, S., \& Garet, M. (2008). Experimenting with teacher professional development: Motives and methods. Educational Researcher, $37(8), 469-479$.

Watzke, J. (2007). Longitudinal research on beginning teacher development: Complexity as a challenge to concerns-based stage theory. Teaching and Teacher Education, 23(1), 106-122.

Wise, A. E. (1991). On teacher accountability. In, Wise, A.E., Voices from the field (pp. 2324). Washington, DC: William T. Grant Foundation Commission on Work, Family, and Citizenship and the Institute for Educational Leadership.

Wooilla, J., Boscardin, M.L., \& Dodds, P. (1997). Time for elementary educators’ professional development. Teaching \& Teacher Education, 13(3), 295-309. 
Yoon, K. S., Duncan, T. S., Lee, S. W.-Y., Scarloss, B., and Shapley, K. (2007). Reviewing the evidence on how teacher professional development affects student achievement (Issues and Answers Report, REL 2007- No. 033). Washington, DC: U.S. Department of Education, Institute of Education Sciences. Retrieved on December 27, 2008, from http://ies.ed.gov/ncee/edlabs/projects/project.asp?id=70. 
Appendix A: Mathematics Professional Development Inventory 


\title{
EMAIL MESSAGE TO CONTACT PARTICIPANTS
}

Please Respond to a Survey on Professional Development Needs for Mathematics Teachers

I am a doctoral student in the Department of Special Education at West Virginia University who is conducting research to complete my dissertation. The research consists of an online survey of stakeholder perceptions of professional development needs for general education mathematics teachers and special education mathematics teachers and their effect on schools and teachers. I need your help to obtain a better understanding of your specific mathematics professional development needs.

The survey form, which will only take 10-15 minutes of your time, will be available from May $11^{\text {th }}$ to June $2^{\text {nd }}, 2009$.

Please click the link below to start the survey:

http://www.surveymonkey.com/s.aspx?sm=G4UpIUmVcuNWSQ5ao7hDJQ_3d 3d

If you have any questions feel free to contact me at kservili@ mix.wvu.edu or 304-2933923.

Sincerely,

Kathryn L. Servilio, ABD

West Virginia University

Department of Special Education

$* * * * * * * * * * * * * * * * * * * * * * * * * * * * * * * * * * * * * * * * * * * * * * * * * * * * * * * * * * * * * * * * *$

\section{SURVEY COVER PAGE}

\section{Survey of Perceptions of Mathematics Professional Development Needs for General Education Mathematics Teachers and Special Education Mathematics Teachers}

\author{
Conducted by \\ Kathryn L. Servilio \\ Co-Principal Investigator \\ Doctoral Student \\ $\&$ \\ Barbara L. Ludlow \\ Principal Investigator \\ Faculty Supervisor
}




\section{Department of Special Education \\ West Virginia University}

The purpose of this study is to explore the perceptions of various stakeholders (general education mathematics teachers and special education mathematics teachers) and look for relationships with their demographic characteristics (e.g., years of experience, highly qualified status, type of certification). The goal is to collect data to be shared with administrators within each of the districts as well as leaders in the field of general education and special education to inform discussion related to the identification of professional development needs for current mathematics teachers to ensure that all teachers acquire the skills to support learning and achievement in mathematics for all students.

- Your completion and return of this online survey is considered to reflect your consent to participate in this study. Your participation is completely voluntary. West Virginia University's 'Acknowledgement' for 'Approval' is on file. If you have questions about the survey or your rights as a participant in the study, you may call the staff of the WVU Institutional Review Board for the Protection of Human Subjects at 304-293-7073.

- All responses to this online survey are completely anonymous and cannot be traced to you or your school district in any way.

- If you do not wish to answer a question, you may choose to not select an indicator or leave the textbox blank.

- If you have any questions about this survey, please contact Kathryn Servilio, study coordinator, at kservili@ mix.wvu.edu or 304-293-3923.

- You may also contact my faculty supervisor, Barbara Ludlow, at Barbara.ludlow@mail.wvu.edu or 304-293-3450.

When you select a response to the first question below, you will be directed to a set of survey questions tailored to a specific group of stakeholders of which you are a member:

1. Do you teach at least one mathematics class?

Yes

No

(If the respondents answer "No" they will be directed out of the survey)

2. What is your current position?

Special education teacher

General education teacher

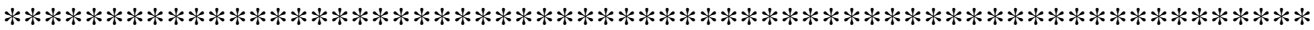

\section{SURVEY COVER PAGE}

\section{Survey of Perceptions of Math Professional Development Needs}




\title{
for General Education Math Teachers and Special Education Math Teachers
}

\author{
Conducted by \\ Kathryn L. Servilio \\ Co-Principal Investigator \\ Doctoral Student \\ $\&$ \\ Barbara L. Ludlow \\ Principal Investigator \\ Faculty Supervisor \\ Department of Special Education \\ West Virginia University
}

The purpose of this study is to explore the perceptions of various stakeholders (general education math teachers and special education math teachers) and look for relationships with their demographic characteristics (e.g., years of experience, highly qualified status, type of certification). The goal is to collect data to be shared with administrators within each of the districts as well as leaders in the field of general education and special education to inform discussion related to the identification of professional development needs for current math teachers to ensure that all teachers acquire the skills to support learning and achievement in math for all students.

- Your participation is completely voluntary. West Virginia's University's Institutional Review Board acknowledgement of this project is on file. If you have questions about the survey or your rights as a participant in the study, you may call the staff of the WVU Institutional Review Board for the Protection of Human Subjects at 304-2937073 .

- All responses to this online survey are completely anonymous and cannot be traced to you or your school district in any way.

- The aggregated data from this study will be shared with your school system.

- If you do not wish to answer a question, you may choose to not select an indicator or leave the textbox blank.

- If you have any questions about this survey, please contact Kathryn Servilio, study coordinator, at kservili@ mix.wvu.edu or 304-293-3923.

- You may also contact my faculty supervisor, Barbara Ludlow, at Barbara.ludlow@mail.wvu.edu or 304-293-3450.

When you select a response to the first question below, you will be directed to a set of survey questions tailored to a specific group of stakeholders of which you are a member:

3. Do you teach at least one math class? 
Yes

No

(If the respondents answer "No" they will be directed out of the survey)

4. What is your current position?

Special education teacher

General education teacher

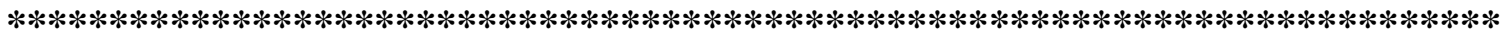

SPECIAL EDUCATION TEACHER SURVEY

1. What is your gender?

Male

Female

Current Teaching Assignment

2. How many math classes do you teach?

1

2

3

4

5

6 or more

3. What grade level do you teach?

Elementary (K-6)

Secondary (7-12)

4. What letter does your school system start with?

B

G

5. How is your school organized?

Students are assigned one teacher for the majority of the day, and remain with him/her for all core academic subjects

Students move from classroom to classroom throughout the day, from one academic subject to another

Other

6. What is your teaching role in special education?

In a self-contained room

In a resource room

An itinerant for multiple locations

Co-teaching in an inclusive classroom 
Other (Please explain: )

\section{Previous Training}

7. Which statement best fits your situation?

I have a doctoral degree in special education

I have a master's degree in special education

I have a bachelor's degree in special education with special education certification I have a bachelor's degree in another area with special education certification

I have a bachelor's degree in another area with special education permit

8. How many math content (learning mathematics content only and/or including math) courses have you taken (including college)?

$1-2$

3-4

$5-6$

$7-8$

8 or more

9. How many math methods (learning how to teach mathematics) courses have you taken (including college)?

Less than 1 year

$1-2$

3-4

$5-6$

$7-8$

8 or more

10. How many years of experience do you have in special education?

Less than 1 year

$1-3$

4-9

$10-19$

20 or more

\section{Certification}

11. What year did you earn your certification in special education?

Prior to 1997

$1997-2003$

2004-2009

I do not have my certification in special education

12. Are you certified to teach math?

Yes 
No

13. Are you "highly qualified" in math (as defined by NCLB)?

Yes

No

13a. How did you become "highly qualified" in math?

I completed a set of math courses

I passed a competency test in math

I submitted a portfolio documenting math knowledge

Other (Please explain: )

\section{B. Questions for Special Education Teachers}

In this section, you will respond to questions about your professional development needs related to mathematics content and mathematics strategies. For the purposes of this study, these are defined as follows:

MATHEMATICS CONTENT- knowledge in the area of Algebra, Geometry, Measurement, Statistics, Probability, Number and Operations, Processes (communication, problem solving, reasoning and proof, representation, and connections)

MATHEMATICS STRATEGIES- specific method or approach to achieve a learning outcome. For example, when teaching the students order of operations using the acrostic poem "PEMDAS."

\section{Professional Development in Mathematics}

14. When reflecting on your own math content knowledge and skills (specific to math such as algebra, geometry, measurement, statistics, etc.), how do you rate yourself?

a. Exceptional

b.Above average

c. Average

d. Below average

e.Poor

15. How would you rank your professional development experiences related to mathematics content thus far?
a. Excellent
b.Above Average
c. Average
d.Below Average
e.Poor

16. How much additional professional development related to mathematics content do you feel you need?

a. A lot 
b.Quite a bit

c. Some

d.A little

e. None

17. If you were to choose ONE area of math in which you feel you NEED more knowledge, what would it be?
a. Algebra
b.Geometry
c. Measurement
d.Statistics
e.Probability

f. Number and Operations

g.Processes (communication, problem solving, reasoning and proof, representation, and connections)

18. If you were to choose ONE area of math in which you feel you DO NOT need more knowledge, what would it be?
a. Algebra
b.Geometry
c. Measurement
d.Statistics
e.Probability
f. Number and Operations
g.Processes (communication, problem solving, reasoning and proof, representation, and connections)

19. If one or more professional development workshops were provided for you based on the answer you chose in Question 16, what are the chances you would attend voluntarily?
a. Definitely
b.Highly likely
c. Most likely
d.Probably not
e. Would not attend

20. How much professional development in mathematics content do you feel needs to be provided by your school system?
a. A lot
b.Quite a bit
c. Some
d.A little 
e. None

21. How useful do you find the professional development sessions in mathematics content that have been provided by your school system?

a. Extremely useful

b.Definitely useful

c. Somewhat useful

d.A little useful

e. Not useful

22. Would you consider professional development or attend workshops in mathematics content if your students' math test scores were decreasing?
a. Absolutely
b.Maybe
c. No

23. Would you be as interested in attending professional development workshops in mathematics content if your students' test scores increased?
a. Absolutely
b.Maybe
c. No

24. How many follow-up sessions are you willing to participate in (throughout the school year) after an initial professional development session in mathematics content?
a. None
b. 1
c. 2
d. 3
e. 4
f. 5
g. 6 or more

25. Should math special education teachers and math general education teachers both participate in the SAME professional development sessions in mathematics content?
a. Yes
b.No
c. Undecided

26. Should you have the SAME professional development needs in mathematics content as a math general education teacher?
a. Yes
b.No 
c. Undecided

\section{Professional Development in Teaching Mathematics}

27. When reflecting on your own ability to teach mathematics, how do you rate your skills?
a. Exceptional
b. Above average
c. Average
d. Below average
e.Poor

28. How would you rank your professional development experiences related to teaching mathematics thus far?
a. Excellent
b.Above Average
c. Average
d.Below Average
e.Poor

29. How much additional professional development in teaching mathematics do you feel that you need?
a. A lot
b.Quite a bit
c. Some
d.A little
e. None

30. If you were to choose ONE area of math in which you feel you NEED more strategies, what would it be?
a. Algebra
b.Geometry
c. Measurement
d.Statistics
e.Probability

f. Number and Operations

g.Processes (communication, problem solving, reasoning and proof, representation, and connections)

31. If you were to choose ONE area of math in which you feel you DO NOT need more strategies, what would it be? 

a. Algebra
b.Geometry
c. Measurement
d.Statistics
e.Probability

f. Number and Operations

g.Processes (communication, problem solving, reasoning and proof, representation, and connections)

32. If one or more professional development workshops were provided for you based on the answer you chose in Question 29, what are the chances you would voluntarily attend?
a. Definitely
b.Highly likely
c. Most likely
d.Probably not
e. Would not attend

33. After attending math workshops, how often do you implement the strategies into your class/lessons?
a. All the time
b.Most of the time
c. Some of the time
d.Seldom
e. Never

34. How much professional development in teaching mathematics do you feel needs to be provided by your school system?
a. A lot
b.Quite a bit
c. Some
d.A little
e. None

35. How useful do you find the professional development sessions in teaching strategies for mathematics that have been provided in your school system?

a. Extremely useful

b.Definitely useful

c. Somewhat useful

d.A little useful

e. Not useful 
36. Would you consider professional development or attending workshops in mathematics strategies if your students' math test scores were decreasing?
a. Absolutely
b.Maybe
c. No

37. Would you be as interested in attending professional development workshops in mathematics strategies if your students' test scores increased?
a. Absolutely
b.Maybe
c. No

38. How many follow-up sessions are you willing to participate in (throughout the school year) after the initial professional development session in mathematics strategies?
a. None
b. 1
c. 2
d. 3
e. 4
f. 5
g. 6 or more

39. Should math special education teachers and math general education teachers both participate in the SAME professional development sessions for mathematics strategies?
a. Yes
b.No
c. Undecided

40. Should you have the SAME professional development needs in mathematics strategies as a math general education teacher?
a. Yes
b.No
c. Undecided

Open-ended Questions and Answers

41. What is one way you feel math professional development can be improved?

42. How do you incorporate the math professional development that you learn into what you are already doing in your instruction? 
Thank you for participating in this study of stakeholder perceptions of math professional development for special educators. I appreciate your willingness to support this research and the time and thought you put into completing the survey questions. If you are interested a separate screen will appear for you to enter the $\$ 100$ Visa gift card drawing. If you are not interested close the screen after it appears. There is no way that your answers will be connected to the personal information you provide in the drawing.

$* * * * * * * * * * * * * * * * * * * * * * * * * * * * * * * * * * * * * * * * * * * * * * * * * * * * * * * * * * * * * * * * * * * * * * * * * * * * *$

\section{ENTER TO WIN \$100 Visa Gift Card}

Thanks so much in your willingness to participate in my study. Please complete the information below and you will be entered to win the $\$ 100$ Visa Gift card. There is no way that your answers from the survey are connected to your personal information. If you win, the researcher will call you and the prize will be mailed.

Name:

Address:

Phone Number:

\section{GENERAL EDUCATION TEACHER SURVEY}

1. What is your gender?

Male

Female

Current Teaching Assignment

2. How many math classes do you teach?

1

2

3

4

5

6 or more

3. What grade level do you teach?

Elementary (K-6)

Secondary (7-12)

4. What letter does your school system start with?

B

G

5. How is your school organized?

Students are assigned one teacher for the majority of the day, and remain with him/her for all core academic subjects 
Students move from classroom to classroom throughout the day, from one academic subject to another

Other

6. What is your teaching role in education?

Teacher in general education setting

Itinerant teacher for multiple math classes

Itinerant teacher for multiple schools

Co-teacher in an inclusive classroom

Other

\section{Previous Training}

7. Which statement best fits your situation?

I have a doctoral degree in education

I have a master's degree in education

I have a bachelor's degree in education

I have a bachelor's degree in another area with general education certification

I have a bachelor's degree in another area with general education permit

8. How many math content (learning mathematics content only and/or including math) courses have you taken (including college)?

$1-2$

3-4

$5-6$

$7-8$

8 or more

9. How many math methods (learning how to teach mathematics) courses have you taken (including college)?

$1-2$

3-4

$5-6$

$7-8$

8 or more

10. How many years of experience do you have in general education?

Less than 1 year

$1-3$

4-9

$10-19$

20 years or more

\section{Certification}

11. What year did you earn your certification? 
Prior to 1997

1997-2003

2004-2009

I do not have my certification

12. Are you certified to teach math?

Yes

No

13. Are you "highly qualified" in math (as defined by NCLB)?

Yes

No

12 a. How did you become "highly qualified" in math?

I completed a set of math courses

I passed a competency test in math

I submitted a portfolio documenting math knowledge

Other (Please explain)

\section{B. Questions for General Education Teachers}

In this section, you will respond to questions about your professional development needs related to mathematics content and mathematics strategies. For the purposes of this study, these are defined as follows:

MATHEMATICS CONTENT- knowledge in the area of Algebra, Geometry, Measurement, Statistics, Probability, Number and Operations, Processes (communication, problem solving, reasoning and proof, representation, and connections)

MATHEMATICS STRATEGIES- specific method or approach to achieve a learning outcome. For example, when teaching the students order of operations using the acrostic poem "PEMDAS."

Professional Development in Mathematics

14. When reflecting on your own math content knowledge and skills (specific to math such as algebra, geometry, measurement, statistics, etc.), how do you rate yourself?

a. Exceptional

b. Above average

c. Average

d.Below average

e.Poor

15. How would you rank your professional development experiences related to mathematics content thus far?
a. Excellent
b.Above Average
c. Average 


\section{d.Below Average \\ e.Poor}

16. How much additional professional development related to mathematics content do you feel that you need?
a. A lot
b.Quite a bit
c. Some
d.A little
e. None

17. If you were to choose ONE area of math that you feel you NEED more knowledge, in what would it be?
a. Algebra
b.Geometry
c. Measurement
d.Statistics
e.Probability

f. Number and Operations

g.Processes (communication, problem solving, reasoning and proof, representation, and connections)

18. If you were to choose ONE area of math that you feel you DO NOT need more knowledge, in what would it be?
a. Algebra
b.Geometry
c. Measurement
d.Statistics
e.Probability

\section{f. Number and Operations}

g.Processes (communication, problem solving, reasoning and proof, representation, and connections)

19. If one or more professional development workshops were provided for you based on the answer you chose in Question 16, what are the chances you would attend voluntarily?
a. Definitely
b.Highly likely
c. Most likely
d.Probably not
e. Would not attend 
20. How much professional development in mathematics content do you feel needs to be provided by your school system?
a. A lot
b.Quite a bit
c. Some
d.A little
e. None

21. How useful do you find the professional development sessions in mathematics content that have already been provided by your school system?
a. Extremely useful
b.Definitely useful
c. Somewhat useful
d.A little useful
e. Not useful

22. Would you consider professional development or attend workshops in mathematics content if your students' math test scores were decreasing?
a. Absolutely
b.Maybe
c. No

23. Would you be as interested in attending professional development workshops in mathematics content if your students' test scores increased?
a. Absolutely
b.Maybe
c. No

24. How many follow-up sessions are you willing to participate in (throughout the school year) after an initial professional development session in mathematics content?
a. None
b. 1
c. 2
d. 3
e. 4
f. 5
g. 6 or more

25. Should math special education teachers and math general education teachers both participate in the SAME professional development sessions in mathematics content?
a. Yes 
b.No

c. Undecided

26. Should you have the SAME professional development needs in mathematics content as a math general education teacher?

a. Yes

b.No

c. Undecided

\section{Professional Development in Teaching Mathematics}

27. When reflecting on your own ability to teach mathematics, how do you rate your skills?
a. Exceptional
b. Above average
c. Average
d.Below average
e.Poor

28. How would you rank your professional development experiences related to teaching mathematics thus far?
a. Excellent
b.Above Average
c. Average
d.Below Average
e.Poor

29. How much additional professional development related to teaching mathematics do you feel that you need?
a. A lot
b.Quite a bit
c. Some
d.A little
e. None

30. If you were to choose ONE area of math that you feel you NEED more strategies in what would it be?
a. Algebra
b.Geometry
c. Measurement
d.Statistics
e.Probability 


\section{f. Number and Operations}

g.Processes (communication, problem solving, reasoning and proof, representation, and connections)

31. If you were to choose ONE area of math that you feel you DO NOT need more strategies in what would it be?
a. Algebra
b.Geometry
c. Measurement
d.Statistics
e.Probability

f. Number and Operations

g.Processes (communication, problem solving, reasoning and proof, representation, and connections)

32. If one or more professional development workshops were provided for you based on the answer you chose in Question 29, what are the chances you would voluntarily attend?
a. Definitely
b.Highly likely
c. Most likely
d.Probably not
e. Would not attend

33. After attending math workshops, how often do you implement the strategies into your class/lessons?
a. All the time
b.Most of the time
c. Some of the time
d.Seldom
e. Never

34. How much professional development in teaching mathematics do you feel needs to be provided by your school system?
a. A lot
b.Quite a bit
c. Some
d.A little
e. None

35. How useful do you find the professional development sessions in teaching strategies for mathematics that have already been provided in your school system? 
a. Extremely useful

b.Definitely useful

c. Somewhat useful

d.A little useful

e. Not useful

36. Would you consider professional development or attending workshops in mathematics strategies if your students' math test scores were decreasing?
a. Absolutely
b.Maybe
c. No

37. Would you be as interested in attending professional development workshops in mathematics strategies if your students' test scores increased?
a. Absolutely
b.Maybe
c. No

38. How many follow-up sessions are you willing to participate in (throughout the school year) after the initial professional development session in mathematics strategies?
a. None
b. 1
c. 2
d. 3
e. 4
f. 5
g. 6 or more

39. Should math special education teachers and math general education teachers both participate in the SAME professional development sessions for mathematics strategies?
a. Yes
b.No
c. Undecided

40. Should you have the SAME professional development needs in mathematics strategies as a math general education teacher?
a. Yes
b.No
c. Undecided

Open-ended Questions and Answers 
41. What is one way you feel math professional development can be improved?

42. How do you incorporate the math professional development that you learn into what you are already doing in your instruction?

Thank you for participating in this study of stakeholder perceptions of math professional development for special educators. I appreciate your willingness to support this research and the time and thought you put into completing the survey questions. If you are interested a separate screen will appear for you to enter the $\$ 100$ Visa gift card drawing. If you are not interested close the screen after it appears. There is no way that your answers will be connected to the personal information you provide in the drawing.

$* * * * * * * * * * * * * * * * * * * * * * * * * * * * * * * * * * * * * * * * * * * * * * * * * * * * * * * * * * * * * * * * * * * * * * * *$

\section{ENTER TO WIN \$100 Visa Gift Card}

Thanks so much in your willingness to participate in my study. Please complete the information below and you will be entered to win the $\$ 100$ Visa Gift card. There is no way that your answers from the survey are connected to your personal information. If you win, the researcher will call you and the prize will be mailed.

Name:

Address:

Phone Number:

Appendix D: Results Tables 
Results Tables

Table E1

Gender (Male or Female) by Survey Item 14 (Math Content Knowledge)

\begin{tabular}{|lccccccc|}
\hline Gender & $\mathrm{N}$ & $\begin{array}{c}\text { Exceptional } \\
(18.7 \%)\end{array}$ & $\begin{array}{c}\text { Above } \\
\text { Average } \\
(15.6 \%)\end{array}$ & $\begin{array}{c}\text { Average } \\
(9.0 \%)\end{array}$ & $\begin{array}{c}\text { Below } \\
\text { Average } \\
(4.4 \%)\end{array}$ & $\begin{array}{c}\text { Poor } \\
(6.7 \%)\end{array}$ & $\begin{array}{c}\text { Chi- } \\
\text { Square }\end{array}$ \\
\hline Male & 57 & 14 & 30 & 13 & 0 & 0 & $\chi 2(4)=11.0$ \\
Female & 379 & $(24.6 \%)$ & $(52.6 \%)$ & $(22.8 \%)$ & $(0 \%)$ & $(0 \%)$ & $p<.05$ \\
& & $(10.8 \%)$ & $(52.5 \%)$ & $(33.5 \%)$ & $(2.9 \%)$ & $(0.3 \%)$ & \\
\hline
\end{tabular}

Note. Values enclosed in parenthesis represent percentage of responses in row. NS= Not statistically significant (at the $p<.05$ level).

Table E2

Gender (Male or Female) by Survey Item 16 (Professional Development Need of Mathematics Content Knowledge

\begin{tabular}{|lccccccc|}
\hline Gender & $\mathrm{N}$ & $\begin{array}{c}\text { A lot } \\
(1.2 \%)\end{array}$ & $\begin{array}{c}\text { Quite a bit } \\
(7.6 \%)\end{array}$ & $\begin{array}{c}\text { Some } \\
(53.0 \%)\end{array}$ & $\begin{array}{c}\text { A Little } \\
(31.6 \%)\end{array}$ & $\begin{array}{c}\text { None } \\
(6.7 \%)\end{array}$ & $\begin{array}{c}\text { Chi- } \\
\text { Square }\end{array}$ \\
\hline Male & 57 & 1 & 8 & 30 & 15 & 3 & $\chi 2(4)=4.5$ \\
& & $(1.8 \%)$ & $(14.0 \%)$ & $(52.6 \%)$ & $(26.3 \%)$ & $(5.3 \%)$ & NS \\
Female & 377 & 4 & 25 & 200 & 122 & 26 & \\
& & $(1.1 \%)$ & $(6.6 \%)$ & $(53.1 \%)$ & $(32.4 \%)$ & $(6.9 \%)$ & \\
\hline
\end{tabular}

Note. Values enclosed in parenthesis represent percentage of responses in row. NS= Not statistically significant (at the $p<.05$ level).

Table E3

Gender (Male or Female) by Survey Item 17 (Need More Knowledge in Subject)

\begin{tabular}{|c|c|c|c|c|c|c|c|c|c|}
\hline Gender & $\mathrm{N}$ & $\begin{array}{l}\text { Algebra } \\
(14.8 \%)\end{array}$ & $\begin{array}{c}\text { Geo. } \\
(10.8 \%)\end{array}$ & $\begin{array}{l}\text { Meas. } \\
(3.8 \%)\end{array}$ & $\begin{array}{c}\text { Statistics } \\
(27.5 \%)\end{array}$ & $\begin{array}{c}\text { Probability } \\
(4.9 \%)\end{array}$ & $\begin{array}{c}\text { \#'s } \\
\text { and } \\
\text { Ops. } \\
(1.9 \%)\end{array}$ & $\begin{array}{l}\text { Process } \\
(36.2 \%)\end{array}$ & $\begin{array}{c}\text { Chi- } \\
\text { Square }\end{array}$ \\
\hline Male & 55 & $\begin{array}{c}10 \\
(18.2 \%)\end{array}$ & $\begin{array}{c}11 \\
(20.0 \%)\end{array}$ & $\begin{array}{c}2 \\
(3.6 \%)\end{array}$ & $\begin{array}{c}15 \\
(27.3 \%)\end{array}$ & $\begin{array}{c}0 \\
(0 \%)\end{array}$ & $\begin{array}{c}0 \\
(0 \%)\end{array}$ & $\begin{array}{c}12 \\
(30.9 \%)\end{array}$ & $\begin{array}{c}\chi 2(6)=10.2 \\
\text { NS }\end{array}$ \\
\hline Female & 370 & $\begin{array}{c}53 \\
(14.3 \%) \\
\end{array}$ & $\begin{array}{c}35 \\
(9.5 \%)\end{array}$ & $\begin{array}{c}14 \\
(3.8 \%)\end{array}$ & $\begin{array}{c}102 \\
(27.6 \%)\end{array}$ & $\begin{array}{c}21 \\
(5.7 \%)\end{array}$ & $\begin{array}{c}8 \\
(2.2 \%) \\
\end{array}$ & $\begin{array}{c}137 \\
(37.0 \%)\end{array}$ & \\
\hline
\end{tabular}

Note. Values enclosed in parenthesis represent percentage of responses in row. NS= Not statistically significant (at the $p<.05$ level). Geo= Geometry. Meas.= Measurement. \#'s and Ops.= Numbers and Operations. Process $=$ Processes (communication, problem solving, reasoning and proof, representation, and connections). 
Table E4

Gender (Male or Female) by Survey Item 18 (Do Not Need More Knowledge in Subject)

\begin{tabular}{|lccccccccc|}
\hline Gender & $\mathrm{N}$ & $\begin{array}{c}\text { Algebra } \\
(20.8 \%)\end{array}$ & $\begin{array}{c}\text { Geo. } \\
(13.1 \%)\end{array}$ & $\begin{array}{c}\text { Meas. } \\
(7.0 \%)\end{array}$ & $\begin{array}{c}\text { Statistics } \\
(3.5 \%)\end{array}$ & $\begin{array}{c}\text { Probability } \\
(5.6 \%)\end{array}$ & $\begin{array}{c}\text { \#'s and } \\
\text { Ops. } \\
(45.7 \%)\end{array}$ & $\begin{array}{c}\text { Process } \\
(4.2 \%)\end{array}$ & $\begin{array}{c}\text { Chi- } \\
\text { Square }\end{array}$ \\
\hline Male & 56 & 18 & 6 & 3 & 4 & 3 & 19 & 3 & $\chi 2(6)=9.1$ \\
& & $(32.1 \%)$ & $(10.7 \%)$ & $(5.4 \%)$ & $(7.1 \%)$ & $(5.4 \%)$ & $(33.9 \%)$ & $(5.4 \%)$ & NS \\
Female & 371 & 71 & 50 & 27 & 11 & 21 & 176 & 15 & \\
& & $(19.1 \%)$ & $(13.5 \%)$ & $(7.3 \%)$ & $(3.0 \%)$ & $(5.7 \%)$ & $(47.4 \%)$ & $(4.0 \%)$ & \\
\hline
\end{tabular}

Note. Values enclosed in parenthesis represent percentage of responses in row. NS= Not statistically significant (at the $p<.05$ level). Geo= Geometry. Meas.= Measurement. \#'s and Ops.= Numbers and Operations. Process $=$ Processes (communication, problem solving, reasoning and proof, representation, and connections).

Table E5

Gender (Male or Female) by Survey Item 27 (Ability to Teach Mathematics)

\begin{tabular}{|lccccccc|}
\hline Gender & $\mathrm{N}$ & $\begin{array}{c}\text { Exceptional } \\
(14.3 \%)\end{array}$ & $\begin{array}{c}\text { Above } \\
\text { Average } \\
(60.6 \%)\end{array}$ & $\begin{array}{c}\text { Average } \\
(24.1 \%)\end{array}$ & $\begin{array}{c}\text { Below } \\
\text { Average } \\
(1.0 \%)\end{array}$ & $\begin{array}{c}\text { Poor } \\
(0 \%)\end{array}$ & $\begin{array}{c}\text { Chi- } \\
\text { Square }\end{array}$ \\
\hline Male & 55 & 12 & 28 & 14 & 1 & 0 & $\chi 2(4)=4.0$ \\
& & $(21.8 \%)$ & $(50.9 \%)$ & $(25.5 \%)$ & $(1.8 \%)$ & $(0 \%)$ & NS \\
Female & 343 & 45 & 213 & 82 & 3 & 0 & \\
& & $(13.1 \%)$ & $(62.1 \%)$ & $(23.9 \%)$ & $(0.9 \%)$ & $(0 \%)$ & \\
\hline
\end{tabular}

Note. Values enclosed in parenthesis represent percentage of responses in row. NS= Not statistically significant (at the $p<.05$ level).

Table E6

Gender (Male or Female) by Survey Item 29 (Professional Development Need for Teaching Mathematics)

\begin{tabular}{|lccccccc|}
\hline Gender & $\mathrm{N}$ & $\begin{array}{c}\text { A lot } \\
(1.3 \%)\end{array}$ & $\begin{array}{c}\text { Quite a bit } \\
(10.6 \%)\end{array}$ & $\begin{array}{c}\text { Some } \\
(41.9 \%)\end{array}$ & $\begin{array}{c}\text { A Little } \\
(39.4 \%)\end{array}$ & $\begin{array}{c}\text { None } \\
(6.8 \%)\end{array}$ & $\begin{array}{c}\text { Chi- } \\
\text { Square }\end{array}$ \\
\hline Male & 33 & 0 & 7 & 17 & 8 & 1 & $\chi 2(4)=8.4$ \\
& & $(0 \%)$ & $(21.2 \%)$ & $(51.5 \%)$ & $(24.2 \%)$ & $(3.0 \%)$ & NS \\
Female & 203 & 3 & 18 & 82 & 85 & 15 & \\
& & $(1.5 \%)$ & $(8.9 \%)$ & $(40.4 \%)$ & $(41.9 \%)$ & $(7.4 \%)$ & \\
\hline
\end{tabular}

Note. Values enclosed in parenthesis represent percentage of responses in row. NS $=$ Not statistically significant (at the $p<.05$ level).

Table E7

Gender (Male or Female) by Survey Item 30 (Need More Strategies for Teaching Mathematics)

\begin{tabular}{|lccccccccc|}
\hline Gender & $\mathrm{N}$ & $\begin{array}{c}\text { Algebra } \\
(15.4 \%)\end{array}$ & $\begin{array}{c}\text { Geo. } \\
(10.4 \%)\end{array}$ & $\begin{array}{c}\text { Meas. } \\
(5.2 \%)\end{array}$ & $\begin{array}{c}\text { Statistics } \\
(20.1 \%)\end{array}$ & $\begin{array}{c}\text { Probability } \\
(4.9 \%)\end{array}$ & $\begin{array}{c}\text { \#'s } \\
\text { and } \\
\text { Ops. } \\
(4.9 \%)\end{array}$ & $\begin{array}{c}\text { Process } \\
(39.0 \%)\end{array}$ & $\begin{array}{c}\text { Chi- } \\
\text { Square }\end{array}$ \\
\hline Male & 54 & 13 & 12 & 2 & 11 & 0 & 2 & 14 & $\chi 2(6)=17.9$
\end{tabular}




\begin{tabular}{|c|c|c|c|c|c|c|c|c|c|}
\hline & & $(24.1 \%)$ & $(22.2 \%)$ & $\begin{array}{l}(3.7 \%) \\
17\end{array}$ & $(20.4 \%)$ & $\begin{array}{c}(0 \%) \\
18\end{array}$ & $\begin{array}{l}(3.7 \%) \\
16\end{array}$ & $\begin{array}{c}(25.9 \%) \\
128\end{array}$ & $p<.05$ \\
\hline Fen & 310 & $\begin{array}{c}43 \\
(13.9 \%)\end{array}$ & $\begin{array}{c}26 \\
(8.4 \%)\end{array}$ & $\begin{array}{c}17 \\
(5.5 \%)\end{array}$ & $\begin{array}{c}62 \\
(20.0 \%)\end{array}$ & $\begin{array}{c}18 \\
(5.8 \%)\end{array}$ & $\begin{array}{c}16 \\
(5.2 \%)\end{array}$ & $\begin{array}{c}128 \\
(41.3 \%)\end{array}$ & \\
\hline
\end{tabular}

Note. Values enclosed in parenthesis represent percentage of responses in row. NS= Not statistically significant (at the $p<.05$ level). Geo= Geometry. Meas.= Measurement. \#'s and Ops. $=$ Numbers and Operations. Process $=$ Processes (communication, problem solving, reasoning and proof, representation, and connections).

Table E8

Gender (Male or Female) by Survey Item 31 (Do Not Need More Strategies for Teaching Mathematics)

\begin{tabular}{|lccccccccc|}
\hline Gender & $\mathrm{N}$ & $\begin{array}{c}\text { Algebra } \\
(18.7 \%)\end{array}$ & $\begin{array}{c}\text { Geo. } \\
(15.6 \%)\end{array}$ & $\begin{array}{c}\text { Meas. } \\
(9.0 \%)\end{array}$ & $\begin{array}{c}\text { Statistics } \\
(4.4 \%)\end{array}$ & $\begin{array}{c}\text { Probability } \\
(6.7 \%)\end{array}$ & $\begin{array}{c}\text { \#'s and } \\
\text { Ops. } \\
(42.1 \%)\end{array}$ & $\begin{array}{c}\text { Process } \\
(3.6 \%)\end{array}$ & $\begin{array}{c}\text { Chi- } \\
\text { Square }\end{array}$ \\
\hline Male & 55 & 16 & 4 & 6 & 4 & 6 & 15 & 4 & $\chi 2(6)=15.5$ \\
& & $(29.1 \%)$ & $(7.3 \%)$ & $(10.9 \%)$ & $(7.3 \%)$ & $(10.9 \%)$ & $(27.3 \%)$ & $(7.3 \%)$ & $p<.05$ \\
Female & 335 & 57 & 57 & 29 & 13 & 20 & 149 & 10 & \\
& & $(17.0 \%)$ & $(17 \%)$ & $(8.7 \%)$ & $(3.9 \%)$ & $(6.0 \%)$ & $(44.5 \%)$ & $(3.0 \%)$ & \\
\hline
\end{tabular}

Note. Values enclosed in parenthesis represent percentage of responses in row. NS= Not statistically significant (at the $p<.05$ level). Geo= Geometry. Meas.= Measurement. \#'s and Ops.= Numbers and Operations. Process $=$ Processes (communication, problem solving, reasoning and proof, representation, and connections). 
Table F1

Number of Math Classes (1, 2, 3, 4, 5, 6 or more) by Survey Item 14 (Math Content Knowledge)

\begin{tabular}{|lccccccc|}
\hline & $\mathrm{N}$ & $\begin{array}{c}\text { Exceptional } \\
(12.6 \%)\end{array}$ & $\begin{array}{c}\text { Above } \\
\text { Average } \\
(52.8 \%)\end{array}$ & $\begin{array}{c}\text { Average } \\
(31.8 \%)\end{array}$ & $\begin{array}{c}\text { Below } \\
\text { Average } \\
(2.6 \%)\end{array}$ & $\begin{array}{c}\text { Poor } \\
(0.2 \%)\end{array}$ & $\begin{array}{c}\text { Chi- } \\
\text { Square }\end{array}$ \\
\hline 1 & 229 & 11 & 115 & 95 & 8 & 0 & $\chi 2(6)=51.0$ \\
& & $(4.8 \%)$ & $(50.2 \%)$ & $(41.5 \%)$ & $(3.5 \%)$ & $(0 \%)$ & $p<.05$ \\
& 73 & 17 & 37 & 16 & 2 & 1 & \\
3 & 44 & $(23.3 \%)$ & $(50.7 \%)$ & $(21.9 \%)$ & $(2.7 \%)$ & $(1.4 \%)$ & \\
& & $(15.9 \%)$ & $(59.1 \%)$ & $(22.7 \%)$ & $(2.3 \%)$ & $(0 \%)$ & \\
4 & 28 & 5 & 17 & 6 & 0 & 0 & \\
& & $(17.9 \%)$ & $(60.7 \%)$ & $(21.4 \%)$ & $(0 \%)$ & $(0 \%)$ & \\
5 & 38 & 10 & 23 & 5 & 0 & 0 & \\
& & $(26.3 \%)$ & $(60.5 \%)$ & $(13.2 \%)$ & $(0 \%)$ & $(0 \%)$ & \\
6 or & 16 & 4 & 8 & 4 & 0 & 0 & \\
more & & $(25.0 \%)$ & $(50.0 \%)$ & $(25.0 \%)$ & $(0 \%)$ & $(0 \%)$ & \\
\hline
\end{tabular}

Note. Values enclosed in parenthesis represent percentage of responses in row. NS= Not statistically significant (at the $p<.05$ level). Geo= Geometry. Meas.= Measurement. \#'s and Ops.= Numbers and Operations. Process $=$ Processes (communication, problem solving, reasoning and proof, representation, and connections).

Table F2

Number of Math Classes (1, 2, 3, 4, 5, 6 or more) by Survey Item 16 (Professional Development Need of Mathematics Content Knowledge)

\begin{tabular}{|lccccccc|}
\hline & $\mathrm{N}$ & $\begin{array}{c}\text { A lot } \\
(1.2 \%)\end{array}$ & $\begin{array}{c}\text { Quite a bit } \\
(7.5 \%)\end{array}$ & $\begin{array}{c}\text { Some } \\
(53.5 \%)\end{array}$ & $\begin{array}{c}\text { A Little } \\
(31.0 \%)\end{array}$ & $\begin{array}{c}\text { None } \\
(6.8 \%)\end{array}$ & $\begin{array}{c}\text { Chi- } \\
\text { Square }\end{array}$ \\
\hline 1 & 227 & 3 & 10 & 133 & 68 & 13 & $\chi 2(4)=22.7$ \\
& & $(1.3 \%)$ & $(4.4 \%)$ & $(58.6 \%)$ & $(30.0 \%)$ & $(5.7 \%)$ & NS \\
2 & 73 & 1 & 9 & 33 & 23 & 7 & \\
& & $(1.4 \%)$ & $(12.3 \%)$ & $(45.2 \%)$ & $(31.5 \%)$ & $(9.6 \%)$ & \\
3 & 44 & 0 & 4 & 22 & 15 & 3 & \\
& & $(0 \%)$ & $(9.1 \%)$ & $(50.0 \%)$ & $(34.1 \%)$ & $(6.8 \%)$ & \\
4 & 28 & 0 & 1 & 15 & 8 & 4 & \\
& & $(0 \%)$ & $(3.6 \%)$ & $(53.6 \%)$ & $(28.6 \%)$ & $(14.3 \%)$ & \\
5 & 38 & 1 & 4 & 18 & 14 & 1 & \\
& & $(2.6 \%)$ & $(10.5 \%)$ & $(47.4 \%)$ & $(36.8 \%)$ & $(2.6 \%)$ & \\
6 or & 16 & 0 & 4 & 7 & 4 & 1 & \\
more & & $(0 \%)$ & $(25.0 \%)$ & $(43.8 \%)$ & $(25.0 \%)$ & $(6.3 \%)$ & \\
\hline
\end{tabular}

Note. Values enclosed in parenthesis represent percentage of responses in row. NS= Not statistically significant (at the $p<.05$ level). 
Table F3

Number of Math Classes (1, 2, 3, 4, 5, 6 or more) by Survey Item 17(Need More Knowledge in Subject)

\begin{tabular}{|c|c|c|c|c|c|c|c|c|c|}
\hline & $\mathrm{N}$ & $\begin{array}{l}\text { Algebra } \\
(14.6 \%)\end{array}$ & $\begin{array}{c}\text { Geo. } \\
(10.5 \%)\end{array}$ & $\begin{array}{l}\text { Meas. } \\
(3.8 \%)\end{array}$ & $\begin{array}{c}\text { Statistics } \\
(28.2 \%)\end{array}$ & $\begin{array}{c}\text { Probability } \\
(4.8 \%)\end{array}$ & $\begin{array}{c}\text { \#'s } \\
\text { and } \\
\text { Ops. } \\
(1.9 \%)\end{array}$ & $\begin{array}{l}\text { Process } \\
(36.1 \%)\end{array}$ & $\begin{array}{l}\text { Chi- } \\
\text { Square }\end{array}$ \\
\hline 1 & 225 & $\begin{array}{c}31 \\
(13.8 \%)\end{array}$ & $\begin{array}{c}18 \\
(8.0 \%)\end{array}$ & $\begin{array}{c}11 \\
(4.9 \%)\end{array}$ & $\begin{array}{c}63 \\
(28.0 \%)\end{array}$ & $\begin{array}{c}8 \\
(3.6 \%)\end{array}$ & $\begin{array}{c}6 \\
(2.7 \%)\end{array}$ & $\begin{array}{c}88 \\
(39.1 \%)\end{array}$ & $\begin{array}{c}\chi^{2(6)}=45.1 \\
p<.05\end{array}$ \\
\hline 2 & 71 & $\begin{array}{c}11 \\
(15.5 \%)\end{array}$ & $\begin{array}{c}4 \\
(5.6 \%)\end{array}$ & $\begin{array}{c}5 \\
(7.0 \%)\end{array}$ & $\begin{array}{c}23 \\
(32.4 \%)\end{array}$ & $\begin{array}{c}1 \\
(1.4 \%)\end{array}$ & $\begin{array}{c}2 \\
(2.8 \%)\end{array}$ & $\begin{array}{c}25 \\
(35.2 \%)\end{array}$ & \\
\hline 3 & 43 & $\begin{array}{c}8 \\
(18.6 \%)\end{array}$ & $\begin{array}{c}9 \\
(20.9 \%)\end{array}$ & $\begin{array}{c}0 \\
(0 \%)\end{array}$ & $\begin{array}{c}15 \\
(34.9 \%)\end{array}$ & $\begin{array}{c}3 \\
(7.0 \%)\end{array}$ & $\begin{array}{c}0 \\
(0 \%)\end{array}$ & $\begin{array}{c}8 \\
(18.6 \%)\end{array}$ & \\
\hline 4 & 27 & $\begin{array}{c}6 \\
(22.2 \%)\end{array}$ & $\begin{array}{c}4 \\
(14.8 \%)\end{array}$ & $\begin{array}{c}0 \\
(0 \%)\end{array}$ & $\begin{array}{c}6 \\
(22.2 \%)\end{array}$ & $\begin{array}{c}2 \\
(7.4 \%)\end{array}$ & $\begin{array}{c}0 \\
(0 \%)\end{array}$ & $\begin{array}{c}9 \\
(33.3 \%)\end{array}$ & \\
\hline 5 & 38 & $\begin{array}{c}3 \\
(7.9 \%)\end{array}$ & $\begin{array}{c}6 \\
(15.8 \%)\end{array}$ & $\begin{array}{c}0 \\
(0 \%)\end{array}$ & $\begin{array}{c}9 \\
(23.7 \%)\end{array}$ & $\begin{array}{c}6 \\
(15.8 \%)\end{array}$ & $\begin{array}{c}0 \\
(0 \%)\end{array}$ & $\begin{array}{c}14 \\
(36.8 \%)\end{array}$ & \\
\hline $\begin{array}{l}6 \text { or } \\
\text { more }\end{array}$ & 14 & $\begin{array}{c}2 \\
(14.3 \%)\end{array}$ & $\begin{array}{c}3 \\
(21.4 \%)\end{array}$ & $\begin{array}{c}0 \\
(0 \%)\end{array}$ & $\begin{array}{c}2 \\
(14.3 \%)\end{array}$ & $\begin{array}{c}0 \\
(0 \%)\end{array}$ & $\begin{array}{c}0 \\
(0 \%)\end{array}$ & $\begin{array}{c}7 \\
(50.0 \%)\end{array}$ & \\
\hline
\end{tabular}

Note. Values enclosed in parenthesis represent percentage of responses in row. NS= Not statistically significant (at the $p<.05$ level). Geo= Geometry. Meas.= Measurement. \#'s and Ops.= Numbers and Operations. Process $=$ Processes (communication, problem solving, reasoning and proof, representation, and connections).

Table F4

Number of Math Classes (1, 2, 3, 4, 5, 6 or more) by Survey Item 18(Do Not Need More Knowledge in Subject)

\begin{tabular}{|lccccccccc|}
\hline & N & $\begin{array}{c}\text { Algebra } \\
(21.0 \%)\end{array}$ & $\begin{array}{c}\text { Geo. } \\
(12.6 \%)\end{array}$ & $\begin{array}{c}\text { Meas. } \\
(6.9 \%)\end{array}$ & $\begin{array}{c}\text { Statistics } \\
(3.6 \%)\end{array}$ & $\begin{array}{c}\text { Probability } \\
(5.7 \%)\end{array}$ & $\begin{array}{c}\text { \#'s and } \\
\text { Ops. } \\
(46.0 \%)\end{array}$ & $\begin{array}{c}\text { Process } \\
(4.3 \%)\end{array}$ & Chi-Square \\
\hline 1 & 225 & 27 & 27 & 20 & 9 & 11 & 122 & 9 & $\chi 2(30)=54.5$ \\
& & $(12.0 \%)$ & $(12.0 \%)$ & $(8.9 \%)$ & $(4.0 \%)$ & $(4.9 \%)$ & $(54.2 \%)$ & $(4.0 \%)$ & $p<.05$ \\
2 & 71 & 18 & 9 & 3 & 2 & 6 & 28 & 5 & \\
& & $(25.4 \%)$ & $(12.7 \%)$ & $(4.2 \%)$ & $(2.8 \%)$ & $(8.5 \%)$ & $(39.4 \%)$ & $(7.0 \%)$ & \\
3 & 44 & 17 & 4 & 2 & 1 & 2 & 16 & 2 & \\
& & $(38.6 \%)$ & $(9.1 \%)$ & $(4.5 \%)$ & $(2.3 \%)$ & $(4.5 \%)$ & $(36.4 \%)$ & $(4.5 \%)$ & \\
4 & 28 & 7 & 1 & 1 & 2 & 2 & 13 & 2 & \\
& & $(25.0 \%)$ & $(3.6 \%)$ & $(3.6 \%)$ & $(7.1 \%)$ & $(7.1 \%)$ & $(46.4 \%)$ & $(7.1 \%)$ & \\
5 & 38 & 15 & 10 & 3 & 1 & 1 & 8 & 0 & \\
& & $(39.5 \%)$ & $(26.3 \%)$ & $(7.9 \%)$ & $(2.6 \%)$ & $(2.6 \%)$ & $(21.2 \%)$ & $(0 \%)$ & \\
6 or & 14 & 4 & 2 & 0 & 0 & 2 & 6 & 0 & \\
more & & $(28.6 \%)$ & $(14.3 \%)$ & $(0 \%)$ & $(0 \%)$ & $(14.3 \%)$ & $(42.9 \%)$ & $(0 \%)$ & \\
\hline
\end{tabular}

Note. Values enclosed in parenthesis represent percentage of responses in row. NS= Not statistically significant (at the $p<.05$ level). Geo= Geometry. Meas.= Measurement. \#'s and Ops.= Numbers and 
Operations. Process $=$ Processes (communication, problem solving, reasoning and proof, representation, and connections). 
Table F5

Number of Math Classes (1, 2, 3, 4, 5, 6 or more) by Survey Item 27(Ability to Teach Mathematics)

\begin{tabular}{|lccccccc|}
\hline & $\mathrm{N}$ & $\begin{array}{c}\text { Exceptional } \\
(14.3 \%)\end{array}$ & $\begin{array}{c}\text { Above } \\
\text { Average } \\
(61.6 \%)\end{array}$ & $\begin{array}{c}\text { Average } \\
(23.5 \%)\end{array}$ & $\begin{array}{c}\text { Below } \\
\text { Average } \\
(1.0 \%)\end{array}$ & $\begin{array}{c}\text { Poor } \\
(0 \%)\end{array}$ & Chi-Square \\
\hline 1 & 202 & 21 & 119 & 60 & 2 & 0 & $\chi 2(20)=19.1$ \\
2 & 68 & $(10.4 \%)$ & $(58.9 \%)$ & $(29.7 \%)$ & $(1.0 \%)$ & $(0 \%)$ & NS \\
& & $(17.6 \%)$ & $(66.2 \%)$ & $(14.7 \%)$ & $(1.5 \%)$ & $(0 \%)$ & \\
3 & 41 & 9 & 24 & 8 & 0 & 0 & \\
& & $(22.0 \%)$ & $(58.5 \%)$ & $(19.5 \%)$ & $(0 \%)$ & $(0 \%)$ & \\
4 & 27 & 5 & 16 & 6 & 0 & 0 & \\
& & $(18.5 \%)$ & $(59.3 \%)$ & $(22.2 \%)$ & $(0 \%)$ & $(0 \%)$ & \\
5 & 37 & 6 & 26 & 5 & 0 & 0 & \\
& & $(16.2 \%)$ & $(70.3 \%)$ & $(13.5 \%)$ & $(0 \%)$ & $(0 \%)$ & \\
6 or & 16 & 3 & 9 & 3 & 1 & 0 & \\
more & & $(18.8 \%)$ & $(56.3 \%)$ & $(18.8 \%)$ & $(6.3 \%)$ & $(0 \%)$ & \\
\hline
\end{tabular}

Note. Values enclosed in parenthesis represent percentage of responses in row. NS= Not statistically significant (at the $p<.05$ level).

Table F6

Number of Math Classes (1, 2, 3, 4, 5, 6 or more) by Survey Item 29 (Professional Development Need for Teaching Math)

\begin{tabular}{|lccccccc|}
\hline & $\mathrm{N}$ & $\begin{array}{c}\text { A lot } \\
(1.3 \%)\end{array}$ & $\begin{array}{c}\text { Quite a bit } \\
(10.8 \%)\end{array}$ & $\begin{array}{c}\text { Some } \\
(42.4 \%)\end{array}$ & $\begin{array}{c}\text { A Little } \\
(38.8 \%)\end{array}$ & $\begin{array}{c}\text { None } \\
(6.9 \%)\end{array}$ & Chi-Square \\
\hline 1 & 110 & 2 & 8 & 45 & 46 & 9 & $\chi 2(20)=16.4$ \\
& & $(1.8 \%)$ & $(7.3 \%)$ & $(40.9 \%)$ & $(41.8 \%)$ & $(8.2 \%)$ & NS \\
2 & 41 & 0 & 7 & 14 & 15 & 5 & \\
& & $(0 \%)$ & $(17.1 \%)$ & $(34.1 \%)$ & $(36.6 \%)$ & $(12.2 \%)$ & \\
3 & 29 & 0 & 3 & 11 & 14 & 1 & \\
& & $(0 \%)$ & $(10.3 \%)$ & $(37.9 \%)$ & $(48.3 \%)$ & $(3.4 \%)$ & \\
4 & 16 & 0 & 2 & 10 & 4 & 0 & \\
& & $(0 \%)$ & $(12.5 \%)$ & $(62.5 \%)$ & $(25.0 \%)$ & $(0 \%)$ & \\
5 & 25 & 1 & 3 & 13 & 7 & 1 & \\
& & $(4.0 \%)$ & $(12.0 \%)$ & $(13.3 \%)$ & $(7.8 \%)$ & $(6.3 \%)$ & \\
6 or & 11 & 0 & 2 & 5 & 4 & 0 & \\
more & & $(0 \%)$ & $(18.2 \%)$ & $(45.5 \%)$ & $(36.4 \%)$ & $(0 \%)$ & \\
\hline
\end{tabular}

Note. Values enclosed in parenthesis represent percentage of responses in row. NS= Not statistically significant (at the $p<.05$ level). 
Table F7

Number of Math Classes (1, 2, 3, 4, 5, 6 or more) by Survey Item 30 (Need More Strategies for Teaching Mathematics)

\begin{tabular}{|lccccccccc|}
\hline & N & $\begin{array}{c}\text { Algebra } \\
(15.1 \%)\end{array}$ & $\begin{array}{c}\text { Geo. } \\
(10.3 \%)\end{array}$ & $\begin{array}{c}\text { Meas. } \\
(5.3 \%)\end{array}$ & $\begin{array}{c}\text { Statistics } \\
(20.7 \%)\end{array}$ & $\begin{array}{c}\text { Probability } \\
(4.7 \%)\end{array}$ & $\begin{array}{c}\text { \#'s } \\
\text { and } \\
\text { Ops. } \\
(5.0 \%)\end{array}$ & $\begin{array}{c}\text { Process } \\
(38.8 \%)\end{array}$ & Chi-Square \\
& & & & & & & & \\
\hline 1 & 187 & 25 & 11 & 13 & 42 & 10 & 11 & 75 & $\chi 2(30)=44.3$ \\
& & $(13.4 \%)$ & $(5.9 \%)$ & $(7.0 \%)$ & $(22.5 \%)$ & $(5.3 \%)$ & $(5.9 \%)$ & $(40.1 \%)$ & $p<.05$ \\
2 & 63 & 11 & 6 & 5 & 12 & 0 & 4 & 25 & \\
& & $(17.5 \%)$ & $(9.5 \%)$ & $(7.9 \%)$ & $(19.0 \%)$ & $(0 \%)$ & $(6.3 \%)$ & $(39.7 \%)$ & \\
3 & 37 & 7 & 9 & 1 & 8 & 5 & 1 & 6 & \\
& & $(18.9 \%)$ & $(24.3 \%)$ & $(2.7 \%)$ & $(21.6 \%)$ & $(13.5 \%)$ & $(2.7 \%)$ & $(16.2 \%)$ & \\
4 & 25 & 5 & 2 & 0 & 5 & 1 & 1 & 11 & \\
& & $(20.0 \%)$ & $(8.0 \%)$ & $(0 \%)$ & $(20.0 \%)$ & $(4.0 \%)$ & $(4.0 \%)$ & $(44.0 \%)$ & \\
5 & 31 & 4 & 7 & 0 & 6 & 0 & 0 & 14 & \\
& & $(12.9 \%)$ & $(22.6 \%)$ & $(0 \%)$ & $(19.4 \%)$ & $(0 \%)$ & $(0 \%)$ & $(45.2 \%)$ & \\
6 or & 15 & 2 & 2 & 0 & 1 & 1 & 1 & 8 & \\
more & & $(13.3 \%)$ & $(13.3 \%)$ & $(0 \%)$ & $(6.7 \%)$ & $(6.7 \%)$ & $(6.7 \%)$ & $(53.3 \%)$ & \\
\hline
\end{tabular}

Note. Values enclosed in parenthesis represent percentage of responses in row. NS= Not statistically significant (at the $p<.05$ level). Geo $=$ Geometry. Meas.= Measurement. \#'s and Ops.= Numbers and Operations. Process $=$ Processes (communication, problem solving, reasoning and proof, representation, and connections).

Table F8

Number of Math Classes (1, 2, 3, 4, 5, 6 or more) by Survey Item 31 (Do Not Need More Strategies for Teaching Mathematics)

\begin{tabular}{|lccccccccc|}
\hline & $\mathrm{N}$ & $\begin{array}{c}\text { Algebra } \\
(18.5 \%)\end{array}$ & $\begin{array}{c}\text { Geo. } \\
(15.4 \%)\end{array}$ & $\begin{array}{c}\text { Meas. } \\
(8.9 \%)\end{array}$ & $\begin{array}{c}\text { Statistics } \\
(4.7 \%)\end{array}$ & $\begin{array}{c}\text { Probability } \\
(6.5 \%)\end{array}$ & $\begin{array}{c}\text { \#'s and } \\
\text { Ops. } \\
(42.4 \%)\end{array}$ & $\begin{array}{c}\text { Process } \\
(3.6 \%)\end{array}$ & Chi-Square \\
\hline 1 & & & & & & & & \\
& & 24 & 29 & 23 & 8 & 10 & 96 & 10 & $\chi 2(30)=50.7$ \\
2 & 67 & 15 & 14 & 4 & 4 & 5 & 24 & 1 & \\
& & $(22.4 \%)$ & $(20.9 \%)$ & $(6.0 \%)$ & $(6.0 \%)$ & $(7.5 \%)$ & $(35.8 \%)$ & $(1.5 \%)$ & \\
3 & 40 & 11 & 2 & 2 & 1 & 5 & 17 & 2 & \\
& & $(27.5 \%)$ & $(5.0 \%)$ & $(5.0 \%)$ & $(2.5 \%)$ & $(12.5 \%)$ & $(42.5 \%)$ & $(5.0 \%)$ & \\
4 & 25 & 5 & 0 & 2 & 1 & 3 & 14 & 0 & \\
& & $(20.0 \%)$ & $(0 \%)$ & $(8.0 \%)$ & $(4.0 \%)$ & $(12.0 \%)$ & $(56.0 \%)$ & $(0 \%)$ & \\
5 & 36 & 13 & 11 & 1 & 3 & 1 & 6 & 1 & \\
& & $(36.1 \%)$ & $(30.6 \%)$ & $(2.8 \%)$ & $(8.3 \%)$ & $(2.8 \%)$ & $(16.7 \%)$ & $(2.8 \%)$ & \\
6 or & 16 & 3 & 3 & 2 & 1 & 1 & 6 & 0 & \\
more & & $(18.8 \%)$ & $(18.8 \%)$ & $(12.5 \%)$ & $(6.3 \%)$ & $(6.3 \%)$ & $(37.5 \%)$ & $(0 \%)$ & \\
\hline
\end{tabular}

Note. Values enclosed in parenthesis represent percentage of responses in row. NS= Not statistically significant (at the $p<.05$ level). Geo= Geometry. Meas.= Measurement. \#'s and Ops.= Numbers and 
Operations. Process $=$ Processes (communication, problem solving, reasoning and proof, representation, and connections). 
Table H1

School Organization (1 Teach, Rotate, or Other) by Survey Item 14 (Math Content Knowledge)

\begin{tabular}{|lccccccc|}
\hline & $\mathrm{N}$ & $\begin{array}{c}\text { Exceptional } \\
(14.5 \%)\end{array}$ & $\begin{array}{c}\text { Above } \\
\text { Average } \\
(52.3 \%)\end{array}$ & $\begin{array}{c}\text { Average } \\
(31.1 \%)\end{array}$ & $\begin{array}{c}\text { Below } \\
\text { Average } \\
(1.8 \%)\end{array}$ & $\begin{array}{c}\text { Poor } \\
(0.3 \%)\end{array}$ & $\begin{array}{c}\text { Chi- } \\
\text { Square }\end{array}$ \\
\hline $1 \mathrm{~T}$ & 171 & 12 & 78 & 74 & 7 & 0 & $\chi 2(8)=45.8$ \\
Rotate & 189 & $(7.0 \%)$ & $(45.6 \%)$ & $(43.3 \%)$ & $(4.1 \%)$ & $(0 \%)$ & $p<.05$ \\
& & $(22.8 \%)$ & $(56.6 \%)$ & $(20.1 \%)$ & $(0 \%)$ & $(0.5 \%)$ & \\
Other & 26 & 1 & 17 & 8 & 0 & 0 & \\
& & $(3.8 \%)$ & $(65.4 \%)$ & $(30.8 \%)$ & $(0 \%)$ & $(0 \%)$ & \\
\hline
\end{tabular}

Note. Values enclosed in parenthesis represent percentage of responses in row. NS= Not statistically significant (at the $p<.05$ level). Process $=$ Processes (communication, problem solving, reasoning and proof, representation, and connections). $1 \mathrm{~T}=$ Students are assigned to one teacher for the majority of the day, and remain with him/her for all core academic subjects. Rotate $=$ Students move from classroom to classroom throughout the day, from one academic subject to another. Other= Math or reading specialists come into teach core academic areas.

Table $\mathrm{H} 2$

School Organization (1 Teach, Rotate, or Other) by Survey Item 16 (Professional Development Need of Mathematics Content Knowledge)

\begin{tabular}{|lccccccc|}
\hline & $\mathrm{N}$ & $\begin{array}{c}\text { A lot } \\
(1.0 \%)\end{array}$ & $\begin{array}{c}\text { Quite a bit } \\
(7.0 \%)\end{array}$ & $\begin{array}{c}\text { Some } \\
(53.0 \%)\end{array}$ & $\begin{array}{c}\text { A Little } \\
(31.9 \%)\end{array}$ & $\begin{array}{c}\text { None } \\
(7.0 \%)\end{array}$ & $\begin{array}{c}\text { Chi- } \\
\text { Square }\end{array}$ \\
\hline $1 \mathrm{~T}$ & 170 & 3 & 15 & 99 & 41 & 12 & $\chi 2(8)=18.6$ \\
& & $(1.8 \%)$ & $(8.8 \%)$ & $(58.2 \%)$ & $(24.1 \%)$ & $(7.1 \%)$ & $p<.05$ \\
Rotate & 189 & 0 & 12 & 88 & 76 & 13 & \\
& & $(0 \%)$ & $(6.3 \%)$ & $(46.6 \%)$ & $(40.2 \%)$ & $(6.9 \%)$ & \\
Other & 26 & 1 & 0 & 17 & 6 & 2 & \\
& & $(3.8 \%)$ & $(0 \%)$ & $(65.4 \%)$ & $(23.1 \%)$ & $(7.7 \%)$ & \\
\hline
\end{tabular}

Note. Values enclosed in parenthesis represent percentage of responses in row. NS= Not statistically significant (at the $p<.05$ level). Process= Processes (communication, problem solving, reasoning and proof, representation, and connections). $1 \mathrm{~T}=$ Students are assigned to one teacher for the majority of the day, and remain with him/her for all core academic subjects. Rotate $=$ Students move from classroom to classroom throughout the day, from one academic subject to another. Other= Math or reading specialists come into teach core academic areas.

Table H3

School Organization (1 Teach, Rotate, or Other) by Survey Item 17 (Need More Knowledge in Subject)

\begin{tabular}{|lccccccccc|}
\hline & $\mathrm{N}$ & $\begin{array}{c}\text { Algebra } \\
(14.4 \%)\end{array}$ & $\begin{array}{c}\text { Geo. } \\
(9.8 \%)\end{array}$ & $\begin{array}{c}\text { Meas. } \\
(3.7 \%)\end{array}$ & $\begin{array}{c}\text { Statistics } \\
(28.5 \%)\end{array}$ & $\begin{array}{c}\text { Probability } \\
(5.3 \%)\end{array}$ & $\begin{array}{c}\text { \#'s } \\
\text { and } \\
\text { Ops. } \\
(2.1 \%)\end{array}$ & $\begin{array}{c}\text { Process } \\
(36.2 \%)\end{array}$ & Chi-Square \\
& & & & & & & \\
\hline $1 \mathrm{~T}$ & 166 & 21 & 10 & 7 & 46 & 7 & 6 & 69 & $\chi 2(12)=14.1$ \\
& & & & & & & & &
\end{tabular}




\begin{tabular}{|lccccccccc|}
\hline & & $(12.7 \%)$ & $(6.0 \%)$ & $(4.2 \%)$ & $(27.7 \%)$ & $(4.2 \%)$ & $(3.6 \%)$ & $(41.6 \%)$ & NS \\
Rotate & 184 & 28 & 25 & 6 & 54 & 12 & 1 & 58 & \\
& & $(15.2 \%)$ & $(13.6 \%)$ & $(3.3 \%)$ & $(29.3 \%)$ & $(6.5 \%)$ & $(0.5 \%)$ & $(31.5 \%)$ & \\
Other & 26 & 5 & 2 & 1 & 7 & 1 & 1 & 9 & \\
& & $(19.2 \%)$ & $(7.7 \%)$ & $(3.8 \%)$ & $(26.9 \%)$ & $(3.8 \%)$ & $(3.8 \%)$ & $(34.6 \%)$ & \\
\hline
\end{tabular}

Note. Values enclosed in parenthesis represent percentage of responses in row. NS= Not statistically significant (at the $p<.05$ level). Process $=$ Processes $($ communication, problem solving, reasoning and proof, representation, and connections). $1 \mathrm{~T}=$ Students are assigned to one teacher for the majority of the day, and remain with him/her for all core academic subjects. Rotate $=$ Students move from classroom to classroom throughout the day, from one academic subject to another. Other= Math or reading specialists come into teach core academic areas. Geo $=$ Geometry. Meas.= Measurement. \#'s and Ops.= Numbers and Operations. Process= Processes (communication, problem solving, reasoning and proof, representation, and connections).

Table H4

School Organization (1 Teach, Rotate, or Other) by Survey Item 18 (Do Not Need More Knowledge in Subject)

\begin{tabular}{|lccccccccc|}
\hline & $\mathrm{N}$ & $\begin{array}{c}\text { Algebra } \\
(22.2 \%)\end{array}$ & $\begin{array}{c}\text { Geo. } \\
(14.3 \%)\end{array}$ & $\begin{array}{c}\text { Meas. } \\
(6.9 \%)\end{array}$ & $\begin{array}{c}\text { Statistics } \\
(3.4 \%)\end{array}$ & $\begin{array}{c}\text { Probability } \\
(5.6 \%)\end{array}$ & $\begin{array}{c}\text { \#'s and } \\
\text { Ops. } \\
(43.7 \%)\end{array}$ & $\begin{array}{c}\text { Process } \\
(4.0 \%)\end{array}$ & Chi-Square \\
\hline $1 \mathrm{~T}$ & 166 & 17 & 25 & 15 & 8 & 8 & 82 & 11 & $\chi 2(12)=43.5$ \\
& & $(10.2 \%)$ & $(15.1 \%)$ & $(9.0 \%)$ & $(4.8 \%)$ & $(4.8 \%)$ & $(49.4 \%)$ & $(6.6 \%)$ & $p<.05$ \\
Rotate & 186 & 64 & 28 & 9 & 4 & 11 & 68 & 2 & \\
& & $(34.4 \%)$ & $(15.1 \%)$ & $(4.8 \%)$ & $(2.2 \%)$ & $(5.9)$ & $(36.6 \%)$ & $(1.1 \%)$ & \\
Other & 26 & 3 & 1 & 2 & 1 & 2 & 15 & 2 & \\
& & $(11.5 \%)$ & $(3.8 \%)$ & $(7.7 \%)$ & $(3.8 \%)$ & $(7.7 \%)$ & $(57.7 \%)$ & $(7.7 \%)$ & \\
\hline
\end{tabular}

Note. Values enclosed in parenthesis represent percentage of responses in row. NS= Not statistically significant (at the $p<.05$ level). Process $=$ Processes (communication, problem solving, reasoning and proof, representation, and connections). $1 \mathrm{~T}=$ Students are assigned to one teacher for the majority of the day, and remain with him/her for all core academic subjects. Rotate $=$ Students move from classroom to classroom throughout the day, from one academic subject to another. Other= Math or reading specialists come into teach core academic areas. Geo $=$ Geometry. Meas. $=$ Measurement. \#'s and Ops. $=$ Numbers and Operations. Process $=$ Processes (communication, problem solving, reasoning and proof, representation, and connections).

Table H5

School Organization (1 Teach, Rotate, or Other) by Survey Item 27(Ability to Teach Mathematics)

\begin{tabular}{|lccccccc|}
\hline & $\mathrm{N}$ & $\begin{array}{c}\text { Exceptional } \\
(16.1 \%)\end{array}$ & $\begin{array}{c}\text { Above } \\
\text { Average } \\
(60.5 \%)\end{array}$ & $\begin{array}{c}\text { Average } \\
(22.3 \%)\end{array}$ & $\begin{array}{c}\text { Below } \\
\text { Average } \\
(1.1 \%)\end{array}$ & $\begin{array}{c}\text { Poor } \\
(0 \%)\end{array}$ & $\begin{array}{c}\text { Chi- } \\
\text { Square }\end{array}$ \\
\hline $1 \mathrm{~T}$ & 155 & 16 & 89 & 47 & 3 & 0 & $\chi^{2}(8)=18.5$ \\
Rotate & 176 & $(10.3 \%)$ & $(57.4 \%)$ & $(30.3 \%)$ & $(1.9 \%)$ & $(0 \%)$ & $p<.05$ \\
& & $(22.2 \%)$ & $(61.4 \%)$ & $(15.9 \%)$ & $(0.6 \%)$ & $(0 \%)$ & \\
Other & 23 & 2 & 17 & 4 & 0 & 0 & \\
& & $(8.7 \%)$ & $(73.9 \%)$ & $(17.4 \%)$ & $(0 \%)$ & $(0 \%)$ & \\
\hline
\end{tabular}


Note. Values enclosed in parenthesis represent percentage of responses in row. NS= Not statistically significant (at the $p<.05$ level). Process= Processes (communication, problem solving, reasoning and proof, representation, and connections). $1 \mathrm{~T}=$ Students are assigned to one teacher for the majority of the day, and remain with him/her for all core academic subjects. Rotate= Students move from classroom to classroom throughout the day, from one academic subject to another. Other= Math or reading specialists come into teach core academic areas. 
Table H6

School Organization (1 Teach, Rotate, or Other) by Survey Item 29 (Professional Development Need for Teaching Math)

\begin{tabular}{|lccccccc|}
\hline & $\mathrm{N}$ & $\begin{array}{c}\text { A lot } \\
(1.4 \%)\end{array}$ & $\begin{array}{c}\text { Quite a bit } \\
(9.6 \%)\end{array}$ & $\begin{array}{c}\text { Some } \\
(42.6 \%)\end{array}$ & $\begin{array}{c}\text { A Little } \\
(41.1 \%)\end{array}$ & $\begin{array}{c}\text { None } \\
(5.3 \%)\end{array}$ & $\begin{array}{c}\text { Chi- } \\
\text { Square }\end{array}$ \\
\hline $1 \mathrm{~T}$ & 87 & 2 & 9 & 42 & 29 & 5 & $\chi 2(8)=6.7$ \\
& & $(2.3 \%)$ & $(10.3 \%)$ & $(48.3 \%)$ & $(33.3 \%)$ & $(5.7 \%)$ & $\mathrm{NS}$ \\
Rotate & 111 & 1 & 11 & 41 & 52 & 6 & \\
& & $(0.9 \%)$ & $(9.9 \%)$ & $(36.9 \%)$ & $(46.8 \%)$ & $(5.4 \%)$ & \\
Other & 11 & 0 & 0 & 6 & 5 & 0 & \\
& & $(0 \%)$ & $(0 \%)$ & $(54.5 \%)$ & $(45.5 \%)$ & $(0 \%)$ & \\
\hline
\end{tabular}

Note. Values enclosed in parenthesis represent percentage of responses in row. NS= Not statistically significant (at the $p<.05$ level). Process $=$ Processes (communication, problem solving, reasoning and proof, representation, and connections). $1 \mathrm{~T}=$ Students are assigned to one teacher for the majority of the day, and remain with him/her for all core academic subjects. Rotate $=$ Students move from classroom to classroom throughout the day, from one academic subject to another. Other= Math or reading specialists come into teach core academic areas.

Table H7

School Organization (1 Teach, Rotate, or Other) by Survey Item 30 (Need More Strategies for Teaching Mathematics)

\begin{tabular}{|lccccccccc|}
\hline & $\mathrm{N}$ & $\begin{array}{c}\text { Algebra } \\
(14.5 \%)\end{array}$ & $\begin{array}{c}\text { Geo } \\
(9.6 \%)\end{array}$ & $\begin{array}{c}\text { Meas. } \\
(5.2 \%)\end{array}$ & $\begin{array}{c}\text { Statistics } \\
(20.4 \%)\end{array}$ & $\begin{array}{c}\text { Probability } \\
(5.2 \%)\end{array}$ & $\begin{array}{c}\text { \#'s } \\
\text { and } \\
\text { Ops. } \\
(4.6 \%)\end{array}$ & $\begin{array}{c}\text { Process } \\
(40.4 \%)\end{array}$ & Chi-Square \\
& & & & & & & & \\
\hline $1 \mathrm{~T}$ & 145 & 17 & 7 & 9 & 24 & 10 & 8 & 70 & $\chi 2(12)=19.9$ \\
& & $(11.5 \%)$ & $(4.8 \%)$ & $(6.2 \%)$ & $(16.6 \%)$ & $(6.9 \%)$ & $(5.5 \%)$ & $(48.3 \%)$ & $p<.05$ \\
Rotate & 157 & 26 & 23 & 7 & 38 & 6 & 5 & 52 & \\
& & $(16.6 \%)$ & $(14.6 \%)$ & $(4.5 \%)$ & $(24.2 \%)$ & $(3.8 \%)$ & $(3.2 \%)$ & $(33.1 \%)$ & \\
Other & 22 & 4 & 1 & 1 & 4 & 1 & 2 & 9 & \\
& & $(18.2 \%)$ & $(4.5 \%)$ & $(4.5 \%)$ & $(18.2 \%)$ & $(4.5 \%)$ & $(9.1 \%)$ & $(40.9 \%)$ & \\
\hline
\end{tabular}

Note. Values enclosed in parenthesis represent percentage of responses in row. NS= Not statistically significant (at the $p<.05$ level). Process= Processes $($ communication, problem solving, reasoning and proof, representation, and connections). $1 \mathrm{~T}=$ Students are assigned to one teacher for the majority of the day, and remain with him/her for all core academic subjects. Rotate $=$ Students move from classroom to classroom throughout the day, from one academic subject to another. Other= Math or reading specialists come into teach core academic areas. Geo $=$ Geometry. Meas.= Measurement. \#'s and Ops.= Numbers and Operations. Process $=$ Processes (communication, problem solving, reasoning and proof, representation, and connections). 
Table H8

School Organization (1 Teach, Rotate, or Other) by Survey Item 31 (Do Not Need More Strategies for Teaching Mathematics)

\begin{tabular}{|lccccccccc|}
\hline & $\mathrm{N}$ & $\begin{array}{c}\text { Algebra } \\
(19.9 \%)\end{array}$ & $\begin{array}{c}\text { Geo } \\
(16.7 \%)\end{array}$ & $\begin{array}{c}\text { Meas. } \\
(8.1 \%)\end{array}$ & $\begin{array}{c}\text { Statistics } \\
(4.9 \%)\end{array}$ & $\begin{array}{c}\text { Probability } \\
(6.3 \%)\end{array}$ & $\begin{array}{c}\text { \#'s and } \\
\text { Ops. } \\
(40.3 \%)\end{array}$ & $\begin{array}{c}\text { Process } \\
(3.7 \%)\end{array}$ & Chi-Square \\
\hline $1 \mathrm{~T}$ & 152 & 15 & 25 & 19 & 8 & 8 & 70 & 7 & $\chi 2(12)=36.7$ \\
& & $(9.9 \%)$ & $(16.4 \%)$ & $(12.5 \%)$ & $(5.3 \%)$ & $(5.3 \%)$ & $(46.1 \%)$ & $(4.6 \%)$ & $p<.05$ \\
Rotate & 173 & 52 & 30 & 8 & 7 & 12 & 61 & 3 & \\
& & $(30.1 \%)$ & $(17.3 \%)$ & $(4.6 \%)$ & $(4.0 \%)$ & $(6.9 \%)$ & $(35.3 \%)$ & $(1.7 \%)$ & \\
Other & 22 & 2 & 3 & 1 & 2 & 2 & 9 & 3 & \\
& & $(9.1 \%)$ & $(13.6 \%)$ & $(4.5 \%)$ & $(9.1 \%)$ & $(9.1 \%)$ & $(40.9 \%)$ & $(13.6 \%)$ & \\
\hline
\end{tabular}

Note. Values enclosed in parenthesis represent percentage of responses in row. NS= Not statistically significant (at the $p<.05$ level). Process= Processes (communication, problem solving, reasoning and proof, representation, and connections). $1 \mathrm{~T}=$ Students are assigned to one teacher for the majority of the day, and remain with him/her for all core academic subjects. Rotate $=$ Students move from classroom to classroom throughout the day, from one academic subject to another. Other= Math or reading specialists come into teach core academic areas. Geo $=$ Geometry. Meas.= Measurement. \#'s and Ops.= Numbers and Operations. Process $=$ Processes (communication, problem solving, reasoning and proof, representation, and connections). 
Table I1

Role in Special Education (Self-Contained, Resource Room, Itinerant, Co-Teaching, or Other) by Survey Item 14 (Math Content Knowledge)

\begin{tabular}{|lccccccc|}
\hline & $\mathrm{N}$ & $\begin{array}{c}\text { Exceptional } \\
(13.1 \%)\end{array}$ & $\begin{array}{c}\text { Above } \\
\text { Average } \\
(51.9 \%)\end{array}$ & $\begin{array}{c}\text { Average } \\
(32.2 \%)\end{array}$ & $\begin{array}{c}\text { Below } \\
\text { Average } \\
(2.6 \%)\end{array}$ & $\begin{array}{c}\text { Poor } \\
(0.2 \%)\end{array}$ & $\begin{array}{c}\text { Chi- } \\
\text { Square }\end{array}$ \\
\hline SC & 380 & 50 & 195 & 125 & 9 & 1 & $\chi 2(16)=9.5$ \\
RR & 19 & $(13.2 \%)$ & $(51.3 \%)$ & $(32.9 \%)$ & $(2.4 \%)$ & $(0.3 \%)$ & NS \\
& & $(21.1 \%)$ & $(52.6 \%)$ & $(26.3 \%)$ & $(0 \%)$ & $(0 \%)$ & \\
I & 4 & 0 & 2 & 2 & 0 & 0 & \\
& & $(0 \%)$ & $(50.0 \%)$ & $(50.0 \%)$ & $(0 \%)$ & $(0 \%)$ & \\
CO & 20 & 2 & 11 & 5 & 2 & 0 & \\
& & $(10.0 \%)$ & $(55.0 \%)$ & $(25.0 \%)$ & $(10.0 \%)$ & $(0 \%)$ & \\
Other & 5 & 0 & 4 & 1 & 0 & 0 & \\
& & $(0 \%)$ & $(80.0 \%)$ & $(20.0 \%)$ & $(0 \%)$ & $(0 \%)$ & \\
\hline
\end{tabular}

Note. Values enclosed in parenthesis represent percentage of responses in row. NS= Not statistically significant (at the $p<.05$ level). SS= Self-contained. RR= Resource room. I= Itinerant for multiple locations. $\mathrm{CO}=\mathrm{Co}$-teaching. Other= Some examples are self-contained itinerant, co-teaching and self-contained.

Table I2

Role in Special Education (Self-Contained, Resource Room, Itinerant, Co-Teaching, or Other) by Survey Item 16 (Professional Development Need of Mathematics Content Knowledge)

\begin{tabular}{|lccccccc|}
\hline & $\mathrm{N}$ & $\begin{array}{c}\text { A lot } \\
(1.2 \%)\end{array}$ & $\begin{array}{c}\text { Quite a bit } \\
(7.7 \%)\end{array}$ & $\begin{array}{c}\text { Some } \\
(53.3 \%)\end{array}$ & $\begin{array}{c}\text { A Little } \\
(31.0 \%)\end{array}$ & $\begin{array}{c}\text { None } \\
(6.8 \%)\end{array}$ & Chi-Square \\
\hline SC & 379 & 5 & 23 & 206 & 117 & 28 & $\chi 2(16)=21.9$ \\
& & $(1.3 \%)$ & $(6.1 \%)$ & $(54.4 \%)$ & $(30.9 \%)$ & $(7.4 \%)$ & NS \\
RR & 19 & 0 & 4 & 9 & 5 & 1 & \\
& & $(0 \%)$ & $(21.1 \%)$ & $(47.4 \%)$ & $(26.3 \%)$ & $(5.3 \%)$ & \\
$\mathrm{I}$ & 4 & 0 & 2 & 1 & 1 & 0 & \\
& & $(0 \%)$ & $(50.0 \%)$ & $(25.0 \%)$ & $(25.0 \%)$ & $(0 \%)$ & \\
$\mathrm{CO}$ & 19 & 0 & 3 & 9 & 7 & 0 & \\
& & $(0 \%)$ & $(15.8 \%)$ & $(47.4 \%)$ & $(36.8 \%)$ & $(0 \%)$ & \\
Other & 5 & 0 & 1 & 2 & 2 & 0 & \\
& & $(0 \%)$ & $(20.0 \%)$ & $(40.0 \%)$ & $(40.0 \%)$ & $(0 \%)$ & \\
\hline
\end{tabular}

Note. Values enclosed in parenthesis represent percentage of responses in row. NS= Not statistically significant (at the $p<.05$ level). SS= Self-contained. RR= Resource room. I= Itinerant for multiple locations. $\mathrm{CO}=\mathrm{Co}$-teaching. Other= Some examples are self-contained itinerant, co-teaching and self-contained. 
Table I3

Role in Special Education (Self-Contained, Resource Room, Itinerant, Co-Teaching, or Other) by Survey Item 17 (Need More Knowledge in Subject)

\begin{tabular}{|lccccccccc|}
\hline & N & $\begin{array}{c}\text { Algebra } \\
(14.9 \%)\end{array}$ & $\begin{array}{c}\text { Geo. } \\
(11.0 \%)\end{array}$ & $\begin{array}{c}\text { Meas. } \\
(3.8 \%)\end{array}$ & $\begin{array}{c}\text { Statistics } \\
(27.8 \%)\end{array}$ & $\begin{array}{c}\text { Probability } \\
(5.0 \%)\end{array}$ & $\begin{array}{c}\text { \#'s } \\
\text { and } \\
\text { Ops. }\end{array}$ & $\begin{array}{c}\text { Process } \\
(35.5 \%)\end{array}$ & Chi-Square \\
& & & & & & & & \\
\hline SC & 369 & 54 & 42 & 15 & 108 & 18 & 7 & 125 & $\chi 2(24)=15.6$ \\
& & $(14.6 \%)$ & $(11.4 \%)$ & $(4.1 \%)$ & $(29.3 \%)$ & $(4.9 \%)$ & $(1.9 \%)$ & $(33.9 \%)$ & NS \\
RR & 19 & 4 & 2 & 1 & 3 & 1 & 0 & 8 & \\
& & $(21.1 \%)$ & $(10.5 \%)$ & $(5.3 \%)$ & $(15.8 \%)$ & $(5.3 \%)$ & $(0 \%)$ & $(42.1 \%)$ & \\
I & 4 & 1 & 0 & 0 & 2 & 0 & 0 & 1 & \\
& & $(25.0 \%)$ & $(0 \%)$ & $(0 \%)$ & $(50.0 \%)$ & $(0 \%)$ & $(0 \%)$ & $(25.0 \%)$ & \\
CO & 20 & 2 & 2 & 0 & 3 & 1 & 1 & 11 & \\
& & $(10.0 \%)$ & $(10.0 \%)$ & $(0 \%)$ & $(15.0 \%)$ & $(5.0 \%)$ & $(5.0 \%)$ & $(55.0 \%)$ & \\
Other & 5 & 1 & 0 & 0 & 0 & 1 & 0 & 3 & \\
& & $(20.0 \%)$ & $(0 \%)$ & $(0 \%)$ & $(0 \%)$ & $(20.0 \%)$ & $(0 \%)$ & $(60.0 \%)$ & \\
\hline
\end{tabular}

Note. Values enclosed in parenthesis represent percentage of responses in row. NS= Not statistically significant (at the $p<.05$ level). SS= Self-contained. $\mathrm{RR}=$ Resource room. I= Itinerant for multiple locations. $\mathrm{CO}=\mathrm{Co}$-teaching. Other= Some examples are self-contained itinerant, co-teaching and self-contained. Geo $=$ Geometry. Meas.= Measurement. \#'s and Ops.= Numbers and Operations. Process $=$ Processes (communication, problem solving, reasoning and proof, representation, and connections).

Table I4

Role in Special Education (Self-Contained, Resource Room, Itinerant, Co-Teaching, or Other) by Survey Item 18 (Do Not Need More Knowledge in Subject)

\begin{tabular}{|lccccccccc|}
\hline & N & $\begin{array}{c}\text { Algebra } \\
(21.0 \%)\end{array}$ & $\begin{array}{c}\text { Geo. } \\
(13.1 \%)\end{array}$ & $\begin{array}{c}\text { Meas. } \\
(6.9 \%)\end{array}$ & $\begin{array}{c}\text { Statistics } \\
(3.6 \%)\end{array}$ & $\begin{array}{c}\text { Probability } \\
(6.0 \%)\end{array}$ & $\begin{array}{c}\text { \#'s and } \\
\text { Ops. } \\
(45.3 \%)\end{array}$ & $\begin{array}{c}\text { Process } \\
(4.1 \%)\end{array}$ & Chi-Square \\
\hline SC & 372 & 83 & 52 & 23 & 13 & 22 & 165 & 14 & $\chi 2(24)=22.7$ \\
& & $(22.3 \%)$ & $(14.0 \%)$ & $(6.2 \%)$ & $(3.5 \%)$ & $(5.9 \%)$ & $(44.4 \%)$ & $(3.8 \%)$ & NS \\
RR & 19 & 2 & 1 & 3 & 1 & 1 & 10 & 1 & \\
& & $(10.5 \%)$ & $(5.3 \%)$ & $(15.8 \%)$ & $(5.3 \%)$ & $(5.3 \%)$ & $(52.6 \%)$ & $(5.3 \%)$ & \\
I & 4 & 1 & 0 & 0 & 0 & 0 & 2 & 1 & \\
& & $(25.0 \%)$ & $(0 \%)$ & $(0 \%)$ & $(0 \%)$ & $(0 \%)$ & $(50.0 \%)$ & $(25.0 \%)$ & \\
CO & 19 & 1 & 1 & 3 & 1 & 2 & 11 & 0 & \\
& & $(5.3 \%)$ & $(5.3 \%)$ & $(15.8 \%)$ & $(5.3 \%)$ & $(10.5 \%)$ & $(57.9 \%)$ & $(0 \%)$ & \\
Other & 5 & 1 & 1 & 0 & 0 & 0 & 2 & 1 & \\
& & $(20.0 \%)$ & $(20.0 \%)$ & $(0 \%)$ & $(0 \%)$ & $(0 \%)$ & $(40.0 \%)$ & $(20.0 \%)$ & \\
\hline
\end{tabular}

Note. Values enclosed in parenthesis represent percentage of responses in row. NS= Not statistically significant (at the $p<.05$ level). $\mathrm{SS}=$ Self-contained. $\mathrm{RR}=$ Resource room. I= Itinerant for multiple locations. $\mathrm{CO}=\mathrm{Co}$-teaching. Other= Some examples are self-contained itinerant, co-teaching and self-contained. $\mathrm{Geo}=$ Geometry. Meas.= Measurement. \#'s and Ops.= Numbers and Operations. 
Process $=$ Processes (communication, problem solving, reasoning and proof, representation, and connections). 
Table I5

Role in Special Education (Self-Contained, Resource Room, Itinerant, Co-Teaching, or Other) by Survey Item 27(Ability to Teach Mathematics)

\begin{tabular}{|lccccccc|}
\hline & $\mathrm{N}$ & $\begin{array}{c}\text { Exceptional } \\
(14.6 \%)\end{array}$ & $\begin{array}{c}\text { Above } \\
\text { Average } \\
(60.3 \%)\end{array}$ & $\begin{array}{c}\text { Average } \\
(24.1 \%)\end{array}$ & $\begin{array}{c}\text { Below } \\
\text { Average } \\
(1.0 \%)\end{array}$ & $\begin{array}{c}\text { Poor } \\
(0 \%)\end{array}$ & $\begin{array}{c}\text { Chi- } \\
\text { Square }\end{array}$ \\
\hline SC & 345 & 49 & 210 & 83 & 3 & 0 & $\chi 2(16)=7.8$ \\
RR & 17 & $(14.2 \%)$ & $(60.9 \%)$ & $(24.1 \%)$ & $(0.9 \%)$ & $(0 \%)$ & NS \\
& & $(17.6 \%)$ & $(52.9 \%)$ & $(29.4 \%)$ & $(0 \%)$ & $(0 \%)$ & \\
I & 4 & 1 & 3 & 0 & 0 & 0 & \\
& & $(25.0 \%)$ & $(75.0 \%)$ & $(0 \%)$ & $(0 \%)$ & $(0 \%)$ & \\
CO & 19 & 4 & 9 & 5 & 1 & 0 & \\
& & $(21.1 \%)$ & $(47.4 \%)$ & $(26.3 \%)$ & $(5.3 \%)$ & $(0 \%)$ & \\
Other & 5 & 0 & 4 & 1 & 0 & 0 & \\
& & $(0 \%)$ & $(80 \%)$ & $(20.0 \%)$ & $(0 \%)$ & $(0 \%)$ & \\
\hline
\end{tabular}

Note. Values enclosed in parenthesis represent percentage of responses in row. NS $=$ Not statistically significant (at the $p<.05$ level). SS= Self-contained. RR= Resource room. I= Itinerant for multiple locations. $\mathrm{CO}=\mathrm{Co}$-teaching. Other $=$ Some examples are self-contained itinerant, co-teaching and self-contained.

Table I6

Role in Special Education (Self-Contained, Resource Room, Itinerant, Co-Teaching, or Other) by Survey Item 29 (Professional Development Need for Teaching Math)

\begin{tabular}{|lccccccc|}
\hline & $\mathrm{N}$ & $\begin{array}{c}\text { A lot } \\
(1.3 \%)\end{array}$ & $\begin{array}{c}\text { Quite a bit } \\
(10.9 \%)\end{array}$ & $\begin{array}{c}\text { Some } \\
(40.9 \%)\end{array}$ & $\begin{array}{c}\text { A Little } \\
(40.4 \%)\end{array}$ & $\begin{array}{c}\text { None } \\
(6.5 \%)\end{array}$ & Chi-Square \\
\hline SC & 198 & 2 & 20 & 78 & 85 & 13 & $\chi 2(16)=21.7$ \\
& & $(1.0 \%)$ & $(10.1 \%)$ & $(39.4 \%)$ & $(42.9 \%)$ & $(6.6 \%)$ & NS \\
RR & 13 & 1 & 1 & 9 & 2 & 0 & \\
& & $(7.7 \%)$ & $(7.7 \%)$ & $(69.2 \%)$ & $(15.4 \%)$ & $(0 \%)$ & \\
I & 4 & 0 & 2 & 0 & 1 & 1 & \\
& & $(0 \%)$ & $(50.0 \%)$ & $(0 \%)$ & $(25.0 \%)$ & $(25.0 \%)$ & \\
CO & 12 & 0 & 2 & 5 & 4 & 1 & \\
& & $(0 \%)$ & $(16.7 \%)$ & $(41.7 \%)$ & $(33.3 \%)$ & $(8.3 \%)$ & \\
Other & 3 & 0 & 0 & 2 & 1 & 0 & \\
& & $(0 \%)$ & $(0 \%)$ & $(66.7 \%)$ & $(33.1 \%)$ & $(0 \%)$ & \\
\hline
\end{tabular}

Note. Values enclosed in parenthesis represent percentage of responses in row. NS= Not statistically significant (at the $p<.05$ level). $\mathrm{SS}=$ Self-contained. $\mathrm{RR}=$ Resource room. I= Itinerant for multiple locations. $\mathrm{CO}=\mathrm{Co}$-teaching. Other= Some examples are self-contained itinerant, co-teaching and self-contained. 
Table I7

Role in Special Education (Self-Contained, Resource Room, Itinerant, Co-Teaching, or Other) by Survey Item 30 (Need More Strategies for Teaching Mathematics)

\begin{tabular}{|lccccccccc|}
\hline & N & $\begin{array}{c}\text { Algebra } \\
(15.8 \%)\end{array}$ & $\begin{array}{c}\text { Geo. } \\
(10.4 \%)\end{array}$ & $\begin{array}{c}\text { Meas. } \\
(5.4 \%)\end{array}$ & $\begin{array}{c}\text { Statistics } \\
(20.3 \%)\end{array}$ & $\begin{array}{c}\text { Probability } \\
(5.1 \%)\end{array}$ & $\begin{array}{c}\text { \#'s and } \\
\text { Ops. } \\
(4.8 \%)\end{array}$ & $\begin{array}{c}\text { Process } \\
(38.3 \%)\end{array}$ & Chi-Square \\
\hline SC & 312 & 46 & 32 & 19 & 66 & 17 & 13 & 119 & $\chi 2(24)=25.1$ \\
& & $(14.7 \%)$ & $(10.3 \%)$ & $(6.1 \%)$ & $(21.2 \%)$ & $(5.4 \%)$ & $(4.2 \%)$ & $(38.1 \%)$ & NS \\
RR & 17 & 5 & 1 & 0 & 2 & 0 & 1 & 8 & \\
& & $(29.4 \%)$ & $(5.9 \%)$ & $(0 \%)$ & $(11.8 \%)$ & $(0 \%)$ & $(5.9 \%)$ & $(47.1 \%)$ & \\
I & 4 & 1 & 1 & 0 & 1 & 1 & 0 & 0 & \\
& & $(25.0 \%)$ & $(25.0 \%)$ & $(0 \%)$ & $(25.0 \%)$ & $(25.0 \%)$ & $(0 \%)$ & $(0 \%)$ & \\
CO & 18 & 2 & 3 & 0 & 3 & 0 & 2 & 8 & \\
& & $(11.1 \%)$ & $(16.7 \%)$ & $(0 \%)$ & $(16.7 \%)$ & $(0 \%)$ & $(11.1 \%)$ & $(44.4 \%)$ & \\
Other & 4 & 2 & 0 & 0 & 0 & 0 & 1 & 1 & \\
& & $(50.0 \%)$ & $(0 \%)$ & $(0 \%)$ & $(0 \%)$ & $(0 \%)$ & $(25.0 \%)$ & $(25.0 \%)$ & \\
\hline
\end{tabular}

Note. Values enclosed in parenthesis represent percentage of responses in row. NS= Not statistically significant (at the $p<.05$ level). SS= Self-contained. RR= Resource room. I= Itinerant for multiple locations. $\mathrm{CO}=\mathrm{Co}$-teaching. Other= Some examples are self-contained itinerant, co-teaching and self-contained. $\mathrm{Geo}=$ Geometry. Meas.= Measurement. \#'s and Ops.= Numbers and Operations. Process $=$ Processes (communication, problem solving, reasoning and proof, representation, and connections).

Table I8

Role in Special Education (Self-Contained, Resource Room, Itinerant, Co-Teaching, or Other) by Survey Item 31 (Do Not Need More Strategies for Teaching Mathematics)

\begin{tabular}{|lccccccccc|}
\hline & N & $\begin{array}{c}\text { Algebra } \\
(18.6 \%)\end{array}$ & $\begin{array}{c}\text { Geo. } \\
(15.7 \%)\end{array}$ & $\begin{array}{c}\text { Meas. } \\
(8.9 \%)\end{array}$ & $\begin{array}{c}\text { Statistics } \\
(4.7 \%)\end{array}$ & $\begin{array}{c}\text { Probability } \\
(6.8 \%)\end{array}$ & $\begin{array}{c}\text { \#'s and } \\
\text { Ops. } \\
(42.1 \%)\end{array}$ & $\begin{array}{c}\text { Process } \\
(3.1 \%)\end{array}$ & Chi-Square \\
\hline SC & 338 & 69 & 58 & 26 & 17 & 22 & 134 & 12 & $\chi 2(24)=28.0$ \\
& & $(20.4 \%)$ & $(17.2 \%)$ & $(7.7 \%)$ & $(5.0 \%)$ & $(6.5 \%)$ & $(39.6 \%)$ & $(3.6 \%)$ & NS \\
RR & 16 & 1 & 1 & 3 & 0 & 1 & 10 & 0 & \\
& & $(6.3 \%)$ & $(6.3 \%)$ & $(18.8 \%)$ & $(0 \%)$ & $(6.3 \%)$ & $(62.5 \%)$ & $(0 \%)$ & \\
I & 4 & 0 & 0 & 1 & 0 & 1 & 2 & 0 & \\
& & $(0 \%)$ & $(0 \%)$ & $(25.0 \%)$ & $(0 \%)$ & $(25.0 \%)$ & $(50.0 \%)$ & $(0 \%)$ & \\
CO & 19 & 0 & 1 & 4 & 1 & 1 & 12 & 0 & \\
& & $(0 \%)$ & $(5.3 \%)$ & $(21.1 \%)$ & $(5.3 \%)$ & $(5.3 \%)$ & $(63.2 \%)$ & $(0 \%)$ & \\
Other & 5 & 1 & 0 & 0 & 0 & 1 & 3 & 0 & \\
& & $(20.0 \%)$ & $(0 \%)$ & $(0 \%)$ & $(0 \%)$ & $(20.0 \%)$ & $(60.0 \%)$ & $(0 \%)$ & \\
\hline
\end{tabular}

Note. Values enclosed in parenthesis represent percentage of responses in row. NS= Not statistically significant (at the $p<.05$ level). SS= Self-contained. $\mathrm{RR}=$ Resource room. I= Itinerant for multiple locations. $\mathrm{CO}=\mathrm{Co}$-teaching. Other= Some examples are self-contained itinerant, co-teaching and self-contained. Geo $=$ Geometry. Meas.= Measurement. \#'s and Ops. = Numbers and Operations. Process $=$ Processes (communication, problem solving, reasoning and proof, representation, and 
connections). 
Table J1

Degree by Survey Item 14 (Math Content Knowledge)

\begin{tabular}{|lccccccc|}
\hline & $\mathrm{N}$ & $\begin{array}{c}\text { Exceptional } \\
(12.9 \%)\end{array}$ & $\begin{array}{c}\text { Above } \\
\text { Average } \\
(52.5 \%)\end{array}$ & $\begin{array}{c}\text { Average } \\
(31.8 \%)\end{array}$ & $\begin{array}{c}\text { Below } \\
\text { Average } \\
(2.5 \%)\end{array}$ & $\begin{array}{c}\text { Poor } \\
(0.2 \%)\end{array}$ & Chi-Square \\
\hline DDSP & 0 & 0 & 0 & 0 & 0 & 0 & $\chi 2(36)=37.1$ \\
MDSP & 1 & $(0 \%)$ & $(0 \%)$ & $(0 \%)$ & $(0 \%)$ & $(0 \%)$ & NS \\
& & $(0 \%)$ & $(0 \%)$ & $(100 \%)$ & $(0 \%)$ & $(0 \%)$ & \\
BDSPC & 37 & 3 & 14 & 18 & 2 & 0 & \\
& & $(8.1 \%)$ & $(37.8 \%)$ & $(48.6 \%)$ & $(5.4 \%)$ & $(0 \%)$ & \\
BDOSP & 17 & 0 & 11 & 5 & 1 & 0 & \\
& & $(0 \%)$ & $(64.7 \%)$ & $(29.4 \%)$ & $(5.9 \%)$ & $(0 \%)$ & \\
BDOP & 9 & 0 & 3 & 5 & 1 & 0 & \\
& & $(0 \%)$ & $(33.3 \%)$ & $(55.6 \%)$ & $(11.1 \%)$ & $(0 \%)$ & \\
DDE & 3 & 0 & 2 & 1 & 0 & 0 & \\
& & $(0 \%)$ & $(66.7 \%)$ & $(33.3 \%)$ & $(0 \%)$ & $(0 \%)$ & \\
MDE & 233 & 38 & 124 & 68 & 2 & 1 & \\
& & $(16.3 \%)$ & $(53.2 \%)$ & $(29.2 \%)$ & $(0.9 \%)$ & $(0.4 \%)$ & \\
BDE & 110 & 9 & 59 & 37 & 5 & 0 & \\
& & $(8.2 \%)$ & $(53.6 \%)$ & $(33.6 \%)$ & $(4.5 \%)$ & $(0 \%)$ & \\
BDOGC & 22 & 6 & 13 & 3 & 0 & 0 & \\
& & $(27.3 \%)$ & $(59.1 \%)$ & $(13.6 \%)$ & $(0 \%)$ & $(0 \%)$ & \\
BDOGP & 2 & 0 & 2 & 0 & 0 & 0 & \\
& & $(0 \%)$ & $(100 \%)$ & $(0 \%)$ & $(0 \%)$ & $(0 \%)$ & \\
\hline
\end{tabular}

Note. Values enclosed in parenthesis represent percentage of responses in row. NS= Not statistically significant (at the $p<.05$ level). DDSP $=$ doctoral degree in special education. MDSP $=$ master's degree in special education. BDSPC= bachelor's degree in special education with special education certification. $\mathrm{BDOSP}=$ bachelor's degree in another area with special education certification. $\mathrm{BDOP}=$ bachelor's degree in another area with special education permit. $\mathrm{DDE}=$ doctoral degree in education. $\mathrm{MDE}=$ master's degree in education. $\mathrm{BDE}=$ bachelor's degree in education. $\mathrm{BDOGC}=$ bachelor's degree in another area with general education certification. BDOGP $=$ bachelor's degree in another area with general education permit. 
Table $\mathbf{J} 2$

Degree by Survey Item 16 (Professional Development Need of Mathematics Content Knowledge)

\begin{tabular}{|lccccccc|}
\hline & $\mathrm{N}$ & $\begin{array}{c}\text { A lot } \\
(1.2 \%)\end{array}$ & $\begin{array}{c}\text { Quite a bit } \\
(7.6 \%)\end{array}$ & $\begin{array}{c}\text { Some } \\
(53.2 \%)\end{array}$ & $\begin{array}{c}\text { A Little } \\
(31.5 \%)\end{array}$ & $\begin{array}{c}\text { None } \\
(6.5 \%)\end{array}$ & Chi-Square \\
\hline DDSP & 0 & 0 & 0 & 0 & 0 & 0 & $\chi 2(36)=96.9$ \\
& & $(0 \%)$ & $(0 \%)$ & $(0 \%)$ & $(0 \%)$ & $(0 \%)$ & $p<.05$ \\
MDSP & 1 & 0 & 0 & 0 & 0 & 1 & \\
& & $(0 \%)$ & $(0 \%)$ & $(0 \%)$ & $(0 \%)$ & $(100 \%)$ & \\
BDSPC & 37 & 0 & 3 & 22 & 10 & 2 & \\
& & $(0 \%)$ & $(8.1 \%)$ & $(59.5 \%)$ & $(27.0 \%)$ & $(5.4 \%)$ & \\
BDOSP & 16 & 0 & 5 & 7 & 4 & 0 & \\
& & $(0 \%)$ & $(31.3 \%)$ & $(43.8 \%)$ & $(25.0 \%)$ & $(0 \%)$ & \\
BDOP & 9 & 0 & 6 & 2 & 1 & 0 & \\
& & $(0 \%)$ & $(66.7 \%)$ & $(22.2 \%)$ & $(11.1 \%)$ & $(0 \%)$ & \\
DDE & 3 & 0 & 0 & 1 & 2 & 0 & \\
& & $(0 \%)$ & $(0 \%)$ & $(33.3 \%)$ & $(66.7 \%)$ & $(0 \%)$ & \\
MDE & 232 & 4 & 13 & 118 & 79 & 18 & \\
& & $(1.7 \%)$ & $(5.6 \%)$ & $(50.9 \%)$ & $(34.1 \%)$ & $(7.8 \%)$ & \\
BDE & 110 & 1 & 6 & 67 & 34 & 2 & \\
& & $(0.9 \%)$ & $(5.5 \%)$ & $(60.9 \%)$ & $(30.9 \%)$ & $(1.8 \%)$ & \\
BDOGC & 22 & 0 & 0 & 11 & 6 & 5 & \\
& & $(0 \%)$ & $(0 \%)$ & $(50.0 \%)$ & $(27.3 \%)$ & $(22.7 \%)$ & \\
BDOGP & 2 & 0 & 0 & 2 & 0 & 0 & \\
& & $(0 \%)$ & $(0 \%)$ & $(0.5 \%)$ & $(0 \%)$ & $(0 \%)$ & \\
\hline
\end{tabular}

Note. Values enclosed in parenthesis represent percentage of responses in row. NS= Not statistically significant (at the $p<.05$ level). DDSP $=$ doctoral degree in special education. MDSP $=$ master's degree in special education. BDSPC= bachelor's degree in special education with special education certification. $\mathrm{BDOSP}=$ bachelor's degree in another area with special education certification. $\mathrm{BDOP}=$ bachelor's degree in another area with special education permit. $\mathrm{DDE}=$ doctoral degree in education. $\mathrm{MDE}=$ master's degree in education. $\mathrm{BDE}=$ bachelor's degree in education. $\mathrm{BDOGC}=$ bachelor's degree in another area with general education certification. BDOGP= bachelor's degree in another area with general education permit. 
Table J3

Degree by Survey Item 17 (Need More Knowledge in Subject)

\begin{tabular}{|c|c|c|c|c|c|c|c|c|c|}
\hline & $\mathrm{N}$ & $\begin{array}{l}\text { Algebra } \\
(14.4 \%)\end{array}$ & $\begin{array}{c}\text { Geo. } \\
(10.9 \%)\end{array}$ & $\begin{array}{l}\text { Meas. } \\
(3.8 \%)\end{array}$ & $\begin{array}{l}\text { Statistics } \\
(28.1 \%)\end{array}$ & $\begin{array}{c}\text { Probability } \\
(5.2 \%)\end{array}$ & $\begin{array}{c}\text { \#'s } \\
\text { and } \\
\text { Ops. } \\
(1.9 \%)\end{array}$ & $\begin{array}{l}\text { Process } \\
(35.7 \%)\end{array}$ & Chi-Square \\
\hline DDSP & 0 & $\begin{array}{c}0 \\
(0 \%)\end{array}$ & $\begin{array}{c}0 \\
(0 \%)\end{array}$ & $\begin{array}{c}0 \\
(0 \%)\end{array}$ & $\begin{array}{c}0 \\
(0 \%)\end{array}$ & $\begin{array}{c}0 \\
(0 \%)\end{array}$ & $\begin{array}{c}0 \\
(0 \%)\end{array}$ & $\begin{array}{c}0 \\
(0 \%)\end{array}$ & $\begin{array}{c}\chi 2(72)=55.1 \\
\text { NS }\end{array}$ \\
\hline MDSP & 1 & $\begin{array}{c}1 \\
(100 \%)\end{array}$ & $\begin{array}{c}0 \\
(0 \%)\end{array}$ & $\begin{array}{c}0 \\
(0 \%)\end{array}$ & $\begin{array}{c}0 \\
(0 \%)\end{array}$ & $\begin{array}{c}0 \\
(0 \%)\end{array}$ & $\begin{array}{c}0 \\
(0 \%)\end{array}$ & $\begin{array}{c}0 \\
(0 \%)\end{array}$ & \\
\hline BDSPC & 36 & $\begin{array}{c}3 \\
(8.3 \%)\end{array}$ & $\begin{array}{c}7 \\
(19.4 \%)\end{array}$ & $\begin{array}{c}0 \\
(0 \%)\end{array}$ & $\begin{array}{c}6 \\
(16.7 \%)\end{array}$ & $\begin{array}{c}4 \\
(11.1 \%)\end{array}$ & $\begin{array}{c}2 \\
(5.6 \%)\end{array}$ & $\begin{array}{c}14 \\
(38.9 \%)\end{array}$ & \\
\hline BDOSP & 17 & $\begin{array}{c}2 \\
(11.8 \%)\end{array}$ & $\begin{array}{c}3 \\
(17.6 \%)\end{array}$ & $\begin{array}{c}1 \\
(5.9 \%)\end{array}$ & $\begin{array}{c}4 \\
(23.5 \%)\end{array}$ & $\begin{array}{c}0 \\
(0 \%)\end{array}$ & $\begin{array}{c}0 \\
(0 \%)\end{array}$ & $\begin{array}{c}7 \\
(41.2 \%)\end{array}$ & \\
\hline BDOP & 9 & $\begin{array}{c}1 \\
(11.1 \%)\end{array}$ & $\begin{array}{c}3 \\
(33.3 \%)\end{array}$ & $\begin{array}{c}0 \\
(0 \%)\end{array}$ & $\begin{array}{c}1 \\
(11.1 \%)\end{array}$ & $\begin{array}{c}0 \\
(0 \%)\end{array}$ & $\begin{array}{c}0 \\
(0 \%)\end{array}$ & $\begin{array}{c}4 \\
(44.4 \%)\end{array}$ & \\
\hline DDE & 3 & $\begin{array}{c}0 \\
(0 \%)\end{array}$ & $\begin{array}{c}1 \\
(33.3 \%)\end{array}$ & $\begin{array}{c}0 \\
(0 \%)\end{array}$ & $\begin{array}{c}1 \\
(33.3 \%)\end{array}$ & $\begin{array}{c}0 \\
(0 \%)\end{array}$ & $\begin{array}{c}0 \\
(0 \%)\end{array}$ & $\begin{array}{c}1 \\
(33.3 \%)\end{array}$ & \\
\hline MDE & 224 & $\begin{array}{c}38 \\
(17.0 \%)\end{array}$ & $\begin{array}{c}17 \\
(7.6 \%)\end{array}$ & $\begin{array}{c}7 \\
(3.1 \%)\end{array}$ & $\begin{array}{c}66 \\
(29.5 \%)\end{array}$ & $\begin{array}{c}12 \\
(5.4 \%)\end{array}$ & $\begin{array}{c}3 \\
(1.3 \%)\end{array}$ & $\begin{array}{c}81 \\
(36.2 \%)\end{array}$ & \\
\hline $\mathrm{BDE}$ & 110 & $\begin{array}{c}15 \\
(13.6 \%)\end{array}$ & $\begin{array}{c}11 \\
(10.0 \%)\end{array}$ & $\begin{array}{c}8 \\
(7.3 \%)\end{array}$ & $\begin{array}{c}27 \\
(24.5 \%)\end{array}$ & $\begin{array}{c}5 \\
(4.5 \%)\end{array}$ & $\begin{array}{c}3 \\
(2.7 \%)\end{array}$ & $\begin{array}{c}41 \\
(37.3 \%)\end{array}$ & \\
\hline BDOGC & 21 & $\begin{array}{c}1 \\
(4.8 \%)\end{array}$ & $\begin{array}{c}4 \\
(19.0 \%)\end{array}$ & $\begin{array}{c}0 \\
(0 \%)\end{array}$ & $\begin{array}{c}12 \\
(57.1 \%)\end{array}$ & $\begin{array}{c}1 \\
(4.8 \%)\end{array}$ & $\begin{array}{c}0 \\
(0 \%)\end{array}$ & $\begin{array}{c}3 \\
(14.3 \%)\end{array}$ & \\
\hline BDOGP & 2 & $\begin{array}{c}0 \\
(0 \%)\end{array}$ & $\begin{array}{c}0 \\
(0 \%)\end{array}$ & $\begin{array}{c}0 \\
(0 \%)\end{array}$ & $\begin{array}{c}2 \\
(100 \%)\end{array}$ & $\begin{array}{c}0 \\
(0 \%)\end{array}$ & $\begin{array}{c}0 \\
(0 \%) \\
\end{array}$ & $\begin{array}{c}0 \\
(0 \%)\end{array}$ & \\
\hline
\end{tabular}

Note. Values enclosed in parenthesis represent percentage of responses in row. NS= Not statistically significant (at the $p<.05$ level). DDSP $=$ doctoral degree in special education. MDSP $=$ master's degree in special education. BDSPC $=$ bachelor's degree in special education with special education certification. $\mathrm{BDOSP}=$ bachelor's degree in another area with special education certification. $\mathrm{BDOP}=$ bachelor's degree in another area with special education permit. $\mathrm{DDE}=$ doctoral degree in education. $\mathrm{MDE}=$ master's degree in education. $\mathrm{BDE}=$ bachelor's degree in education. $\mathrm{BDOGC}=$ bachelor's degree in another area with general education certification. BDOGP $=$ bachelor's degree in another area with general education permit. $\mathrm{Geo}=$ Geometry. Meas.= Measurement. \#'s and Ops. $=$ Numbers and Operations. Process $=$ Processes (communication, problem solving, reasoning and proof, representation, and connections). 
Table J4

Degree by Survey Item 18 (Do Not Need More Knowledge in Subject)

\begin{tabular}{|c|c|c|c|c|c|c|c|c|c|}
\hline & $\mathrm{N}$ & $\begin{array}{l}\text { Algebra } \\
(21.2 \%)\end{array}$ & $\begin{array}{c}\text { Geo. } \\
(12.9 \%)\end{array}$ & $\begin{array}{l}\text { Meas. } \\
(6.8 \%)\end{array}$ & $\begin{array}{c}\text { Statistics } \\
(3.5 \%)\end{array}$ & $\begin{array}{c}\text { Probability } \\
(5.6 \%)\end{array}$ & $\begin{array}{c}\text { \#'s and } \\
\text { Ops. } \\
(45.6 \%)\end{array}$ & $\begin{array}{c}\text { Process } \\
(4.2 \%)\end{array}$ & Chi-Square \\
\hline DDSP & 0 & $\begin{array}{c}0 \\
(0 \%)\end{array}$ & $\begin{array}{c}0 \\
(0 \%)\end{array}$ & $\begin{array}{c}0 \\
(0 \%)\end{array}$ & $\begin{array}{c}0 \\
(0 \%)\end{array}$ & $\begin{array}{c}0 \\
(0 \%)\end{array}$ & $\begin{array}{c}0 \\
(0 \%)\end{array}$ & $\begin{array}{c}0 \\
(0 \%)\end{array}$ & $\begin{array}{c}\chi 2(72)=61.1 \\
\text { NS }\end{array}$ \\
\hline MDSP & 1 & $\begin{array}{c}0 \\
(0 \%)\end{array}$ & $\begin{array}{c}0 \\
(0 \%)\end{array}$ & $\begin{array}{c}0 \\
(0 \%)\end{array}$ & $\begin{array}{c}0 \\
(0 \%)\end{array}$ & $\begin{array}{c}0 \\
(0 \%)\end{array}$ & $\begin{array}{c}1 \\
(100 \%)\end{array}$ & $\begin{array}{c}0 \\
(0 \%)\end{array}$ & \\
\hline BDSPC & 35 & $\begin{array}{c}9 \\
(25.7 \%)\end{array}$ & $\begin{array}{c}4 \\
(11.4 \%)\end{array}$ & $\begin{array}{c}2 \\
(5.7 \%)\end{array}$ & $\begin{array}{c}0 \\
(0 \%)\end{array}$ & $\begin{array}{c}0 \\
(0 \%)\end{array}$ & $\begin{array}{c}18 \\
(51.4 \%)\end{array}$ & $\begin{array}{c}2 \\
(5.7 \%)\end{array}$ & \\
\hline BDOSP & 16 & $\begin{array}{c}0 \\
(0 \%)\end{array}$ & $\begin{array}{c}1 \\
(6.3 \%)\end{array}$ & $\begin{array}{c}1 \\
(6.3 \%)\end{array}$ & $\begin{array}{c}2 \\
(12.5 \%)\end{array}$ & $\begin{array}{c}1 \\
(6.3 \%)\end{array}$ & $\begin{array}{c}8 \\
(50.0 \%)\end{array}$ & $\begin{array}{c}3 \\
(18.8 \%)\end{array}$ & \\
\hline BDOP & 9 & $\begin{array}{c}1 \\
(11.1 \%)\end{array}$ & $\begin{array}{c}0 \\
(0 \%)\end{array}$ & $\begin{array}{c}0 \\
(0 \%)\end{array}$ & $\begin{array}{c}0 \\
(0 \%)\end{array}$ & $\begin{array}{c}2 \\
(22.2 \%)\end{array}$ & $\begin{array}{c}6 \\
(66.7 \%)\end{array}$ & $\begin{array}{c}0 \\
(0 \%)\end{array}$ & \\
\hline DDE & 3 & $\begin{array}{c}1 \\
(33.3 \%)\end{array}$ & $\begin{array}{c}0 \\
(0 \%)\end{array}$ & $\begin{array}{c}0 \\
(0 \%)\end{array}$ & $\begin{array}{c}0 \\
(0 \%)\end{array}$ & $\begin{array}{c}0 \\
(0 \%)\end{array}$ & $\begin{array}{c}2 \\
(44.1 \%)\end{array}$ & $\begin{array}{c}0 \\
(0 \%)\end{array}$ & \\
\hline MDE & 229 & $\begin{array}{c}50 \\
(21.8 \%)\end{array}$ & $\begin{array}{c}31 \\
(13.5 \%)\end{array}$ & $\begin{array}{c}16 \\
(7.0 \%)\end{array}$ & $\begin{array}{c}8 \\
(3.5 \%)\end{array}$ & $\begin{array}{c}11 \\
(4.8 \%)\end{array}$ & $\begin{array}{c}101 \\
(44.1 \%)\end{array}$ & $\begin{array}{c}12 \\
(5.2 \%)\end{array}$ & \\
\hline $\mathrm{BDE}$ & 109 & $\begin{array}{c}16 \\
(14.7 \%)\end{array}$ & $\begin{array}{c}16 \\
(14.7 \%)\end{array}$ & $\begin{array}{c}10 \\
(9.2 \%)\end{array}$ & $\begin{array}{c}5 \\
(4.6 \%)\end{array}$ & $\begin{array}{c}9 \\
(8.3 \%)\end{array}$ & $\begin{array}{c}52 \\
(47.7 \%)\end{array}$ & $\begin{array}{c}1 \\
(0.9 \%)\end{array}$ & \\
\hline BDOGC & 21 & $\begin{array}{c}11 \\
(52.4 \%)\end{array}$ & $\begin{array}{c}3 \\
(14.3 \%)\end{array}$ & $\begin{array}{c}0 \\
(0 \%)\end{array}$ & $\begin{array}{c}0 \\
(0 \%)\end{array}$ & $\begin{array}{c}1 \\
(4.8 \%)\end{array}$ & $\begin{array}{c}6 \\
(28.6 \%)\end{array}$ & $\begin{array}{c}0 \\
(0 \%)\end{array}$ & \\
\hline BDOGP & 2 & $\begin{array}{c}2 \\
(100 \%)\end{array}$ & $\begin{array}{c}0 \\
(0 \%)\end{array}$ & $\begin{array}{c}0 \\
(0 \%)\end{array}$ & $\begin{array}{c}0 \\
(0 \%)\end{array}$ & $\begin{array}{c}0 \\
(0 \%)\end{array}$ & $\begin{array}{c}0 \\
(0 \%)\end{array}$ & $\begin{array}{c}0 \\
(0 \%)\end{array}$ & \\
\hline
\end{tabular}

Note. Values enclosed in parenthesis represent percentage of responses in row. NS= Not statistically significant (at the $p<.05$ level). DDSP $=$ doctoral degree in special education. MDSP $=$ master's degree in special education. BDSPC= bachelor's degree in special education with special education certification. BDOSP $=$ bachelor's degree in another area with special education certification. $\mathrm{BDOP}=$ bachelor's degree in another area with special education permit. $\mathrm{DDE}=$ doctoral degree in education. $\mathrm{MDE}=$ master's degree in education. $\mathrm{BDE}=$ bachelor's degree in education. $\mathrm{BDOGC}=$ bachelor's degree in another area with general education certification. BDOGP $=$ bachelor's degree in another area with general education permit. $\mathrm{Geo}=$ Geometry. Meas.= Measurement. \#'s and Ops.= Numbers and Operations. Process $=$ Processes (communication, problem solving, reasoning and proof, representation, and connections). 
Table J5

Degree by Survey Item 27(Ability to Teach Mathematics)

\begin{tabular}{|c|c|c|c|c|c|c|c|}
\hline & $\mathrm{N}$ & $\begin{array}{c}\text { Exceptional } \\
(14.6 \%)\end{array}$ & $\begin{array}{c}\text { Above } \\
\text { Average } \\
(60.9 \%)\end{array}$ & $\begin{array}{l}\text { Average } \\
(23.5 \%)\end{array}$ & $\begin{array}{c}\text { Below } \\
\text { Average } \\
(1.0 \%)\end{array}$ & $\begin{array}{l}\text { Poor } \\
(0 \%)\end{array}$ & Chi-Square \\
\hline DDSP & 0 & $\begin{array}{c}0 \\
(0 \%)\end{array}$ & $\begin{array}{c}0 \\
(0 \%)\end{array}$ & $\begin{array}{c}0 \\
(0 \%)\end{array}$ & $\begin{array}{c}0 \\
(0 \%)\end{array}$ & $\begin{array}{c}0 \\
(0 \%)\end{array}$ & $\begin{array}{c}\chi 2(36)=37.3 \\
p<.05\end{array}$ \\
\hline MDSP & 1 & $\begin{array}{c}0 \\
(0 \%)\end{array}$ & $\begin{array}{c}0 \\
(0 \%)\end{array}$ & $\begin{array}{c}1 \\
(100 \%)\end{array}$ & $\begin{array}{c}0 \\
(0 \%)\end{array}$ & $\begin{array}{c}0 \\
(0 \%)\end{array}$ & \\
\hline BDSPC & 34 & $\begin{array}{c}5 \\
(14.7 \%)\end{array}$ & $\begin{array}{c}12 \\
(35.3 \%)\end{array}$ & $\begin{array}{c}16 \\
(47.1 \%)\end{array}$ & $\begin{array}{c}1 \\
(2.9 \%)\end{array}$ & $\begin{array}{c}0 \\
(0 \%)\end{array}$ & \\
\hline BDOSP & 16 & $\begin{array}{c}0 \\
(0 \%)\end{array}$ & $\begin{array}{c}11 \\
(68.8 \%)\end{array}$ & $\begin{array}{c}5 \\
(31.3 \%)\end{array}$ & $\begin{array}{c}0 \\
(0 \%)\end{array}$ & $\begin{array}{c}0 \\
(0 \%)\end{array}$ & \\
\hline BDOP & 7 & $\begin{array}{c}0 \\
(0 \%)\end{array}$ & $\begin{array}{c}4 \\
(57.1 \%)\end{array}$ & $\begin{array}{c}3 \\
(42.9 \%)\end{array}$ & $\begin{array}{c}0 \\
(0 \%)\end{array}$ & $\begin{array}{c}0 \\
(0 \%)\end{array}$ & \\
\hline DDE & 3 & $\begin{array}{c}0 \\
(0 \%)\end{array}$ & $\begin{array}{c}2 \\
(66.7 \%)\end{array}$ & $\begin{array}{c}1 \\
(33.3 \%)\end{array}$ & $\begin{array}{c}0 \\
(0 \%)\end{array}$ & $\begin{array}{c}0 \\
(0 \%)\end{array}$ & \\
\hline MDE & 215 & $\begin{array}{c}40 \\
(18.6 \%)\end{array}$ & $\begin{array}{c}134 \\
(62.3 \%)\end{array}$ & $\begin{array}{c}40 \\
(18.6 \%)\end{array}$ & $\begin{array}{c}1 \\
(0.5 \%)\end{array}$ & $\begin{array}{c}0 \\
(0 \%)\end{array}$ & \\
\hline $\mathrm{BDE}$ & 97 & $\begin{array}{c}7 \\
(7.2 \%)\end{array}$ & $\begin{array}{c}65 \\
(67.0 \%)\end{array}$ & $\begin{array}{c}23 \\
(23.7 \%)\end{array}$ & $\begin{array}{c}2 \\
(2.1 \%)\end{array}$ & $\begin{array}{c}0 \\
(0 \%)\end{array}$ & \\
\hline BDOGC & 21 & $\begin{array}{c}6 \\
(28.6 \%)\end{array}$ & $\begin{array}{c}11 \\
(52.4 \%)\end{array}$ & $\begin{array}{c}4 \\
(19.0 \%)\end{array}$ & $\begin{array}{c}0 \\
(0 \%)\end{array}$ & $\begin{array}{c}0 \\
(0 \%)\end{array}$ & \\
\hline BDOGP & 2 & $\begin{array}{c}0 \\
(0 \%)\end{array}$ & $\begin{array}{c}2 \\
(100 \%)\end{array}$ & $\begin{array}{c}0 \\
(0 \%)\end{array}$ & $\begin{array}{c}0 \\
(0 \%)\end{array}$ & $\begin{array}{c}0 \\
(0 \%)\end{array}$ & \\
\hline
\end{tabular}

Note. Values enclosed in parenthesis represent percentage of responses in row. NS= Not statistically significant (at the $p<.05$ level). DDSP $=$ doctoral degree in special education. MDSP $=$ master's degree in special education. BDSPC= bachelor's degree in special education with special education certification. BDOSP $=$ bachelor's degree in another area with special education certification. $\mathrm{BDOP}=$ bachelor's degree in another area with special education permit. $\mathrm{DDE}=$ doctoral degree in education. $\mathrm{MDE}=$ master's degree in education. $\mathrm{BDE}=$ bachelor's degree in education. $\mathrm{BDOGC}=$ bachelor's degree in another area with general education certification. $\mathrm{BDOGP}=$ bachelor's degree in another area with general education permit. 
Table J6

Degree by Survey Item 29 (Professional Development Need for Teaching Math)

\begin{tabular}{|lccccccc|}
\hline & $\mathrm{N}$ & $\begin{array}{c}\text { A lot } \\
(1.3 \%)\end{array}$ & $\begin{array}{c}\text { Quite a bit } \\
(10.2 \%)\end{array}$ & $\begin{array}{c}\text { Some } \\
(42.1 \%)\end{array}$ & $\begin{array}{c}\text { A Little } \\
(39.6 \%)\end{array}$ & $\begin{array}{c}\text { None } \\
(6.8 \%)\end{array}$ & Chi-Square \\
\hline DDSP & 0 & 0 & 0 & 0 & 0 & 0 & $\chi 2(36)=40.6$ \\
& & $(0 \%)$ & $(0 \%)$ & $(0 \%)$ & $(0 \%)$ & $(0 \%)$ & NS \\
MDSP & 0 & 0 & 0 & 0 & 0 & 0 & \\
& & $(0 \%)$ & $(0 \%)$ & $(0 \%)$ & $(0 \%)$ & $(0 \%)$ & \\
BDSPC & 19 & 0 & 2 & 8 & 8 & 1 & \\
& & $(0 \%)$ & $(10.5 \%)$ & $(42.1 \%)$ & $(42.1 \%)$ & $(5.3 \%)$ & \\
BDOSP & 6 & 1 & 2 & 3 & 0 & 0 & \\
& & $(16.7 \%)$ & $(33.3 \%)$ & $(50.0 \%)$ & $(0 \%)$ & $(0 \%)$ & \\
BDOP & 4 & 0 & 2 & 1 & 1 & 0 & \\
& & $(0 \%)$ & $(50.0 \%)$ & $(25.0 \%)$ & $(25.0 \%)$ & $(0 \%)$ & \\
DDE & 3 & 0 & 1 & 1 & 0 & 1 & \\
& & $(0 \%)$ & $(33.3 \%)$ & $(33.3 \%)$ & $(0 \%)$ & $(33.3 \%)$ & \\
MDE & 121 & 2 & 8 & 47 & 57 & 7 & \\
& & $(1.7 \%)$ & $(6.6 \%)$ & $(38.8 \%)$ & $(47.1 \%)$ & $(5.8 \%)$ & 7 \\
BDE & 69 & 0 & 8 & 31 & 23 & $(10.1 \%)$ & \\
& & $(0 \%)$ & $(11.6 \%)$ & $(44.9 \%)$ & $(33.3 \%)$ & 0 & \\
BDOGC & 12 & 0 & 1 & 7 & 4 & 0 \\
BDOGP & 1 & $(0 \%)$ & $(8.3 \%)$ & $(58.3 \%)$ & $(33.3 \%)$ & $(0 \%)$ & \\
& & $(0 \%)$ & $(0 \%)$ & $(100 \%)$ & $(0 \%)$ & $(0 \%)$ & \\
\hline
\end{tabular}

Note. Values enclosed in parenthesis represent percentage of responses in row. NS= Not statistically significant (at the $p<.05$ level). DDSP $=$ doctoral degree in special education. MDSP $=$ master's degree in special education. BDSPC= bachelor's degree in special education with special education certification. $\mathrm{BDOSP}=$ bachelor's degree in another area with special education certification. $\mathrm{BDOP}=$ bachelor's degree in another area with special education permit. $\mathrm{DDE}=$ doctoral degree in education. $\mathrm{MDE}=$ master's degree in education. $\mathrm{BDE}=$ bachelor's degree in education. $\mathrm{BDOGC}=$ bachelor's degree in another area with general education certification. BDOGP= bachelor's degree in another area with general education permit. 
Table $\mathbf{J} 7$

Degree by Survey Item 30 (Need More Strategies for Teaching Mathematics)

\begin{tabular}{|lccccccccc|}
\hline & N & $\begin{array}{c}\text { Algebra } \\
(15.3 \%)\end{array}$ & $\begin{array}{c}\text { Geo. } \\
(10.6 \%)\end{array}$ & $\begin{array}{c}\text { Meas. } \\
(5.3 \%)\end{array}$ & $\begin{array}{c}\text { Statistics } \\
(20.6 \%)\end{array}$ & $\begin{array}{c}\text { Probability } \\
(4.7 \%)\end{array}$ & $\begin{array}{c}\# \text { 's } \\
\text { and } \\
\text { Ops. }\end{array}$ & $\begin{array}{c}\text { Process } \\
(38.9 \%)\end{array}$ & Chi-Square \\
& & & & & & & & \\
& & & & & & & $(4.7 \%)$ & & \\
\hline DDSP & 0 & 0 & 0 & 0 & 0 & 0 & 0 & 0 & $\chi 2(72)=56.1$ \\
& & $(0 \%)$ & $(0 \%)$ & $(0 \%)$ & $(0 \%)$ & $(0 \%)$ & $(0 \%)$ & $(0 \%)$ & NS \\
MDSP & 1 & 1 & 0 & 0 & 0 & 0 & 0 & 0 & \\
& & $(100 \%)$ & $(0 \%)$ & $(0 \%)$ & $(0 \%)$ & $(0 \%)$ & $(0 \%)$ & $(0 \%)$ & \\
BDSPC & 32 & 5 & 5 & 1 & 4 & 0 & 2 & 15 & \\
& & $(15.6 \%)$ & $(15.6 \%)$ & $(3.1 \%)$ & $(12.5 \%)$ & $(0 \%)$ & $(6.3 \%)$ & $(46.9 \%)$ & \\
BDOSP & 15 & 2 & 3 & 2 & 1 & 1 & 1 & 5 & \\
& & $(13.3 \%)$ & $(20.0 \%$ & $(13.3 \%)$ & $(6.7 \%)$ & $(6.7 \%)$ & $(6.7 \%)$ & $(33.3 \%)$ & \\
& & & & & & & & & \\
BDOP & 6 & 0 & 2 & 0 & 0 & 0 & 0 & 4 \\
& & $(0 \%)$ & $(33.3 \%)$ & $(0 \%)$ & $(0 \%)$ & $(0 \%)$ & $(0 \%)$ & $(66.7 \%)$ & \\
DDE & 3 & 0 & 1 & 0 & 1 & 0 & 0 & 1 & \\
& & $(0 \%)$ & $(33.3 \%)$ & $(0 \%)$ & $(33.3 \%)$ & $(0 \%)$ & $(0 \%)$ & $(33.3 \%)$ & \\
MDE & 190 & 31 & 14 & 7 & 45 & 9 & 9 & 74 & \\
& & $(16.3 \%)$ & $(7.4 \%)$ & $(3.7 \%)$ & $(23.7 \%)$ & $(5.3 \%)$ & $(4.7 \%)$ & $(38.9 \%)$ & \\
BDE & 91 & 12 & 7 & 9 & 17 & 4 & 4 & 37 & \\
& & $(13.2 \%)$ & $(7.7 \%)$ & $(9.9 \%)$ & $(18.7 \%)$ & $(5.5 \%)$ & $(4.4 \%)$ & $(40.7 \%)$ & \\
BDOGC & 20 & 4 & 4 & 0 & 6 & 1 & 1 & 4 & \\
& & $(20.0 \%)$ & $(20.0 \%)$ & $(0 \%)$ & $(30.0 \%)$ & $(5.0 \%)$ & $(5.0 \%)$ & $(20.0 \%)$ & \\
BDOGP & 2 & 0 & 2 & 0 & 0 & 0 & 0 & 0 & \\
& & $(0 \%)$ & $(100 \%)$ & $(0 \%)$ & $(0 \%)$ & $(0 \%)$ & $(0 \%)$ & $(0 \%)$ & \\
\hline
\end{tabular}

Note. Values enclosed in parenthesis represent percentage of responses in row. NS= Not statistically significant (at the $p<.05$ level). $\mathrm{DDSP}=$ doctoral degree in special education. $\mathrm{MDSP}=$ master's degree in special education. BDSPC $=$ bachelor's degree in special education with special education certification. $\mathrm{BDOSP}=$ bachelor's degree in another area with special education certification. $\mathrm{BDOP}=$ bachelor's degree in another area with special education permit. $\mathrm{DDE}=$ doctoral degree in education. $\mathrm{MDE}=$ master's degree in education. $\mathrm{BDE}=$ bachelor's degree in education. $\mathrm{BDOGC}=$ bachelor's degree in another area with general education certification. BDOGP $=$ bachelor's degree in another area with general education permit. $\mathrm{Geo}=$ Geometry. Meas.= Measurement. \#'s and Ops.= Numbers and Operations. Process= Processes (communication, problem solving, reasoning and proof, representation, and connections). 
Table $\mathbf{J} 8$

Degree by Survey Item 31 (Do Not Need More Strategies for Teaching Mathematics)

\begin{tabular}{|lccccccccc|}
\hline & N & $\begin{array}{c}\text { Algebra } \\
(18.8 \%)\end{array}$ & $\begin{array}{c}\text { Geo. } \\
(15.7 \%)\end{array}$ & $\begin{array}{c}\text { Meas. } \\
(8.8 \%)\end{array}$ & $\begin{array}{c}\text { Statistics } \\
(4.6 \%)\end{array}$ & $\begin{array}{c}\text { Probability } \\
(6.4 \%)\end{array}$ & $\begin{array}{c}\text { \#'s and } \\
\text { Ops. } \\
(42.0 \%)\end{array}$ & $\begin{array}{c}\text { Process } \\
(3.6 \%)\end{array}$ & Chi-Square \\
\hline DDSP & 0 & 0 & 0 & 0 & 0 & 0 & 0 & 0 & $\chi 2(72)=49.0$ \\
& & $(0 \%)$ & $(0 \%)$ & $(0 \%)$ & $(0 \%)$ & $(0 \%)$ & $(0 \%)$ & $(0 \%)$ & NS \\
MDSP & 1 & 0 & 0 & 0 & 0 & 0 & 1 & 0 & \\
& & $(0 \%)$ & $(0 \%)$ & $(0 \%)$ & $(0 \%)$ & $(0 \%)$ & $(100 \%)$ & $(0 \%)$ & \\
BDSPC & 34 & 4 & 7 & 2 & 1 & 2 & 17 & 1 & \\
& & $(11.8 \%)$ & $(20.6 \%)$ & $(5.9 \%)$ & $(2.9 \%)$ & $(5.9 \%)$ & $(50.0 \%)$ & $(2.9 \%)$ & \\
BDOSP & 16 & 0 & 1 & 3 & 2 & 2 & 8 & 0 & \\
& & $(0 \%)$ & $(6.3 \%)$ & $(18.8 \%)$ & $(12.5 \%)$ & $(12.5 \%)$ & $(50.0 \%)$ & $(0 \%)$ & \\
BDOP & 7 & 1 & 1 & 0 & 0 & 1 & 4 & 0 & \\
& & $(14.3 \%)$ & $(14.3 \%)$ & $(0 \%)$ & $(0 \%)$ & $(14.3 \%)$ & $(57.1 \%)$ & $(0 \%)$ & \\
DDE & 3 & 0 & 0 & 0 & 0 & 0 & 3 & 0 & \\
& & $(0 \%)$ & $(0 \%)$ & $(0 \%)$ & $(0 \%)$ & $(0 \%)$ & $(100 \%)$ & $(0 \%)$ & \\
MDE & 207 & 46 & 33 & 18 & 9 & 11 & 78 & 12 & \\
& & $(22.2 \%)$ & $(15.9 \%)$ & $(8.7 \%)$ & $(4.3 \%)$ & $(5.3 \%)$ & $(37.7 \%)$ & $(5.8 \%)$ & \\
BDE & 97 & 14 & 14 & 11 & 3 & 8 & 46 & 1 & \\
& & $(14.4 \%)$ & $(14.4 \%)$ & $(11.3 \%)$ & $(3.1 \%)$ & $(8.2 \%)$ & $(47.4 \%)$ & $(1.0 \%)$ & \\
BDOGC & 21 & 6 & 5 & 0 & 3 & 1 & 6 & 0 & \\
& & $(28.6 \%)$ & $(23.8 \%)$ & $(0 \%)$ & $(14.3 \%)$ & $(4.8 \%)$ & $(28.6 \%)$ & $(0 \%)$ & \\
BDOGP & 2 & 2 & 0 & 0 & 0 & 0 & 0 & 0 & \\
& & $(100 \%)$ & $(0 \%)$ & $(0 \%)$ & $(0 \%)$ & $(0 \%)$ & $(0 \%)$ & $(0 \%)$ & \\
\hline
\end{tabular}

Note. Values enclosed in parenthesis represent percentage of responses in row. NS= Not statistically significant (at the $p<.05$ level). DDSP $=$ doctoral degree in special education. MDSP $=$ master's degree in special education. BDSPC= bachelor's degree in special education with special education certification. BDOSP $=$ bachelor's degree in another area with special education certification. $\mathrm{BDOP}=$ bachelor's degree in another area with special education permit. $\mathrm{DDE}=$ doctoral degree in education. $\mathrm{MDE}=$ master's degree in education. $\mathrm{BDE}=$ bachelor's degree in education. $\mathrm{BDOGC}=$ bachelor's degree in another area with general education certification. BDOGP $=$ bachelor's degree in another area with general education permit. Geo= Geometry. Meas.= Measurement. \#'s and Ops. $=$ Numbers and Operations. Process $=$ Processes (communication, problem solving, reasoning and proof, representation, and connections). 
Table K1

Number of Math Content Courses (1-2, 3-4, 5- 6, 7-8, 8 or more) by Survey Item 14 (Math Content Knowledge)

\begin{tabular}{|lccccccc|}
\hline $\mathrm{N}$ & $\begin{array}{c}\text { Exceptional } \\
(13.0 \%)\end{array}$ & $\begin{array}{c}\text { Above } \\
\text { Average } \\
(52.0 \%)\end{array}$ & $\begin{array}{c}\text { Average } \\
(32.3 \%)\end{array}$ & $\begin{array}{c}\text { Below } \\
\text { Average } \\
(2.6 \%)\end{array}$ & $\begin{array}{c}\text { Poor } \\
(0.2 \%)\end{array}$ & Chi-Square \\
\hline $1-2$ & 54 & 0 & 21 & 29 & 4 & 0 & $\chi 2(16)=104.1$ \\
& & $(0 \%)$ & $(38.9 \%)$ & $(53.7 \%)$ & $(7.4 \%)$ & $(0 \%)$ & $p<.05$ \\
$3-4$ & 140 & 7 & 62 & 65 & 5 & 1 & \\
& & $(5.0 \%)$ & $(44.3 \%)$ & $(46.4 \%)$ & $(3.6 \%)$ & $(0.7 \%)$ & \\
$5-6$ & 90 & 8 & 53 & 27 & 2 & 0 & \\
& & $(8.9 \%)$ & $(58.9 \%)$ & $(30.0 \%)$ & $(2.2 \%)$ & $(0 \%)$ & \\
$7-8$ & 38 & 5 & 23 & 10 & 0 & 0 & \\
& & $(13.2 \%)$ & $(60.5 \%)$ & $(26.3 \%)$ & $(0 \%)$ & $(0 \%)$ & \\
8 or & 109 & 36 & 65 & 8 & 0 & 0 & \\
more & & $(33.0 \%)$ & $(59.6 \%)$ & $(7.3 \%)$ & $(0 \%)$ & $(0 \%)$ & \\
\hline
\end{tabular}

Note. Values enclosed in parenthesis represent percentage of responses in row. NS= Not statistically significant (at the $p<.05$ level).

Table K2

Number of Math Content Courses (1-2, 3-4, 5- 6, 7-8, 8 or more) by Survey Item 16 (Professional Development Need of Mathematics Content Knowledge)

\begin{tabular}{|lccccccc|}
\hline & $\mathrm{N}$ & $\begin{array}{c}\text { A lot } \\
(1.2 \%)\end{array}$ & $\begin{array}{c}\text { Quite a bit } \\
(7.4 \%)\end{array}$ & $\begin{array}{c}\text { Some } \\
(53.0 \%)\end{array}$ & $\begin{array}{c}\text { A Little } \\
(31.6 \%)\end{array}$ & $\begin{array}{c}\text { None } \\
(6.7 \%)\end{array}$ & Chi-Square \\
\hline $1-2$ & 54 & 0 & 9 & 31 & 13 & 1 & $\chi 2(16)=27.7$ \\
& & $(0 \%)$ & $(16.7 \%)$ & $(57.4 \%)$ & $(24.1 \%)$ & $(1.9 \%)$ & $p<.05$ \\
$3-4$ & 140 & 0 & 8 & 82 & 36 & 14 & \\
& & $(0 \%)$ & $(5.7 \%)$ & $(58.6 \%)$ & $(25.7 \%)$ & $(10.0 \%)$ & \\
$5-6$ & 89 & 2 & 6 & 46 & 31 & 4 & \\
& & $(2.2 \%)$ & $(6.7 \%)$ & $(51.7 \%)$ & $(34.8 \%)$ & $(4.5 \%)$ & \\
$7-8$ & 38 & 1 & 4 & 21 & 11 & 1 & \\
& & $(2.6 \%)$ & $(10.5 \%)$ & $(55.3 \%)$ & $(28.9 \%)$ & $(2.6 \%)$ & \\
8 or & 109 & 2 & 5 & 48 & 45 & 9 & \\
more & & $(1.8 \%)$ & $(4.6 \%)$ & $(44.0 \%)$ & $(41.3 \%)$ & $(8.3 \%)$ & \\
\hline
\end{tabular}

Note. Values enclosed in parenthesis represent percentage of responses in row. NS= Not statistically significant (at the $p<.05$ level). 
Table K3

Number of Math Content Courses (1-2, 3-4, 5- 6, 7-8, 8 or more) by Survey Item 17 (Need More Knowledge in Subject)

\begin{tabular}{|c|c|c|c|c|c|c|c|c|c|}
\hline & $\mathrm{N}$ & $\begin{array}{l}\text { Algebra } \\
(15.0 \%)\end{array}$ & $\begin{array}{c}\text { Geo. } \\
(10.2 \%)\end{array}$ & $\begin{array}{l}\text { Meas. } \\
(3.8 \%)\end{array}$ & $\begin{array}{c}\text { Statistics } \\
(27.4 \%)\end{array}$ & $\begin{array}{c}\text { Probability } \\
(5.0 \%)\end{array}$ & $\begin{array}{c}\text { \#'s } \\
\text { and } \\
\text { Ops. } \\
(1.9 \%)\end{array}$ & $\begin{array}{l}\text { Process } \\
(36.7 \%)\end{array}$ & Chi-Square \\
\hline $1-2$ & 53 & $\begin{array}{c}10 \\
(18.9 \%)\end{array}$ & $\begin{array}{c}4 \\
(7.5 \%)\end{array}$ & $\begin{array}{c}3 \\
(5.7 \%)\end{array}$ & $\begin{array}{c}7 \\
(13.2 \%)\end{array}$ & $\begin{array}{c}1 \\
(1.9 \%)\end{array}$ & $\begin{array}{c}0 \\
(0 \%)\end{array}$ & $\begin{array}{c}28 \\
(52.8 \%)\end{array}$ & $\begin{array}{c}\chi 2(24)=50.9 \\
p<.05\end{array}$ \\
\hline $3-4$ & 136 & $\begin{array}{c}18 \\
(13.2 \%)\end{array}$ & $\begin{array}{c}11 \\
(8.1 \%)\end{array}$ & $\begin{array}{c}7 \\
(5.1 \%)\end{array}$ & $\begin{array}{c}38 \\
(27.9 \%)\end{array}$ & $\begin{array}{c}6 \\
(4.4 \%)\end{array}$ & $\begin{array}{c}6 \\
(4.4 \%)\end{array}$ & $\begin{array}{c}50 \\
(36.8 \%)\end{array}$ & \\
\hline $5-6$ & 86 & $\begin{array}{c}14 \\
(16.3 \%)\end{array}$ & $\begin{array}{c}9 \\
(10.5 \%)\end{array}$ & $\begin{array}{c}2 \\
(2.3 \%)\end{array}$ & $\begin{array}{c}20 \\
(23.3 \%)\end{array}$ & $\begin{array}{c}1 \\
(1.2 \%)\end{array}$ & $\begin{array}{c}1 \\
(1.2 \%)\end{array}$ & $\begin{array}{c}39 \\
(45.3 \%)\end{array}$ & \\
\hline $7-8$ & 38 & $\begin{array}{c}10 \\
(26.3 \%)\end{array}$ & $\begin{array}{c}5 \\
(13.2 \%)\end{array}$ & $\begin{array}{c}2 \\
(5.3 \%)\end{array}$ & $\begin{array}{c}7 \\
(18.4 \%)\end{array}$ & $\begin{array}{c}2 \\
(5.3 \%)\end{array}$ & $\begin{array}{c}1 \\
(2.6 \%)\end{array}$ & $\begin{array}{c}11 \\
(28.9 \%)\end{array}$ & \\
\hline $\begin{array}{l}8 \text { or } \\
\text { more }\end{array}$ & 107 & $\begin{array}{c}11 \\
(10.3 \%)\end{array}$ & $\begin{array}{c}14 \\
(13.1 \%)\end{array}$ & $\begin{array}{c}2 \\
(1.9 \%)\end{array}$ & $\begin{array}{c}43 \\
(40.2 \%)\end{array}$ & $\begin{array}{c}11 \\
(10.3 \%)\end{array}$ & $\begin{array}{c}0 \\
(0 \%)\end{array}$ & $\begin{array}{c}26 \\
(24.3 \%)\end{array}$ & \\
\hline
\end{tabular}

Note. Values enclosed in parenthesis represent percentage of responses in row. NS= Not statistically significant (at the $p<.05$ level). Geo $=$ Geometry. Meas.= Measurement. \#'s and Ops. $=$ Numbers and Operations. Process $=$ Processes (communication, problem solving, reasoning and proof, representation, and connections).

Table K4

Number of Math Content Courses (1-2, 3-4, 5- 6, 7-8, 8 or more) by Survey Item 18 (Do Not Need More Knowledge in Subject)

\begin{tabular}{|lccccccccc|}
\hline & $\mathrm{N}$ & $\begin{array}{c}\text { Algebra } \\
(20.3 \%)\end{array}$ & $\begin{array}{c}\text { Geo. } \\
(13.2 \%)\end{array}$ & $\begin{array}{c}\text { Meas. } \\
(7.1 \%)\end{array}$ & $\begin{array}{c}\text { Statistics } \\
(3.3 \%)\end{array}$ & $\begin{array}{c}\text { Probability } \\
(5.7 \%)\end{array}$ & $\begin{array}{c}\text { \#'s and } \\
\text { Ops. } \\
(46.1 \%)\end{array}$ & $\begin{array}{c}\text { Process } \\
(4.3 \%)\end{array}$ & Chi-Square \\
\hline $1-2$ & 51 & 6 & 7 & 7 & 1 & 2 & 25 & 3 & $\chi 2(24)=58.6$ \\
& & $(11.8 \%)$ & $(13.7 \%)$ & $(13.7 \%)$ & $(2.0 \%)$ & $(3.9 \%)$ & $(49.0 \%)$ & $(5.9 \%)$ & $p<.05$ \\
$3-4$ & 137 & 17 & 15 & 9 & 4 & 7 & 79 & 6 & \\
& & $(12.4 \%)$ & $(10.9 \%)$ & $(6.6 \%)$ & $(2.9 \%)$ & $(5.1 \%)$ & $(57.7 \%)$ & $(4.4 \%)$ & \\
$5-6$ & 88 & 13 & 12 & 8 & 3 & 5 & 43 & 4 & \\
& & $(14.8 \%)$ & $(13.6 \%)$ & $(9.1 \%)$ & $(3.4 \%)$ & $(5.7 \%)$ & $(48.9 \%)$ & $(4.5 \%)$ & \\
$7-8$ & 38 & 6 & 2 & 4 & 2 & 4 & 18 & 2 & \\
& & $(15.8 \%)$ & $(5.3 \%)$ & $(10.5 \%)$ & $(5.3 \%)$ & $(10.5 \%)$ & $(47.4 \%)$ & $(5.3 \%)$ & \\
8 or & 109 & 44 & 20 & 2 & 4 & 6 & 30 & 3 & \\
more & & $(40.4 \%)$ & $(18.3 \%)$ & $(1.8 \%)$ & $(3.7 \%)$ & $(5.5 \%)$ & $(27.5 \%)$ & $(2.8 \%)$ & \\
\hline
\end{tabular}

Note. Values enclosed in parenthesis represent percentage of responses in row. NS= Not statistically significant (at the $p<.05$ level). Geo= Geometry. Meas.= Measurement. \#'s and Ops.= Numbers and Operations. Process $=$ Processes (communication, problem solving, reasoning and proof, representation, and connections). 
Table K5

Number of Math Content Courses (1-2, 3-4, 5- 6, 7-8, 8 or more) by Survey Item 27(Ability to Teach Mathematics)

\begin{tabular}{|lccccccc|}
\hline $\mathrm{N}$ & $\begin{array}{c}\text { Exceptional } \\
(14.7 \%)\end{array}$ & $\begin{array}{c}\text { Above } \\
\text { Average } \\
(60.3 \%)\end{array}$ & $\begin{array}{c}\text { Average } \\
(24.1 \%)\end{array}$ & $\begin{array}{c}\text { Below } \\
\text { Average } \\
(1.0 \%)\end{array}$ & $\begin{array}{c}\text { Poor } \\
(0 \%)\end{array}$ & Chi-Square \\
\hline $1-2$ & 47 & 2 & 23 & 21 & 1 & 0 & $\chi 2(16)=59.1$ \\
$3-4$ & 124 & $(4.3 \%)$ & $(48.9 \%)$ & $(44.7 \%)$ & $(2.1 \%)$ & $(0 \%)$ & $p<.05$ \\
& & $(9.7 \%)$ & $(56.5 \%)$ & $(32.3 \%)$ & $(1.6 \%)$ & $(0 \%)$ & \\
$5-6$ & 84 & 5 & 59 & 20 & 0 & 0 & \\
& & $(6.0 \%)$ & $(70.2 \%)$ & $(23.8 \%)$ & $(0 \%)$ & $(0 \%)$ & \\
$7-8$ & 37 & 11 & 18 & 8 & 0 & 0 & \\
& & $(29.7 \%)$ & $(48.6 \%)$ & $(21.6 \%)$ & $(0 \%)$ & $(0 \%)$ & \\
8 or & 103 & 28 & 68 & 6 & 1 & 0 & \\
more & & $(27.2 \%)$ & $(66.0 \%)$ & $(5.8 \%)$ & $(1.0 \%$ & $(0 \%)$ & \\
\hline
\end{tabular}

Note. Values enclosed in parenthesis represent percentage of responses in row. NS $=$ Not statistically significant (at the $p<.05$ level).

Table K6

Number of Math Content Courses (1-2, 3-4, 5- 6, 7-8, 8 or more) by Survey Item 29 (Professional Development Need for Teaching Math)

\begin{tabular}{|lccccccc|}
\hline & $\mathrm{N}$ & $\begin{array}{c}\text { A lot } \\
(1.3 \%)\end{array}$ & $\begin{array}{c}\text { Quite a bit } \\
(10.6 \%)\end{array}$ & $\begin{array}{c}\text { Some } \\
(41.7 \%)\end{array}$ & $\begin{array}{c}\text { A Little } \\
(39.6 \%)\end{array}$ & $\begin{array}{c}\text { None } \\
(6.8 \%)\end{array}$ & Chi-Square \\
\hline $1-2$ & 31 & 1 & 7 & 13 & 7 & 3 & $\chi 2(16)=24.6$ \\
& & $(3.2 \%)$ & $(22.6 \%)$ & $(41.9 \%)$ & $(22.6 \%)$ & $(9.7 \%)$ & NS \\
$3-4$ & 73 & 0 & 7 & 28 & 33 & 5 & \\
& & $(0 \%)$ & $(9.6 \%)$ & $(38.4 \%)$ & $(45.2 \%)$ & $(6.8 \%)$ & \\
$5-6$ & 42 & 0 & 5 & 20 & 14 & 3 & \\
& & $(0 \%)$ & $(11.9 \%)$ & $(47.6 \%)$ & $(33.3 \%)$ & $(7.1 \%)$ & \\
$7-8$ & 23 & 2 & 2 & 8 & 9 & 2 & \\
& & $(8.7 \%)$ & $(8.7 \%)$ & $(34.8 \%)$ & $(39.1 \%)$ & $(8.7 \%)$ & \\
8 or & 66 & 0 & 4 & 29 & 30 & 3 & \\
more & & $(0 \%)$ & $(6.1 \%)$ & $(43.9 \%)$ & $(45.5 \%)$ & $(45.5 \%)$ & \\
\hline
\end{tabular}

Note. Values enclosed in parenthesis represent percentage of responses in row. NS= Not statistically significant (at the $p<.05$ level). 
Table K7

Number of Math Content Courses (1-2, 3-4, 5- 6, 7-8, 8 or more) by Survey Item 30 (Need More Strategies for Teaching Mathematics)

\begin{tabular}{|c|c|c|c|c|c|c|c|c|c|}
\hline & $\mathrm{N}$ & $\begin{array}{l}\text { Algebra } \\
(15.6 \%)\end{array}$ & $\begin{array}{c}\text { Geo. } \\
(16.0 \%)\end{array}$ & $\begin{array}{l}\text { Meas. } \\
(5.3 \%)\end{array}$ & $\begin{array}{c}\text { Statistics } \\
(19.7 \%)\end{array}$ & $\begin{array}{c}\text { Probability } \\
(5.0 \%)\end{array}$ & $\begin{array}{c}\text { \#'s } \\
\text { and } \\
\text { Ops. } \\
(5.0 \%)\end{array}$ & $\begin{array}{l}\text { Process } \\
(39.4 \%)\end{array}$ & Chi-Square \\
\hline $1-2$ & 44 & $\begin{array}{c}7 \\
(15.9 \%)\end{array}$ & $\begin{array}{c}4 \\
(9.1 \%)\end{array}$ & $\begin{array}{c}2 \\
(4.5 \%)\end{array}$ & $\begin{array}{c}5 \\
(11.4 \%)\end{array}$ & $\begin{array}{c}2 \\
(4.5 \%)\end{array}$ & $\begin{array}{c}3 \\
(6.8 \%)\end{array}$ & $\begin{array}{c}21 \\
(47.4 \%)\end{array}$ & $\begin{array}{c}\chi 2(24)=32.4 \\
\text { NS }\end{array}$ \\
\hline $3-4$ & 114 & $\begin{array}{c}15 \\
(13.2 \%)\end{array}$ & $\begin{array}{c}9 \\
(7.9 \%)\end{array}$ & $\begin{array}{c}9 \\
(7.9 \%)\end{array}$ & $\begin{array}{c}22 \\
(19.3 \%)\end{array}$ & $\begin{array}{c}3 \\
(2.6 \%)\end{array}$ & $\begin{array}{c}7 \\
(6.1 \%)\end{array}$ & $\begin{array}{c}49 \\
(43.0 \%)\end{array}$ & \\
\hline $5-6$ & 81 & $\begin{array}{c}13 \\
(16.0 \%)\end{array}$ & $\begin{array}{c}6 \\
(7.4 \%)\end{array}$ & $\begin{array}{c}4 \\
(4.9 \%)\end{array}$ & $\begin{array}{c}13 \\
(16.0 \%)\end{array}$ & $\begin{array}{c}7 \\
(8.6 \%)\end{array}$ & $\begin{array}{c}5 \\
(6.2 \%)\end{array}$ & $\begin{array}{c}33 \\
(40.7 \%)\end{array}$ & \\
\hline $7-8$ & 36 & $\begin{array}{c}10 \\
(27.8 \%)\end{array}$ & $\begin{array}{c}2 \\
(5.6 \%)\end{array}$ & $\begin{array}{c}2 \\
(5.6 \%)\end{array}$ & $\begin{array}{c}5 \\
(13.9 \%)\end{array}$ & $\begin{array}{c}1 \\
(2.8 \%)\end{array}$ & $\begin{array}{c}2 \\
(5.6 \%)\end{array}$ & $\begin{array}{c}14 \\
(38.9 \%)\end{array}$ & \\
\hline $\begin{array}{l}8 \text { or } \\
\text { more }\end{array}$ & 85 & $\begin{array}{c}11 \\
(12.9 \%)\end{array}$ & $\begin{array}{c}15 \\
(17.6 \%)\end{array}$ & $\begin{array}{c}2 \\
(2.4 \%)\end{array}$ & $\begin{array}{c}26 \\
(30.6 \%)\end{array}$ & $\begin{array}{c}5 \\
(5.9 \%)\end{array}$ & $\begin{array}{c}1 \\
(1.2 \%)\end{array}$ & $\begin{array}{c}25 \\
(29.4 \%)\end{array}$ & \\
\hline
\end{tabular}

Note. Values enclosed in parenthesis represent percentage of responses in row. NS= Not statistically significant (at the $p<.05$ level). Geo= Geometry. Meas.= Measurement. \#'s and Ops.= Numbers and Operations. Process $=$ Processes (communication, problem solving, reasoning and proof, representation, and connections).

Table K8

Number of Math Content Courses (1-2, 3-4, 5- 6, 7-8, 8 or more) by Survey Item 31 (Do Not Need More Strategies for Teaching Mathematics)

\begin{tabular}{|lccccccccc|}
\hline & $\mathrm{N}$ & $\begin{array}{c}\text { Algebra } \\
(18.3 \%)\end{array}$ & $\begin{array}{c}\text { Geo. } \\
(15.8 \%)\end{array}$ & $\begin{array}{c}\text { Meas. } \\
(9.0)\end{array}$ & $\begin{array}{c}\text { Statistics } \\
(4.1 \%)\end{array}$ & $\begin{array}{c}\text { Probability } \\
(6.7 \%)\end{array}$ & $\begin{array}{c}\text { \#'s and } \\
\text { Ops. } \\
(42.4 \%)\end{array}$ & $\begin{array}{c}\text { Process } \\
(3.6 \%)\end{array}$ & Chi-Square \\
& & & & & & & & \\
\hline $1-2$ & 47 & 6 & 7 & 8 & 1 & 3 & 19 & 3 & $\chi 2(24)=61.2$ \\
& & $(12.8 \%)$ & $(14.9 \%)$ & $(17.0 \%)$ & $(2.1 \%)$ & $(6.4 \%)$ & $(40.4 \%)$ & $(6.4 \%)$ & $p<.05$ \\
$3-4$ & 123 & 12 & 17 & 12 & 5 & 6 & 67 & 4 & \\
& & $(9.8 \%)$ & $(13.8 \%)$ & $(9.8 \%)$ & $(4.1 \%)$ & $(4.9 \%)$ & $(54.5 \%)$ & $(3.3 \%)$ & \\
$5-6$ & 82 & 10 & 16 & 10 & 2 & 7 & 34 & 3 & \\
& & $(12.2 \%)$ & $(19.5 \%)$ & $(12.2 \%)$ & $(2.4 \%)$ & $(8.5 \%)$ & $(41.5 \%)$ & $(3.7 \%)$ & \\
$7-8$ & 37 & 5 & 3 & 4 & 2 & 5 & 17 & 1 & \\
& & $(13.5 \%)$ & $(8.1 \%)$ & $(10.8 \%)$ & $(5.4 \%)$ & $(13.5 \%)$ & $(45.9 \%)$ & $(2.7 \%)$ & \\
8 or & 98 & 38 & 18 & 1 & 6 & 5 & 27 & 3 & \\
more & & $(38.8 \%)$ & $(18.4 \%)$ & $(1.0 \%)$ & $(6.1 \%)$ & $(5.1 \%)$ & $(27.6 \%)$ & $(3.1 \%)$ & \\
\hline
\end{tabular}

Note. Values enclosed in parenthesis represent percentage of responses in row. NS= Not statistically significant (at the $p<.05$ level). Geo= Geometry. Meas.= Measurement. \#'s and Ops. $=$ Numbers and Operations. Process $=$ Processes (communication, problem solving, reasoning and proof, representation, and connections). 
Table L1

Number of Math Methods Courses (1, 2, 3, 4, 5, 6 or more) by Survey Item 14 (Math Content Knowledge)

\begin{tabular}{|lccccccc|}
\hline & $\mathrm{N}$ & $\begin{array}{c}\text { Exceptional } \\
(13.1 \%)\end{array}$ & $\begin{array}{c}\text { Above } \\
\text { Average } \\
(52.6 \%)\end{array}$ & $\begin{array}{c}\text { Average } \\
(31.4 \%)\end{array}$ & $\begin{array}{c}\text { Below } \\
\text { Average } \\
(2.6 \%)\end{array}$ & $\begin{array}{c}\text { Poor } \\
(0.2 \%)\end{array}$ & Chi-Square \\
\hline 1 & 135 & 22 & 55 & 53 & 5 & 0 & $\chi 2(20)=41.9$ \\
& & $(16.3 \%)$ & $(40.7 \%)$ & $(39.3 \%)$ & $(3.7 \%)$ & $(0 \%)$ & $p<.05$ \\
2 & 174 & 18 & 92 & 60 & 4 & 0 & \\
& & $(10.3 \%)$ & $(52.9 \%)$ & $(34.5 \%)$ & $(2.3 \%)$ & $(0 \%)$ & \\
3 & 56 & 8 & 40 & 8 & 0 & 0 & \\
& & $(14.3 \%)$ & $(71.4 \%)$ & $(14.3 \%)$ & $(0 \%)$ & $(0 \%)$ & \\
4 & 22 & 3 & 14 & 3 & 2 & 0 & \\
& & $(13.6 \%)$ & $(63.6 \%)$ & $(13.6 \%)$ & $(9.1 \%)$ & $(0 \%)$ & \\
5 & 31 & 4 & 18 & 8 & 0 & 1 & \\
& & $(12.9 \%)$ & $(58.1 \%)$ & $(25.8 \%)$ & $(0 \%)$ & $(3.2 \%)$ & \\
6 or & 2 & 0 & 2 & 0 & 0 & 0 & \\
more & & $(0 \%)$ & $(100 \%)$ & $(0 \%)$ & $(0 \%)$ & $(0 \%)$ & \\
\hline
\end{tabular}

Note. Values enclosed in parenthesis represent percentage of responses in row. NS $=$ Not statistically significant (at the $p<.05$ level). $1=$ Less than 1 class. $2=1-2$ classes. $3=3-4$ classes. $4=5-6$ classes. $5=7-8$ classes. $6=8$ or more classes.

Table L2

Number of Math Methods Courses (1, 2, 3, 4, 5, 6 or more) by Survey Item 16 (Professional Development Need of Mathematics Content Knowledge)

\begin{tabular}{|lccccccc|}
\hline & $\mathrm{N}$ & $\begin{array}{c}\text { A lot } \\
(1.2 \%)\end{array}$ & $\begin{array}{c}\text { Quite a bit } \\
(7.2 \%)\end{array}$ & $\begin{array}{c}\text { Some } \\
(53.8 \%)\end{array}$ & $\begin{array}{c}\text { A Little } \\
(30.9 \%)\end{array}$ & $\begin{array}{c}\text { None } \\
(6.9 \%)\end{array}$ & Chi-Square \\
\hline 1 & 135 & 1 & 11 & 73 & 39 & 11 & $\chi 2(20)=20.1$ \\
& & $(0.7 \%)$ & $(8.1 \%)$ & $(54.1 \%)$ & $(28.9 \%)$ & $(8.1 \%)$ & NS \\
2 & 174 & 1 & 12 & 107 & 43 & 11 & \\
& & $(0.6 \%)$ & $(6.9 \%)$ & $(61.5 \%)$ & $(24.7 \%)$ & $(6.3 \%)$ & \\
3 & 55 & 2 & 3 & 21 & 26 & 3 & \\
& & $(3.6 \%)$ & $(5.5 \%)$ & $(38.2 \%)$ & $(47.3 \%)$ & $(5.5 \%)$ & \\
4 & 21 & 0 & 1 & 10 & 9 & 1 & \\
& & $(0 \%)$ & $(4.8 \%)$ & $(47.6 \%)$ & $(42.9 \%)$ & $(4.8 \%)$ & \\
5 & 31 & 1 & 3 & 13 & 11 & 3 & \\
& & $(3.2 \%)$ & $(9.7 \%)$ & $(41.9 \%)$ & $(35.5 \%)$ & $(9.7 \%)$ & \\
6 or & 2 & 0 & 0 & 1 & 1 & 0 & \\
more & & $(0 \%)$ & $(0 \%)$ & $(50.0 \%)$ & $(50.0 \%)$ & $(0 \%)$ & \\
\hline
\end{tabular}

Note. Values enclosed in parenthesis represent percentage of responses in row. NS= Not statistically significant (at the $p<.05$ level). $1=$ Less than 1 class. $2=1-2$ classes. $3=3-4$ classes. $4=5-6$ classes. $5=7-8$ classes. $6=8$ or more classes. 
Table L3

Number of Math Methods Courses (1, 2, 3, 4, 5, 6 or more) by Survey Item 17 (Need More Knowledge in Subject)

\begin{tabular}{|c|c|c|c|c|c|c|c|c|c|}
\hline & $\mathrm{N}$ & $\begin{array}{l}\text { Algebra } \\
(15.2 \%)\end{array}$ & $\begin{array}{c}\text { Geo. } \\
(10.5 \%)\end{array}$ & $\begin{array}{l}\text { Meas. } \\
(3.9 \%)\end{array}$ & $\begin{array}{c}\text { Statistics } \\
(28.6 \%)\end{array}$ & $\begin{array}{c}\text { Probability } \\
(4.9 \%)\end{array}$ & $\begin{array}{c}\text { \#'s } \\
\text { and } \\
\text { Ops. } \\
(1.7 \%)\end{array}$ & $\begin{array}{l}\text { Process } \\
(35.2 \%)\end{array}$ & Chi-Square \\
\hline 1 & 132 & $\begin{array}{c}20 \\
(15.2 \%)\end{array}$ & $\begin{array}{c}16 \\
(12.1 \%)\end{array}$ & $\begin{array}{c}8 \\
(6.1 \%)\end{array}$ & $\begin{array}{c}32 \\
(24.2 \%)\end{array}$ & $\begin{array}{c}5 \\
(3.8 \%)\end{array}$ & $\begin{array}{c}2 \\
(1.5 \%)\end{array}$ & $\begin{array}{c}49 \\
(37.1 \%)\end{array}$ & $\begin{array}{c}\chi 2(30)=27.9 \\
\text { NS }\end{array}$ \\
\hline 2 & 170 & $\begin{array}{c}24 \\
(14.1 \%)\end{array}$ & $\begin{array}{c}17 \\
(10.0 \%)\end{array}$ & $\begin{array}{c}5 \\
(2.9 \%)\end{array}$ & $\begin{array}{c}51 \\
(30.0 \%)\end{array}$ & $\begin{array}{c}6 \\
(3.5 \%)\end{array}$ & $\begin{array}{c}3 \\
(1.8 \%)\end{array}$ & $\begin{array}{c}64 \\
(37.6 \%)\end{array}$ & \\
\hline 3 & 54 & $\begin{array}{c}11 \\
(20.4 \%)\end{array}$ & $\begin{array}{c}6 \\
(11.1 \%)\end{array}$ & $\begin{array}{c}3 \\
(5.6 \%)\end{array}$ & $\begin{array}{c}13 \\
(24.1 \%)\end{array}$ & $\begin{array}{c}4 \\
(7.4 \%)\end{array}$ & $\begin{array}{c}1 \\
(1.9 \%)\end{array}$ & $\begin{array}{c}16 \\
(29.6 \%)\end{array}$ & \\
\hline 4 & 21 & $\begin{array}{c}4 \\
(19.0 \%)\end{array}$ & $\begin{array}{c}1 \\
(4.8 \%)\end{array}$ & $\begin{array}{c}0 \\
(0 \%)\end{array}$ & $\begin{array}{c}8 \\
(38.1 \%)\end{array}$ & $\begin{array}{c}1 \\
(4.8 \%)\end{array}$ & $\begin{array}{c}1 \\
(4.8 \%)\end{array}$ & $\begin{array}{c}6 \\
(28.6 \%)\end{array}$ & \\
\hline 5 & 30 & $\begin{array}{c}3 \\
(10.0 \%)\end{array}$ & $\begin{array}{c}3 \\
(10.0 \%)\end{array}$ & $\begin{array}{c}0 \\
(0 \%)\end{array}$ & $\begin{array}{c}13 \\
(43.3 \%)\end{array}$ & $\begin{array}{c}3 \\
(10.0 \%)\end{array}$ & $\begin{array}{c}0 \\
(0 \%)\end{array}$ & $\begin{array}{c}8 \\
(26.7 \%)\end{array}$ & \\
\hline $\begin{array}{l}6 \text { or } \\
\text { more }\end{array}$ & 2 & $\begin{array}{c}0 \\
(0 \%)\end{array}$ & $\begin{array}{c}0 \\
(0 \%)\end{array}$ & $\begin{array}{c}0 \\
(0 \%)\end{array}$ & $\begin{array}{c}0 \\
(0 \%)\end{array}$ & $\begin{array}{c}1 \\
(50.0 \%)\end{array}$ & $\begin{array}{c}0 \\
(0 \%)\end{array}$ & $\begin{array}{c}1 \\
(50.0 \%)\end{array}$ & \\
\hline
\end{tabular}

Note. Values enclosed in parenthesis represent percentage of responses in row. NS= Not statistically significant (at the $p<.05$ level). $1=$ Less than 1 class. $2=1-2$ classes. $3=3-4$ classes. $4=5-6$ classes. $5=7-8$ classes. $6=8$ or more classes. Geo $=$ Geometry. Meas. $=$ Measurement. \#'s and Ops. $=$ Numbers and Operations. Process= Processes (communication, problem solving, reasoning and proof, representation, and connections).

Table L4

Number of Math Methods Courses (1, 2, 3, 4, 5, 6 or more) by Survey Item 18 (Do Not Need More Knowledge in Subject)

\begin{tabular}{|lccccccccc|}
\hline & $\mathrm{N}$ & $\begin{array}{c}\text { Algebra } \\
(21.9 \%)\end{array}$ & $\begin{array}{c}\text { Geo. } \\
(13.1 \%)\end{array}$ & $\begin{array}{c}\text { Meas. } \\
(6.8 \%)\end{array}$ & $\begin{array}{c}\text { Statistics } \\
(3.4 \%)\end{array}$ & $\begin{array}{c}\text { Probability } \\
(5.6 \%)\end{array}$ & $\begin{array}{c}\text { \#'s and } \\
\text { Ops. } \\
(45 \%)\end{array}$ & $\begin{array}{c}\text { Process } \\
(4.1 \%)\end{array}$ & Chi-Square \\
\hline 1 & 132 & 28 & 21 & 10 & 5 & 4 & 61 & 3 & $\chi 2(30)=32.3$ \\
& & $(21.2 \%)$ & $(15.9 \%)$ & $(7.6 \%)$ & $(3.8 \%)$ & $(3.0 \%)$ & $(46.2 \%)$ & $(2.3 \%)$ & NS \\
2 & 171 & 41 & 13 & 11 & 5 & 9 & 82 & 10 & \\
& & $(24.0 \%)$ & $(7.6 \%)$ & $(6.4 \%)$ & $(2.9 \%)$ & $(5.3 \%)$ & $(48 \%)$ & $(5.8 \%)$ & \\
3 & 55 & 12 & 8 & 4 & 1 & 5 & 23 & 2 & \\
& & $(21.8 \%)$ & $(14.5 \%)$ & $(7.3 \%)$ & $(1.8 \%)$ & $(9.1 \%)$ & $(41.8 \%)$ & $(3.6 \%)$ & \\
4 & 21 & 2 & 5 & 0 & 2 & 3 & 8 & 1 & \\
& & $(9.5 \%)$ & $(23.8 \%)$ & $(0 \%)$ & $(9.5 \%)$ & $(14.3 \%)$ & $(38.1 \%)$ & $(4.8 \%)$ & \\
5 & 30 & 6 & 7 & 2 & 1 & 2 & 11 & 1 & \\
& & $(20 \%)$ & $(23.3 \%)$ & $(6.7 \%)$ & $(3.3 \%)$ & $(6.7 \%)$ & $(36.7 \%)$ & $(3.3 \%)$ & \\
6 or & 2 & 1 & 0 & 1 & 0 & 0 & 0 & 0 & \\
more & & $(50 \%)$ & $(0 \%)$ & $(50.0 \%)$ & $(0 \%)$ & $(0 \%)$ & $(0 \%)$ & $(0 \%)$ & \\
\hline
\end{tabular}


Note. Values enclosed in parenthesis represent percentage of responses in row. NS $=$ Not statistically significant (at the $p<.05$ level). $1=$ Less than 1 class. $2=1-2$ classes. $3=3-4$ classes. $4=5-6$ classes. $5=7-8$ classes. $6=8$ or more classes. Geo $=$ Geometry. Meas. $=$ Measurement. \#'s and Ops. $=$ Numbers and Operations. Process= Processes (communication, problem solving, reasoning and proof, representation, and connections).

Table L5

Number of Math Methods Courses (1, 2, 3, 4, 5, 6 or more) by Survey Item 27(Ability to Teach Mathematics)

\begin{tabular}{|lccccccc|}
\hline & $\mathrm{N}$ & $\begin{array}{c}\text { Exceptional } \\
(14.4 \%)\end{array}$ & $\begin{array}{c}\text { Above } \\
\text { Average } \\
(61.1 \%)\end{array}$ & $\begin{array}{c}\text { Average } \\
(23.5 \%)\end{array}$ & $\begin{array}{c}\text { Below } \\
\text { Average } \\
(1.0 \%)\end{array}$ & $\begin{array}{c}\text { Poor } \\
(0 \%)\end{array}$ & Chi-Square \\
\hline 1 & 121 & 11 & 67 & 41 & 2 & 0 & $\chi 2(20)=23.4$ \\
& & $(9.1 \%)$ & $(55.4 \%)$ & $(33.9 \%)$ & $(1.7 \%)$ & $(0 \%)$ & NS \\
2 & 161 & 23 & 98 & 38 & 2 & 0 & \\
& & $(14.3 \%)$ & $(60.9 \%)$ & $(23.6 \%)$ & $(1.2 \%)$ & $(0 \%)$ & \\
3 & 51 & 10 & 36 & 5 & 0 & 0 & \\
& & $(19.6 \%)$ & $(70.6 \%)$ & $(9.8 \%)$ & $(0 \%)$ & $(0 \%)$ & \\
4 & 21 & 6 & 14 & 1 & 0 & 0 & \\
& & $(28.6 \%)$ & $(66.7 \%)$ & $(4.8 \%)$ & $(0 \%)$ & $(0 \%)$ & \\
5 & 28 & 5 & 18 & 5 & 0 & 0 & \\
& & $(17.9 \%)$ & $(64.3 \%)$ & $(17.9 \%)$ & $(0 \%)$ & $(0 \%)$ & \\
6 or & 1 & 0 & 1 & 0 & 0 & 0 & \\
more & & $(0 \%)$ & $(100 \%)$ & $(0 \%)$ & $(0 \%)$ & $(0 \%)$ & \\
\hline
\end{tabular}

Note. Values enclosed in parenthesis represent percentage of responses in row. NS $=$ Not statistically significant (at the $p<.05$ level). $1=$ Less than 1 class. $2=1-2$ classes. $3=3-4$ classes. $4=5-6$ classes. $5=7-8$ classes. $6=8$ or more classes.

Table L6

Number of Math Methods Courses (1, 2, 3, 4, 5, 6 or more) by Survey Item 29 (Professional Development Need for Teaching Math)

\begin{tabular}{|lccccccc|}
\hline & $\mathrm{N}$ & $\begin{array}{c}\text { A lot } \\
(1.3 \%)\end{array}$ & $\begin{array}{c}\text { Quite a bit } \\
(10.5 \%)\end{array}$ & $\begin{array}{c}\text { Some } \\
(43.0 \%)\end{array}$ & $\begin{array}{c}\text { A Little } \\
(39.0 \%)\end{array}$ & $\begin{array}{c}\text { None } \\
(6.1 \%)\end{array}$ & Chi-Square \\
\hline 1 & 78 & 0 & 12 & 27 & 30 & 9 & $\chi 2(20)=30.7$ \\
& & $(0 \%)$ & $(15.4 \%)$ & $(34.6 \%)$ & $(38.5 \%)$ & $(11.5 \%)$ & NS \\
2 & 92 & 1 & 11 & 47 & 32 & 1 & \\
& & $(1.1 \%)$ & $(12.0 \%)$ & $(51.1 \%)$ & $(34.8 \%)$ & $(1.1 \%)$ & \\
3 & 31 & 2 & 0 & 14 & 14 & 1 & \\
& & $(6.5 \%)$ & $(0 \%)$ & $(54.2 \%)$ & $(45.2 \%)$ & $(3.2 \%)$ & \\
4 & 11 & 0 & 0 & 3 & 7 & 1 & \\
& & $(0 \%)$ & $(0 \%)$ & $(27.3 \%)$ & $(63.6 \%)$ & $(9.1 \%)$ & \\
5 & 15 & 0 & 1 & 6 & 6 & 2 & \\
& & $(0 \%)$ & $(6.7 \%)$ & $(40.0 \%)$ & $(40.0 \%)$ & $(13.3 \%)$ & \\
6 or & 1 & 0 & 0 & 1 & 0 & 0 & \\
more & & $(0 \%)$ & $(0 \%)$ & $(100 \%)$ & $(0 \%)$ & $(0 \%)$ & \\
\hline
\end{tabular}


Note. Values enclosed in parenthesis represent percentage of responses in row. NS $=$ Not statistically significant (at the $p<.05$ level). $1=$ Less than 1 class. $2=1-2$ classes. $3=3-4$ classes. $4=5-6$ classes. $5=7-8$ classes. $6=8$ or more classes.

Table L7

Number of Math Methods Courses (1, 2, 3, 4, 5, 6 or more) by Survey Item 30 (Need More Strategies for Teaching Mathematics)

\begin{tabular}{|lccccccccc|}
\hline & $\mathrm{N}$ & $\begin{array}{c}\text { Algebra } \\
(15.4 \%)\end{array}$ & $\begin{array}{c}\text { Geo. } \\
(10.6 \%)\end{array}$ & $\begin{array}{c}\text { Meas. } \\
(5.4 \%)\end{array}$ & $\begin{array}{c}\text { Statistics } \\
(20.6 \%)\end{array}$ & $\begin{array}{c}\text { Probability } \\
(5.1 \%)\end{array}$ & $\begin{array}{c}\text { \#'s and } \\
\text { Ops. } \\
(4.6 \%)\end{array}$ & $\begin{array}{c}\text { Process } \\
(38.3 \%)\end{array}$ & Chi-Square \\
\hline 1 & 113 & 13 & 13 & 10 & 16 & 6 & 6 & 49 & $\chi 2(30)=25.9$ \\
& & $(11.5 \%)$ & $(11.5 \%)$ & $(8.8 \%)$ & $(14.2 \%)$ & $(5.3 \%)$ & $(5.3 \%)$ & $(43.4 \%)$ & NS \\
2 & 149 & 26 & 18 & 6 & 29 & 7 & 7 & 56 & \\
& & $(17.4 \%)$ & $(12.1 \%)$ & $(4.0 \%)$ & $(19.5 \%)$ & $(4.7 \%)$ & $(4.7 \%)$ & $(37.6 \%)$ & \\
3 & 48 & 10 & 4 & 3 & 14 & 1 & 1 & 14 & \\
& & $(20.8 \%)$ & $(8.3 \%)$ & $(6.3 \%)$ & $(29.2 \%)$ & $(4.2 \%)$ & $(2.1 \%)$ & $(29.2 \%)$ & \\
4 & 19 & 3 & 0 & 0 & 7 & 1 & 2 & 6 & \\
& & $(15.8 \%)$ & $(0 \%)$ & $(0 \%)$ & $(36.8 \%)$ & $(5.3 \%)$ & $(10.5 \%)$ & $(31.6 \%)$ & \\
5 & 20 & 2 & 2 & 0 & 6 & 2 & 0 & 8 & \\
& & $(10.0 \%)$ & $(10.0 \%)$ & $(0 \%)$ & $(30.0 \%)$ & $(10.0 \%)$ & $(0 \%)$ & $(40.0 \%)$ & \\
6 or & 1 & 0 & 0 & 0 & 0 & 0 & 0 & 1 & \\
more & & $(0 \%)$ & $(0 \%)$ & $(0 \%)$ & $(0 \%)$ & $(0 \%)$ & $(0 \%)$ & $(100 \%)$ & \\
\hline
\end{tabular}

Note. Values enclosed in parenthesis represent percentage of responses in row. NS= Not statistically significant (at the $p<.05$ level). $1=$ Less than 1 class. $2=1-2$ classes. $3=3-4$ classes. $4=5-6$ classes. $5=7-8$ classes. $6=8$ or more classes. Geo $=$ Geometry. Meas. $=$ Measurement. \#'s and Ops.= Numbers and Operations. Process= Processes (communication, problem solving, reasoning and proof, representation, and connections).

Table L8

Number of Math Methods Courses (1, 2, 3, 4, 5, 6 or more) by Survey Item 31 (Do Not Need More Strategies for Teaching Mathematics)

\begin{tabular}{|lccccccccc|}
\hline & $\mathrm{N}$ & $\begin{array}{c}\text { Algebra } \\
(19.5 \%)\end{array}$ & $\begin{array}{c}\text { Geo. } \\
(16.0 \%)\end{array}$ & $\begin{array}{c}\text { Meas. } \\
(8.5 \%)\end{array}$ & $\begin{array}{c}\text { Statistics } \\
(4.5 \%)\end{array}$ & $\begin{array}{c}\text { Probability } \\
(6.7 \%)\end{array}$ & $\begin{array}{c}\text { \#'s and } \\
\text { Ops. } \\
(41.1 \%)\end{array}$ & $\begin{array}{c}\text { Process } \\
(3.7 \%)\end{array}$ & Chi-Square \\
\hline 1 & 120 & 24 & 24 & 11 & 5 & 4 & 48 & 4 & $\chi 2(30)=27.7$ \\
& & $(20.0 \%)$ & $(20.0 \%)$ & $(9.2 \%)$ & $(4.2 \%)$ & $(3.3 \%)$ & $(40.0 \%)$ & $(3.3 \%)$ & NS \\
2 & 158 & 31 & 17 & 15 & 7 & 12 & 70 & 6 & \\
& & $(19.6 \%)$ & $(10.8 \%)$ & $(9.5 \%)$ & $(4.4 \%)$ & $(7.6 \%)$ & $(44.3 \%)$ & $(3.8 \%)$ & \\
3 & 50 & 9 & 9 & 4 & 2 & 5 & 18 & 3 & \\
& & $(18.0 \%)$ & $(18.0 \%)$ & $(8.0 \%)$ & $(4.0 \%)$ & $(10.0 \%)$ & $(36.0 \%)$ & $(6.0 \%)$ & \\
4 & 20 & 2 & 4 & 1 & 2 & 2 & 9 & 0 & \\
& & $(10.0 \%)$ & $(20.0 \%)$ & $(5.0 \%)$ & $(10.0 \%)$ & $(10.0 \%)$ & $(45.0 \%)$ & $(0 \%)$ & \\
5 & 26 & 7 & 6 & 0 & 1 & 2 & 9 & 1 & \\
& & $(26.9 \%)$ & $(23.1 \%)$ & $(0 \%)$ & $(3.8 \%)$ & $(7.7 \%)$ & $(34.6 \%)$ & $(3.8 \%)$ & \\
6 or & 1 & 0 & 0 & 1 & 0 & 0 & 0 & 0 & \\
more & & $(0 \%)$ & $(0 \%)$ & $(100 \%)$ & $(0 \%)$ & $(0 \%)$ & $(0 \%)$ & $(0 \%)$ & \\
\hline
\end{tabular}


Note. Values enclosed in parenthesis represent percentage of responses in row. NS $=$ Not statistically significant (at the $p<.05$ level). $1=$ Less than 1 class. $2=1-2$ classes. $3=3-4$ classes. $4=5-6$ classes. $5=7-8$ classes. $6=8$ or more classes. Geo= Geometry. Meas. $=$ Measurement. \#'s and Ops. $=$ Numbers and Operations. Process $=$ Processes (communication, problem solving, reasoning and proof, representation, and connections). 
Table M1

Years of Experience ( $<1,1-3,4-9,10-19,20$ or more) by Survey Item 14 (Math Content Knowledge)

\begin{tabular}{|lccccccc|}
\hline & $\mathrm{N}$ & $\begin{array}{c}\text { Exceptional } \\
(12.8 \%)\end{array}$ & $\begin{array}{c}\text { Above } \\
\text { Average } \\
(52.3 \%)\end{array}$ & $\begin{array}{c}\text { Average } \\
(32.2 \%)\end{array}$ & $\begin{array}{c}\text { Below } \\
\text { Average } \\
(2.5 \%)\end{array}$ & $\begin{array}{c}\text { Poor } \\
(0.2 \%)\end{array}$ & Chi-Square \\
\hline$<1$ & 18 & 1 & 10 & 7 & 0 & 0 & $\chi 2(16)=13.8$ \\
& & $(5.6 \%)$ & $(55.6 \%)$ & $(38.9 \%)$ & $(0 \%)$ & $(0 \%)$ & NS \\
$1-3$ & 59 & 9 & 34 & 16 & 0 & 0 & \\
& & $(15.3 \%)$ & $(57.6 \%)$ & $(27.1 \%)$ & $(0 \%)$ & $(0 \%)$ & \\
$4-9$ & 146 & 17 & 71 & 54 & 4 & 0 & \\
$10-19$ & 126 & $(11.6 \%)$ & $(48.6 \%)$ & $(37.0 \%)$ & $(2.7 \%)$ & $(0 \%)$ & \\
& & $(15.9 \%)$ & $(48.4 \%)$ & $(32.5 \%)$ & $(3.2 \%)$ & $(0 \%)$ & \\
20 or & 89 & 9 & 53 & 23 & 3 & 1 & \\
more & & $(10.1 \%)$ & $(59.6 \%)$ & $(25.8 \%)$ & $(3.4 \%)$ & $(1.1 \%)$ & \\
\hline
\end{tabular}

Note. Values enclosed in parenthesis represent percentage of responses in row. NS= Not statistically significant (at the $p<.05$ level).

Table M2

Years of Experience (<1, 1-3, 4-9, 10-19, 20 or more) by Survey Item 16 (Professional Development Need of Mathematics Content Knowledge)

\begin{tabular}{|lccccccc|}
\hline & $\mathrm{N}$ & $\begin{array}{c}\text { A lot } \\
(1.1 \%)\end{array}$ & $\begin{array}{c}\text { Quite a bit } \\
(7.6 \%)\end{array}$ & $\begin{array}{c}\text { Some } \\
(53.2 \%)\end{array}$ & $\begin{array}{c}\text { A Little } \\
(31.4 \%)\end{array}$ & $\begin{array}{c}\text { None } \\
(6.7 \%)\end{array}$ & Chi-Square \\
\hline$<1$ & 18 & 0 & 1 & 12 & 5 & 0 & $\chi 2(16)=25.9$ \\
& & $(0 \%)$ & $(5.6 \%)$ & $(66.7 \%)$ & $(27.9 \%)$ & $(0 \%)$ & NS \\
$1-3$ & 59 & 1 & 9 & 32 & 14 & 3 & \\
& & $(1.7 \%)$ & $(15.3 \%)$ & $(54.2 \%)$ & $(23.7 \%)$ & $(5.1 \%)$ & \\
$4-9$ & 144 & 1 & 11 & 81 & 46 & 5 & \\
& & $(0.7 \%)$ & $(7.6 \%)$ & $(56.3 \%)$ & $(31.9 \%)$ & $(3.5 \%)$ & \\
$10-19$ & 126 & 2 & 8 & 72 & 35 & 9 & \\
& & $(1.6 \%)$ & $(6.3 \%)$ & $(57.1 \%)$ & $(27.8 \%)$ & $(7.1 \%)$ & \\
20 or & 89 & 1 & 4 & 35 & 37 & 12 & \\
more & & $(1.1 \%)$ & $(4.5 \%)$ & $(39.3 \%)$ & $(41.6 \%)$ & $(13.5 \%)$ & \\
\hline
\end{tabular}

Note. Values enclosed in parenthesis represent percentage of responses in row. NS= Not statistically significant (at the $p<.05$ level). 
Table M3

Years of Experience (<1, 1-3, 4-9, 10-19, 20 or more) by Survey Item 17 (Need More Knowledge in Subject)

\begin{tabular}{|lccccccccc|}
\hline & $\mathrm{N}$ & $\begin{array}{c}\text { Algebra } \\
(14.8 \%)\end{array}$ & $\begin{array}{c}\text { Geo. } \\
(10.8 \%)\end{array}$ & $\begin{array}{c}\text { Meas. } \\
(3.7 \%)\end{array}$ & $\begin{array}{c}\text { Statistics } \\
(28.1 \%)\end{array}$ & $\begin{array}{c}\text { Probability } \\
(4.9 \%)\end{array}$ & $\begin{array}{c}\text { \#'s } \\
\text { and } \\
\text { Ops. } \\
(1.9 \%)\end{array}$ & $\begin{array}{c}\text { Process } \\
(35.8 \%)\end{array}$ & Chi-Square \\
& & & & & & & & \\
& & & & & & & & \\
& 18 & 1 & 3 & 0 & 6 & 0 & 1 & 7 & $\chi 2(24)=29.9$ \\
$1-3$ & 58 & 16 & 8 & 4 & 13 & 4 & 2 & 21 & NS \\
& & $(10.3 \%)$ & $(13.8 \%)$ & $(6.9 \%)$ & $(22.4 \%)$ & $(6.9 \%)$ & $(3.4 \%)$ & $(36.2 \%)$ & \\
$4-9$ & 143 & 15 & 17 & 4 & 38 & 4 & 3 & 62 & \\
& & $(10.5 \%)$ & $(11.9 \%)$ & $(2.8 \%)$ & $(26.6 \%)$ & $(2.8 \%)$ & $(2.1 \%)$ & $(43.4 \%)$ & \\
$10-$ & 125 & 26 & 13 & 6 & 35 & 5 & 2 & 38 & \\
19 & & $(20.8 \%)$ & $(10.4 \%)$ & $(4.8 \%)$ & $(28.0 \%)$ & $(4.0 \%)$ & $(1.6 \%)$ & $(30.4 \%)$ & \\
20 & 83 & 15 & 5 & 2 & 28 & 8 & 0 & 25 & \\
or & & $(18.1 \%)$ & $(6.0 \%)$ & $(2.4 \%)$ & $(33.7 \%)$ & $(9.6 \%)$ & $(0 \%)$ & $(30.1 \%)$ & \\
more & & & & & & & & & \\
\hline
\end{tabular}

Note. Values enclosed in parenthesis represent percentage of responses in row. NS= Not statistically significant (at the $p<.05$ level). Geo $=$ Geometry. Meas.= Measurement. \#'s and Ops. $=$ Numbers and Operations. Process $=$ Processes (communication, problem solving, reasoning and proof, representation, and connections).

Table M4

Years of Experience (<1, 1-3, 4-9, 10-19, 20 or more) by Survey Item 18 (Do Not Need More Knowledge in Subject)

\begin{tabular}{|lccccccccc|}
\hline & $\mathrm{N}$ & $\begin{array}{c}\text { Algebra } \\
(21.2 \%)\end{array}$ & $\begin{array}{c}\text { Geo. } \\
(12.8 \%)\end{array}$ & $\begin{array}{c}\text { Meas. } \\
(6.8 \%)\end{array}$ & $\begin{array}{c}\text { Statistics } \\
(3.5 \%)\end{array}$ & $\begin{array}{c}\text { Probability } \\
(5.8 \%)\end{array}$ & $\begin{array}{c}\text { \#'s and } \\
\text { Ops. } \\
(45.7 \%)\end{array}$ & $\begin{array}{c}\text { Process } \\
(4.2 \%)\end{array}$ & Chi-Square \\
\hline$<1$ & 18 & 5 & 0 & 3 & 1 & 0 & 8 & 1 & $\chi 2(24)=44.8$ \\
& & $(27.8 \%)$ & $(0 \%)$ & $(16.7 \%)$ & $(5.6 \%)$ & $(0 \%)$ & $(44.4 \%)$ & $(5.6 \%)$ & $p<.05$ \\
$1-3$ & 57 & 19 & 10 & 2 & 5 & 4 & 15 & 2 & \\
& & $(33.3 \%)$ & $(17.5 \%)$ & $(3.5 \%)$ & $(8.8 \%)$ & $(7.0 \%)$ & $(26.3 \%)$ & $(3.5 \%)$ & \\
$4-9$ & 142 & 25 & 28 & 12 & 5 & 9 & 60 & 3 & \\
& & $(17.6 \%)$ & $(19.7 \%)$ & $(8.5 \%)$ & $(3.5 \%)$ & $(6.3 \%)$ & $(42.3 \%)$ & $(2.1 \%)$ & \\
$10-$ & 126 & 23 & 10 & 4 & 2 & 8 & 71 & 8 & \\
19 & & $(18.3 \%)$ & $(7.9 \%)$ & $(3.2 \%)$ & $(1.6 \%)$ & $(6.3 \%)$ & $(56.3 \%)$ & $(6.3 \%)$ & \\
20 & 86 & 19 & 7 & 8 & 2 & 4 & 42 & 4 & \\
or & & $(22.1 \%)$ & $(8.1 \%)$ & $(9.3 \%)$ & $(2.3 \%)$ & $(4.7 \%)$ & $(48.8 \%)$ & $(4.7 \%)$ & \\
more & & & & & & & & & \\
\hline
\end{tabular}

Note. Values enclosed in parenthesis represent percentage of responses in row. NS= Not statistically significant (at the $p<.05$ level). Geo= Geometry. Meas.= Measurement. \#'s and Ops.= Numbers and Operations. Process $=$ Processes (communication, problem solving, reasoning and proof, representation, and connections). 
Table M5

Years of Experience (<1, 1-3, 4-9, 10-19, 20 or more) by Survey Item 27(Ability to Teach Mathematics)

\begin{tabular}{|lccccccc|}
\hline $\mathrm{N}$ & $\begin{array}{c}\text { Exceptional } \\
(14.5 \%)\end{array}$ & $\begin{array}{c}\text { Above } \\
\text { Average } \\
(60.5 \%)\end{array}$ & $\begin{array}{c}\text { Average } \\
(24.0 \%)\end{array}$ & $\begin{array}{c}\text { Below } \\
\text { Average } \\
(1.0 \%)\end{array}$ & $\begin{array}{c}\text { Poor } \\
(0 \%)\end{array}$ & Chi-Square \\
\hline$<1$ & 16 & 0 & 6 & 10 & 0 & 0 & $\chi 2(16)=31.9$ \\
& & $(0 \%)$ & $(37.5 \%)$ & $(62.5 \%)$ & $(0 \%)$ & $(0 \%)$ & $p<.05$ \\
$1-3$ & 51 & 3 & 36 & 12 & 0 & 0 & \\
& & $(5.9 \%)$ & $(70.6 \%)$ & $(23.5 \%)$ & $(0 \%)$ & $(0 \%)$ & \\
$4-9$ & 135 & 17 & 80 & 36 & 2 & 0 & \\
& & $(12.6 \%)$ & $(59.3 \%)$ & $(26.7 \%)$ & $(1.5 \%)$ & $(0 \%)$ & \\
$10-19$ & 116 & 18 & 67 & 30 & 1 & 0 & \\
& & $(15.5 \%)$ & $(57.8 \%)$ & $(25.9 \%)$ & $(0.9 \%)$ & $(0 \%)$ & \\
20 or & 82 & 20 & 53 & 8 & 1 & 0 & \\
more & & $(24.4 \%)$ & $(64.6 \%)$ & $(9.8 \%)$ & $(1.2 \%)$ & $(0 \%)$ & \\
\hline
\end{tabular}

Note. Values enclosed in parenthesis represent percentage of responses in row. NS $=$ Not statistically significant (at the $p<.05$ level).

Table M6

Years of Experience ( $<1,1-3,4-9,10-19,20$ or more) by Survey Item 29 (Professional Development Need for Teaching Math)

\begin{tabular}{|lccccccc|}
\hline & $\mathrm{N}$ & $\begin{array}{c}\text { A lot } \\
(1.3 \%)\end{array}$ & $\begin{array}{c}\text { Quite a bit } \\
(10.6 \%)\end{array}$ & $\begin{array}{c}\text { Some } \\
(41.9 \%)\end{array}$ & $\begin{array}{c}\text { A Little } \\
(39.4 \%)\end{array}$ & $\begin{array}{c}\text { None } \\
(6.8 \%)\end{array}$ & Chi-Square \\
\hline$<1$ & 10 & 0 & 2 & 6 & 1 & 1 & $\chi 2(16)=31.5$ \\
& & $(0 \%)$ & $(20.0 \%)$ & $(60.0 \%)$ & $(10.0 \%)$ & $(10.0 \%)$ & $p<.05$ \\
$1-3$ & 33 & 2 & 8 & 11 & 9 & 3 & \\
& & $(6.1 \%)$ & $(24.2 \%)$ & $(33.3 \%)$ & $(27.3 \%)$ & $(9.1 \%)$ & \\
$4-9$ & 81 & 0 & 10 & 35 & 28 & 8 & \\
& & $(0 \%)$ & $(12.3 \%)$ & $(43.2 \%)$ & $(34.6 \%)$ & $(9.9 \%)$ & \\
$10-19$ & 60 & 1 & 4 & 25 & 27 & 3 & \\
& & $(1.7 \%)$ & $(6.7 \%)$ & $(41.7 \%)$ & $(45.0 \%)$ & $(5.0 \%)$ & \\
20 or & 52 & 0 & 1 & 22 & 28 & 1 & \\
more & & $(0 \%)$ & $(1.9 \%)$ & $(42.3 \%)$ & $(53.8 \%)$ & $(1.9 \%)$ & \\
\hline
\end{tabular}

Note. Values enclosed in parenthesis represent percentage of responses in row. NS= Not statistically significant (at the $p<.05$ level). 
Table M7

Years of Experience (<1, 1-3, 4-9, 10-19, 20 or more) by Survey Item 30 (Need More Strategies for Teaching Mathematics)

\begin{tabular}{|lccccccccc|}
\hline & $\mathrm{N}$ & $\begin{array}{c}\text { Algebra } \\
(15.3 \%)\end{array}$ & $\begin{array}{c}\text { Geo. } \\
(10.4 \%)\end{array}$ & $\begin{array}{c}\text { Meas. } \\
(5.2 \%)\end{array}$ & $\begin{array}{c}\text { Statistics } \\
(20.5 \%)\end{array}$ & $\begin{array}{c}\text { Probability } \\
(4.9 \%)\end{array}$ & $\begin{array}{c}\text { \#'s and } \\
\text { Ops. } \\
(4.9 \%)\end{array}$ & $\begin{array}{c}\text { Process } \\
(38.6 \%)\end{array}$ & Chi-Square \\
\hline$<1$ & 16 & 1 & 4 & 1 & 3 & 0 & 2 & 5 & $\chi 2(24)=39.3$ \\
& & $(6.3 \%)$ & $(25.0 \%)$ & $(6.3 \%)$ & $(18.8 \%)$ & $(0 \%)$ & $(12.5 \%)$ & $(31.3 \%)$ & $p<.05$ \\
$1-3$ & 46 & 3 & 6 & 3 & 6 & 4 & 6 & 18 & \\
& & $(6.5 \%)$ & $(13.0 \%)$ & $(6.5 \%)$ & $(13.0 \%)$ & $(8.7 \%)$ & $(13.0 \%)$ & $(39.1 \%)$ & \\
$4-9$ & 125 & 21 & 13 & 7 & 18 & 4 & 5 & 57 & \\
& & $(16.8 \%)$ & $(10.4 \%)$ & $(5.6 \%)$ & $(14.4 \%)$ & $(3.2 \%)$ & $(4.0 \%)$ & $(45.6 \%)$ & \\
$10-$ & 110 & 20 & 11 & 4 & 28 & 3 & 2 & 42 & \\
19 & & $(18.2 \%)$ & $(10.0 \%)$ & $(3.6 \%)$ & $(25.5 \%)$ & $(2.7 \%)$ & $(1.8 \%)$ & $(38.2 \%)$ & \\
20 & 68 & 11 & 4( & 4 & 20 & 7 & 3 & 19 & \\
or & & $(16.2 \%)$ & $5.9 \%)$ & $(5.9 \%)$ & $(29.4 \%)$ & $(7.3 \%)$ & $(4.4 \%)$ & $(27.9 \%)$ & \\
more & & & & & & & & & \\
\hline
\end{tabular}

Note. Values enclosed in parenthesis represent percentage of response in row s. NS= Not statistically significant (at the $p<.05$ level). Geo $=$ Geometry. Meas.= Measurement. \#'s and Ops.= Numbers and Operations. Process= Processes (communication, problem solving, reasoning and proof, representation, and connections).

Table M8

Years of Experience (<1, 1-3, 4-9, 10-19, 20 or more) by Survey Item 31 (Do Not Need More Strategies for Teaching Mathematics)

\begin{tabular}{|lccccccccc|}
\hline & $\mathrm{N}$ & $\begin{array}{c}\text { Algebra } \\
(18.9 \%)\end{array}$ & $\begin{array}{c}\text { Geo. } \\
(15.6 \%)\end{array}$ & $\begin{array}{c}\text { Meas. } \\
(8.7 \%)\end{array}$ & $\begin{array}{c}\text { Statistics } \\
(4.6 \%)\end{array}$ & $\begin{array}{c}\text { Probability } \\
(6.6 \%)\end{array}$ & $\begin{array}{c}\text { \#'s and } \\
\text { Ops. } \\
(42.1 \%)\end{array}$ & $\begin{array}{c}\text { Process } \\
(3.6 \%)\end{array}$ & Chi-Square \\
\hline$<1$ & 16 & 5 & 1 & 2 & 0 & 2 & 5 & 1 & $\chi 2(24)=39.7$ \\
& & $(31.3 \%)$ & $(6.3 \%)$ & $(12.5 \%)$ & $(0 \%)$ & $(12.5 \%)$ & $(31.3 \%)$ & $(6.3 \%)$ & $p<.05$ \\
$1-3$ & 50 & 16 & 7 & 5 & 4 & 2 & 16 & 0 & \\
& & $(32.0 \%)$ & $(14.0 \%)$ & $(10.0 \%)$ & $(8.0 \%)$ & $(4.0 \%)$ & $(32.0 \%)$ & $(0 \%)$ & \\
$4-9$ & 133 & 19 & 27 & 16 & 5 & 12 & 53 & 1 & \\
& & $(14.3 \%)$ & $(20.3 \%)$ & $(12.0 \%)$ & $(3.8 \%)$ & $(9.0 \%)$ & $(39.8 \%)$ & $(0.8 \%)$ & \\
$10-$ & 116 & 18 & 15 & 5 & 3 & 5 & 62 & 8 & \\
19 & & $(15.5 \%)$ & $(12.9 \%)$ & $(4.3 \%)$ & $(2.6 \%)$ & $(4.3 \%)$ & $(53.4 \%)$ & $(6.9 \%)$ & \\
20 & 77 & 16 & 11 & 6 & 6 & 5 & 29 & 4 & \\
or & & $(20.8 \%)$ & $(14.3 \%)$ & $(7.8 \%)$ & $(7.8 \%)$ & $(6.5 \%)$ & $(37.7 \%)$ & $(5.2 \%)$ & \\
more & & & & & & & & & \\
\hline
\end{tabular}

Note. Values enclosed in parenthesis represent percentage of responses in row. NS= Not statistically significant (at the $p<.05$ level). $\mathrm{Geo}=$ Geometry. Meas.= Measurement. \#'s and Ops.= Numbers and Operations. Process $=$ Processes (communication, problem solving, reasoning and proof, representation, and connections). 
PT97= Earned certification before 1997. 9703= Earned certification between 1997 and 2003. 0409= Earned certification between 2004 and 2009. NC= I do not have my certification.

Table N1

Certification Year (Prior to 1997, 97-03, 04-09, NC) by Survey Item 14 (Math Content Knowledge)

\begin{tabular}{|cccccccc|}
\hline & $\mathrm{N}$ & $\begin{array}{c}\text { Exceptional } \\
(12.8 \%)\end{array}$ & $\begin{array}{c}\text { Above } \\
\text { Average } \\
(52.3 \%)\end{array}$ & $\begin{array}{c}\text { Average } \\
(32.2 \%)\end{array}$ & $\begin{array}{c}\text { Below } \\
\text { Average } \\
(2.5 \%)\end{array}$ & $\begin{array}{c}\text { Poor } \\
(0.2 \%)\end{array}$ & $\begin{array}{c}\text { Chi- } \\
\text { Square }\end{array}$ \\
\hline PT97 & 174 & 23 & 94 & 49 & 7 & 1 & $\chi 2(12)=9.6$ \\
& & $(13.2 \%)$ & $(54.0 \%)$ & $(28.2 \%)$ & $(4.0 \%)$ & $(0.6 \%)$ & NS \\
9703 & 131 & 13 & 70 & 45 & 3 & 0 & \\
& & $(9.9 \%)$ & $(53.4 \%)$ & $(34.4 \%)$ & $(2.3 \%)$ & $(0 \%)$ & \\
0409 & 127 & 20 & 61 & 45 & 1 & 0 & \\
& & $(15.7 \%)$ & $(48.0 \%)$ & $(35.4 \%)$ & $(0.8 \%)$ & $(0 \%)$ & \\
NC & 6 & 0 & 4 & 2 & 0 & 0 & \\
& & $(0 \%)$ & $(66.7 \%)$ & $(33.3 \%)$ & $(0 \%)$ & $(0 \%)$ & \\
\hline
\end{tabular}

Note. Values enclosed in parenthesis represent percentage of responses in row. NS= Not statistically significant (at the $p<.05$ level). PT97= Earned certification before 1997. 9703= Earned certification between 1997 and 2003. 0409= Earned certification between 2004 and 2009. NC= I do not have my certification.

Table N2

Certification Year (Prior to 1997, 97-03, 04-09, NC) by Survey Item 16 (Professional Development Need of Mathematics Content Knowledge)

\begin{tabular}{|cccccccc|}
\hline & $\mathrm{N}$ & $\begin{array}{c}\text { A lot } \\
(1.1 \%)\end{array}$ & $\begin{array}{c}\text { Quite a bit } \\
(7.6 \%)\end{array}$ & $\begin{array}{c}\text { Some } \\
(53.4 \%)\end{array}$ & $\begin{array}{c}\text { A Little } \\
(31.2 \%)\end{array}$ & $\begin{array}{c}\text { None } \\
(6.7 \%)\end{array}$ & Chi-Square \\
\hline PT97 & 173 & 1 & 9 & 87 & 57 & 19 & $\chi 2(12)=18.2$ \\
& & $(0.6 \%)$ & $(5.2 \%)$ & $(50.3 \%)$ & $(32.9 \%)$ & $(11.0 \%)$ & NS \\
9703 & 130 & 3 & 10 & 66 & 45 & 6 & \\
& & $(2.3 \%)$ & $(7.7 \%)$ & $(50.8 \%)$ & $(34.6 \%)$ & $(4.6 \%)$ & \\
0409 & 127 & 1 & 14 & 76 & 32 & 4 & \\
& & $(0.8 \%)$ & $(11.0 \%)$ & $(59.8 \%)$ & $(25.2 \%)$ & $(3.1 \%)$ & \\
NC & 6 & 0 & 0 & 4 & 2 & 0 & \\
& & $(0 \%)$ & $(0 \%)$ & $(66.7 \%)$ & $(33.3 \%)$ & $(0 \%)$ & \\
\hline
\end{tabular}

Note. Values enclosed in parenthesis represent percentage of responses in row. NS= Not statistically significant (at the $p<.05$ level). PT97= Earned certification before 1997. 9703= Earned certification between 1997 and 2003. 0409= Earned certification between 2004 and 2009. NC= I do not have my certification.

Table N3 
Certification Year (Prior to 1997, 97-03, 04-09, NC) by Survey Item 17 (Need More Knowledge in Subject)

\begin{tabular}{|cccccccccc|}
\hline & $\mathrm{N}$ & $\begin{array}{c}\text { Algebra } \\
(14.8 \%)\end{array}$ & $\begin{array}{c}\text { Geo. } \\
(10.8 \%)\end{array}$ & $\begin{array}{c}\text { Meas. } \\
(3.7 \%)\end{array}$ & $\begin{array}{c}\text { Statistics } \\
(27.9 \%)\end{array}$ & $\begin{array}{c}\text { Probability } \\
(5.2 \%)\end{array}$ & $\begin{array}{c}\text { \#'s } \\
\text { and } \\
\text { Ops. } \\
(1.9 \%)\end{array}$ & $\begin{array}{c}\text { Process } \\
(35.8 \%)\end{array}$ & Chi-Square \\
& & & & & & & & \\
& & & & & & & 2 & \\
PT97 & 167 & 34 & 11 & 7 & 49 & 11 & 2 & 53 & $\chi 2(18)=19.8$ \\
& & $(20.4 \%)$ & $(6.6 \%)$ & $(4.2 \%)$ & $(29.3 \%)$ & $(6.6 \%)$ & $(1.2 \%)$ & $(31.7 \%)$ & NS \\
9703 & 129 & 17 & 16 & 4 & 39 & 4 & 3 & 46 & \\
& & $(13.2 \%)$ & $(12.4 \%)$ & $(3.1 \%)$ & $(30.2 \%)$ & $(3.1 \%)$ & $(2.3 \%)$ & $(35.7 \%)$ & \\
0409 & 125 & 12 & 18 & 5 & 28 & 7 & 3 & 52 & \\
& & $(9.6 \%)$ & $(14.4 \%)$ & $(4.0 \%)$ & $(22.4 \%)$ & $(5.6 \%)$ & $(2.4 \%)$ & $(41.6 \%)$ & \\
NC & 6 & 0 & 1 & 0 & 3 & 0 & 0 & 2 & \\
& & $(0 \%)$ & $(16.7 \%)$ & $(0 \%)$ & $(50.0 \%)$ & $(0 \%)$ & $(0 \%)$ & $(33.3 \%)$ & \\
\hline
\end{tabular}

Note. Values enclosed in parenthesis represent percentage of responses in row. NS $=$ Not statistically significant (at the $p<.05$ level). PT97= Earned certification before 1997. 9703= Earned certification between 1997 and 2003. 0409= Earned certification between 2004 and 2009. NC= I do not have my certification. Geo $=$ Geometry. Meas.= Measurement. \#'s and Ops. $=$ Numbers and Operations. Process $=$ Processes (communication, problem solving, reasoning and proof, representation, and connections).

Table N4

Certification Year (Prior to 1997, 97-03, 04-09, NC) by Survey Item 18 (Do Not Need More Knowledge in Subject)

\begin{tabular}{|cccccccccc|}
\hline & N & $\begin{array}{c}\text { Algebra } \\
(21.0 \%)\end{array}$ & $\begin{array}{c}\text { Geo. } \\
(13.1 \%)\end{array}$ & $\begin{array}{c}\text { Meas. } \\
(6.8 \%)\end{array}$ & $\begin{array}{c}\text { Statistics } \\
(3.5 \%)\end{array}$ & $\begin{array}{c}\text { Probability } \\
(5.8 \%)\end{array}$ & $\begin{array}{c}\text { \#'s and } \\
\text { Ops. } \\
(45.7 \%)\end{array}$ & $\begin{array}{c}\text { Process } \\
(4.2 \%)\end{array}$ & Chi-Square \\
\hline PT97 & 170 & 32 & 14 & 11 & 4 & 8 & 91 & 10 & $\chi 2(18)=36.2$ \\
& & $(18.8 \%)$ & $(8.2 \%)$ & $(6.5 \%)$ & $(2.4 \%)$ & $(4.7 \%)$ & $(53.5 \%)$ & $(5.9 \%)$ & $p<.05$ \\
9703 & 129 & 23 & 19 & 8 & 1 & 11 & 63 & 4 & \\
& & $(17.8 \%)$ & $(14.7 \%)$ & $(6.2 \%)$ & $(0.8 \%)$ & $(8.5 \%)$ & $(48.8 \%)$ & $(3.1 \%)$ & \\
0409 & 124 & 32 & 23 & 10 & 10 & 6 & 39 & 4 & \\
& & $(25.8 \%)$ & $(18.5 \%)$ & $(8.1 \%)$ & $(8.1 \%)$ & $(4.8 \%)$ & $(31.5 \%)$ & $(3.2 \%)$ & \\
NC & 6 & 3 & 0 & 0 & 0 & 0 & 3 & 0 & \\
& & $(50.0 \%)$ & $(0 \%)$ & $(0 \%)$ & $(0 \%)$ & $(0 \%)$ & $(50.0 \%)$ & $(0 \%)$ & \\
\hline
\end{tabular}

Note. Values enclosed in parenthesis represent percentage of responses in row. NS= Not statistically significant (at the $p<.05$ level). PT97= Earned certification before 1997. 9703= Earned certification between 1997 and 2003. 0409= Earned certification between 2004 and 2009. NC= I do not have my certification. $\mathrm{Geo}=$ Geometry. Meas.= Measurement. \#'s and Ops.= Numbers and Operations. Process $=$ Processes (communication, problem solving, reasoning and proof, representation, and connections).

Table N5 
Certification Year (Prior to 1997, 97-03, 04-09, NC) by Survey Item 27(Ability to Teach Mathematics)

\begin{tabular}{|cccccccc|}
\hline $\mathrm{N}$ & $\begin{array}{c}\text { Exceptional } \\
(14.5 \%)\end{array}$ & $\begin{array}{c}\text { Above } \\
\text { Average } \\
(60.5 \%)\end{array}$ & $\begin{array}{c}\text { Average } \\
(24.0 \%)\end{array}$ & $\begin{array}{c}\text { Below } \\
\text { Average } \\
(1.0 \%)\end{array}$ & $\begin{array}{c}\text { Poor } \\
(0 \%)\end{array}$ & Chi-Square \\
\hline PT97 & 161 & 33 & 98 & 28 & 2 & 0 & $\chi 2(12)=16.8$ \\
& & $(20.5 \%)$ & $(60.9 \%)$ & $(17.4 \%)$ & $(1.2 \%)$ & $(0 \%)$ & NS \\
9703 & 122 & 16 & 77 & 28 & 1 & 0 & \\
& & $(13.1 \%)$ & $(63.1 \%)$ & $(23.0 \%)$ & $(0.8 \%)$ & $(0 \%)$ & \\
0409 & 111 & 9 & 63 & 38 & 1 & 0 & \\
& & $(8.1 \%)$ & $(56.8 \%)$ & $(34.2 \%)$ & $(0.9 \%)$ & $(0 \%)$ & \\
NC & 6 & 0 & 4 & 2 & 0 & 0 & \\
& & $(0 \%)$ & $(66.7 \%)$ & $(33.3 \%)$ & $(0 \%)$ & $(0 \%)$ & \\
\hline
\end{tabular}

Note. Values enclosed in parenthesis represent percentage of responses in row. NS $=$ Not statistically significant (at the $p<.05$ level). PT97= Earned certification before 1997. 9703= Earned certification between 1997 and 2003. 0409= Earned certification between 2004 and 2009. NC= I do not have my certification.

Table N6

Certification Year (Prior to 1997, 97-03, 04-09, NC) by Survey Item 29 (Professional Development Need for Teaching Math)

\begin{tabular}{|cccccccc|}
\hline & $\mathrm{N}$ & $\begin{array}{c}\text { A lot } \\
(1.3 \%)\end{array}$ & $\begin{array}{c}\text { Quite a bit } \\
(10.5 \%)\end{array}$ & $\begin{array}{c}\text { Some } \\
(42.2 \%)\end{array}$ & $\begin{array}{c}\text { A Little } \\
(39.2 \%)\end{array}$ & $\begin{array}{c}\text { None } \\
(6.8 \%)\end{array}$ & Chi-Square \\
\hline PT97 & 95 & 1 & 4 & 43 & 44 & 3 & $\chi 2(12)=24.2$ \\
& & $(1.1 \%)$ & $(4.2 \%)$ & $(45.3 \%)$ & $(46.3 \%)$ & $(3.2 \%)$ & $p<.05$ \\
9703 & 75 & 0 & 8 & 27 & 31 & 9 & \\
& & $(0 \%)$ & $(10.7 \%)$ & $(36.0 \%)$ & $(41.3 \%)$ & $(12.0 \%)$ & \\
0409 & 62 & 2 & 12 & 27 & 18 & 3 & \\
& & $(3.2 \%)$ & $(19.4 \%)$ & $(43.5 \%)$ & $(29.0 \%)$ & $(4.8 \%)$ & \\
NC & 5 & 0 & 1 & 3 & 0 & 1 & \\
& & $(0 \%)$ & $(20.0 \%)$ & $(60.0 \%)$ & $(0 \%)$ & $(20.0 \%)$ & \\
\hline
\end{tabular}

Note. Values enclosed in parenthesis represent percentage of responses in row. NS= Not statistically significant (at the $p<.05$ level). PT97= Earned certification before 1997. 9703= Earned certification between 1997 and 2003. 0409= Earned certification between 2004 and 2009. NC= I do not have my certification.

Table N7

Certification Year (Prior to 1997, 97-03, 04-09, NC) by Survey Item 30 (Need More Strategies for Teaching Mathematics)

\begin{tabular}{|cccccccccc|}
\hline & N & $\begin{array}{c}\text { Algebra } \\
(15.4 \%)\end{array}$ & $\begin{array}{c}\text { Geo } \\
(10.4 \%)\end{array}$ & $\begin{array}{c}\text { Meas. } \\
(5.2 \%)\end{array}$ & $\begin{array}{c}\text { Statistics } \\
(20.3 \%)\end{array}$ & $\begin{array}{c}\text { Probability } \\
(4.9 \%)\end{array}$ & $\begin{array}{c}\text { \#'s and } \\
\text { Ops. } \\
(4.9 \%)\end{array}$ & $\begin{array}{c}\text { Process } \\
(38.7 \%)\end{array}$ & Chi-Square \\
\hline PT97 & 144 & 26 & 10 & 7 & 40 & 7 & 3 & 51 & $\chi 2(18)=37.9$ \\
& & $(18.1 \%)$ & $(6.9 \%)$ & $(4.9 \%)$ & $(27.8 \%)$ & $(4.9 \%)$ & $(2.1 \%)$ & $(35.4 \%)$ & $p<.05$ \\
9703 & 114 & 23 & 11 & 5 & 21 & 6 & 7 & 41 & \\
& & $(20.2 \%)$ & $(9.6 \%)$ & $(4.4 \%)$ & $(18.4 \%)$ & $(5.3 \%)$ & $(6.1 \%)$ & $(36.0 \%)$ & \\
0409 & 100 & 7 & 14 & 7 & 12 & 5 & 7 & 48 &
\end{tabular}




\begin{tabular}{|lcccccccc|} 
& & $(7.0 \%)$ & $(14.0 \%)$ & $(7.0 \%)$ & $(12.0 \%)$ & $(5.0 \%)$ & $(7.0 \%)$ & $(48.0 \%)$ \\
$\mathrm{NC}$ & 6 & 0 & 3 & 0 & 1 & 0 & 1 & 1 \\
& & $(0 \%)$ & $(50.0 \%)$ & $(0 \%)$ & $(16.7 \%)$ & $(0 \%)$ & $(16.7 \%)$ & $(16.7 \%)$ \\
\hline
\end{tabular}

Note. Values enclosed in parenthesis represent percentage of responses in row. NS= Not statistically significant (at the $p<.05$ level). PT97= Earned certification before 1997. 9703= Earned certification between 1997 and 2003. 0409= Earned certification between 2004 and 2009. NC= I do not have my certification. Geo $=$ Geometry. Meas.= Measurement. \#'s and Ops. $=$ Numbers and Operations. Process $=$ Processes (communication, problem solving, reasoning and proof, representation, and connections).

Table N8

Certification Year (Prior to 1997, 97-03, 04-09, NC) by Survey Item 31 (Do Not Need More Strategies for Teaching Mathematics)

\begin{tabular}{|cccccccccc|}
\hline & $\mathrm{N}$ & $\begin{array}{c}\text { Algebra } \\
(18.6 \%)\end{array}$ & $\begin{array}{c}\text { Geo } \\
(15.8 \%)\end{array}$ & $\begin{array}{c}\text { Meas. } \\
(8.7 \%)\end{array}$ & $\begin{array}{c}\text { Statistics } \\
(4.6 \%)\end{array}$ & $\begin{array}{c}\text { Probability } \\
(6.6 \%)\end{array}$ & $\begin{array}{c}\text { \#'s and } \\
\text { Ops. } \\
(42.1 \%)\end{array}$ & $\begin{array}{c}\text { Process } \\
(3.6 \%)\end{array}$ & Chi-Square \\
\hline PT97 & 156 & 25 & 20 & 9 & 8 & 8 & 76 & 10 & $\chi 2(18)=24.1$ \\
& & $(16.0 \%)$ & $(12.8 \%)$ & $(5.8 \%)$ & $(5.1 \%)$ & $(5.1 \%)$ & $(48.7 \%)$ & $(6.4 \%)$ & NS \\
9703 & 120 & 19 & 24 & 12 & 4 & 9 & 50 & 2 & \\
& & $(15.8 \%)$ & $(20.0 \%)$ & $(10.0 \%)$ & $(3.3 \%)$ & $(7.5 \%)$ & $(41.7 \%)$ & $(1.7 \%)$ & \\
0409 & 110 & 27 & 18 & 13 & 6 & 9 & 35 & 2 & \\
& & $(24.5 \%)$ & $(16.4 \%)$ & $(11.8 \%)$ & $(5.5 \%)$ & $(8.2 \%)$ & $(31.8 \%)$ & $(1.8 \%)$ & \\
NC & 6 & 2 & 0 & 0 & 0 & 0 & 4 & 0 & \\
& & $(33.3 \%)$ & $(0 \%)$ & $(0 \%)$ & $(0 \%)$ & $(0 \%)$ & $(66.7 \%)$ & $(0 \%)$ & \\
\hline
\end{tabular}

Note. Values enclosed in parenthesis represent percentage of responses in row. NS= Not statistically significant (at the $p<.05$ level). PT97= Earned certification before 1997. 9703= Earned certification between 1997 and 2003. 0409= Earned certification between 2004 and 2009. NC= I do not have my certification. $\mathrm{Geo}=$ Geometry. Meas.= Measurement. \#'s and Ops. $=$ Numbers and Operations. Process $=$ Processes (communication, problem solving, reasoning and proof, representation, and connections). 
Table O1

Certification in Math (Yes or No) by Survey Item 14 (Math Content Knowledge)

\begin{tabular}{|cccccccc|}
\hline & $\mathrm{N}$ & $\begin{array}{c}\text { Exceptional } \\
(12.8 \%)\end{array}$ & $\begin{array}{c}\text { Above } \\
\text { Average } \\
(52.4 \%)\end{array}$ & $\begin{array}{c}\text { Average } \\
(32.1 \%)\end{array}$ & $\begin{array}{c}\text { Below } \\
\text { Average } \\
(2.5 \%)\end{array}$ & $\begin{array}{c}\text { Poor } \\
(0.2 \%)\end{array}$ & $\begin{array}{c}\text { Chi- } \\
\text { Square }\end{array}$ \\
\hline Yes & 373 & 49 & 103 & 112 & 8 & 1 & $\chi 2(4)=7.1$ \\
& & $(13.1 \%)$ & $(54.4 \%)$ & $(30.0 \%)$ & $(2.1 \%)$ & $(0.3 \%)$ & NS \\
No & 66 & 7 & 27 & 29 & 3 & 0 & \\
& & $(10.6 \%)$ & $(40.9 \%)$ & $(43.9 \%)$ & $(4.5 \%)$ & $(0 \%)$ & \\
\hline
\end{tabular}

Note. Values enclosed in parenthesis represent percentage of responses in row. NS= Not statistically significant (at the $p<.05$ level).

Table $\mathrm{O} 2$

Certification in Math (Yes or No) by Survey Item 16 (Professional Development Need of Mathematics Content Knowledge)

\begin{tabular}{|cccccccc|}
\hline & $\mathrm{N}$ & $\begin{array}{c}\text { A lot } \\
(1.1 \%)\end{array}$ & $\begin{array}{c}\text { Quite a bit } \\
(7.6 \%)\end{array}$ & $\begin{array}{c}\text { Some } \\
(53.3 \%)\end{array}$ & $\begin{array}{c}\text { A Little } \\
(31.6 \%)\end{array}$ & $\begin{array}{c}\text { None } \\
(6.4 \%)\end{array}$ & Chi-Square \\
\hline Yes & 371 & 4 & 22 & 198 & 121 & 26 & $\chi 2(4)=10.9$, \\
& & $(1.1 \%)$ & $(5.9 \%)$ & $(53.4 \%)$ & $(32.6 \%)$ & $(7.0 \%)$ & $p<.05$ \\
No & 66 & 1 & 11 & 35 & 17 & 2 & \\
& & $(1.5 \%)$ & $(16.7 \%)$ & $(53.0 \%)$ & $(25.8 \%)$ & $(3.0 \%)$ & \\
\hline
\end{tabular}

Note. Values enclosed in parenthesis represent percentage of responses in row. NS= Not statistically significant (at the $p<.05$ level).

Table O3

Certification in Math (Yes or No) by Survey Item 17 (Need More Knowledge in Subject)

\begin{tabular}{|cccccccccc|}
\hline & $\mathrm{N}$ & $\begin{array}{c}\text { Algebra } \\
(14.7 \%)\end{array}$ & $\begin{array}{c}\text { Geo. } \\
(10.7 \%)\end{array}$ & $\begin{array}{c}\text { Meas. } \\
(3.7 \%)\end{array}$ & $\begin{array}{c}\text { Statistics } \\
(28.0 \%)\end{array}$ & $\begin{array}{c}\text { Probability } \\
(5.1 \%)\end{array}$ & $\begin{array}{c}\text { \#'s and } \\
\text { Ops. } \\
(1.9 \%)\end{array}$ & $\begin{array}{c}\text { Process } \\
(35.9 \%)\end{array}$ & $\begin{array}{c}\text { Chi- } \\
\text { Square }\end{array}$ \\
\hline Yes & 364 & 54 & 39 & 15 & 102 & 18 & 5 & 131 & $\chi 2(6)=4.1$ \\
& & $(14.8 \%)$ & $(10.7 \%)$ & $(4.1 \%)$ & $(28.0 \%)$ & $(4.9 \%)$ & $(1.4 \%)$ & $(36.0 \%)$ & NS \\
No & 65 & 9 & 7 & 1 & 18 & 4 & 3 & 23 & \\
& & $(13.8 \%)$ & $(10.8 \%)$ & $(1.5 \%)$ & $(27.7 \%)$ & $(6.2 \%)$ & $(4.6 \%)$ & $(35.4 \%)$ & \\
\hline
\end{tabular}

Note. Values enclosed in parenthesis represent percentage of responses in row. NS= Not statistically significant (at the $p<.05$ level). Geo= Geometry. Meas.= Measurement. \#'s and Ops. $=$ Numbers and Operations. Process $=$ Processes (communication, problem solving, reasoning and proof, representation, and connections).

Table $\mathrm{O} 4$

Certification in Math (Yes or No) by Survey Item 18 (Do Not Need More Knowledge in Subject)

\begin{tabular}{|cccccccccc|}
\hline & $\mathrm{N}$ & $\begin{array}{c}\text { Algebra } \\
(21.2 \%)\end{array}$ & $\begin{array}{c}\text { Geo. } \\
(13.0 \%)\end{array}$ & $\begin{array}{c}\text { Meas. } \\
(7.0 \%)\end{array}$ & $\begin{array}{c}\text { Statistics } \\
(3.5 \%)\end{array}$ & $\begin{array}{c}\text { Probability } \\
(5.8 \%)\end{array}$ & $\begin{array}{c}\text { \#'s and } \\
\text { Ops. } \\
(45.6 \%)\end{array}$ & $\begin{array}{c}\text { Process } \\
(4.0 \%)\end{array}$ & $\begin{array}{c}\text { Chi- } \\
\text { Square }\end{array}$ \\
\hline Yes & 365 & 81 & 47 & 27 & 13 & 22 & 162 & 13 & $\chi 2(6)=3.8$
\end{tabular}




\begin{tabular}{|c|c|c|c|c|c|c|c|c|c|}
\hline & & $(22.2 \%)$ & $(12.9 \%)$ & $(7.4 \%)$ & $(3.6 \%)$ & $(6.0 \%)$ & $(44.4 \%)$ & $(3.6 \%)$ & NS \\
\hline No & 65 & $\begin{array}{c}10 \\
(15.4 \%)\end{array}$ & $\begin{array}{c}9 \\
(13.8 \%)\end{array}$ & $\begin{array}{c}3 \\
(4.6 \%)\end{array}$ & $\begin{array}{c}2 \\
(3.1 \%)\end{array}$ & $\begin{array}{c}3 \\
(4.6 \%)\end{array}$ & $\begin{array}{c}34 \\
(52.3 \%)\end{array}$ & $\begin{array}{c}4 \\
(6.2 \%)\end{array}$ & \\
\hline
\end{tabular}

Note. Values enclosed in parenthesis represent percentage of responses in row. NS= Not statistically significant (at the $p<.05$ level). Geo= Geometry. Meas.= Measurement. \#'s and Ops. $=$ Numbers and Operations. Process $=$ Processes (communication, problem solving, reasoning and proof, representation, and connections).

Table O5

Certification in Math (Yes or No) by Survey Item 27(Ability to Teach Mathematics)

\begin{tabular}{|cccccccc|}
\hline & $\mathrm{N}$ & $\begin{array}{c}\text { Exceptional } \\
(14.2 \%)\end{array}$ & $\begin{array}{c}\text { Above } \\
\text { Average } \\
(60.8 \%)\end{array}$ & $\begin{array}{c}\text { Average } \\
(23.9 \%)\end{array}$ & $\begin{array}{c}\text { Below } \\
\text { Average } \\
(1.0 \%)\end{array}$ & $\begin{array}{c}\text { Poor } \\
(0 \%)\end{array}$ & $\begin{array}{c}\text { Chi- } \\
\text { Square }\end{array}$ \\
\hline Yes & 342 & 51 & 209 & 78 & 4 & 0 & $\chi 2(4)=2.8$ \\
& & $(14.9 \%)$ & $(61.1 \%)$ & $(22.8 \%)$ & $(1.2 \%)$ & $(0 \%)$ & NS \\
No & 59 & 6 & 35 & 18 & 0 & 0 & \\
& & $(10.2 \%)$ & $(59.3 \%)$ & $(30.5 \%)$ & $(0 \%)$ & $(0 \%)$ & \\
\hline
\end{tabular}

Note. Values enclosed in parenthesis represent percentage of responses in row. NS= Not statistically significant (at the $p<.05$ level).

Table O6

Certification in Math (Yes or No) by Survey Item 29 (Professional Development Need for Teaching Math)

\begin{tabular}{|cccccccc|}
\hline & $\mathrm{N}$ & $\begin{array}{c}\text { A lot } \\
(1.3 \%)\end{array}$ & $\begin{array}{c}\text { Quite a bit } \\
(10.5 \%)\end{array}$ & $\begin{array}{c}\text { Some } \\
(42.4 \%)\end{array}$ & $\begin{array}{c}\text { A Little } \\
(39.1 \%)\end{array}$ & $\begin{array}{c}\text { None } \\
(6.7 \%)\end{array}$ & $\begin{array}{c}\text { Chi- } \\
\text { Square }\end{array}$ \\
\hline Yes & 203 & 2 & 21 & 83 & 83 & 14 & $\chi 2(4)=2.9$ \\
& & $(1.0 \%)$ & $(10.3 \%)$ & $(40.9 \%)$ & $(40.9 \%)$ & $(6.9 \%)$ & NS \\
No & 35 & 1 & 4 & 18 & 10 & 2 & \\
& & $(2.9 \%)$ & $(11.4 \%)$ & $(51.4 \%)$ & $(28.6 \%)$ & $(5.7 \%)$ & \\
\hline
\end{tabular}

Note. Values enclosed in parenthesis represent percentage of responses in row. NS= Not statistically significant (at the $p<.05$ level).

Table $\mathrm{O} 7$

Certification in Math (Yes or No) by Survey Item 30 (Need More Strategies for Teaching Mathematics)

\begin{tabular}{|cccccccccc|}
\hline & N & Algebra & Geo. & Meas. & Statistics & Probability & \#'s & Process & Chi- \\
& & & & & & \\
& & & & & & & Ond \\
Ops. & $(38.8 \%)$ & Square \\
& & & & & & & \\
\hline Yes & 312 & 50 & $28.9 \%)$ & & \\
& & $(16.0 \%)$ & $(9.0 \%)$ & $(5.8 \%)$ & $(22.1 \%)$ & $(4.8 \%)$ & $(4.5 \%)$ & $(37.8 \%)$ & NS \\
No & 54 & 6 & 10 & 1 & 6 & 3 & 4 & 24 & \\
& & $(11.1 \%)$ & $(18.5 \%)$ & $(1.9 \%)$ & $(11.1 \%)$ & $(5.6 \%)$ & $(7.4 \%)$ & $(44.4 \%)$ & \\
\hline
\end{tabular}

Note. Values enclosed in parenthesis represent percentage of responses in row. NS= Not statistically significant (at the $p<.05$ level). Geo $=$ Geometry. Meas.= Measurement. \#'s and Ops. $=$ Numbers and Operations. Process $=$ Processes (communication, problem solving, reasoning and proof, representation, and connections). 
Table O8

Certification in Math (Yes or No) by Survey Item 31 (Do Not Need More Strategies for Teaching Mathematics)

\begin{tabular}{|cccccccccc|}
\hline & $\mathrm{N}$ & $\begin{array}{c}\text { Algebra } \\
(18.8 \%)\end{array}$ & $\begin{array}{c}\text { Geo. } \\
(15.8 \%)\end{array}$ & $\begin{array}{c}\text { Meas. } \\
(8.9 \%)\end{array}$ & $\begin{array}{c}\text { Statistics } \\
(4.6 \%)\end{array}$ & $\begin{array}{c}\text { Probability } \\
(6.6 \%)\end{array}$ & $\begin{array}{c}\text { \#'s and } \\
\text { Ops. } \\
(42.0 \%)\end{array}$ & $\begin{array}{c}\text { Process } \\
(3.3 \%)\end{array}$ & $\begin{array}{c}\text { Chi- } \\
\text { Square }\end{array}$ \\
\hline Yes & 334 & 71 & 51 & 31 & 13 & 19 & 140 & 9 & $\chi 2(6)=15.4$ \\
& & $(21.3 \%)$ & $(15.3 \%)$ & $(9.3 \%)$ & $(3.9 \%)$ & $(5.7 \%)$ & $(41.9 \%)$ & $(2.7 \%)$ & $p<.05$ \\
No & 59 & 3 & 11 & 4 & 5 & 7 & 25 & 4 & \\
& & $(5.1 \%)$ & $(18.6 \%)$ & $(6.8 \%)$ & $(8.5 \%)$ & $(11.5 \%)$ & $(42.4 \%)$ & $(6.8 \%)$ & \\
\hline
\end{tabular}

Note. Values enclosed in parenthesis represent percentage of responses in row. NS= Not statistically significant (at the $p<.05$ level). Geo= Geometry. Meas.= Measurement. \#'s and Ops.= Numbers and Operations. Process $=$ Processes (communication, problem solving, reasoning and proof, representation, and connections). 
Table: Q1

Highly Qualified (Yes or No) by Survey Item 14 (Math Content Knowledge)

\begin{tabular}{|cccccccc|}
\hline & $\mathrm{N}$ & $\begin{array}{c}\text { Exceptional } \\
(12.7 \%)\end{array}$ & $\begin{array}{c}\text { Above } \\
\text { Average } \\
(52.8 \%)\end{array}$ & $\begin{array}{c}\text { Average } \\
(31.7 \%)\end{array}$ & $\begin{array}{c}\text { Below } \\
\text { Average } \\
(2.5 \%)\end{array}$ & $\begin{array}{c}\text { Poor } \\
(0.2 \%)\end{array}$ & $\begin{array}{c}\text { Chi- } \\
\text { Square }\end{array}$ \\
\hline Yes & 287 & 40 & 154 & 85 & 7 & 1 & $\chi 2(4)=2.8$ \\
& & $(13.9 \%)$ & $(53.7 \%)$ & $(29.6 \%)$ & $(2.4 \%)$ & $(0.3 \%)$ & NS \\
No & 145 & 15 & 74 & 52 & 4 & 0 & \\
& & $(10.3 \%)$ & $(51.0 \%)$ & $(35.9 \%)$ & $(2.8 \%)$ & $(0 \%)$ & \\
\hline
\end{tabular}

Note. Values enclosed in parenthesis represent percentage of responses in row. NS= Not statistically significant (at the $p<.05$ level).

Table: Q2

Highly Qualified (Yes or No) by Survey Item 16 (Professional Development Need of Mathematics Content Knowledge)

\begin{tabular}{|cccccccc|}
\hline & $\mathrm{N}$ & $\begin{array}{c}\text { A lot } \\
(1.2 \%)\end{array}$ & $\begin{array}{c}\text { Quite a bit } \\
(7.4 \%)\end{array}$ & $\begin{array}{c}\text { Some } \\
(53.3 \%)\end{array}$ & $\begin{array}{c}\text { A Little } \\
(31.4 \%)\end{array}$ & $\begin{array}{c}\text { None } \\
(6.7 \%)\end{array}$ & $\begin{array}{c}\text { Chi- } \\
\text { Square }\end{array}$ \\
\hline Yes & 285 & 3 & 19 & 151 & 89 & 23 & $\chi 2(4)=3.4$ \\
& & $(1.1 \%)$ & $(6.7 \%)$ & $(53.0 \%)$ & $(31.2 \%)$ & $(8.1 \%)$ & NS \\
No & 145 & 2 & 13 & 78 & 46 & 6 & \\
& & $(1.4 \%)$ & $(9.0 \%)$ & $(53.8 \%)$ & $(31.7 \%)$ & $(4.1 \%)$ & \\
\hline
\end{tabular}

Note. Values enclosed in parenthesis represent percentage of responses in row. NS= Not statistically significant (at the $p<.05$ level).

Table: Q3

Highly Qualified (Yes or No) by Survey Item 17 (Need More Knowledge in Subject)

\begin{tabular}{|cccccccccc|}
\hline & $\mathrm{N}$ & $\begin{array}{c}\text { Algebra } \\
(14.7 \%)\end{array}$ & $\begin{array}{c}\text { Geo. } \\
(10.9 \%)\end{array}$ & $\begin{array}{c}\text { Meas. } \\
(3.8 \%)\end{array}$ & $\begin{array}{c}\text { Statistics } \\
(27.7 \%)\end{array}$ & $\begin{array}{c}\text { Probability } \\
(5.0 \%)\end{array}$ & $\begin{array}{c}\text { \#'s and } \\
\text { Ops. } \\
(1.9 \%)\end{array}$ & $\begin{array}{c}\text { Process } \\
(36.0 \%)\end{array}$ & $\begin{array}{c}\text { Chi- } \\
\text { Square }\end{array}$ \\
\hline Yes & 280 & 43 & 34 & 12 & 78 & 14 & 5 & 94 & $\chi 2(6)=3.4$ \\
& & $(15.4 \%)$ & $(12.1 \%)$ & $(4.3 \%)$ & $(27.9 \%)$ & $(5.0 \%)$ & $(1.8 \%)$ & $(33.6 \%)$ & NS \\
No & 142 & 19 & 12 & 4 & 39 & 5 & 3 & 58 & \\
& & $(13.4 \%)$ & $(8.5 \%)$ & $(2.8 \%)$ & $(27.5 \%)$ & $(4.9 \%)$ & $(2.1 \%)$ & $(40.8 \%)$ & \\
\hline
\end{tabular}

Note. Values enclosed in parenthesis represent percentage of responses in row. NS= Not statistically significant (at the $p<.05$ level). Geo= Geometry. Meas.= Measurement. \#'s and Ops.= Numbers and Operations. Process $=$ Processes (communication, problem solving, reasoning and proof, representation, and connections).

Table: Q4

Highly Qualified (Yes or No) by Survey Item 18 (Do Not Need More Knowledge in Subject)

\begin{tabular}{|cccccccccc|}
\hline & $\mathrm{N}$ & $\begin{array}{c}\text { Algebra } \\
(21.2 \%)\end{array}$ & $\begin{array}{c}\text { Geo. } \\
(13.0 \%)\end{array}$ & $\begin{array}{c}\text { Meas. } \\
(7.1 \%)\end{array}$ & $\begin{array}{c}\text { Statistics } \\
(3.5 \%)\end{array}$ & $\begin{array}{c}\text { Probability } \\
(5.9 \%)\end{array}$ & $\begin{array}{c}\text { \#'s and } \\
\text { Ops. } \\
(45.3 \%)\end{array}$ & $\begin{array}{c}\text { Process } \\
(4.0 \%)\end{array}$ & $\begin{array}{c}\text { Chi- } \\
\text { Square }\end{array}$ \\
\hline Yes & & & & & & & 11 & \\
& & 69 & 41 & 18 & 12 & 17 & 112 & 11 & $\chi 2(6)=13.2$ \\
& $(24.6 \%)$ & $(14.6 \%)$ & $(6.4 \%)$ & $(4.3 \%)$ & $(6.1 \%)$ & $(40.0 \%)$ & $(3.9 \%)$ & $p<.05$
\end{tabular}




\begin{tabular}{|c|c|c|c|c|c|c|c|c|}
\hline No & 144 & $\begin{array}{c}21 \\
(14.6 \%)\end{array}$ & $\begin{array}{c}14 \\
(9.7 \%)\end{array}$ & $\begin{array}{c}12 \\
(8.3 \%)\end{array}$ & $\begin{array}{c}3 \\
(2.1 \%)\end{array}$ & $\begin{array}{c}8 \\
(5.6 \%)\end{array}$ & $\begin{array}{c}80 \\
(55.6 \%)\end{array}$ & $\begin{array}{c}6 \\
(4.2 \%)\end{array}$ \\
\hline
\end{tabular}

Note. Values enclosed in parenthesis represent percentage of responses in row. NS= Not statistically significant (at the $p<.05$ level). Geo= Geometry. Meas.= Measurement. \#'s and Ops. $=$ Numbers and Operations. Process $=$ Processes (communication, problem solving, reasoning and proof, representation, and connections).

Table: Q5

Highly Qualified (Yes or No) by Survey Item 27(Ability to Teach Mathematics)

\begin{tabular}{|cccccccc|}
\hline & $\mathrm{N}$ & $\begin{array}{c}\text { Exceptional } \\
(14.2 \%)\end{array}$ & $\begin{array}{c}\text { Above } \\
\text { Average } \\
(61.2 \%)\end{array}$ & $\begin{array}{c}\text { Average } \\
(23.6 \%)\end{array}$ & $\begin{array}{c}\text { Below } \\
\text { Average } \\
(1.0 \%)\end{array}$ & $\begin{array}{c}\text { Poor } \\
(0 \%)\end{array}$ & $\begin{array}{c}\text { Chi- } \\
\text { Square }\end{array}$ \\
\hline Yes & 265 & 40 & 159 & 63 & 3 & 0 & $\chi 2(6)=0.7$ \\
& & $(15.1 \%)$ & $(60.0 \%)$ & $(23.8 \%)$ & $(1.1 \%)$ & $(0 \%)$ & NS \\
No & 129 & 16 & 82 & 30 & 1 & 0 & \\
& & $(12.4 \%)$ & $(63.6 \%)$ & $(23.3 \%)$ & $(0.8 \%)$ & $(0 \%)$ & \\
\hline
\end{tabular}

Note. Values enclosed in parenthesis represent percentage of responses in row. NS= Not statistically significant (at the $p<.05$ level).

Table: Q6

Highly Qualified (Yes or No) by Survey Item 29 (Professional Development Need for Teaching Math)

\begin{tabular}{|cccccccc|}
\hline & $\mathrm{N}$ & $\begin{array}{c}\text { A lot } \\
(1.3 \%)\end{array}$ & $\begin{array}{c}\text { Quite a bit } \\
(10.7 \%)\end{array}$ & $\begin{array}{c}\text { Some } \\
(42.5 \%)\end{array}$ & $\begin{array}{c}\text { A Little } \\
(39.1 \%)\end{array}$ & $\begin{array}{c}\text { None } \\
(6.4 \%)\end{array}$ & $\begin{array}{c}\text { Chi- } \\
\text { Square }\end{array}$ \\
\hline Yes & 160 & 2 & 17 & 68 & 63 & 10 & $\chi 2(4)=0.1$ \\
& & $(1.3 \%)$ & $(10.6 \%)$ & $(42.5 \%)$ & $(39.4 \%)$ & $(6.3 \%)$ & NS \\
No & 73 & 1 & 8 & 31 & 28 & 5 & \\
& & $(1.4 \%)$ & $(11.0 \%)$ & $(42.5 \%)$ & $(38.4 \%)$ & $(6.8 \%)$ & \\
\hline
\end{tabular}

Note. Values enclosed in parenthesis represent percentage of responses in row. NS= Not statistically significant (at the $p<.05$ level).

Table: Q7

Highly Qualified (Yes or No) by Survey Item 30 (Need More Strategies for Teaching Mathematics)

\begin{tabular}{|cccccccccc|}
\hline & $\mathrm{N}$ & $\begin{array}{c}\text { Algebra } \\
(15.3 \%)\end{array}$ & $\begin{array}{c}\text { Geo. } \\
(10.6 \%)\end{array}$ & $\begin{array}{c}\text { Meas. } \\
(5.3 \%)\end{array}$ & $\begin{array}{c}\text { Statistics } \\
(20.3 \%)\end{array}$ & $\begin{array}{c}\text { Probability } \\
(4.5 \%)\end{array}$ & $\begin{array}{c}\text { \#'s and } \\
\text { Ops. } \\
(5.0 \%)\end{array}$ & $\begin{array}{c}\text { Process } \\
(39.0 \%)\end{array}$ & $\begin{array}{c}\text { Chi- } \\
\text { Square }\end{array}$ \\
\hline Yes & 241 & 43 & 27 & 16 & 47 & 11 & 10 & 87 & $\chi 2(6)=8.8$ \\
& & $(17.8 \%)$ & $(11.2 \%)$ & $(6.6 \%)$ & $(19.5 \%)$ & $(4.6 \%)$ & $(4.1 \%)$ & $(36.1 \%)$ & NS \\
No & 118 & 12 & 11 & 3 & 26 & 5 & 8 & 53 & \\
& & $(10.2 \%)$ & $(9.3 \%)$ & $(2.5 \%)$ & $(22.0 \%)$ & $(4.2 \%)$ & $(6.8 \%)$ & $(44.9 \%)$ & \\
\hline
\end{tabular}

Note. Values enclosed in parenthesis represent percentage of responses in row. NS= Not statistically significant (at the $p<.05$ level). Geo $=$ Geometry. Meas.= Measurement. \#'s and Ops. = Numbers and Operations. Process $=$ Processes (communication, problem solving, reasoning and proof, representation, and connections).

Table: Q8 
Highly Qualified (Yes or No) by Survey Item 31 (Do Not Need More Strategies for Teaching Mathematics)

\begin{tabular}{|cccccccccc|}
\hline & $\mathrm{N}$ & $\begin{array}{c}\text { Algebra } \\
(18.9 \%)\end{array}$ & $\begin{array}{c}\text { Geo. } \\
(15.8 \%)\end{array}$ & $\begin{array}{c}\text { Meas. } \\
(9.0 \%)\end{array}$ & $\begin{array}{c}\text { Statistics } \\
(4.7 \%)\end{array}$ & $\begin{array}{c}\text { Probability } \\
(6.7 \%)\end{array}$ & $\begin{array}{c}\text { \#'s and } \\
\text { Ops. } \\
(41.3 \%)\end{array}$ & $\begin{array}{c}\text { Process } \\
(3.6 \%)\end{array}$ & $\begin{array}{c}\text { Chi- } \\
\text { Square }\end{array}$ \\
\hline Yes & 258 & 58 & 40 & 20 & 13 & 16 & 103 & 8 & $\chi 2(6)=8.3$ \\
& & $(22.5 \%)$ & $(15.5 \%)$ & $(7.8 \%)$ & $(5.0 \%)$ & $(6.2 \%)$ & $(39.9 \%)$ & $(3.1 \%)$ & NS \\
No & 129 & 15 & 21 & 15 & 5 & 10 & 57 & 6 & \\
& & $(11.6 \%)$ & $(16.3 \%)$ & $(11.6 \%)$ & $(3.9 \%)$ & $(7.8 \%)$ & $(44.2 \%)$ & $(4.7 \%)$ & \\
\hline
\end{tabular}

Note. Values enclosed in parenthesis represent percentage of responses in row. NS $=$ Not statistically significant (at the $p<.05$ level). Geo= Geometry. Meas.= Measurement. \#'s and Ops.= Numbers and Operations. Process $=$ Processes (communication, problem solving, reasoning and proof, representation, and connections).

Research Question 2: What are similarities and differences in identified mathematics professional development needs by general education and special education mathematics teachers by grade level (elementary vs. secondary)?

Table G1

Grade Level (Elementary or Secondary) by Survey Item 14 (Math Content Knowledge)

\begin{tabular}{|cccccccc|}
\hline $\mathrm{N}$ & $\begin{array}{c}\text { Exceptional } \\
(12.8 \%)\end{array}$ & $\begin{array}{c}\text { Above } \\
\text { Average } \\
(52.6 \%)\end{array}$ & $\begin{array}{c}\text { Average } \\
(31.9 \%)\end{array}$ & $\begin{array}{c}\text { Below } \\
\text { Average } \\
(2.5 \%)\end{array}$ & $\begin{array}{c}\text { Poor } \\
(0.2 \%)\end{array}$ & $\begin{array}{c}\text { Chi- } \\
\text { Square }\end{array}$ \\
\hline EL & 329 & 26 & 167 & 125 & 10 & 1 & $\chi 2(4)=42.3$ \\
& & $(7.9 \%)$ & $(50.8 \%)$ & $(38.0 \%)$ & $(3.0 \%)$ & $(0.3 \%)$ & $p<.05$ \\
SEC & 110 & 30 & 64 & 15 & 1 & 0 & \\
& & $(27.3 \%)$ & $(58.2 \%)$ & $(13.6 \%)$ & $(0.9 \%)$ & $(0 \%)$ & \\
\hline
\end{tabular}

Note. Values enclosed in parenthesis represent percentage of responses in row. NS= Not statistically significant (at the $p<.05$ level). $\mathrm{EL}=$ Elementary. $\mathrm{SEC}=$ Secondary. Geo= Geometry. Meas.= Measurement. \#'s and Ops.= Numbers and Operations. Process $=$ Processes (communication, problem solving, reasoning and proof, representation, and connections).

Table G2

Grade Level (Elementary or Secondary) by Survey Item 16 (Professional Development Need of Mathematics Content Knowledge)

\begin{tabular}{|cccccccc|}
\hline & $\mathrm{N}$ & $\begin{array}{c}\text { A lot } \\
(1.1 \%)\end{array}$ & $\begin{array}{c}\text { Quite a bit } \\
(7.6 \%)\end{array}$ & $\begin{array}{c}\text { Some } \\
(53.1 \%)\end{array}$ & $\begin{array}{c}\text { A Little } \\
(31.6 \%)\end{array}$ & $\begin{array}{c}\text { None } \\
(6.6 \%)\end{array}$ & $\begin{array}{c}\text { Chi- } \\
\text { Square }\end{array}$ \\
\hline EL & 327 & 5 & 22 & 187 & 92 & 21 & $\chi 2(4)=11.9$ \\
& & $(1.5 \%)$ & $(6.7 \%)$ & $(57.2 \%)$ & $(28.1 \%)$ & $(6.4 \%)$ & $p<.05$ \\
SEC & 110 & 0 & 11 & 45 & 46 & 8 & \\
& & $(0 \%)$ & $(10 \%)$ & $(40.9 \%)$ & $(41.8 \%)$ & $(7.3 \%)$ & \\
\hline
\end{tabular}

Note. Values enclosed in parenthesis represent percentage of responses in row. NS $=$ Not statistically significant (at the $p<.05$ level). $\mathrm{EL}=$ Elementary. $\mathrm{SEC}=$ Secondary. Geo $=$ Geometry. Meas. $=$ Measurement. \#'s and Ops. $=$ Numbers and Operations. Process $=$ Processes (communication, problem solving, reasoning and proof, representation, and connections). 
Table G3

Grade Level (Elementary or Secondary) by Survey Item 17(Need More Knowledge in Subject)

\begin{tabular}{|c|c|c|c|c|c|c|c|c|c|}
\hline & $\mathrm{N}$ & $\begin{array}{l}\text { Algebra } \\
(14.7 \%)\end{array}$ & $\begin{array}{c}\text { Geo. } \\
(10.5 \%)\end{array}$ & $\begin{array}{l}\text { Meas. } \\
(3.7 \%)\end{array}$ & $\begin{array}{l}\text { Statistics } \\
(28.0 \%)\end{array}$ & $\begin{array}{c}\text { Probability } \\
(5.1 \%)\end{array}$ & $\begin{array}{c}\text { \#'s } \\
\text { and } \\
\text { Ops. } \\
(1.9 \%)\end{array}$ & $\begin{array}{l}\text { Process } \\
(36.0 \%)\end{array}$ & $\begin{array}{l}\text { Chi- } \\
\text { Square }\end{array}$ \\
\hline$\overline{E L}$ & 320 & $\begin{array}{c}47 \\
(14.7 \%)\end{array}$ & $\begin{array}{c}20 \\
(6.3 \%)\end{array}$ & $\begin{array}{c}16 \\
(5.0 \%)\end{array}$ & $\begin{array}{c}83 \\
(25.9 \%)\end{array}$ & $\begin{array}{c}10 \\
(3.1 \%)\end{array}$ & $\begin{array}{c}8 \\
(2.5 \%)\end{array}$ & $\begin{array}{c}136 \\
(42.5 \%)\end{array}$ & $\begin{array}{c}\chi^{2(6)}=57.2 \\
p<.05\end{array}$ \\
\hline SEC & 208 & $\begin{array}{c}16 \\
(14.8 \%)\end{array}$ & $\begin{array}{c}25 \\
(23.1 \%)\end{array}$ & $\begin{array}{c}0 \\
(0 \%)\end{array}$ & $\begin{array}{c}37 \\
(34.3 \%)\end{array}$ & $\begin{array}{c}12 \\
(11.1 \%)\end{array}$ & $\begin{array}{c}0 \\
(0 \%)\end{array}$ & $\begin{array}{c}18 \\
(16.7 \%)\end{array}$ & \\
\hline
\end{tabular}

Note. Values enclosed in parenthesis represent percentage of responses in row. NS= Not statistically significant (at the $p<.05$ level). $\mathrm{EL}=$ Elementary. $\mathrm{SEC}=$ Secondary. Geo $=$ Geometry. Meas.= Measurement. \#'s and Ops. $=$ Numbers and Operations. Process $=$ Processes (communication, problem solving, reasoning and proof, representation, and connections).

Table G4

Grade Level (Elementary or Secondary) by Survey Item 18(Do Not Need More Knowledge in Subject)

\begin{tabular}{|cccccccccc|}
\hline & $\mathrm{N}$ & $\begin{array}{c}\text { Algebra } \\
(21.2 \%)\end{array}$ & $\begin{array}{c}\text { Geo. } \\
(13.0 \%)\end{array}$ & $\begin{array}{c}\text { Meas. } \\
(7.0 \%)\end{array}$ & $\begin{array}{c}\text { Statistics } \\
(3.5 \%)\end{array}$ & $\begin{array}{c}\text { Probability } \\
(5.6 \%)\end{array}$ & $\begin{array}{c}\text { \#'s and } \\
\text { Ops. } \\
(45.6 \%)\end{array}$ & $\begin{array}{c}\text { Process } \\
(4.2 \%)\end{array}$ & $\begin{array}{c}\text { Chi- } \\
\text { Square }\end{array}$ \\
\hline EL & 320 & 40 & 43 & 30 & 13 & 18 & 161 & 15 & $\chi 2(6)=62.9$ \\
& & $(12.5 \%)$ & $(13.4 \%)$ & $(9.4 \%)$ & $(4.1 \%)$ & $(5.6 \%)$ & $(50.3 \%)$ & $(4.7 \%)$ & $p<.05$ \\
SEC & 110 & 51 & 13 & 0 & 2 & 6 & 35 & 3 & \\
& & $(46.4 \%)$ & $(11.8 \%)$ & $(0 \%)$ & $(1.8 \%)$ & $(5.5 \%)$ & $(31.8 \%)$ & $(2.7 \%)$ & \\
\hline
\end{tabular}

Note. Values enclosed in parenthesis represent percentage of responses in row. NS $=$ Not statistically significant (at the $p<.05$ level). $\mathrm{EL}=$ Elementary. $\mathrm{SEC}=$ Secondary. Geo $=$ Geometry. Meas.= Measurement. \#'s and Ops. $=$ Numbers and Operations. Process $=$ Processes (communication, problem solving, reasoning and proof, representation, and connections).

Table G5

Grade Level (Elementary or Secondary) by Survey Item 27(Ability to Teach Mathematics)

\begin{tabular}{|cccccccc|}
\hline $\mathrm{N}$ & $\begin{array}{c}\text { Exceptional } \\
(14.4 \%)\end{array}$ & $\begin{array}{c}\text { Above } \\
\text { Average } \\
(60.7 \%)\end{array}$ & $\begin{array}{c}\text { Average } \\
(23.9 \%)\end{array}$ & $\begin{array}{c}\text { Below } \\
\text { Average } \\
(1.0 \%)\end{array}$ & $\begin{array}{c}\text { Poor } \\
(0 \%)\end{array}$ & $\begin{array}{c}\text { Chi- } \\
\text { Square }\end{array}$ \\
\hline EL & 297 & 34 & 183 & 77 & 3 & 0 & $\chi 2(4)=9.15$ \\
& & $(11.4 \%)$ & $(61.6 \%)$ & $(25.9 \%)$ & $(1.0 \%)$ & $(0 \%)$ & $p<.05$ \\
SEC & 105 & 24 & 61 & 19 & 1 & 0 & \\
& & $(22.9 \%)$ & $(58.1 \%)$ & $(18.1 \%)$ & $(1.0 \%)$ & $(0 \%)$ & \\
\hline
\end{tabular}

Note. Values enclosed in parenthesis represent percentage of responses in row. NS $=$ Not statistically significant (at the $p<.05$ level). $\mathrm{EL}=$ Elementary. $\mathrm{SEC}=$ Secondary. Geo= Geometry. Meas.= Measurement. \#'s and Ops.= Numbers and Operations. Process= Processes (communication, problem solving, reasoning and proof, representation, and connections).

Table G6

Grade Level (Elementary or Secondary) by Survey Item 29 (Professional Development Need for Teaching Math) 


\begin{tabular}{|cccccccc|}
\hline & $\mathrm{N}$ & $\begin{array}{c}\text { A lot } \\
(1.3 \%)\end{array}$ & $\begin{array}{c}\text { Quite a bit } \\
(10.5 \%)\end{array}$ & $\begin{array}{c}\text { Some } \\
(42.4 \%)\end{array}$ & $\begin{array}{c}\text { A Little } \\
(39.1 \%)\end{array}$ & $\begin{array}{c}\text { None } \\
(6.7 \%)\end{array}$ & $\begin{array}{c}\text { Chi- } \\
\text { Square }\end{array}$ \\
\hline EL & 169 & 3 & 16 & 76 & 60 & 14 & $\chi 2(4)=6.7$ \\
& & $(1.8 \%)$ & $(9.5 \%)$ & $(45.0 \%)$ & $(35.5 \%)$ & $(8.3 \%)$ & NS \\
SEC & 69 & 0 & 9 & 25 & 33 & 2 & \\
& & $(0 \%)$ & $(13.0 \%)$ & $(36.2 \%)$ & $(47.8 \%)$ & $(2.9 \%)$ & \\
\hline
\end{tabular}

Note. Values enclosed in parenthesis represent percentage of responses in row. NS= Not statistically significant (at the $p<.05$ level). $\mathrm{EL}=$ Elementary. $\mathrm{SEC}=$ Secondary. Geo= Geometry. Meas.= Measurement. \#'s and Ops. $=$ Numbers and Operations. Process $=$ Processes (communication, problem solving, reasoning and proof, representation, and connections).

Table G7

Grade Level (Elementary or Secondary) by Survey Item 30 (Need More Strategies for Teaching Mathematics)

\begin{tabular}{|cccccccccc|}
\hline & $\mathrm{N}$ & $\begin{array}{c}\text { Algebra } \\
(15.3 \%)\end{array}$ & $\begin{array}{c}\text { Geo. } \\
(10.4 \%)\end{array}$ & $\begin{array}{c}\text { Meas. } \\
(5.2 \%)\end{array}$ & $\begin{array}{c}\text { Statistics } \\
(20.5 \%)\end{array}$ & $\begin{array}{c}\text { Probability } \\
(4.9 \%)\end{array}$ & $\begin{array}{c}\# \text { 's } \\
\text { and } \\
\text { Ops. }\end{array}$ & $\begin{array}{c}\text { Process } \\
(38.8 \%)\end{array}$ & $\begin{array}{c}\text { Chi- } \\
\text { Square } \\
\end{array}$ \\
& & & & & & $(4.9 \%)$ & & \\
\hline EL & 276 & 37 & 15 & 19 & 52 & 17 & 16 & 120 & $\chi 2(6)=48.4$ \\
& & $(13.4 \%)$ & $(5.4 \%)$ & $(6.9 \%)$ & $(18.8 \%)$ & $(6.2 \%)$ & $(5.8 \%)$ & $(43.5 \%)$ & $p<.05$ \\
SEC & 90 & 19 & 23 & 0 & 23 & 1 & 2 & 22 & \\
& & $(21.1 \%)$ & $(25.6 \%)$ & $(0 \%)$ & $(25.6 \%)$ & $(1.1 \%)$ & $(2.2 \%)$ & $(24.4 \%)$ & \\
\hline
\end{tabular}

Note. Values enclosed in parenthesis represent percentage of responses in row. NS= Not statistically significant (at the $p<.05$ level). $\mathrm{EL}=$ Elementary. $\mathrm{SEC}=$ Secondary. Geo= Geometry. Meas.= Measurement. \#'s and Ops. $=$ Numbers and Operations. Process $=$ Processes (communication, problem solving, reasoning and proof, representation, and connections).

Table G8

Grade Level (Elementary or Secondary) by Survey Item 31 (Do Not Need More Strategies for Teaching Mathematics)

\begin{tabular}{|cccccccccc|}
\hline & $\mathrm{N}$ & $\begin{array}{c}\text { Algebra } \\
(18.8 \%)\end{array}$ & $\begin{array}{c}\text { Geo. } \\
(15.7 \%)\end{array}$ & $\begin{array}{c}\text { Meas. } \\
(8.9 \%)\end{array}$ & $\begin{array}{c}\text { Statistics } \\
(4.6 \%)\end{array}$ & $\begin{array}{c}\text { Probability } \\
(6.6 \%)\end{array}$ & $\begin{array}{c}\text { \#'s and } \\
\text { Ops. } \\
(41.9 \%)\end{array}$ & $\begin{array}{c}\text { Process } \\
(3.6 \%)\end{array}$ & $\begin{array}{c}\text { Chi- } \\
\text { Square }\end{array}$ \\
\hline EL & 291 & 33 & 49 & 34 & 14 & 17 & 133 & 11 & $\chi 2(6)=48.6$ \\
& & $(11.3 \%)$ & $(16.8 \%)$ & $(11.7 \%)$ & $(4.8 \%)$ & $(5.8 \%)$ & $(45.7 \%)$ & $(3.8 \%)$ & $p<.05$ \\
SEC & 103 & 41 & 13 & 1 & 4 & 9 & 32 & 3 & \\
& & $(39.8 \%)$ & $(12.6 \%)$ & $(1.0 \%)$ & $(3.9 \%)$ & $(8.7 \%)$ & $(31.1 \%)$ & $(2.9 \%)$ & \\
\hline
\end{tabular}

Note. Values enclosed in parenthesis represent percentage of responses in row. NS= Not statistically significant (at the $p<.05$ level). $\mathrm{EL}=$ Elementary. $\mathrm{SEC}=$ Secondary. Geo= Geometry. Meas.= Measurement. \#'s and Ops.= Numbers and Operations. Process $=$ Processes (communication, problem solving, reasoning and proof, representation, and connections).

Research Question 3: What are similarities and differences in identified mathematics professional development needs by teacher classification (general education vs. special education)?

Table R1 
Teacher Classification (General Education or Special Education) by Survey Item 14 (Math Content Knowledge)

\begin{tabular}{|lccccccc|}
\hline & $\mathrm{N}$ & $\begin{array}{c}\text { Exceptional } \\
(12.8 \%)\end{array}$ & $\begin{array}{c}\text { Above } \\
\text { Average } \\
(52.4 \%)\end{array}$ & $\begin{array}{c}\text { Average } \\
(32.0 \%)\end{array}$ & $\begin{array}{c}\text { Below } \\
\text { Average } \\
(2.5 \%)\end{array}$ & $\begin{array}{c}\text { Poor } \\
(0.2 \%)\end{array}$ & $\begin{array}{c}\text { Chi- } \\
\text { Square }\end{array}$ \\
\hline GE & 369 & 53 & 198 & 110 & 7 & 1 & $\chi 2(4)=12.6$ \\
SPED & 68 & $(14.4 \%)$ & $(53.7 \%)$ & $(29.8 \%)$ & $(1.9 \%)$ & $(0.3 \%)$ & $p<.05$ \\
& & $(4.4 \%)$ & $(45.6 \%)$ & $(44.1 \%)$ & $(5.9 \%)$ & $(0 \%)$ & \\
\hline
\end{tabular}

Note. Values enclosed in parenthesis represent percentage of responses in row. NS $=$ Not statistically significant (at the $p<.05$ level). GE= General Education. SPED= Special Education.

Table R2

Teacher Classification (General Education or Special Education) by Survey Item 16 (Professional Development Need of Mathematics Content Knowledge)

\begin{tabular}{|lccccccc|}
\hline & $\mathrm{N}$ & $\begin{array}{c}\text { A lot } \\
(1.1 \%)\end{array}$ & $\begin{array}{c}\text { Quite a bit } \\
(7.6 \%)\end{array}$ & $\begin{array}{c}\text { Some } \\
(53.3 \%)\end{array}$ & $\begin{array}{c}\text { A Little } \\
(31.3 \%)\end{array}$ & $\begin{array}{c}\text { None } \\
(6.7 \%)\end{array}$ & $\begin{array}{c}\text { Chi- } \\
\text { Square }\end{array}$ \\
\hline GE & 368 & 5 & 19 & 199 & 119 & 26 & $\chi 2(4)=21.1$ \\
& & $(1.4 \%)$ & $(5.2 \%)$ & $(54.1 \%)$ & $(32.3 \%)$ & $(7.1 \%)$ & $p<.05$ \\
SPED & 67 & 0 & 14 & 33 & 17 & 3 & \\
& & $(0 \%)$ & $(20.9 \%)$ & $(49.3 \%)$ & $(25.4 \%)$ & $(4.5 \%)$ & \\
\hline
\end{tabular}

Note. Values enclosed in parenthesis represent percentage of responses in row. NS= Not statistically significant (at the $p<.05$ level). GE $=$ General Education. $\mathrm{SPED}=$ Special Education.

Table R3

Teacher Classification (General Education or Special Education) by Survey Item 17 (Need More Knowledge in Subject)

\begin{tabular}{|lccccccccc|}
\hline & N & $\begin{array}{c}\text { Algebra } \\
(14.8 \%)\end{array}$ & $\begin{array}{c}\text { Geo. } \\
(10.8 \%)\end{array}$ & $\begin{array}{c}\text { Meas. } \\
(3.8 \%)\end{array}$ & $\begin{array}{c}\text { Statistics } \\
(27.9 \%)\end{array}$ & $\begin{array}{c}\text { Probability } \\
(5.2 \%)\end{array}$ & $\begin{array}{c}\text { \#'s } \\
\text { and } \\
\text { Ops. }\end{array}$ & $\begin{array}{c}\text { Process } \\
(35.7 \%)\end{array}$ & $\begin{array}{c}\text { Chi- } \\
\text { Square } \\
\end{array}$ \\
& & & & & & $(1.9 \%)$ & & \\
\hline GE & 359 & 56 & 32 & 15 & 107 & 18 & 6 & 125 & $\chi 2(6)=13.6$ \\
& & $(15.6 \%)$ & $(8.9 \%)$ & $(4.2 \%)$ & $(29.8 \%)$ & $(5.0 \%)$ & $(1.7 \%)$ & $(34.8 \%)$ & $p<.05$ \\
SPED & 67 & 7 & 14 & 1 & 12 & 4 & 2 & 27 & \\
& & $(10.4 \%)$ & $(20.9 \%)$ & $(1.5 \%)$ & $(17.9 \%)$ & $(6.0 \%)$ & $(3.0 \%)$ & $(40.3 \%)$ & \\
\hline
\end{tabular}

Note. Values enclosed in parenthesis represent percentage of responses in row. NS= Not statistically significant (at the $p<.05$ level). $\mathrm{GE}=$ General Education. $\mathrm{SPED}=$ Special Education. $\mathrm{Geo}=$ Geometry. Meas.= Measurement. \#'s and Ops.= Numbers and Operations. Process $=$ Processes (communication, problem solving, reasoning and proof, representation, and connections).

Table R4

Teacher Classification (General Education or Special Education) by Survey Item 18 (Do Not Need More Knowledge in Subject)

\begin{tabular}{|ccccccccc|}
\hline $\mathrm{N}$ & Algebra & Geo. & Meas. & Statistics & Probability & \#'s and & Process & Chi- \\
& $(21.3 \%)$ & $(13.1 \%)$ & $(6.8 \%)$ & $(3.5 \%)$ & $(5.8 \%)$ & Ops. & $(4.2 \%)$ & Square \\
\hline
\end{tabular}




\begin{tabular}{|lccccccccc|}
\hline \multicolumn{10}{|c|}{$(45.3 \%)$} \\
\hline GE & 363 & 79 & 50 & 26 & 13 & 22 & 160 & 13 & $\chi 2(6)=5.0$ \\
& & $(21.8 \%)$ & $(13.8 \%)$ & $(7.2 \%)$ & $(3.6 \%)$ & $(6.1 \%)$ & $(44.1 \%)$ & $(3.6 \%)$ & NS \\
SPED & 65 & 12 & 6 & 3 & 2 & 3 & 34 & 5 & \\
& & $(18.5 \%)$ & $(9.2 \%)$ & $(4.6 \%)$ & $(3.1 \%)$ & $(4.6 \%)$ & $(52.3 \%)$ & $(7.7 \%)$ & \\
\hline
\end{tabular}

Note. Values enclosed in parenthesis represent percentage of responses in row. NS= Not statistically significant (at the $p<.05$ level). $\mathrm{GE}=$ General Education. SPED $=$ Special Education. Geo= Geometry. Meas. $=$ Measurement. \#'s and Ops. $=$ Numbers and Operations. Process $=$ Processes (communication, problem solving, reasoning and proof, representation, and connections).

Table R5

Teacher Classification (General Education or Special Education) by Survey Item 27(Ability to Teach Mathematics)

\begin{tabular}{|lccccccc|}
\hline $\mathrm{N}$ & $\begin{array}{c}\text { Exceptional } \\
(14.5 \%)\end{array}$ & $\begin{array}{c}\text { Above } \\
\text { Average } \\
(60.7 \%)\end{array}$ & $\begin{array}{c}\text { Average } \\
(23.8 \%)\end{array}$ & $\begin{array}{c}\text { Below } \\
\text { Average } \\
(1.0 \%)\end{array}$ & $\begin{array}{c}\text { Poor } \\
(0 \%)\end{array}$ & $\begin{array}{c}\text { Chi- } \\
\text { Square }\end{array}$ \\
\hline GE & 337 & 53 & 212 & 69 & 3 & 0 & $\chi 2(4)=14.3$ \\
SPED & 62 & $(15.7 \%)$ & $(62.9 \%)$ & $(20.5 \%)$ & $(0.9 \%)$ & $(0 \%)$ & $p<.05$ \\
& & $(8.1 \%)$ & $(48.4 \%)$ & $(41.9 \%)$ & $(1.6 \%)$ & $(0 \%)$ & \\
\hline
\end{tabular}

Note. Values enclosed in parenthesis represent percentage of responses in row. NS= Not statistically significant (at the $p<.05$ level). GE= General Education. $\mathrm{SPED}=$ Special Education. 
Table R6

Teacher Classification (General Education or Special Education) by Survey Item 29 (Professional Development Need for Teaching Math)

\begin{tabular}{|lccccccc|}
\hline & $\mathrm{N}$ & $\begin{array}{c}\text { A lot } \\
(1.3 \%)\end{array}$ & $\begin{array}{c}\text { Quite a bit } \\
(10.6 \%)\end{array}$ & $\begin{array}{c}\text { Some } \\
(42.4 \%)\end{array}$ & $\begin{array}{c}\text { A Little } \\
(39.4 \%)\end{array}$ & $\begin{array}{c}\text { None } \\
(6.4 \%)\end{array}$ & $\begin{array}{c}\text { Chi- } \\
\text { Square }\end{array}$ \\
\hline GE & 204 & 2 & 17 & 87 & 84 & 14 & $\chi 2(4)=10.1$ \\
& & $(1.0 \%)$ & $(8.3 \%)$ & $(42.6 \%)$ & $(41.2 \%)$ & $(6.9 \%)$ & $p<.05$ \\
SPED & 32 & 1 & 8 & 13 & 9 & 1 & \\
& & $(3.1 \%)$ & $(25.0 \%)$ & $(40.6 \%)$ & $(28.1 \%)$ & $(3.1 \%)$ & \\
\hline
\end{tabular}

Note. Values enclosed in parenthesis represent percentage of responses in row. NS= Not statistically significant (at the $p<.05$ level). GE $=$ General Education. SPED= Special Education.

Table R7

Teacher Classification (General Education or Special Education) by Survey Item 30 (Need More Strategies for Teaching Mathematics)

\begin{tabular}{|c|c|c|c|c|c|c|c|c|c|}
\hline & $\mathrm{N}$ & $\begin{array}{l}\text { Algebra } \\
(15.4 \%)\end{array}$ & $\begin{array}{c}\text { Geo. } \\
(10.5 \%)\end{array}$ & $\begin{array}{l}\text { Meas. } \\
(5.2 \%)\end{array}$ & $\begin{array}{c}\text { Statistics } \\
(20.4 \%)\end{array}$ & $\begin{array}{c}\text { Probability } \\
(5.0 \%)\end{array}$ & $\begin{array}{c}\text { \#'s } \\
\text { and } \\
\text { Ops. } \\
(4.7 \%)\end{array}$ & $\begin{array}{l}\text { Process } \\
(38.8 \%)\end{array}$ & $\begin{array}{c}\text { Chi- } \\
\text { Square }\end{array}$ \\
\hline GE & 305 & $\begin{array}{c}48 \\
(15.7 \%)\end{array}$ & $\begin{array}{c}27 \\
(8.9 \%)\end{array}$ & $\begin{array}{c}16 \\
(5.2 \%)\end{array}$ & $\begin{array}{c}68 \\
(22.3 \%)\end{array}$ & $\begin{array}{c}17 \\
(5.6 \%)\end{array}$ & $\begin{array}{c}14 \\
(4.6 \%)\end{array}$ & $\begin{array}{c}115 \\
(37.7 \%)\end{array}$ & $\begin{array}{c}\chi 2(6)=10.4 \\
\text { NS }\end{array}$ \\
\hline SPED & 58 & $\begin{array}{c}8 \\
(13.8 \%) \\
\end{array}$ & $\begin{array}{c}11 \\
(19.0 \%) \\
\end{array}$ & $\begin{array}{c}3 \\
(5.2 \%) \\
\end{array}$ & $\begin{array}{c}6 \\
(10.3 \%) \\
\end{array}$ & $\begin{array}{c}1 \\
(1.7 \%) \\
\end{array}$ & $\begin{array}{c}3 \\
(5.2 \%) \\
\end{array}$ & $\begin{array}{c}26 \\
(44.8 \%) \\
\end{array}$ & \\
\hline
\end{tabular}

Note. Values enclosed in parenthesis represent percentage of responses in row. NS= Not statistically significant (at the $p<.05$ level). $\mathrm{GE}=$ General Education. SPED $=$ Special Education. Geo= Geometry. Meas. $=$ Measurement. \#'s and Ops. $=$ Numbers and Operations. Process $=$ Processes (communication, problem solving, reasoning and proof, representation, and connections).

Table R8

Teacher Classification (General Education or Special Education) by Survey Item 31 (Do Not Need More Strategies for Teaching Mathematics)

\begin{tabular}{|lccccccccc|}
\hline & $\mathrm{N}$ & $\begin{array}{c}\text { Algebra } \\
(18.9 \%)\end{array}$ & $\begin{array}{c}\text { Geo. } \\
(15.9 \%)\end{array}$ & $\begin{array}{c}\text { Meas. } \\
(8.7 \%)\end{array}$ & $\begin{array}{c}\text { Statistics } \\
(4.6 \%)\end{array}$ & $\begin{array}{c}\text { Probability } \\
(6.6 \%)\end{array}$ & $\begin{array}{c}\text { \#'s and } \\
\text { Ops. } \\
(41.7 \%)\end{array}$ & $\begin{array}{c}\text { Process } \\
(3.6 \%)\end{array}$ & $\begin{array}{c}\text { Chi- } \\
\text { Square }\end{array}$ \\
\hline GE & 329 & 68 & 52 & 29 & 15 & 21 & 131 & 13 & $\chi 2(6)=6.1$ \\
& & $(20.7 \%)$ & $(15.8 \%)$ & $(8.8 \%)$ & $(4.6 \%)$ & $(6.4 \%)$ & $(39.8 \%)$ & $(4.0 \%)$ & NS \\
SPED & 62 & 6 & 10 & 5 & 3 & 5 & 32 & 1 & \\
& & $(9.7 \%)$ & $(16.1 \%)$ & $(8.1 \%)$ & $(4.8 \%)$ & $(8.1 \%)$ & $(51.6 \%)$ & $(1.6 \%)$ & \\
\hline
\end{tabular}

Note. Values enclosed in parenthesis represent percentage of responses in row. NS= Not statistically significant (at the $p<.05$ level). $\mathrm{GE}=$ General Education. SPED $=$ Special Education. $\mathrm{Geo}=$ Geometry. Meas.= Measurement. \#'s and Ops. $=$ Numbers and Operations. Process $=$ Processes (communication, problem solving, reasoning and proof, representation, and connections). 
Research Question 4: What are similarities and differences in identified mathematics professional development needs of special education teachers by grade level (elementary vs. secondary)? 
Table S1

Special Education Teacher Classification (Elementary or Secondary) by Survey Item 14 (Math Content Knowledge)

\begin{tabular}{|lccccccc|}
\hline & $\mathrm{N}$ & $\begin{array}{c}\text { Exceptional } \\
(4.4 \%)\end{array}$ & $\begin{array}{c}\text { Above } \\
\text { Average } \\
(45.6 \%)\end{array}$ & $\begin{array}{c}\text { Average } \\
(44.1 \%)\end{array}$ & $\begin{array}{c}\text { Below } \\
\text { Average } \\
(5.9 \%)\end{array}$ & $\begin{array}{c}\text { Poor } \\
(0 \%)\end{array}$ & $\begin{array}{c}\text { Chi- } \\
\text { Square }\end{array}$ \\
\hline ELSP & 51 & 2 & 23 & 23 & 3 & 0 & $\chi 2(4)=0.2$ \\
& & $(3.9 \%)$ & $(45.1 \%)$ & $(45.1 \%)$ & $(5.9 \%)$ & $(0 \%)$ & NS \\
SECSP & 17 & 1 & 8 & 7 & 1 & 0 & \\
& & $(5.9 \%)$ & $(47.1 \%)$ & $(41.2 \%)$ & $(5.9 \%)$ & $(0 \%)$ & \\
\hline
\end{tabular}

Note. Values enclosed in parenthesis represent percentage of responses in row. NS= Not statistically significant (at the $p<.05$ level). ELSP= Elementary Special Education Teacher. SECSP= Secondary Special Education Teacher.

Table S2

Special Education Teacher Classification (Elementary or Secondary) by Survey Item 16 (Professional Development Need of Mathematics Content Knowledge)

\begin{tabular}{|lccccccc|}
\hline & $\mathrm{N}$ & $\begin{array}{c}\text { A lot } \\
(0 \%)\end{array}$ & $\begin{array}{c}\text { Quite a bit } \\
(20.9 \%)\end{array}$ & $\begin{array}{c}\text { Some } \\
(49.3 \%)\end{array}$ & $\begin{array}{c}\text { A Little } \\
(25.4 \%)\end{array}$ & $\begin{array}{c}\text { None } \\
(4.5 \%)\end{array}$ & $\begin{array}{c}\text { Chi- } \\
\text { Square }\end{array}$ \\
\hline ELSP & 50 & 0 & 9 & 27 & 11 & 3 & $\chi 2(4)=3.6$ \\
& & $(0 \%)$ & $(12.0 \%)$ & $(54.0 \%)$ & $(22.0 \%)$ & $(6.0 \%)$ & NS \\
SECSP & 17 & 0 & 5 & 6 & 6 & 0 & \\
& & $(0 \%)$ & $(47.1 \%)$ & $(35.3 \%)$ & $(35.3 \%)$ & $(0 \%)$ & \\
\hline
\end{tabular}

Note. Values enclosed in parenthesis represent percentage of responses in row. NS= Not statistically significant (at the $p<.05$ level). ELSP= Elementary Special Education Teacher. SECSP= Secondary Special Education Teacher.

Table S3

Special Education Teacher Classification (Elementary or Secondary) by Survey Item 17 (Need More Knowledge in Subject)

\begin{tabular}{|lccccccccc|}
\hline & $\mathrm{N}$ & $\begin{array}{c}\text { Algebra } \\
(10.4 \%)\end{array}$ & $\begin{array}{c}\text { Geo. } \\
(20.9 \%)\end{array}$ & $\begin{array}{c}\text { Meas. } \\
(1.5 \%)\end{array}$ & $\begin{array}{c}\text { Statistics } \\
(17.9 \%)\end{array}$ & $\begin{array}{c}\text { Probability } \\
(6.0 \%)\end{array}$ & $\begin{array}{c}\# \text { 's } \\
\text { and } \\
\text { Ops. }\end{array}$ & $\begin{array}{c}\text { Process } \\
(40.3 \%)\end{array}$ & $\begin{array}{c}\text { Chi- } \\
\text { Square }\end{array}$ \\
& & & & & & & $(3.0 \%)$ & & \\
\hline ELSP & 50 & 4 & 6 & 1 & 9 & 3 & 2 & 25 & $\chi 2(6)=14.2$ \\
& & $(8.0 \%)$ & $(12.0 \%)$ & $(2.0 \%)$ & $(18.0 \%)$ & $(6.0 \%)$ & $(4.0 \%)$ & $(50.0 \%)$ & $p<.05$ \\
SECSP & 17 & 3 & 8 & 0 & 3 & 1 & 0 & 2 & \\
& & $(17.6 \%)$ & $(47.1 \%)$ & $(0 \%)$ & $(17.6 \%)$ & $(5.9 \%)$ & $(0 \%)$ & $(11.8 \%)$ & \\
\hline
\end{tabular}

Note. Values enclosed in parenthesis represent percentage of responses in row. NS= Not statistically significant (at the $p<.05$ level). ELSP= Elementary Special Education Teacher. SECSP= Secondary Special Education Teacher. Geo= Geometry. Meas.= Measurement. \#'s and Ops.= Numbers and Operations. Process $=$ Processes (communication, problem solving, reasoning and proof, representation, and connections). 
Table S4

Special Education Teacher Classification (Elementary or Secondary) by Survey Item 18 (Do Not Need More Knowledge in Subject)

\begin{tabular}{|lccccccccc|}
\hline & $\mathrm{N}$ & $\begin{array}{c}\text { Algebra } \\
(18.5 \%)\end{array}$ & $\begin{array}{c}\text { Geo. } \\
(9.2 \%)\end{array}$ & $\begin{array}{c}\text { Meas. } \\
(4.6 \%)\end{array}$ & $\begin{array}{c}\text { Statistics } \\
(3.1 \%)\end{array}$ & $\begin{array}{c}\text { Probability } \\
(4.6 \%)\end{array}$ & $\begin{array}{c}\text { \#'s and } \\
\text { Ops. } \\
(52.3 \%)\end{array}$ & $\begin{array}{c}\text { Process } \\
(7.7 \%)\end{array}$ & $\begin{array}{c}\text { Chi- } \\
\text { Square }\end{array}$ \\
\hline ELSP & 48 & 6 & 6 & 3 & 2 & 3 & 24 & 4 & $\chi 2(6)=8.8$ \\
& & $(12.5 \%)$ & $(12.5 \%)$ & $(6.3 \%)$ & $(4.2 \%)$ & $(6.3 \%)$ & $(50.0 \%)$ & $(8.3 \%)$ & NS \\
SECSP & 17 & 6 & 0 & 0 & 0 & 0 & 10 & 1 & \\
& & $(35.3 \%)$ & $(0 \%)$ & $(0 \%)$ & $(0 \%)$ & $(0 \%)$ & $(58.8 \%)$ & $(5.9 \%)$ & \\
\hline
\end{tabular}

Note. Values enclosed in parenthesis represent percentage of responses in row. NS= Not statistically significant (at the $p<.05$ level). ELSP= Elementary Special Education Teacher. SECSP= Secondary Special Education Teacher. Geo= Geometry. Meas.= Measurement. \#'s and Ops.= Numbers and Operations. Process $=$ Processes (communication, problem solving, reasoning and proof, representation, and connections).

Table S5

Special Education Teacher Classification (Elementary or Secondary) by Survey Item 27(Ability to Teach Mathematics)

\begin{tabular}{|cccccccc|}
\hline & $\mathrm{N}$ & $\begin{array}{c}\text { Exceptional } \\
(8.1 \%)\end{array}$ & $\begin{array}{c}\text { Above } \\
\text { Average } \\
(48.4 \%)\end{array}$ & $\begin{array}{c}\text { Average } \\
(41.9 \%)\end{array}$ & $\begin{array}{c}\text { Below } \\
\text { Average } \\
(1.6 \%)\end{array}$ & $\begin{array}{c}\text { Poor } \\
(0 \%)\end{array}$ & $\begin{array}{c}\text { Chi- } \\
\text { Square }\end{array}$ \\
\hline ELSP & 47 & 4 & 24 & 18 & 1 & 0 & $\chi 2(4)=1.3$ \\
SECSP & 15 & $(8.5 \%)$ & $(51.1 \%)$ & $(38.3 \%)$ & $(2.1 \%)$ & $(0 \%)$ & NS \\
& & $(6.7 \%)$ & $(40.0 \%)$ & $(53.3 \%)$ & $(0 \%)$ & $(0 \%)$ & \\
\hline
\end{tabular}

Note. Values enclosed in parenthesis represent percentage of responses in row. NS= Not statistically significant (at the $p<.05$ level). ELSP= Elementary Special Education Teacher. SECSP= Secondary Special Education Teacher.

Table S6

Special Education Teacher Classification (Elementary or Secondary) by Survey Item 29 (Professional Development Need for Teaching Math)

\begin{tabular}{|lccccccc|}
\hline & $\mathrm{N}$ & $\begin{array}{c}\text { A lot } \\
(3.1 \%)\end{array}$ & $\begin{array}{c}\text { Quite a bit } \\
(25.0 \%)\end{array}$ & $\begin{array}{c}\text { Some } \\
(40.6 \%)\end{array}$ & $\begin{array}{c}\text { A Little } \\
(28.1 \%)\end{array}$ & $\begin{array}{c}\text { None } \\
(3.1 \%)\end{array}$ & $\begin{array}{c}\text { Chi- } \\
\text { Square }\end{array}$ \\
\hline ELSP & 22 & 1 & 6 & 8 & 6 & 1 & $\chi 2(4)=1.4$ \\
& & $(4.5 \%)$ & $(27.3 \%)$ & $(36.4 \%)$ & $(27.3 \%)$ & $(4.5 \%)$ & NS \\
SECSP & 10 & 0 & 2 & 5 & 3 & 0 & \\
& & $(0 \%)$ & $(20.0 \%)$ & $(50.0 \%)$ & $(30.0 \%)$ & $(0 \%)$ & \\
\hline
\end{tabular}

Note. Values enclosed in parenthesis represent percentage of responses in row. NS= Not statistically significant (at the $p<.05$ level). ELSP= Elementary Special Education Teacher. SECSP= Secondary Special Education Teacher. 
Table S7

Special Education Teacher Classification (Elementary or Secondary) by Survey Item 30 (Need More Strategies for Teaching Mathematics)

\begin{tabular}{|c|c|c|c|c|c|c|c|c|c|}
\hline & $\mathrm{N}$ & $\begin{array}{l}\text { Algebra } \\
(13.8 \%)\end{array}$ & $\begin{array}{c}\text { Geo. } \\
(19.0 \%)\end{array}$ & $\begin{array}{l}\text { Meas. } \\
(5.2 \%)\end{array}$ & $\begin{array}{c}\text { Statistics } \\
(10.3 \%)\end{array}$ & $\begin{array}{c}\text { Probability } \\
(1.7 \%)\end{array}$ & $\begin{array}{c}\text { \#'s } \\
\text { and } \\
\text { Ops. } \\
(5.2 \%)\end{array}$ & $\begin{array}{l}\text { Process } \\
(44.8 \%)\end{array}$ & $\begin{array}{c}\text { Chi- } \\
\text { Square }\end{array}$ \\
\hline ELSP & 44 & $\begin{array}{c}5 \\
(11.4 \%)\end{array}$ & $\begin{array}{c}5 \\
(11.4 \%)\end{array}$ & $\begin{array}{c}3 \\
(6.8 \%)\end{array}$ & $\begin{array}{c}4 \\
(9.1 \%)\end{array}$ & $\begin{array}{c}1 \\
(2.3 \%)\end{array}$ & $\begin{array}{c}3 \\
(6.8 \%)\end{array}$ & $\begin{array}{c}23 \\
(52.3 \%)\end{array}$ & $\begin{array}{c}\chi 2(6)=11.1 \\
\text { NS }\end{array}$ \\
\hline SECSP & 14 & $\begin{array}{c}3 \\
(21.4 \%)\end{array}$ & $\begin{array}{c}6 \\
(42.9 \%)\end{array}$ & $\begin{array}{c}0 \\
(0 \%)\end{array}$ & $\begin{array}{c}2 \\
(14.3 \%)\end{array}$ & $\begin{array}{c}0 \\
(0 \%)\end{array}$ & $\begin{array}{c}0 \\
(0 \%)\end{array}$ & $\begin{array}{c}3 \\
(21.4 \%)\end{array}$ & \\
\hline
\end{tabular}

Note. Values enclosed in parenthesis represent percentage of responses in row. NS= Not statistically significant (at the $p<.05$ level). ELSP= Elementary Special Education Teacher. SECSP= Secondary Special Education Teacher. Geo= Geometry. Meas.= Measurement. \#'s and Ops.= Numbers and Operations. Process $=$ Processes (communication, problem solving, reasoning and proof, representation, and connections).

Table S8

Special Education Teacher Classification (Elementary or Secondary) by Survey Item 31 (Do Not Need More Strategies for Teaching Mathematics)

\begin{tabular}{|lccccccccc|}
\hline & $\mathrm{N}$ & $\begin{array}{c}\text { Algebra } \\
(9.7 \%)\end{array}$ & $\begin{array}{c}\text { Geo. } \\
(16.1 \%)\end{array}$ & $\begin{array}{c}\text { Meas. } \\
(8.1 \%)\end{array}$ & $\begin{array}{c}\text { Statistics } \\
(4.8 \%)\end{array}$ & $\begin{array}{c}\text { Probability } \\
(8.1 \%)\end{array}$ & $\begin{array}{c}\text { \#'s and } \\
\text { Ops. } \\
(51.6 \%)\end{array}$ & $\begin{array}{c}\text { Process } \\
(1.6 \%)\end{array}$ & $\begin{array}{c}\text { Chi- } \\
\text { Square }\end{array}$ \\
\hline ELSP & 47 & 4 & 10 & 5 & 3 & 3 & 22 & 0 & $\chi 2(6)=10.7$ \\
& & $(8.5 \%)$ & $(21.3 \%)$ & $(10.6 \%)$ & $(6.4 \%)$ & $(6.4 \%)$ & $(46.8 \%)$ & $(0 \%)$ & NS \\
SECSP & 15 & 2 & 0 & 0 & 0 & 2 & 10 & 1 & \\
& & $(13.3 \%)$ & $(0 \%)$ & $(0 \%)$ & $(0 \%)$ & $(13.3 \%)$ & $(66.7 \%)$ & $(6.7 \%)$ & \\
\hline
\end{tabular}

Note. Values enclosed in parenthesis represent percentage of responses in row. NS= Not statistically significant (at the $p<.05$ level). ELSP= Elementary Special Education Teacher. SECSP= Secondary Special Education Teacher. Geo= Geometry. Meas.= Measurement. \#'s and Ops.= Numbers and Operations. Process $=$ Processes (communication, problem solving, reasoning and proof, representation, and connections).

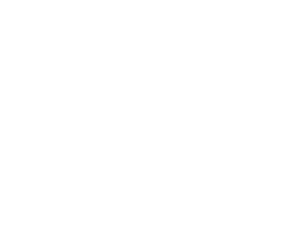

